Mapeamento semântico entre UNL e componentes de software para execução de requisições imperativas em linguagem natural 
SERVIÇO DE PÓS-GRADUAÇÃO DO ICMC-USP

Data de Depósito:

Assinatura:

\section{Mapeamento semântico entre UNL e componentes de software para execução de requisições imperativas em linguagem natural}

\section{Flávia Linhalis}

Orientador: Prof. Dr. Dilvan de Abreu Moreira

Tese apresentada ao Instituto de Ciências Matemáticas e de Computação - ICMC-USP, como parte dos requisitos para obtenção do título de Doutor em Ciências - Ciências de Computação e Matemática Computacional.

USP - São Carlos

Fevereiro de 2007 


\section{Agradecimentos}

Agradeço a Deus por ter me concedido uma oportunidade que poucos têm e pela força para enfrentar as dificuldades que encontrei pelo caminho.

Aos meus pais que sempre acreditaram em mim, me apoiaram e estão sempre ao meu lado. Vocês são meu porto seguro.

Ao Rudinei pelo companheirismo, apoio e momentos de carinho. Se não fosse por você eu talvez não tivesse ficado aqui para fazer o doutorado.

Ao meu orientador Dilvan de Abreu Moreira por ter aberto as portas do doutorado para mim. Não foi fácil fazer o doutorado em tempo parcial, mas você confiou em minha capacidade.

Às professoras Renata Pontin, Graça Pimentel e Rosely Sanches pelas contribuições que deram ao meu trabalho.

Aos amigos Rudinei Goularte, Renata Pontin, Renato Bulcão, Luciana Fondazzi Martimiano, Renata Porto, Augusto Carbol e Verônica Oliveira de Carvalho pelas revisões no texto e pelas sugestões.

Aos amigos que com seus sorrisos, palavras de incentivo e carinho tornaram minha caminhada mais suave. Agradeço em especial àqueles que estiveram mais próximos durante o desenvolvimento do doutorado: Rudinei Goularte, Taciana Kudo, Renato Bulcão, Elaine Quintino, Alessandra Alaniz Macedo, José “Toño" Camacho, Luciana Fondazzi Martimiano, Richard Ropelato Rizo, Renata Porto, Renata Pontin e Graça Pimentel. 


\section{Resumo}

A linguagem natural corresponde ao meio mais convencional de comunicação entre as pessoas. O desejo que os seres humanos possuem de se comunicar com as máquinas é evidenciado por pesquisas, que têm sido realizadas desde o final da década de 70 , com o objetivo de ter requisições expressas em linguagem natural executadas pelas máquinas. Alguns trabalhos na literatura têm sido propostos com esse fim, entretanto a maioria deles considera requisições expressas apenas em Inglês. Uma maneira de flexibilizar a utilização de várias línguas em sistemas que utilizam linguagem natural é por meio de uma interlíngua, pois essa é uma representação intermediária e processável por máquina das informações contidas em diversas línguas naturais. O trabalho descrito nesta tese propõe que requisições imperativas em linguagem natural sejam convertidas para a interlíngua UNL (Universal Networking Language) e executadas por meio da ativação dos componentes de software apropriados. Para atingir esse objetivo, este trabalho propõe a Arquitetura OntoMap (Ontology-based Semantic Mapping), que utiliza ontologias para realizar o mapeamento semântico entre UNL e componentes de software e para realizar a busca pelos componentes mais apropriados para executar as requisições. A Arquitetura OntoMap conta com (i) um serviço para converter requisições em linguagem natural para UNL; (ii) uma ontologia de alto nível, chamada Ontologia InterComp (Interlíngua-Componentes), que juntamente com regras e inferência, fornece informações semânticas a respeito dos componentes que podem ser utilizados para executar a requisição; (iii) uma Ontologia de Componentes, que relaciona dados das interfaces dos componentes com informações semânticas do domínio de aplicação dos mesmos; e (iv) um Módulo de Busca que utiliza as informações semânticas inferidas e a Ontologia de Componentes para encontrar os componentes apropriados para executar as requisições expressas em linguagem natural. Este trabalho propõe ainda um processo para utilizar a Arquitetura OntoMap em diversos domínios de aplicação e com diferentes conjuntos de componentes. Esse processo foi instanciado considerando componentes desenvolvidos para o domínio de gerenciamento de cursos. 
Natural Language is the common way of communication between people. The desire of human beings to communicate with machines is evidenced by research, that has been conducted since the late 70's, triyng to express requests in natural language that can be executed by machines. However, most of the works that have pursued this goal consider requests expressed only in English. A way to facilitate the use of several languages in natural language systems is by using an interlingua. An interlingua is an intermediary representation for natural language information that can be processed by machines. The work described in this thesis proposes to convert imperative natural language requests into the UNL (Universal Networking Language) interlingua and to execute those requests using the apropriate software components. In order to achieve this goal, this work proposes the OntoMap (Ontology-based Semantic Mapping) architecture. It uses ontologies to perform a semantic mapping between UNL and software componente and to search for software components to execute the requests. The OntoMap architecture is composed by (i) a service to convert natural language requests into UNL; (ii) an upper ontology, named InterComp (Interlingua-Components), that uses inference to provide semantic information about components that could be used to execute the requests; (iii) a Components Ontology that relates the component's interfaces to semantic information about the application domain of the components; and (iv) a search module that uses the infered information and the Components Ontology to reach the components to execute the requests. This work also proposes a process to help the use of the OntoMap architecture in several application domains using different component sets. This process is intanciated considering compoments developed for the course management domain. 


\section{Lista de Figuras}

FIGURA 1.1 - O SISTEMA UNL (UNDL FOUNDATION, 2006) .........................................................................4

FIGURA 2.1 - REPRESENTAÇÃO UNL PARA A SENTENÇA “O CÉU ERA AZUL!” (UNDL BRASIL, 2005)..................13

FIGURA 2.2 - REPRESENTAÇÃO TABULAR DA SENTENÇA "EU OUÇO UM CÃO LATINDO LÁ FORA" (UNL SPECIFICATIONS, 2005).

FIGURA 2.3 - REPRESENTAÇÃO EM LISTA DA SENTENÇA "EU OUÇO UM CÃO LATINDO LÁ FORA" (UNL

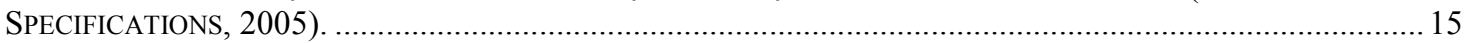

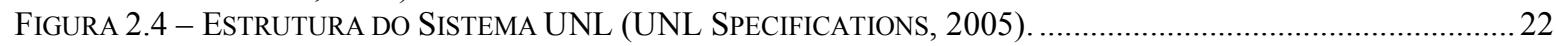

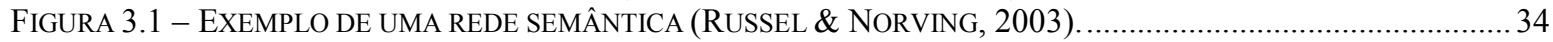

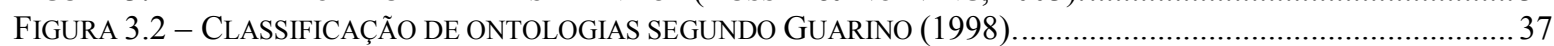

FigURA 3.3 - AS CAMADAS DA WEB SEMÂNTICA (KOIVUNEN \& MILLER, 2001) ................................................44

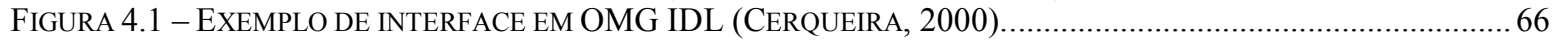

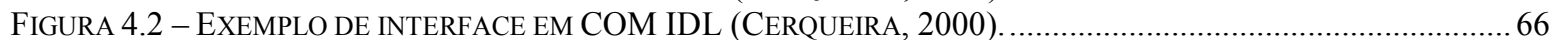

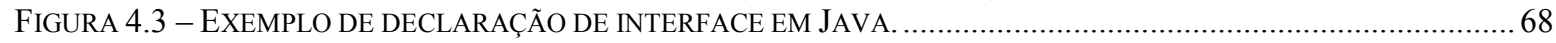

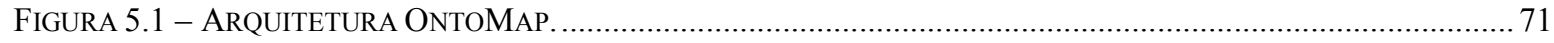

FIGURA 5.2 - TRECHO DE UM DICIONÁRIO DESENVOLVIDO PARA O ENCO HERMETO............................................ 73

FIGURA 5.3 - TRECHO DE UMA GRAMÁTICA SIMPLES DESENVOLVIDA PARA O ENCO HERMETO............................ 74

FIGURA 5.4 - ILUSTRAÇÃO DE UM POSSÍVEL MAPEAMENTO SEMÂNTICO ENTRE AS RELAÇÕES UNL DA SENTENÇA

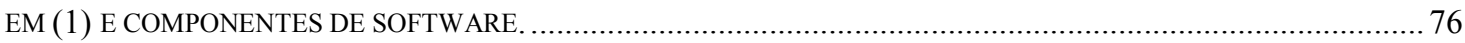

FIGURA 5.5 - HIERARQUIA DE CLASSES DA ONTOLOGIA INTERCOMP COM RELACIONAMENTOS DA RELAÇÃO

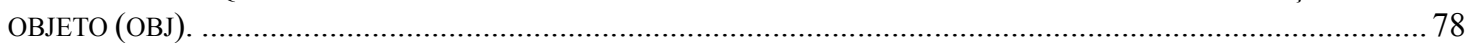

FIGURA 5.6 - ASSOCIAÇÕES QUE RELACIONAM UNL COM INFORMAÇÕES SEMÂNTICAS SOBRE COMPONENTES. ....80

FIGURA 5.7 - INSTÂNCIAS CRIADAS NA ONTOLOGIA INTERCOMP PELO CLASSIFICADOR DE TOKENS......................83

FIGURA 5.8 - EXEMPLOS DE REGRAS PARA AS RELAÇÕES NOME E OBJETO. ...................................................... 84

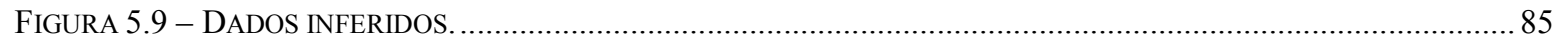

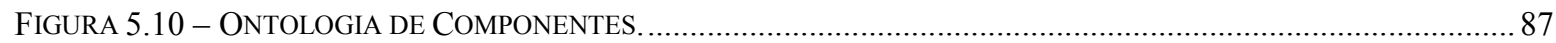

FigURA 5.11 - POSSÍVEIS DADOS A SEREM RECEBIDOS PELO MÓDULO DE BUSCA...............................................89

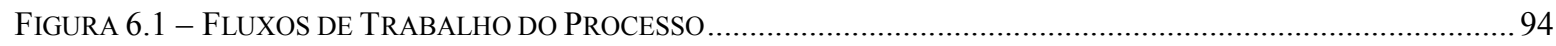

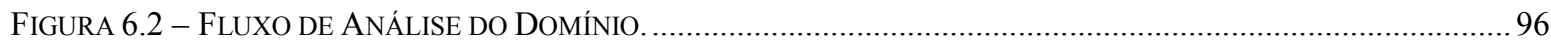

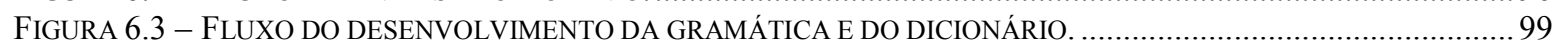

FIGURA 6.4 - FLUXO DE MAPEAMENTO SEMÂNTICO. .................................................................................. 104

FIGURA 6.5 - FLUXO PARA DESENVOLVIMENTO E INSTANCIAÇÃO DAS ONTOLOGIAS........................................ 107

FIGURA 7.1 - PROGRAMA QUE PODE SER PROCESSADO POR NLC (BALLARD \& BIERMAN, 1979)....................... 114

FIGURA 7.2 - PROGRAMA QUE PODE SER PROCESSADO POR NATURALJAVA (PRICE ET AL., 2000)....................... 115

FigURA 7.3 - Código FONTE GERADO POR NATURAL JAVA (PRICE ET AL., 2000)........................................ 115

FIGURA A. 1 - RELACIONAMENTOS DAS RELAÇÕES UNL AGENTE (AGT) ATÉ DURAÇÃO (DUR). ........................... 142

FIGURA A. 2- RELACIONAMENTOS DAS RELAÇÕES UNL SINONÍMIA (EQU) ATÉ MODIFICAÇÃO (MOD).................143

FigURA A. 3 - RELACIONAMENTOS DAS RELAÇÕES UNL NOME (NAM) ATÉ PROPÓSITO (PUR).............................144

FiguRA A. 4 - RELACIONAMENTOS DAS RELAÇÕES UNL QUANTIDADE (QUA) ATÉ LUGAR POR ONDE (VIA)........ 145

FiguRA B. 1 - ESTRUTURA DO DOCUMENTO DE FunCIONALIDADE DO COMPONENTE. ........................................ 147

FIGURA B. 2 - ESTRUTURA DO DOCUMENTO DE SENTENÇAS IMPERATIVAS. ................................................... 148

FIGURA B. 3 - ESTRUTURA DO DOCUMENTO DE SINÔNIMOS. ................................................................. 149 
Figura B.4 - REPRESENTAÇÃO DO DOCUMENTO DE SENTENÇAS UNL.

FIgURA B. 5 - ESTRUTURA DO DOCUMENTO DE MAPEAMENTO SEMÂNTICO. ................................................ 152

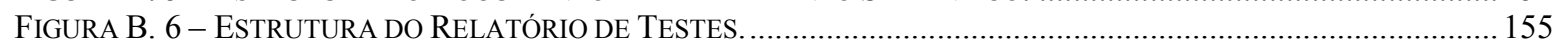

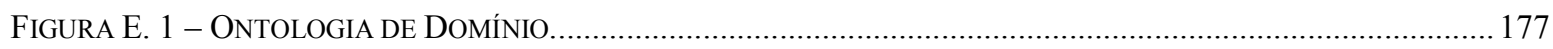




\section{Lista de Tabelas}

TABELA 2.1 - EXEMPLOS DE RELAÇÕES UNL (UNDL BRASIL, 2005; UNL SPECIFICATIONS, 2005).................... 16

TABELA 2.2 - ATRIBUTOS DE UNL (UNL SPECIFICATIONS, 2005; UNDL BRASIL, 2005).............................. 17

TABELA 2.3 - TRECHO DOS PRIMEIROS NÍVEIS DA ESTRUTURA DO SISTEMA DE UWS (UNL SPECIFICATIONS, 2005).

TABELA 3.1 - CARACTERÍSTICAS DAS LINGUAGENS PARA REPRESENTAÇÃO DE ONTOLOGIAS. ..............................48

TABELA 4.1 - RESUMO DAS ABORDAGENS PARA RECUPERAÇÃO DE COMPONENTES (SUGUMARAN \& STOREY, 2003).

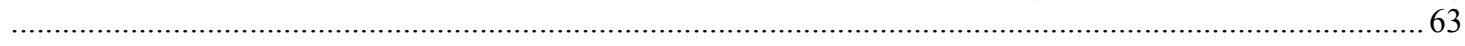

TABELA 5.1 - RELAÇÕES UNL PRESENTES NA SENTENÇA ANALISADA E SEUS SIGNIFICADOS................................76

TABELA 6.1 - TEMPLATE DA NORMA ISO/IEC 15504-5 (ISO/IEC, 2004) UTILIZADO PARA DESCRIÇÃO DOS

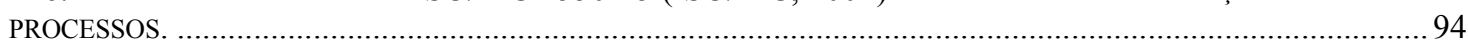

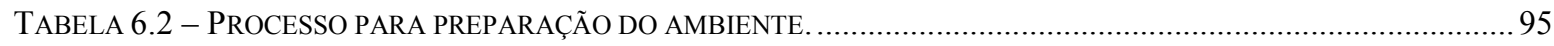

TABELA 6.3 - PROCESSO DE ANÁLISE DA FUNCIONALIDADE DOS COMPONENTES. ..............................................97

TABELA 6.4 - PROCESSO PARA ANÁLISE DO VOCABULÁRIO DO DOMÍNIO. ........................................................... 98

TABELA 6.5 - PROCESSO PARA DESENVOLVIMENTO DO DICIONÁRIO. .............................................................. 100

TABELA 6.6 - PROCESSO PARA DESENVOLVIMENTO DA GRAMÁTICA.......................................................... 101

TABELA 6.7 - PROCESSO PARA TESTES COM A GRAMÁTICA E O DICIONÁRIO...................................................... 102

TABELA 6.8 - PROCESSO PARA ENCAPSULAMENTO DA GRAMÁTICA E DO DICIONÁRIO. ....................................... 103

TABELA 6.9 - PROCESSO PARA REALIZAÇÃO DO MAPEAMENTO SEMÂNTICO. ..................................................... 105

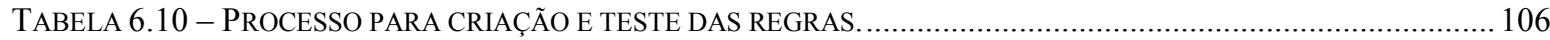

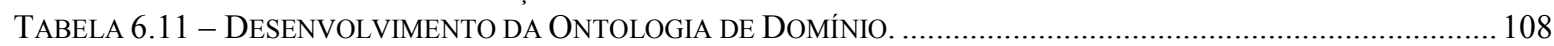

TABELA 6.12 - INSTANCIAÇÃO DA ONTOLOGIA DE COMPONENTES............................................................... 109

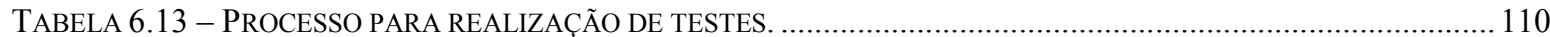

TABELA 7.1 - COMPARAÇÃO COM TRABALHOS RELACIONADOS...................................................................... 123

TABELA 1 - FORMATO DESCRITIVO DE UM DOCUMENTO UNL (UNL SPECIFICATIONS, 2005)..........................203

TABELA 2 - ETIQUETAS DOS DOCUMENTOS UNL (UNL SPECIFICATIONS, 2005)........................................205

TABELA 3 - FORMATO DESCRITIVO DE <DESCRIÇÃO DA REFERÊNCIA> (UNL SPECIFICATIONS, 2005) .......................205

TABELA 4 - FORMATO DESCRITIVO DE <DESCRIÇÃO DE ESTRUTURA> (UNL SPECIFICATIONS, 2005) ......................206

TABELA 5 - FORMA TABULAR DE UMA EXPRESSÃO UNL (UNL SPECIFICATIONS, 2005)...............................207

TABELA 6 - SINTAXE DE UMA RELAÇÃO BINÁRIA NA FORMA TABULAR (UNL SPECIFICATIONS, 2005)..............208

TABELA 7 - FORMATO EM LISTA DE UMA EXPRESSÃO UNL (UNL SPECIFICATIONS, 2005). ..............................208

TABELA 8 - SiNTAXE DE UMA RELAÇÃO BINÁRIA NO FORMATO EM LISTA (UNL SPECIFICATIONS, 2005)...........208

TABELA 9 - RELAÇÕES ONTOLÓGICAS (UNDL BRASIL, 2005; UNL SPECIFICATIONS, 2005)..........................209

TABELA 10 - RELAÇÕES LÓGICAS (UNDL BRASIL, 2005; UNL SPECIFICATIONS, 2005).................................209

TABELA 11 - RELAÇÕES PSICOLÓGICAS SOBRE ATORES (UNDL BRASIL, 2005; UNL SPECIFICATIONS, 2005)...210

TABELA 12 - RELAÇÕES PSICOLÓGICAS SOBRE ESPAÇO (UNDL BRASIL, 2005; UNL SPECIFICATIONS, 2005)...210

TABELA 13 - RELAÇÕES PSICOLÓGICAS SOBRE TEMPO (UNDL BRASIL, 2005; UNL SPECIFICATIONS, 2005)... 210

TABELA 14 - RELAÇÕES PSICOLÓGICAS SOBRE QUALIDADE E DETERMINAÇÃO (UNDL BRASIL, 2005; UNL SPECIFICATIONS, 2005).

TABELA 15 - RELAÇÕES PSICOLÓGICAS SOBRE TRANSFORMAÇÃO (UNDL BRASIL, 2005; UNL SPECIFICATIONS, 2005).

TABELA 16 - ATRIBUTOS RELATIVOS A EXPRESSÕES LÓGICAS (UNL SPECIFICATIONS, 2005).........................213

TABELA 17 - ATRIBUTOS RELATIVOS A REFERÊNCIA (UNL SPECIFICATIONS, 2005)....................................213

TABELA 18 - ATRIBUTOS RELATIVOS A TEMPO (UNL SPECIFICATIONS, 2005) ...............................................2 213

TABELA 19 - ATRIBUTOS RELATIVOS A PONTO DE VISTA (UNL SPECIFICATIONS, 2005)................................214 
TABELA 20 - ATRIBUTOS RELATIVOS A CONVENÇÃo (UNL SPECIFICATIONS, 2005).

TABELA 21 - ATRIBUTOS RELATIVOS A ASPECTO (UNL SPECIFICATIONS, 2005)........................................215

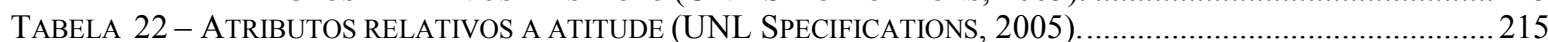

TABELA 23 - ATRIBUTOS RELATIVOS A CONVENÇÃO (UNL SPECIFICATIONS, 2005)......................................216 


\section{Lista de Abreviaturas}

AL - Attribute Label

API - Application Program Interfaces

CHESt - Computer History Expert System

CLIPS - C Language Integrated Production System

CNRS - Centre National de la Recherche Scientifique

COOL - C Object-Oriented Language

COM - Component Object Model

CoSMoS - Component Service Model with Semantics

CORBA - Common Object Request Broker Architecture

DARPA - Defense Advanced Research Projects Agency

DAML - DARPA Agente Markup Language

DCOM - Distributed COM

DeCo-DeConverter

DL - Description Logics

EJB - Enterprise JavaBeans

EnCo - EnConverter

GUI - Graphical User Interfaces

HTML - HyperText Markup Language

IA - Inteligência Artificial

ICL - Interagent Communication Language

IDL - Interface Definition Language 
IEC - International Electronics Commission

ISO - International Organization for Standardization

J2EE (ou Java EE) - Java 2 Enterprise Edition

JDBC - Java DataBase Connectivity

JESS - Java Expert System Shell

JMS - Java Message Service

JNDI - Java Naming and Directory Interface

JSDK - Java Software Development Kit

JSP - Java Server Pages

JTS - Java Transaction Service

KAON - KArlsruhe ONtology

KCIC - Key Concept in Context

KIF - Knowledge Information Format

KB - Knowledge Base

LN - Linguagem Natural

NILC - Núcleo Interinstitucional de Lingüística Computacional

NLC - Natural Language Computing

NLE - Natural Language Entry

NLL - Natural Language Lemma

NS - Namespace

OAA - Open Agent Architecture

OCML - Operational Conceptual Modeling Language

ODE - Ontology Design Environment

OIL - Ontology Interchange Language

OKBC - Open Knowledge Based Connectivity

OMG - Object Management Group

OWL - Ontology Web Language 
PAL - Protégé Axiomatic Language

PT - Produto de Trabalho

RDF - Resource Descriptor Framework

RL - Relation Label

RMI - Remote Method Invocation

SEC - Search Engine for Components

SeMaComp - Semantic Mapping between UNL relations and software Components

SOAP - Simple Object Access Protocol

SPEM - Software Process Engineering Metamodel

SQL - Structured Query Language

SUMO - Suggested Upper Merged Ontology

SWRL - Semantic Web Rule Language

UCL - Universal Communication Language

UNDL - Universal Networking Digital Language

UNL - Universal Networking Language

UNU - United Nations University

URI - Uniform Resource Identifier

USD - UNL Development Set

UW - Universal Word

W3C - World Wide Web Consortium

WSDL - Web Services Description Language

WWW - World Wide Web

XML - eXtensible Markup Language 


\section{Sumário}

INTRODUÇÃO

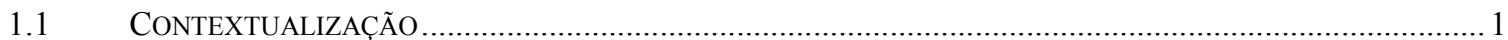

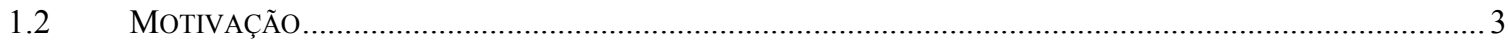

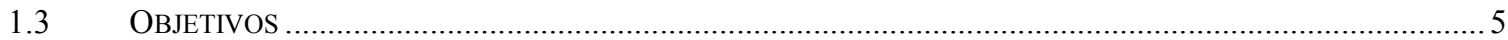

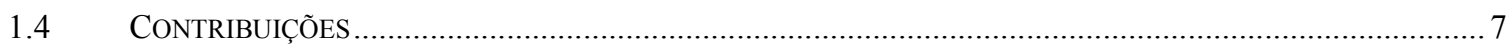

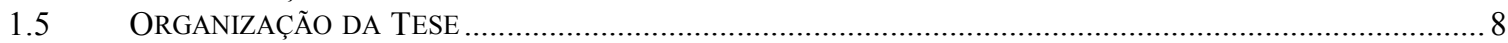

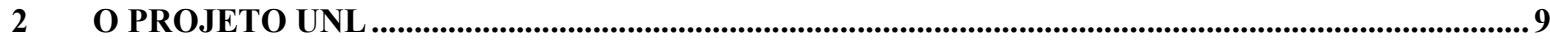

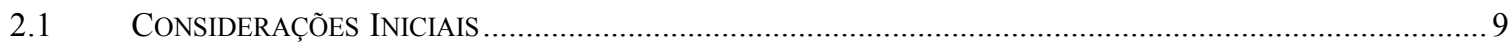

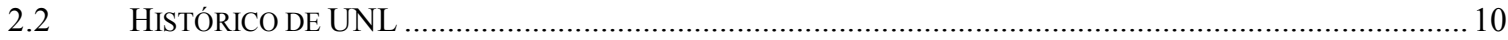

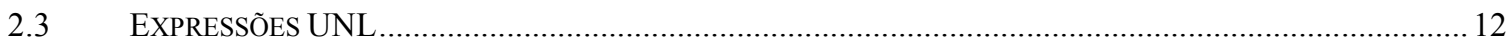

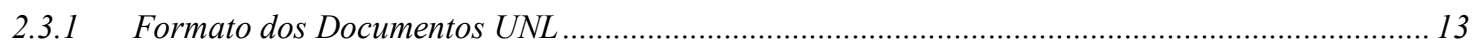

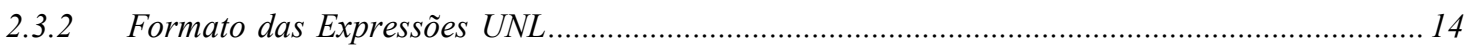

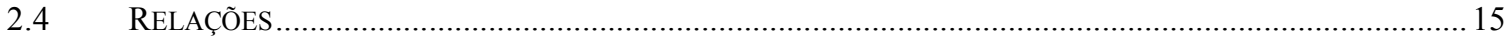

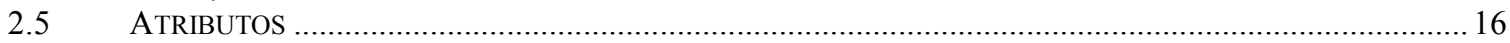

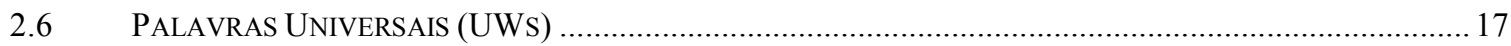

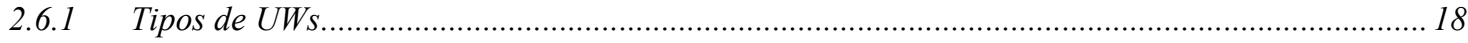

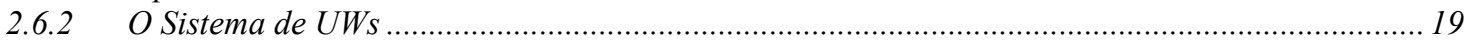

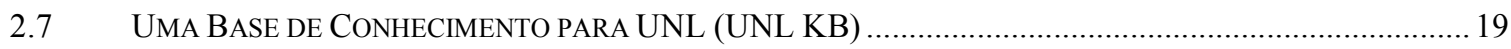

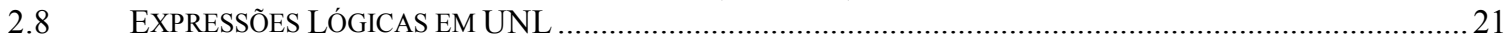

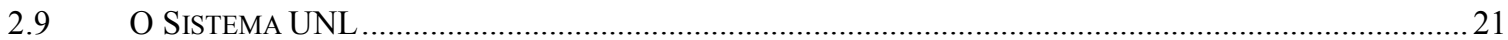

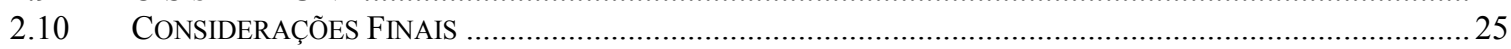

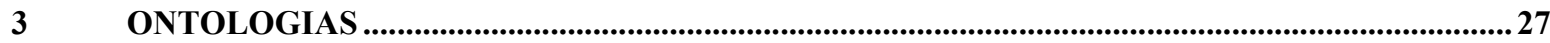

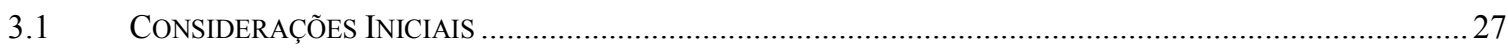

3.2 FORMALISMOS PARA REPRESENTAÇÃO DE CONHECIMENTO ........................................................28

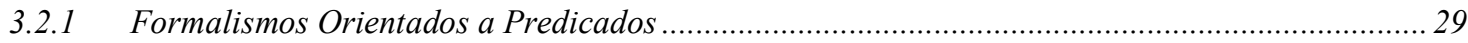

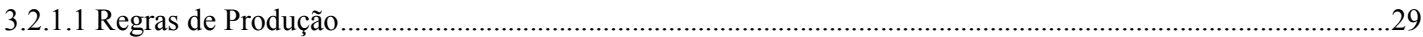

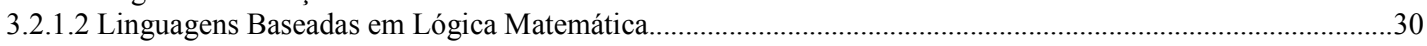

3.2.2 Formalismos Orientados a Classes e Relações Hierárquicas ..................................................... 32

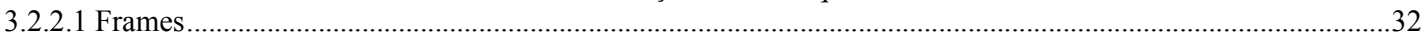

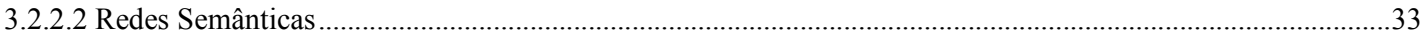

3.2.2.3 Lógica de Descrições (DL - Description Logics) …………...........................................................................34

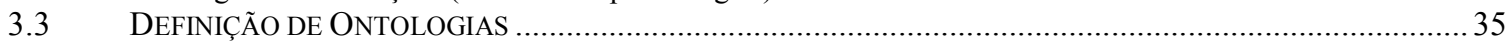

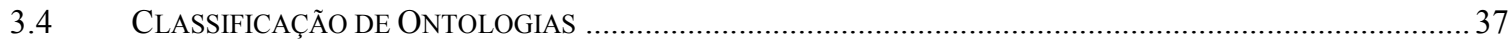

3.5 METODOLOGIAS PARA DESENVOLVIMENTO DE ONTOLOGIAS ............................................................ 38

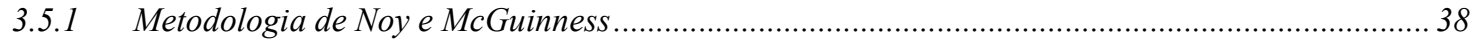

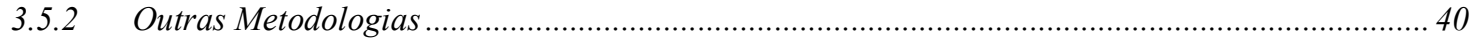

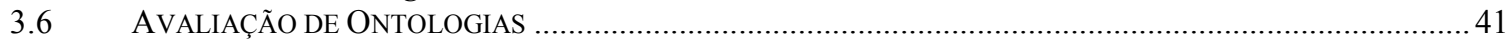

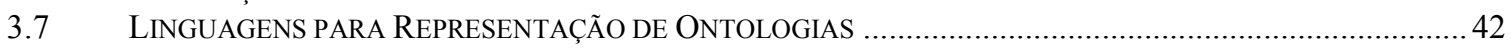

3.7.1 Linguagens para Representar Ontologias fora da Web Semântica........................................... 43

3.7.2 Ontologias na Web Semântica .......................................................................................... 44

3.7.3 Comparação entre as Linguagens para Representação de Ontologias........................................... 47 
3.8 FERRAMENTAS PARA DESENVOLVIMENTO DE ONTOLOGIAS .................................................... 49

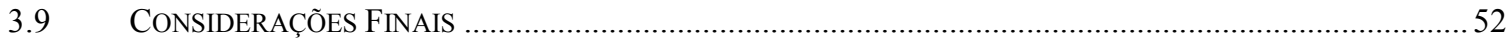

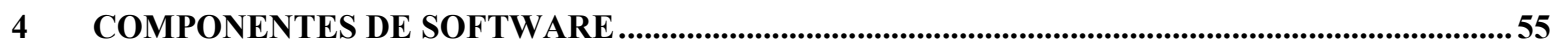

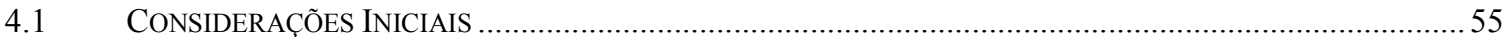

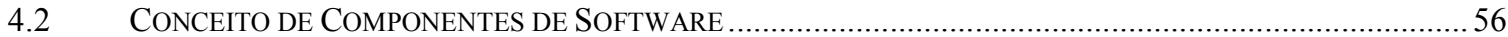

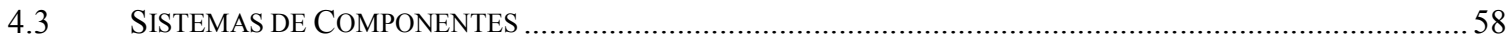

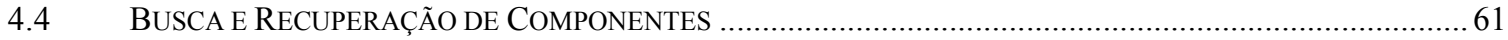

4.4.1 Abordagens tradicionais para busca por componentes............................................................... 61

4.4.2 Ontologias para Auxiliar na Busca por Componentes ............................................................... 63

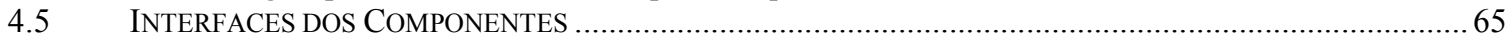

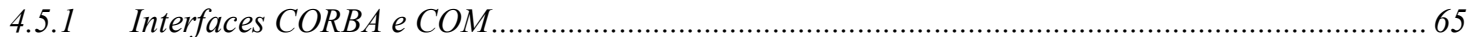

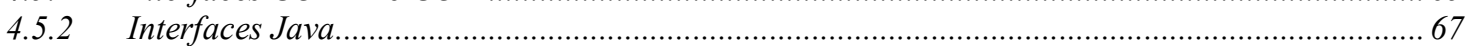

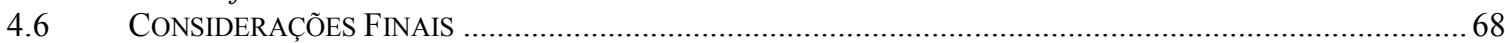

\section{ONTOMAP: UMA ARQUITETURA PARA REALIZAR O MAPEAMENTO SEMÂNTICO}

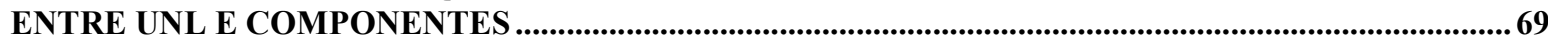

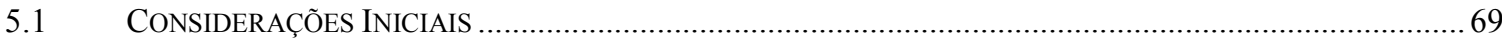

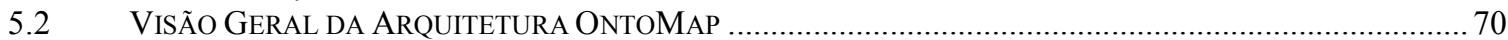

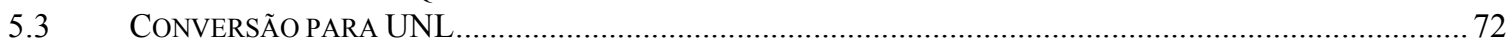

5.4 MAPEAMENTO SEMÂNTICO ENTRE UNL E COMPONENTES …........................................................ 74

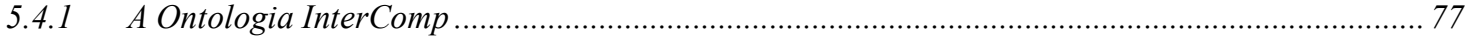

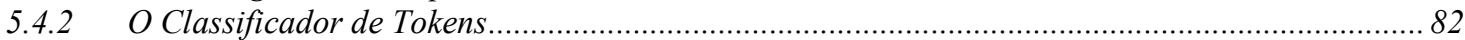

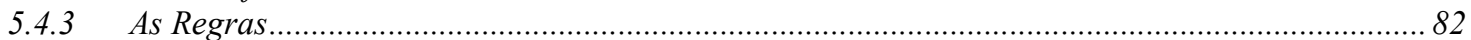

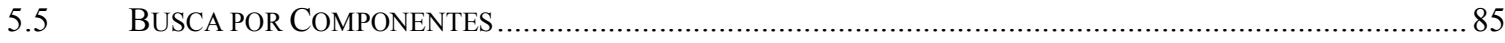

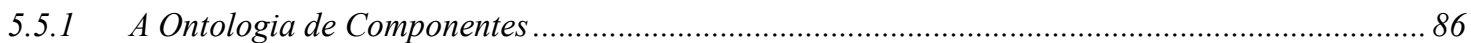

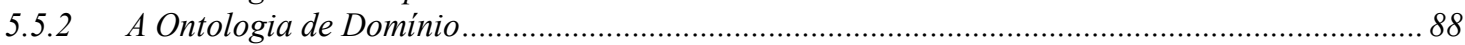

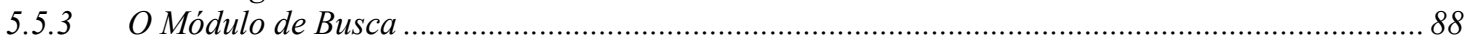

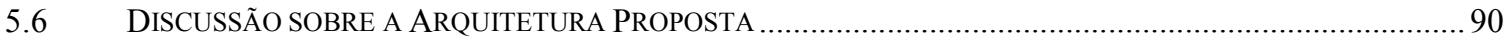

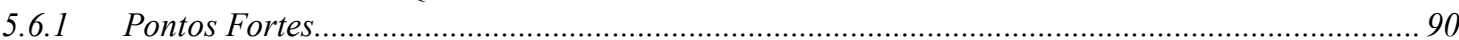

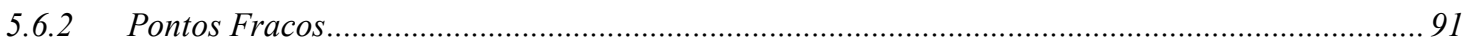

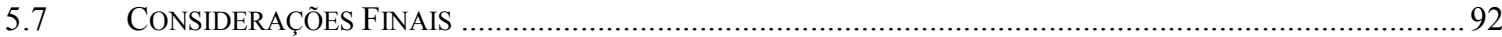

6 DEFINIÇÃO E INSTANCIAÇÃO DE UM PROCESSO PARA UTILIZAÇÃO DA ARQUITETURA

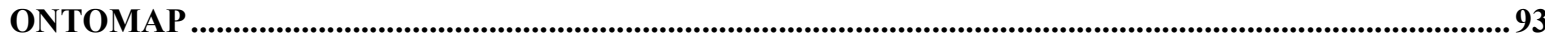

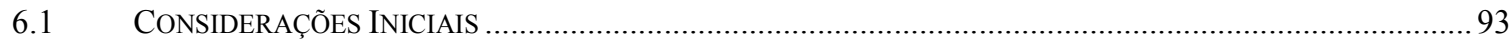

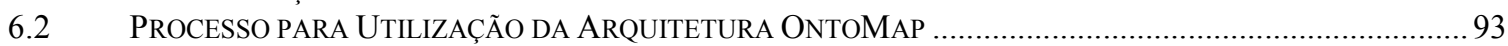

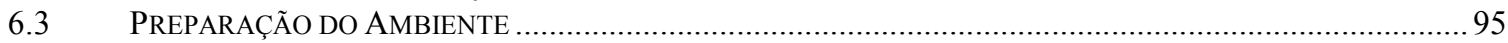

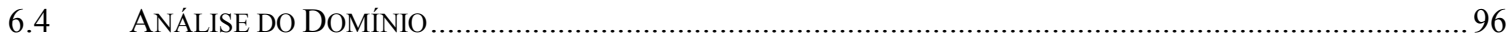

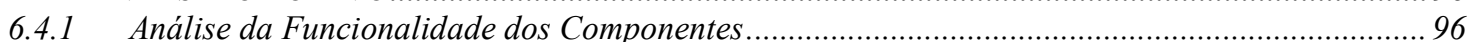

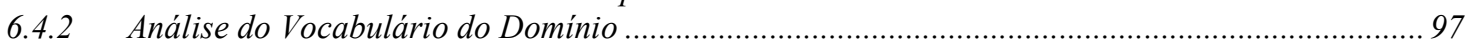

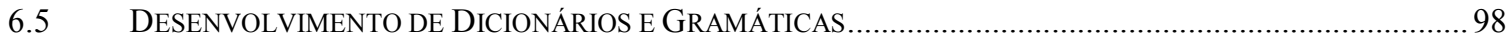

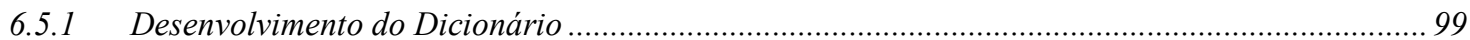

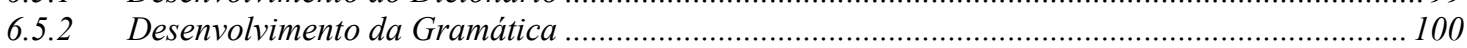

6.5.3 Realização de Testes com a Gramática e o Dicionário no Hermeto ........................................... 101

6.5.4 Encapsulamento dos Arquivos da Gramática e do Dicionário .................................................. 102

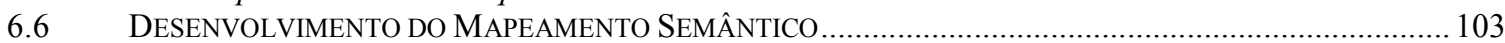

6.6.1 Realização do Mapeamento Semântico ....................................................................................... 104

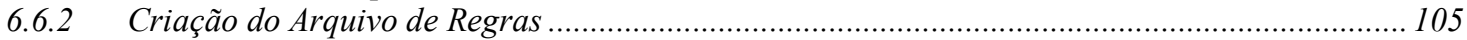

6.7 DESENVOLVIMENTO E INSTANCIAÇÃO DAS ONTOLOGIAS ............................................................. 106

6.7.1 Desenvolvimento da Ontologia de Domínio ................................................................................ 107

6.7.2 Instanciação da Ontologia de Componentes ......................................................................... 108

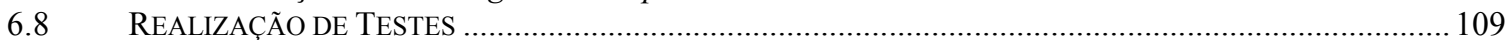

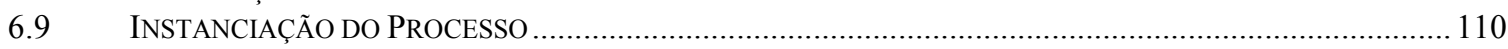

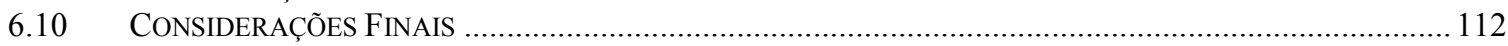




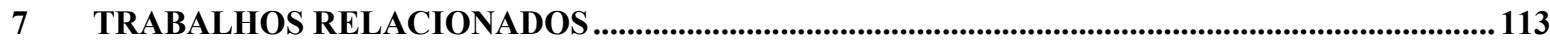

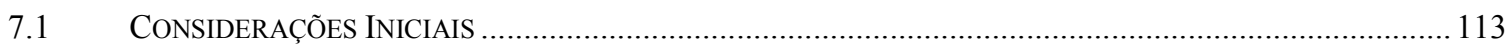

EXECUÇÃO DE REQUISIÇÕES EM LINGUAGEM NATURAL ........................................................... 114

7.3 USO DE COMPONENTES OU AGENTES PARA EXECUTAR REQUISIÇÕES EM LINGUAGEM NATURAL..... 116

7.4 BUSCA POR COMPONENTES USANDO SEMÂNTICA DE ONTOLOGIAS ............................................ 118

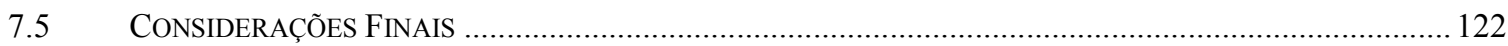

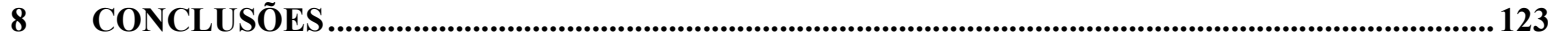

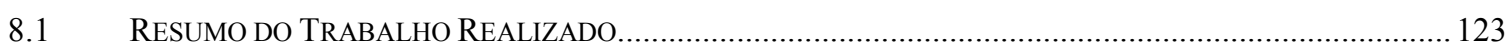

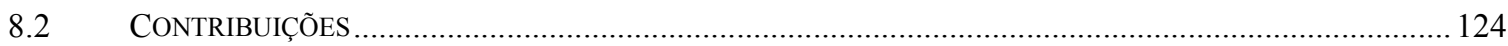

8.2.1 Aplicações Baseadas em Linguagem Natural..................................................................... 124

8.2.2 Busca por Componentes de Software .................................................................................... 125

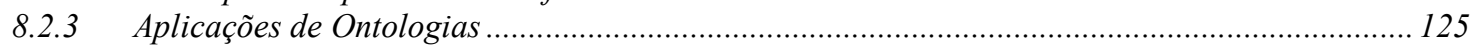

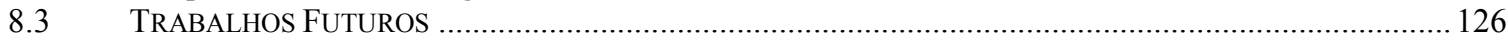

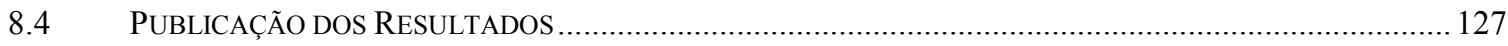

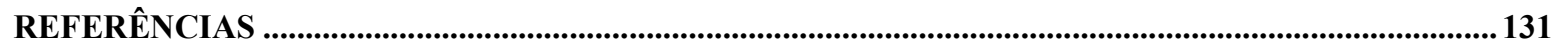

APÊNDICE A - DIAGRAMAS DE CLASSES DA ONTOLOGIA INTERCOMP.....................................141

APÊNDICE B - PRODUTOS DE TRABALHO (PT) DO PROCESSO .......................................................147

APÊNDICE C - INTERFACES DOS COMPONENTES ..................................................................157

APÊNDICE D - PRODUTOS DE TRABALHO (PT) DA INSTANCIAÇÃO DO PROCESSO .................. 165

APÊNDICE E - CÓDIGO OWL DA ONTOLOGIA DE DOMÍNIO (PT-10) ............................................181

APÊNDICE F - CÓDIGO OWL DA ONTOLOGIA DE COMPONENTES INSTANCIADA E

RELACIONADA COM A ONTOLOGIA DE DOMÍNIO (PT-11) ........................................................185

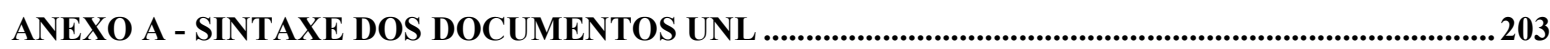

ANEXO B - SINTAXE DAS REPRESENTAÇÕES TABULAR E EM LISTA DE EXPRESSÕES UNL 207

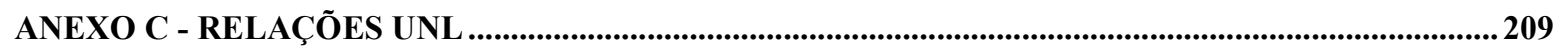

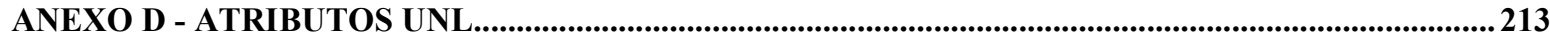




\section{CAPÍTULO}

\begin{tabular}{lr}
\hline \hline 4 & Introdução
\end{tabular}

\subsection{Contextualização}

Durante a história da computação sempre se buscou modos de interagir com os computadores que fossem mais próximos do modo de se comunicar dos seres humanos. Esforços têm sido feitos para tornar a interação entre pessoas e máquinas o mais natural possível. Por isso, interfaces que consideram a fala, os gestos e os textos em linguagem natural têm sido alvos de constantes pesquisas (Jaimes \& Sebe, 2005; Oviatt, 2003). Tantos esforços se devem ao desejo que os serem humanos possuem de poder se comunicar com máquinas em linguagem natural.

A linguagem natural é de fato a maneira mais convencional e utilizada para comunicação entre as pessoas. Em sistemas computacionais, a utilização de interfaces em linguagem natural pode trazer benefícios como (Manaris \& Slator, 1996):

- Facilidade de uso e aprendizado: a linguagem natural é fácil de aprender e de recordar, uma vez que sua estrutura e seu vocabulário já são familiares ao usuário e ele não precisa, portanto, aprender a sintaxe de comandos, nem saber como encontrar comandos específicos.

- Flexibilidade: devido à quantidade e variedade de construções lingüísticas possíveis, são permitidas múltiplas maneiras de se realizar uma ação. 
- Rapidez e eficiência: a linguagem natural é mais rápida e eficiente, uma vez que o usuário não precisa navegar entre telas de formulários ou menus e pode combinar as ações em uma única sentença.

Sistemas que utilizam interfaces em linguagem natural, na maioria das vezes,

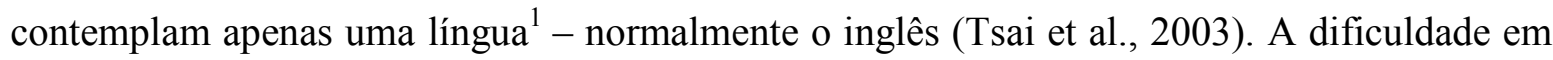
utilizar mais de uma língua em sistemas que trabalham com linguagem natural está no fato de que cada língua possui suas particularidades, o que dificulta o processamento e a adaptação da aplicação que utiliza linguagem natural como interface.

Uma maneira de flexibilizar o uso de diversas línguas em aplicações baseadas em linguagem natural é utilizando uma interlíngua. Uma interlíngua é uma representação intermediária e processável por máquina das informações presentes em várias línguas naturais (UNL Specifications, 2005). Com isso, a mesma sentença expressa em diversas línguas naturais pode ter a mesma representação, o que facilita e flexibiliza o uso de mais de uma língua natural por uma aplicação. Além disso, as línguas naturais são naturalmente ambíguas, o que pode ser contornado com o uso de uma interlíngua.

Outra área de pesquisa que tem adquirido cada vez mais importância ao longo da história da computação é a área de componentes de software, que vem se desenvolvendo rapidamente nos últimos anos. Os componentes têm ganhado atenção principalmente devido à grande possibilidade de reutilização que eles podem proporcionar, resultando em melhorias na produtividade e na qualidade do desenvolvimento de software. Além disso, a utilização de componentes pode proporcionar benefícios como (Fujii \& Suda, 2004):

- Flexibilidade: vários aplicativos úteis podem ser compostos a partir de um conjunto de componentes já existentes.

- Adaptabilidade: aplicações podem ser compostas levando em consideração um domínio específico.

- Disponibilidade: componentes que não estejam funcionando a contento podem ser substituídos automaticamente por outros.

Atualmente, uma tendência na área de componentes de software é que eles sejam utilizados em níveis de abstração cada vez mais elevados e levando em consideração domínios

\footnotetext{
${ }^{1} \mathrm{O}$ termo língua é utilizado neste documento com o significado de idioma.
} 
específicos (Tetlow et al., 2006). Mas, para possibilitar a utilização de componentes considerando determinado domínio, é preciso representar formalmente a terminologia desse domínio. Ontologias podem representar a semântica necessária para descrever o domínio de aplicação para o qual um componente foi desenvolvido, e assim auxiliar, por exemplo, aplicativos na tarefa de encontrar componentes apropriados para realizar determinadas tarefas.

\subsection{Motivação}

Recentemente, pesquisas em ciência da computação têm investigado o uso de componentes para executar comandos computacionais utilizando requisições em linguagem natural. A possibilidade de acessar operações de um computador por meio da mesma língua utilizada na interação com outras pessoas, mesmo que de maneira restrita, tem motivado diversas pesquisas desde o final dos anos 70 (Ballard \& Bierman, 1979; Cheyer \& Martin, 2001; Tsai et al., 2003; Herzog et al., 2004; Ishida, 2006).

Diversos trabalhos têm procurado explorar a possibilidade de ter as ações dos usuários descritas em linguagem natural e executadas pelo computador. Alguns desses trabalhos são muito limitados porque as requisições de entrada devem ser feitas de forma algorítmica (Ballard \& Bierman, 1979; Price et al., 2000). Mais recentemente, alguns trabalhos têm utilizado componentes ou agentes de software, relacionados a determinado domínio de aplicação, para conseguir um nível de abstração semântico mais elevado (Cheyer \& Martin, 2001; Lucena et al., 2003; Tsai et al., 2003; Herzog et al., 2004; Ishida, 2006).

Para possibilitar o uso de linguagem natural na interação com computadores, a maior parte da funcionalidade das aplicações baseadas em linguagem natural tem sido implementada por componentes de software. Com isso, comandos (ou requisições) podem ser dados em linguagem natural e executados pelo componente apropriado. Exemplos de requisições com alto nível semântico de abstração, no domínio de gerenciamento de cursos seriam:

(a) "Cadastre a aluna Flávia Linhalis no curso de Sistemas Operacionais".

(b) "Envie um e-mail para todos os alunos da turma de Programação I informando que o trabalho deve ser entregue até o dia 11/03/2007”. 
Apesar do apelo intuitivo da linguagem natural, discute-se que línguas como inglês e português possuem muitas ambigüidades para serem usadas na comunicação com computadores. O Projeto UNL (Universal Networking Language) pretende representar, no mundo dos computadores, a funcionalidade da linguagem natural usada na comunicação entre as pessoas. Mas, as contrário das línguas naturais, as expressões em UNL podem ser não ambíguas. UNL é uma interlíngua que permite que computadores processem informações e conhecimento relacionados a diversas línguas naturais como inglês, espanhol, português, etc. Com isso, UNL permite uma intercomunicação entre computadores, fornecendo assim uma infra-estrutura lingüística para distribuir, receber e compreender informações em diversas línguas (UNL Specifications, 2005).

O grande objetivo do Projeto UNL é permitir que a linguagem UNL seja usada na Internet para diminuir a barreira da linguagem entre os povos. $\mathrm{O}$ princípio é que qualquer pessoa com acesso à Internet seja capaz de converter (“EnConvert”) texto escrito em sua língua nativa para UNL. Do mesmo modo, qualquer texto em UNL pode ser revertido (“DeConverted") em uma variedade de outras línguas, como ilustrado na Figura 1.1.

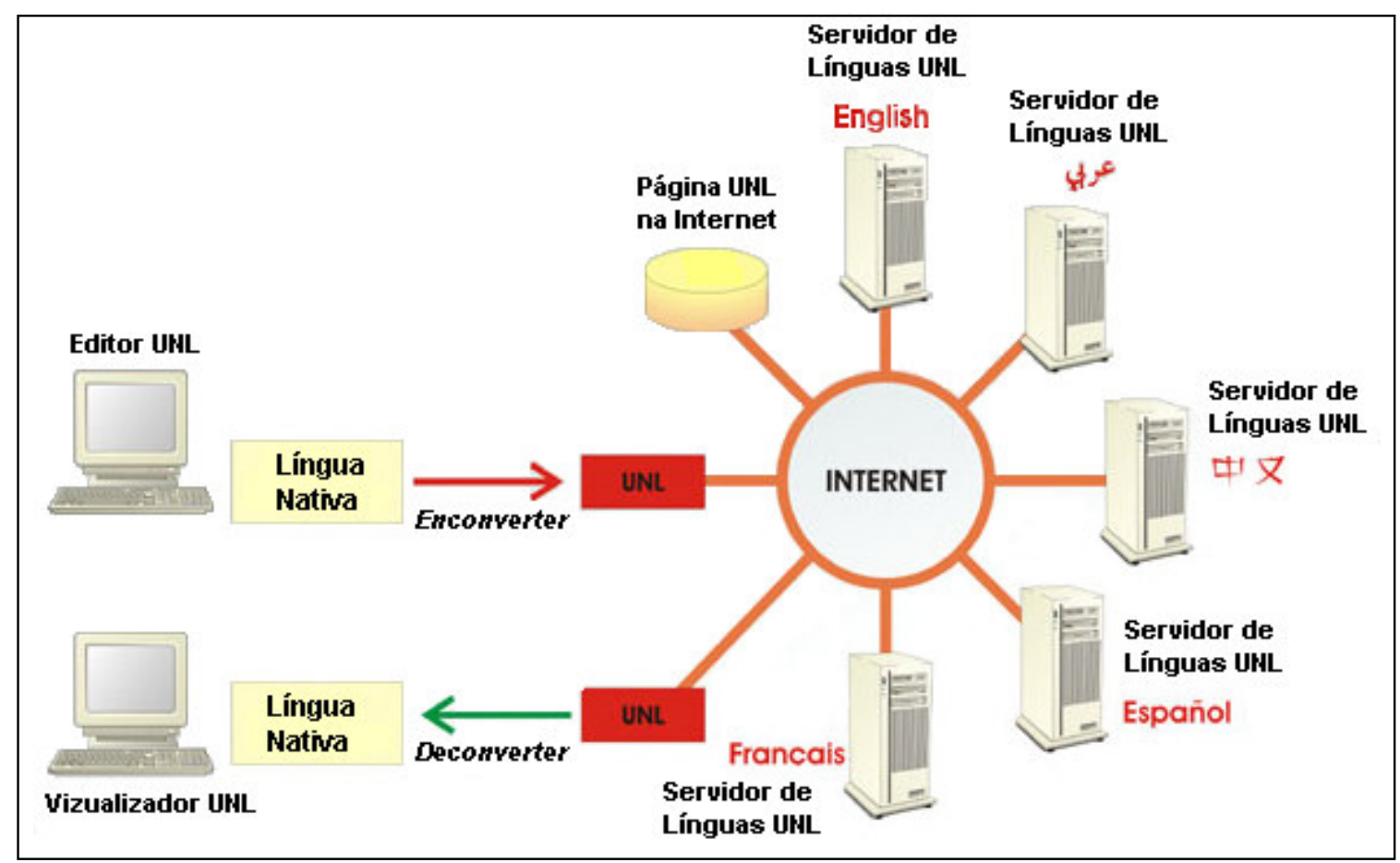

Figura 1.1 - O Sistema UNL (UNDL Foundation, 2006). 
Usando o Sistema UNL, se uma página da Internet está escrita em inglês, será possível ler essa página, por exemplo, em espanhol. Os processos de conversão e reversão são feitos por Servidores de Línguas que residem na Internet. Um conversor (EnConverter) converte uma língua em UNL, enquanto o "deconversor" (DeConverter) converte UNL em uma determinada língua natural. No exemplo da Figura 1.1, os servidores de línguas de inglês e espanhol irão realizar as conversões necessárias.

A utilização de uma representação intermediária (interlíngua) possibilita que sentenças possam ser processadas pela máquina, de maneira não ambígua e independente da língua utilizada. Diante das vantagens apresentadas na utilização de uma interlíngua como UNL, uma abordagem que relacione essa interlíngua com componentes de software, para possibilitar a execução de requisições em linguagem natural, merece ser investigada.

\subsection{Objetivos}

O trabalho descrito nesta tese se propõe a receber requisições em linguagem natural restrita, descritas em um em alto nível semântico de abstração, e executá-las por meio da chamada a componentes de software apropriados. Mas, diferente de outros trabalhos encontrados na literatura, este trabalho propõe que as requisições em linguagem natural sejam primeiramente convertidas para UNL.

O objetivo deste trabalho é relacionar UNL com componentes de software e assim encontrar, nos componentes apropriados, métodos para executar requisições imperativas em linguagem natural. Esse relacionamento entre UNL e componentes está sendo chamado aqui de mapeamento semântico entre UNL e componentes ${ }^{2}$. O mapeamento semântico, portanto, extrai informações semânticas sobre possíveis componentes que podem ser utilizados para executar uma requisição em linguagem natural. As informações extraídas com o mapeamento semântico são, então, utilizadas para fazer a busca pelo componente mais apropriado.

As ontologias têm um papel muito importante no mapeamento semântico e na busca por componentes propostos nesta tese, pois elas auxiliam o mapeamento semântico por meio

\footnotetext{
${ }^{2} \mathrm{O}$ mapeamento semântico é feito considerando os conceitos de UNL, também chamados de palavras universais (UWs - seção 2.6), e as relações de UNL (seção 2.4) com esses conceitos. Os atributos de UNL (seção 2.5) não são considerados, conforme explicado no Capítulo 5.
} 
do relacionamento de UNL com informações sobre componentes, além de auxiliar na busca por componentes fornecendo semântica sobre os mesmos.

Os objetivos específicos deste trabalho consistiram na realização das seguintes atividades:

1) Foi realizado um estudo sobre ontologias (conceitos, metodologias para construção, linguagens para representação, ferramentas e máquinas de inferência) para desenvolver a Ontologia de Componentes. Essa ontologia tem o objetivo de relacionar dados das interfaces dos componentes com informações semânticas sobre os mesmos.

2) Foi realizado um estudo sobre UNL, sobre quais informações poderiam ser extraídas da representação UNL e como essas informações poderiam estar relacionadas com componentes. O mapeamento semântico entre UNL e componentes começou a ser realizado.

3) Componentes relacionados ao domínio de gerenciamento de cursos foram desenvolvidos para realizar testes iniciais.

4) Foi desenvolvido um módulo de mapeamento semântico e um módulo de busca que utilizavam informações da representação UNL para encontrar componentes relacionados ao domínio de gerenciamento de cursos, desenvolvidos no passo anterior.

5) Foi feita uma investigação sobre uma Ontologia de Domínio que seria substituída sempre que o domínio de aplicação mudasse. Foi desenvolvida uma Ontologia de Domínio relacionada ao domínio de gerenciamento de cursos.

6) Identificou-se a necessidade de uma ontologia de alto nível (upper ontology) que pudesse relacionar UNL com informações sobre componentes para flexibilizar o mapeamento semântico. Com isso procedeu-se o desenvolvimento da Ontologia InterComp e de regras específicas para o conjunto de componentes desenvolvidos no item 3.

7) Novos testes foram realizados com a ontologia InterComp, utilizando os componentes já desenvolvidos (item 3) e outros componentes, desenvolvidos por terceiros. Os módulos de mapeamento semântico e busca foram refinados.

8) Foi feita a definição de uma arquitetura de software genérica, chamada de Arquitetura OntoMap (Ontology-based Semantic Mapping), que define os elementos de software necessários para realizar o mapeamento semântico e a posterior busca por componentes. A 
definição da Arquitetura OntoMap possibilita realizar o mapeamento semântico em diversos domínios, utilizando diferentes conjuntos de componentes.

9) Um processo para auxiliar a utilização da Arquitetura OntoMap por outros grupos de pesquisa foi definido e instanciado.

\subsection{Contribuiç̧ões}

Este trabalho tem como principais contribuições:

1) Definição do mapeamento semântico entre a representação UNL e componentes de software.

2) Definição da Arquitetura OntoMap que indica os elementos de software e os relacionamentos entre eles, necessários para realizar o mapeamento semântico e a busca por componentes.

3) Definição e instanciação de um processo para auxiliar outros grupos de pesquisa a utilizarem a Arquitetura OntoMap em diversos domínios de aplicação com diferentes conjuntos de componentes.

Os resultados produzidos durante o desenvolvimento deste projeto são:

1) Desenvolvimento da Ontologia InterComp para flexibilizar o mapeamento semântico. Essa ontologia relaciona a interlíngua UNL com componentes de software e, por meio da aplicação de regras, possibilita inferir informações semânticas relacionadas ao possível método que será utilizado para executar a requisição em linguagem natural.

2) Desenvolvimento de uma Ontologia de Componentes, que relaciona dados das interfaces de um conjunto de componentes com informações semânticas formalizadas na Ontologia de Domínio, que deve ser substituída quando o domínio de aplicação mudar.

3) Desenvolvimento de um Módulo de Busca, que utiliza a Ontologia de Componentes e informações extraídas da interlíngua UNL para encontrar possíveis componentes para executar uma requisição expressa em linguagem natural. 


\subsection{Organização da Tese}

Esta tese está organizada de modo a apresentar o contexto teórico no qual está inserida, bem como os resultados obtidos e suas contribuições para a comunidade acadêmica.

No Capítulo 2, a interlíngua UNL (Universal Networking Language) é descrita. O objetivo desse Capítulo é apresentar a linguagem UNL, a qual fornece uma infra-estrutura lingüística para representar informações relevantes de diversas línguas naturais. Além disso, esse Capítulo tem o objetivo de mostrar que a UNL pode também fornecer infra-estrutura para representar conhecimento na Internet.

No Capítulo 3 é feita uma revisão da literatura sobre ontologias, destacando as principais definições para o termo, metodologias para o desenvolvimento de ontologias, métodos de avaliação, linguagens para formalização de ontologias e ferramentas para auxiliar no desenvolvimento das mesmas.

No Capítulo 4 é feita uma breve revisão bibliográfica sobre componentes de software. Inicialmente, é dada uma visão geral sobre componentes, incluindo algumas definições e uma breve descrição dos principais sistemas de componentes. Posteriormente, são abordados alguns assuntos mais relacionados a esta tese, como busca e recuperação de componentes utilizando ontologias e interfaces dos componentes.

No Capítulo 5 é apresentada a Arquitetura OntoMap (Ontology-based Semantic Mapping), proposta para realizar o mapeamento semântico entre UNL e componentes, com o objetivo de identificar informações semânticas que são usadas para encontrar os componentes apropriados para executar requisições imperativas em linguagem natural.

No Capítulo 6 é descrito um processo detalhado para a utilização da Arquitetura OntoMap. Além disso, é apresentada uma instanciação do processo para o domínio de gerenciamento de cursos.

No Capítulo 7 são apresentados os principais trabalhos relacionados a este, buscando comparar o trabalho descrito nesta tese com outras abordagens.

Finalmente, no Capítulo 8, são apresentadas as conclusões desta tese, incluindo propostas de continuidade desta pesquisa. 


\section{CAPÍTULO \\ 2 \\ O Projeto UNL}

\subsection{Considerações Iniciais}

O projeto UNL (Uchida \& Zhu, 2001; Uchida et al, 1999) foi criado pelas Nações Unidas e propõe uma interlíngua (ou língua-pivot), chamada Universal Networking Language (UNL), com expressividade suficiente para representar informações relevantes presentes em línguas naturais de uma forma processável pelo computador e de maneira não ambígua. Para cada língua, dois sistemas devem ser desenvolvidos: um EnConverter (EnCo) que converte textos em linguagem natural para UNL, e um DeConverter (DeCo) capaz de traduzir textos de UNL para uma língua alvo.

Um EnCo e um DeCo para cada língua formam um servidor de línguas e utilizam um dicionário e regras gramaticais para cada língua natural. A idéia é que todos os servidores de línguas sejam conectados à rede UNL na Internet. Eles irão permitir que qualquer usuário da Internet possa decodificar um documento UNL encontrado na web para sua língua nativa, assim como produzir representações UNL de textos que o usuário deseje tornar disponíveis ao público de outras nações (Boguslavsky et al., 2000).

UNL não é a primeira linguagem criada para traduzir textos utilizando para isso uma representação intermediária (interlíngua). Outros exemplos dessa mesma idéia podem ser encontrados em tradutores acadêmicos e comerciais, como ATLAS (Uchida, 1986), 
SYSTRAN $^{3}$ (Gachot et al., 1998) e Ergane ${ }^{4}$. UNL foi a linguagem escolhida por este trabalho porque o objetivo do projeto UNL não é simplesmente criar uma interlíngua para fazer tradução de textos, mas diminuir a barreira da língua na Internet. A missão das Nações Unidas com o projeto UNL é diminuir a barreira lingüística que exclui da comunidade global um grande segmento da população, que não domina nenhuma das línguas em que circula a maior parte dos valores culturais e do conhecimento (UNDL Foundation, 2006; UNDL Brasil, 2005).

A seção 2.2 apresenta um breve histórico sobre o projeto UNL, incluindo sua criação, evolução e as principais instituições envolvidas com o projeto ao redor do mundo. As demais seções estão divididas de acordo com a especificação de 2005 (UNL Specifications, 2005) em expressões UNL, relações, atributos, palavras universais, base de conhecimento (UNL KB), expressões lógicas em UNL e sistema UNL.

\subsection{Histórico de UNL}

O projeto UNL foi criado em 1996 pelo Instituto de Estudos Avançados (IAS Institute of Advanced Studies) da Universidade das Nações Unidas (UNU - United Nations University) $^{5}$, sediada em Tóquio. Em 2001, a UNU criou a Fundação UNDL (Universal Networking Digital Language $)^{6}$, que é uma instituição internacional independente e sem fins lucrativos, com sede em Genebra. A função da Fundação UNDL é continuar o trabalho de desenvolver e promover o projeto UNL.

Desde sua criação, o projeto conta com uma comunidade ativa espalhada pelo mundo. Workshops e simpósios a respeito da linguagem e do projeto UNL têm acontecido periodicamente (UNDL Brasil, 2005; Cardeñosa et. al, 2005).

Até a especificação de dezembro de 2004, o principal objetivo de UNL era fornecer a infra-estrutura para uma linguagem (UNL Specifications, 2004). A especificação de junho de 2005 (UNL Specifications, 2005) foi uma evolução com relação às anteriores, pois com ela pretende-se fornecer também infra-estrutura para representar conhecimento (Uchida \& Zhu, 2005). Em agosto de 2006 foi lançada a última especificação até o momento (UNL

\footnotetext{
${ }^{3}$ http://www.systransoft.com/. Acesso em: 22 jan. 2007.

${ }^{4} \mathrm{http}: / /$ download.travlang.com/. Acesso em: 22 jan. 2007.

${ }^{5} \mathrm{http}: / /$ www.ias.unu.edu. Acesso em: 22 jan. 2007.

${ }^{6} \mathrm{http}: / /$ www.undl.org. Acesso em: 22 jan. 2007.
} 
Specifications, 2006). Ela apenas acrescenta como lidar com expressões idiomáticas em UNL, tais como "rely on", "give rise to" e "take one's choice".

O Projeto UNL estava previsto para ter 10 anos de duração, mas tudo indica que não deverá terminar tão cedo. Várias equipes de pesquisadores ao redor do mundo estão desenvolvendo servidores de línguas para as 16 línguas a seguir (UNDL Brasil, 2005):

- Alemão: Instituto para Ciências Aplicadas à Informação, de Saarbrücken, na Alemanha;

- Árabe: Biblioteca Alexandrina, no Egito, e Sociedade Científica Real da Jordânia;

- Armênio: Academia Nacional de Ciências da Armênia, em Yerevan;

- Chinês: Centro de Pesquisa para o Desenvolvimento Industrial da Microeletrônica e da Computação (CCID) do Ministério da Indústria e da Informação da República Popular da China;

- Francês: Laboratório GETA-CLIPS, da Universidade Joseph Fourier, e o CNRS (Centre National de la Recherche Scientifique), da França;

- Japonês: Universidade Tecnológica de Tóquio;

- Inglês: Centro UNL, em Genebra, na Suíça;

- Hindi: Instituto Indiano de Tecnologia de Mumbai, na Índia;

- Indonésio: Diretório para Tecnologia em Informática e Eletrônica da Agência para Avaliação e Aplicação de Tecnologia, na Indonésia;

- Italiano: Instituto de Lingüística Computacional de Pisa, e o CNRS, da Itália;

- Lituano: o Instituto de Matemática e de Ciência da Computação da Universidade da Letônia;

- Mongol: Universidade Estadual Pedagógica da Mongólia;

- Português: Universidade de São Paulo, em São Carlos, Brasil; Instituto UNDL Brasil, em Florianópolis, Brasil;

- Russo: Instituto para Problemas de Transmissão de Informações da Academia de Ciências da Rússia; e a empresa STAR SPB Ltd, de São Petersburgo, na Rússia;

- Espanhol: Universidade Politécnica de Madri, na Espanha;

- Tailandês: Centro Nacional para Tecnologia de Computação e Eletrônica da Tailândia. 
O português do Brasil integra o Projeto desde 1997, através do NILC (Núcleo Interinstitucional de Lingüística Computacional) ${ }^{7}$, em São Carlos, São Paulo e, mais recentemente, do Instituto UNDL no Brasil ${ }^{8}$, sediado em Florianópolis, Santa Catarina (UNDL Brasil, 2005).

\subsection{Expressões UNL}

A linguagem UNL representa informação e conhecimento das línguas naturais. Para isso, ela é composta de palavras que expressam conceitos, chamadas de "palavras universais" ou simplesmente UWs (Universal Words) (seção 2.6). As UWs são ligadas com outras UWs para formar as "expressões UNL", que representam sentenças. Essas ligações entre as UWs são chamadas de "relações" (seção 2.4) e especificam o papel de cada palavra em uma sentença. Há ainda os "atributos" (seção 2.5), que fornecem informações adicionais às sentenças, por exemplo, a respeito do ponto de vista do autor da sentença. Qualquer componente de uma sentença, tal como uma palavra, uma frase e a própria sentença de uma língua natural podem ser representadas com expressões UNL. (UNL Specifications, 2005; Uchida \& Zhu, 2005).

UNL expressa informação e conhecimento na forma de rede semântica (seção 3.2.2.2), onde nodos representam conceitos (ou UWs) e arcos representam relações entre conceitos, que podem ser anotados por atributos. Tal rede semântica é chamada de expressão UNL. Com isso, a sentença do português 'O céu era azul!' é representada em UNL como na Figura 2.1.

Como pode ser observado pela Figura 2.1, as UWs ("sky" e "blue") da expressão UNL são representadas por nodos e as relações (no exemplo, “aoj”) por arcos. O rótulo de relação “aoj” indica uma relação semântica entre as duas UWs; que, neste caso, significa que o céu tem a característica de ser azul.

Um nodo (UW) pode ainda conter uma rede semântica com uma expressão UNL. Quando isso acontece, o nodo é chamado de "escopo". Um escopo pode estar conectado a outra UW ou a outro escopo, pois um escopo é considerado uma UW composta. Uma relação

\footnotetext{
${ }^{7}$ http://www.nilc.icmc.usp.br. Acesso em: 22 jan. 2007.

${ }^{8}$ http://undl.org.br. Acesso em: 21 set. 2006.
} 
binária em um escopo se diferencia das outras por meio de um identificador (ID). O restante desta seção mostra os formatos para descrever documentos e expressões UNL.

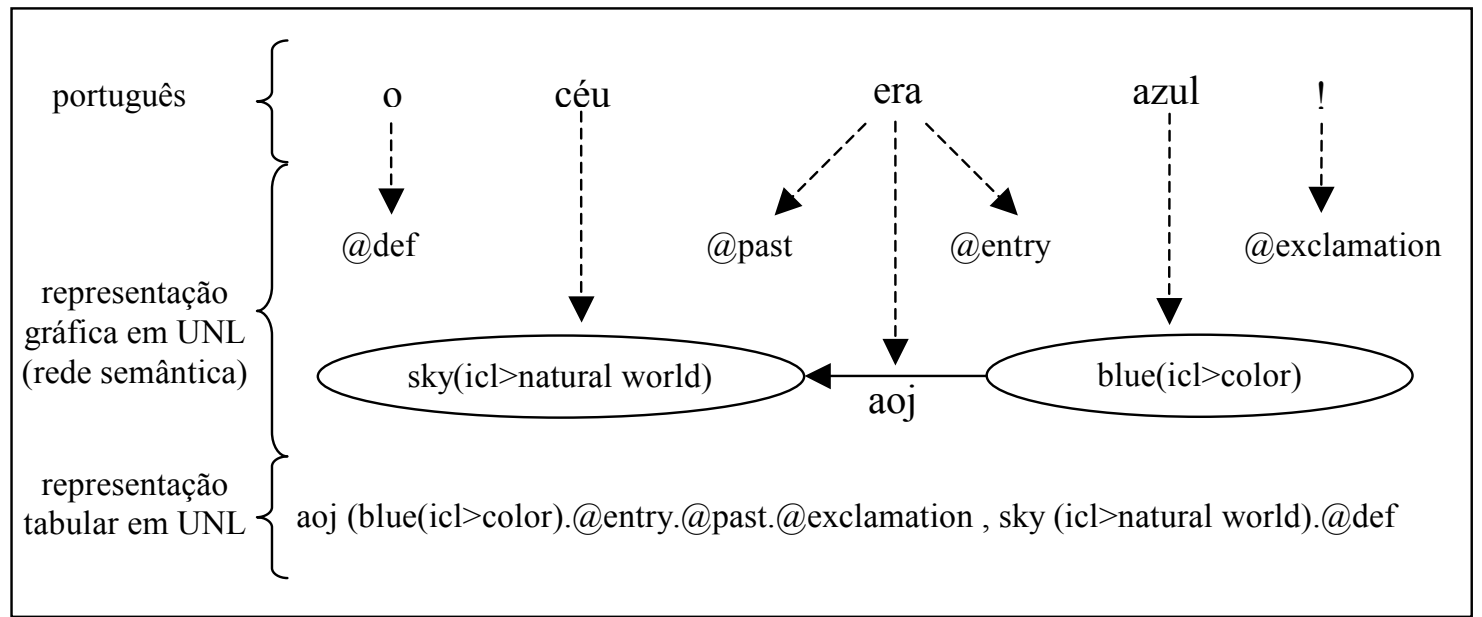

Figura 2.1 - Representação UNL para a sentença "O céu era azul!" (UNDL Brasil, 2005).

\subsubsection{Formato dos Documentos UNL}

As expressões UNL (UNL Specifications, 2005) são descritas em documentos UNL. Um documento UNL é um arquivo texto, contendo as sentenças originais, expressões UNL e sentenças na língua destino.

Um documento UNL deve estar delimitado entre as etiquetas " $[\mathrm{D}:<\operatorname{dinf}>]$ " e "[/D]". Dentro dessas etiquetas, cada parágrafo está entre as etiquetas “[P: $<$ p_num $>$ ]" e "[/P]" e cada sentença está entre as etiquetas "[S: $<$ s_num $>$ ]" e "[/S]". Dentro de uma sentença, o texto da sentença original está entre as etiquetas " $\left\{\right.$ org: $<1 \_$tag $\left.>\right\}$" e " $\{/$org $\}$” e suas expressões UNL estão entre " $\{$ unl: $<$ uinf $>\}$ " e " $\{/$ unl $\} "$. Sentenças nas linguagens destino também podem ser armazenadas no documento UNL, cada uma delas entre as etiquetas " $\{<1$ tag $>\}$ " e " $\left\{</ 1 \_\right.$tag $\left.>\right\} "$, seguidas da expressão UNL de cada sentença. O Anexo A apresenta a sintaxe de um documento UNL. 


\subsubsection{Formato das Expressões UNL}

Em documentos UNL (UNL Specifications, 2005), uma expressão UNL para uma sentença fica entre as etiquetas $\{\mathrm{unl}\}$ e $\{/ \mathrm{unl}\}$ dentro de [S] e [/S]. Se uma expressão UNL consiste de uma UW, essa UW deve estar entre as etiquetas [W] e [/W]. Se necessário, a sentença pode ser representada como um escopo. Neste caso, o ID do escopo deve estar entre as etiquetas $[\mathrm{W}]$ e $[/ \mathrm{W}]$.

Há duas formas de representar expressões UNL: tabular e lista. A forma tabular contém um conjunto de relações (seção 2.4) e cada relação é expressa pela conexão das duas UWs (seção 2.6) relacionadas diretamente. A Figura 2.2 mostra a forma tabular para representação da sentença "Eu ouço um cão latindo lá fora". A sintaxe utilizada na representação tabular pode ser encontrada no Anexo B.

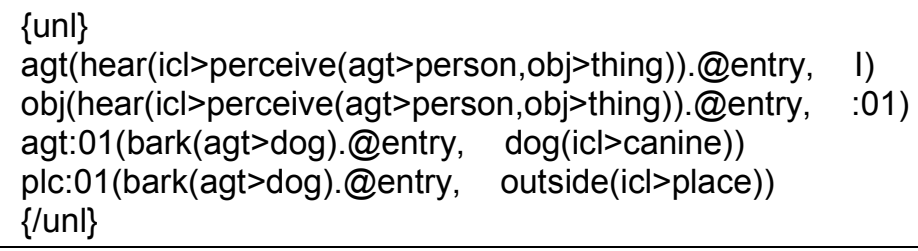

Figura 2.2 - Representação tabular da sentença "Eu ouço um cão latindo lá fora" (UNL Specifications, 2005).

No exemplo, “agt", “obj” e "plc” são rótulos de relações (seção 2.4) “l”, “bark(agt>dog)", "dog(icl>canine)", "hear(icl>perceive(agt>person,obj>thing))" e "outside(icl>place)" são UWs. "um cão latindo lá fora" é expresso por um escopo e "01” é o ID do escopo. “:01” é usado para se referir ao escopo e aparece na posição de uma UW. As relações binárias indicadas pelo ID do escopo (no exemplo, "agt" e "plc") definem o conteúdo do escopo.

O formato em lista de uma expressão UNL consiste de um conjunto de UWs, onde cada UW possui um ID, e um conjunto de relações, que referenciam as UWs por seus IDs. No caso de uma sentença ser tratada como um escopo, o ID do escopo pode ser incluído na lista de UWs entre [W] e [/W]. Um exemplo com a mesma sentença (Eu ouço um cão latindo lá fora) é dado na Figura 2.3. A sintaxe utilizada na representação em lista pode ser encontrada no Anexo B. 
No exemplo, entre [W] e [/W], estão as UWs “l”, "hear(icl>perceive(agt>thing, obj>thing))", "dog(icl>canine)", "bark(agt>dog)", "outside(icl>place)" e o escopo ":01”, que é tratado como uma UW. Para cada UW foi dado um ID de 01 a 06 respectivamente.

Entre $[R]$ e [/R], as relações binárias estão descritas usando os IDs das UWs. Por exemplo, "02obj06" mostra que o conceito indicado pelo ID 06 é o objeto ("obj”) do conceito indicado pelo ID 02. As relações binárias “04agt:0103” e “04plc:0105” formam a expressão UNL do escopo "01". Isso é indicado pelo ID do escopo "01" logo após as relações "agt" e "plc".

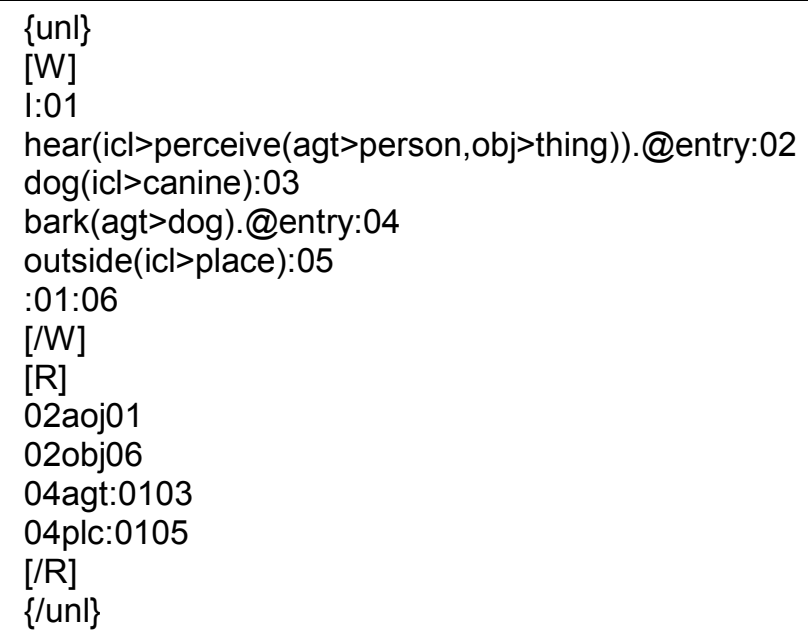

Figura 2.3 - Representação em lista da sentença "Eu ouço um cão latindo lá fora" (UNL Specifications, 2005).

\subsection{Relações}

As relações expressam informações semânticas entre UWs (conceitos). Cada relação é representada por um rótulo com no máximo três caracteres (Relation Label ou apenas RL). Sua representação genérica é um par do tipo $\mathrm{RL}\left(\mathrm{UW}_{1}, \mathrm{UW}_{2}\right)$, onde $\mathrm{UW}_{1}$ e $\mathrm{UW}_{2}$ são relacionadas através da relação semântica denotada pelo RL.

UNL possui atualmente 46 relações (UNL Specifications, 2005), que podem ser divididas em grupos, de acordo com o tipo de informação semântica que fornecem. As relações fornecem informações sobre a estrutura ontológica do dicionário (relações de hiponímia e sinonímia, por exemplo), a estrutura lógica da sentença (por meio de operadores 
de conjunção e de disjunção, entre outros) e a estrutura cognitiva do evento (por meio de variados casos semânticos, como os de agente, objeto, instrumento, etc.). Portanto, as relações podem ser divididas em três grupos: ontológicas, lógicas e psicológicas (UNDL Brasil, 2005). A Tabela 2.1 mostra algumas relações UNL, com seus rótulos e significados. O Anexo C apresenta todas as 46 relações, divididas em seus respectivos grupos.

Tabela 2.1 - Exemplos de relações UNL (UNDL Brasil, 2005; UNL Specifications, 2005).

\begin{tabular}{|l|c|l|l|}
\hline \multicolumn{1}{|c|}{ RELAÇÃO } & RÓTULO & \multicolumn{1}{|c|}{ EXEMPLO (UNL) } & \multicolumn{1}{|c|}{ EXEMPLO (português) } \\
\hline Hiponímia & icl & $\begin{array}{l}\text { icl(table(icl>furniture), } \\
\text { furniture(icl>functional thing)) }\end{array}$ & mesa \\
\hline Instância & iof & $\begin{array}{l}\text { iof(São Carlos(iof>city), } \\
\text { city(icl>region)) }\end{array}$ & São Carlos \\
\hline Conjunção & and & and(Pedro, Maria) & Maria e Pedro \\
\hline Agente & agt & agt(hold, João) & JOÃO SEGUROU Maria \\
\hline Objeto & obj & obj(hold, Maria) & João SEGUROU MARIA \\
\hline Lugar & plc & plc(meet, church) & João ENCONTROU Pedro na IGREJA \\
\hline Tempo & tim & tim(meet, evening) & João ENCONTROU Pedro à TARDE \\
\hline Atribuição & aoj & aoj(jealous, João) & JOÃO é CIUMENTO \\
\hline Nome & nam & nam(city, São Carlos) & CIDADE DE SÃO CARLOS \\
\hline Parte & pof & pof(neck, Pedro) & O PESCOÇO DE PEDRO \\
\hline Estado Final & gol & gol(change, red) & MUDAR de azul para VERMELHO \\
\hline
\end{tabular}

\subsection{Atributos}

Atributos são usados para descrever informações subjetivas das sentenças (UNL Specifications, 2005; Uchida \& Zhu, 2005), principalmente para mostrar a sentença do ponto de vista de quem a falou.

Cada atributo possui um rótulo (Attribute Label - AL). Portanto, uma UW com $n$ atributos tem a forma: UW.@AL $. @ \mathrm{AL}_{2} \ldots . . @ \mathrm{AL}_{n}$. Atualmente, existem 87 atributos divididos em 8 grupos, mas esse conjunto é extensível. A Tabela 2.2 mostra alguns atributos de cada grupo, juntamente com o significado de cada atributo. A lista completa de atributos, separados por grupos, pode ser obtida no Anexo D. 
Tabela 2.2 - Atributos de UNL (UNL Specifications, 2005; UNDL Brasil, 2005).

\begin{tabular}{|c|c|c|}
\hline GRUPO & ATRIBUTO & RÓTULO DO ATRIBUTO (AL) \\
\hline \multirow[t]{2}{*}{ Expressões Lógicas } & transitividade & @transitive \\
\hline & simetria & @symmetric \\
\hline \multirow[t]{2}{*}{ Tempo } & passado & @past \\
\hline & futuro & @future \\
\hline \multirow[t]{2}{*}{ Aspecto } & início & @begin \\
\hline & continuação & @continue \\
\hline \multirow[t]{2}{*}{ Referência } & definida & $@$ def \\
\hline & complementar & @not \\
\hline \multirow[t]{2}{*}{ Foco } & principal & @entry \\
\hline & contraste & @contrast \\
\hline \multirow[t]{2}{*}{ Atitude } & afirmativa & @affirmative \\
\hline & imperativa & @imperative \\
\hline \multirow[t]{2}{*}{ Ponto de vista } & necessidade & @need \\
\hline & certeza & @certain \\
\hline \multirow[t]{2}{*}{ Convenção } & plural & @pl \\
\hline & \{\} & @brace \\
\hline
\end{tabular}

\subsection{Palavras Universais (UWs)}

As palavras universais (Universal Words - UWs) constituem o vocabulário de UNL (UNL Specifications, 2005). Cada UW denota um significado específico e é representada por uma palavra da língua inglesa, que pode ser acompanhada de restrições para retirar a ambigüidade ou restringir o significado da palavra. Por exemplo, a UW "book" pode ter outras UWs associadas a ela, para indicar os seus vários significados, como em:

book(icl>publication), ou seja, livro

ou

book(obj>room), ou seja, reservar um quarto.

Para este exemplo deve-se considerar que a UW book está associada com outras UWs como "publication" e "room", além disso para auxiliar na definição de uma UW se utilizam rótulos de relação como “ïcl” e "obj” (seção 2.4).

Portanto, a UW book contém todos os significados possíveis, ao passo que as outras, com restrições, servem para retirar a ambigüidade da UW book (Sossolote, et al., 1997). 
Observa-se no exemplo que a restrição (icl>publication) limita o significado da palavra book referindo esta a uma publicação. A outra restrição $(o b j>r o o m)$ indica que a palavra book está relacionada com a reserva de um quarto.

\subsubsection{Tipos de UWs}

As UWs podem ser classificadas em seis tipos: básicas, restritas, extras, temporárias, compostas e nulas (UNL Specifications 2005; UNDL Brasil, 2005). A UW básica é uma palavra em inglês e denota todos os conceitos que podem corresponder àquela palavra. As UWs básicas não devem ser usadas se a expressão em inglês for ambígua. O exemplo dado com a palavra "book”, no início da seção 2.6, diz respeito a uma UW básica.

Uma UW restrita é formada por uma palavra em inglês (UW básica) seguida de restrições. Os exemplos "book(icl>publication)" e "book(obj>room)", apresentados no inicio da seção 2.6, são exemplos de UWs restritas.

As UWs extras são palavras que não existem na língua inglesa e por isso precisam ser expressas em uma língua estrangeira. A UW "samba (icl>dance)" é um exemplo de UW extra.

Não é necessário definir as UWs temporárias, pois elas só aparecem em determinado documento UNL e não são classificadas como "conceitos". Elas podem ser vistas como valores de instância de outras UWs. Exemplos de UWs temporárias são números de telefone, nomes de pessoa, endereços de e-mail, etc.

As UWs compostas são expressas através de escopos nas expressões UNL. Uma UW composta é um conjunto de relações binárias que são agrupadas para expressar um conceito complexo, isto é, são conceitos que só podem ser compreendidos como um todo considerando todas as suas partes ao mesmo tempo. A seção 2.3.2 apresenta o exemplo de um escopo em uma expressão UNL.

As UWs nulas (UNDL Brasil, 2005) são utilizadas quando um dos conceitos da relação é omitido na sentença, como no exemplo agt(kill(agt>thing,obj>thing).@entry. @past, “”. 


\subsubsection{O Sistema de UWs}

Como definir um conceito (ou UW) depende de como esse conceito será usado para representar o conhecimento. Em UNL, a definição de um conceito envolve quais relações semânticas ele pode ter com outros, ou com quais conceitos ele pode ter essas relações semânticas, ou quais papéis ele pode assumir no caso de satisfazer várias relações semânticas. Partindo desse ponto de vista, as possíveis relações que um conceito pode ter com outros são percebidas por meio da definição do conceito. Essas possíveis relações não apenas identificam o conceito, mas também descrevem seu comportamento, o que fornece informação sobre como ele deve ser utilizado em uma expressão UNL (UNL Specifications, 2005; Uchida \& Zhu, 2005).

Baseado nisso, a partir da especificação 2005, os conceitos UWs foram divididos nas quatro seguintes categorias (UNL Specifications, 2005; Uchida \& Zhu, 2005): conceitos nominais (nominal concepts), conceitos verbais (verbal concepts), conceitos adjetivos (adjective concepts) e conceitos adverbiais (adverbial concepts). Cada uma dessas categorias possui uma estrutura hierárquica de conceitos que serve para definir como cada um deles será usado para representar o conhecimento. Tal estrutura hierárquica é a base do sistema de UWs, que forma a UNL KB (ver seção 2.7). A Tabela 2.3 mostra um trecho da estrutura do sistema de UWs.

\subsection{Uma Base de Conhecimento para UNL (UNL KB)}

A UNL KB (UNL Knowledge Base) ${ }^{9}$ contém todas as relações binárias diretas entre UWs (UNL Specifications, 2005). Os objetivos da UNL KB são:

- Definir a semântica das UWs: uma UW é um rótulo para um conceito. Os conceitos rotulados por UWs são definidos através da descrição do conjunto de possíveis relações que os conceitos podem ter com outros na UNL KB.

- Fornecer conhecimento lingüístico sobre os conceitos: o comportamento de um conceito é considerado como conhecimento lingüístico sobre o conceito. Por exemplo, um “autor" é uma "pessoa”, que pode executar várias ações cabíveis a

\footnotetext{
${ }^{9}$ Disponível em: www.undl.org/unlsys/uw/UNLKB_tree.txt. Acesso em: 22 jan. 2007.
} 
uma pessoa, como escrever algo, que pode ser um livro e diversas outras coisas. Esse nível de conhecimento é necessário para fornecer a semântica das sentenças em linguagem natural.

Tabela 2.3 - Trecho dos primeiros níveis da estrutura do sistema de UWs (UNL Specifications, 2005).

\begin{tabular}{|c|c|c|c|}
\hline 1ํ nível & $2^{\circ}$ nível & 3ํnível & $4^{\circ}$ nível \\
\hline \multirow[t]{8}{*}{$\begin{array}{l}\text { Universal } \\
\text { Word } \\
\text { uw }\end{array}$} & $\begin{array}{l}\text { nominal } \\
\text { concept }\end{array}$ & thing & $\begin{array}{l}\text { abstract thing } \\
\text { concrete thing } \\
\text { functional thing } \\
\text { place(icl>thing) } \\
\text { pronominal thing } \\
\text { time(icl>thing) } \\
\text { volitional thing }\end{array}$ \\
\hline & verbal concept & be & $\begin{array}{l}\text { be(aoj>thing) } \\
\text { be(aoj>thing,obj>thing) }\end{array}$ \\
\hline & & do & $\begin{array}{l}\text { do(agt>thing) } \\
\text { do(agt>thing, bas }>\text { thing, obj>thing) } \\
\ldots\end{array}$ \\
\hline & & occur & $\begin{array}{l}\text { occur(gol>thing,obj>thing) } \\
\text { occur(gol>thing,obj>thing,src>thing) } \\
\ldots\end{array}$ \\
\hline & $\begin{array}{l}\text { adjective } \\
\text { concept }\end{array}$ & uw(aoj>thing) & $\begin{array}{l}\text { uw(aoj>abstract thing) } \\
\text { uw(aoj>concrete thing) } \\
\ldots\end{array}$ \\
\hline & & $\mathrm{uw}$ (mod>thing) & $\begin{array}{l}\text { uw(mod>abstract thing }) \\
\text { uw(mod>concrete thing) } \\
\ldots\end{array}$ \\
\hline & & uw(qua>thing) & \\
\hline & $\begin{array}{l}\text { adverbial } \\
\text { concept }\end{array}$ & how & $\begin{array}{l}\text { how(man>adjective concept) } \\
\text { how(man>djective concept,obj>thing) } \\
\text {... }\end{array}$ \\
\hline
\end{tabular}

Na UNL KB, a semântica das UWs e o conhecimento lingüístico dos conceitos são definidos usando o sistema de UWs (descrito na seção 2.6.2). Na UNL KB, todas as UWs são ligadas umas às outras por meio das relações de subclasse (icl), instância (iof) ou equivalência (equ). Esses relacionamentos formam uma hierarquia de UWs ou sistema de UWs. Nesse sistema, todas as possíveis relações que uma UW pode ter com outras, tais como agente (agt), objeto (obj), etc, são definidas para cada UW. Toda relação possível é definida entre os dois conceitos mais genéricos de UWs. Utilizando a propriedade de herança do sistema de UW, possíveis relações com conceitos menos genéricos podem ser inferidas, o que reduz o número 
de relações binárias entre UWs na UNL KB. Mais informações sobre a estrutura da UNL KB e sobre o sistema de UWs podem ser obtidas na especificação de UNL (UNL Specifications, 2005).

\subsection{Expressões Lógicas em UNL}

UNL pode ser usada como linguagem lógica (UNL Specifications, 2005; Uchida \& Zhu, 2005). As funções para expressar lógica em UNL e os mecanismos de raciocínio usando UNL são essenciais para estabelecer infra-estrutura de conhecimento baseada em UNL, entretanto ainda não existem máquinas de inferência para processar expressões lógicas em UNL.

Em expressões UNL, todo conceito é representado usando UWs. Mas é necessário expressar também regras para inferência e expressões lógicas. Para isso, é preciso representar também as variáveis, que são necessárias para escrever regras e expressões lógicas. Em UNL, variáveis são expressas como UWs temporárias. Por exemplo, "x(iof>dog(icl>canine))" é uma variável expressando qualquer elemento pertencente a "dog(icl>canine)". A expressão lógica para a sentença "cães são espertos" é representada como em (1):

$$
\forall \mathrm{x} \text { (cão(x) -> esperto(x)) }
$$

A expressão UNL para essa expressão lógica é a seguinte:

$$
\begin{aligned}
& \text { aoj:01 ( dog(icl>canine).@entry, x(iof>dog }(\text { icl>canine }))) \\
& \text { con ( :02.@entry, :01) } \\
& \text { aoj:02 ( clever(aoj>thing).@entry, x(iof>dog(icl>canine })) \text { ) }
\end{aligned}
$$

O exemplo em UNL descreve que "se x é um cão, então é esperto". Portanto, usar uma expressão lógica em UNL para dizer que "se x é um cão, então é esperto" é o mesmo que usar uma expressão UNL para dizer que "cães são espertos". Mais informações sobre expressões lógicas em UNL podem ser encontradas na especificação de UNL (UNL Specifications, 2005).

\subsection{O Sistema UNL}

Para que UNL possa alcançar a meta de diminuir a barreira da língua na Internet, é necessário viabilizar o sistema UNL. Esse sistema consiste de três partes: recursos de 
linguagem, programas para processar os recursos de linguagem e ferramentas e sistemas para manter e operar as duas partes anteriores. Os recursos de linguagem podem ser dependentes ou independentes de determinada língua. Os conceitos considerados universais para qualquer língua são classificados como independentes e devem ser armazenados em uma base de dados comum, a UNL KB. Recursos dependentes de linguagem, como dicionários de palavras, regras gramaticais e programas para processar sentenças (EnCo e DeCo), são armazenados no servidor de língua correspondente. Os diversos servidores de línguas são conectados através da Internet. Ferramentas de suporte para produzir documentos UNL podem ser usadas localmente. Tais ferramentas podem consultar servidores de línguas para, por exemplo, verificar documentos UNL.

No Capítulo 1 foi apresentada uma visão simplificada do sistema UNL (ver Figura 1.1). A Figura 2.4 apresenta a estrutura completa do sistema UNL. As partes em amarelo mostram os componentes do sistema, as partes em azul mostram ferramentas que podem auxiliar a utilizar os componentes do sistema UNL e as partes em branco mostram aplicações e suas bases de dados UNL.

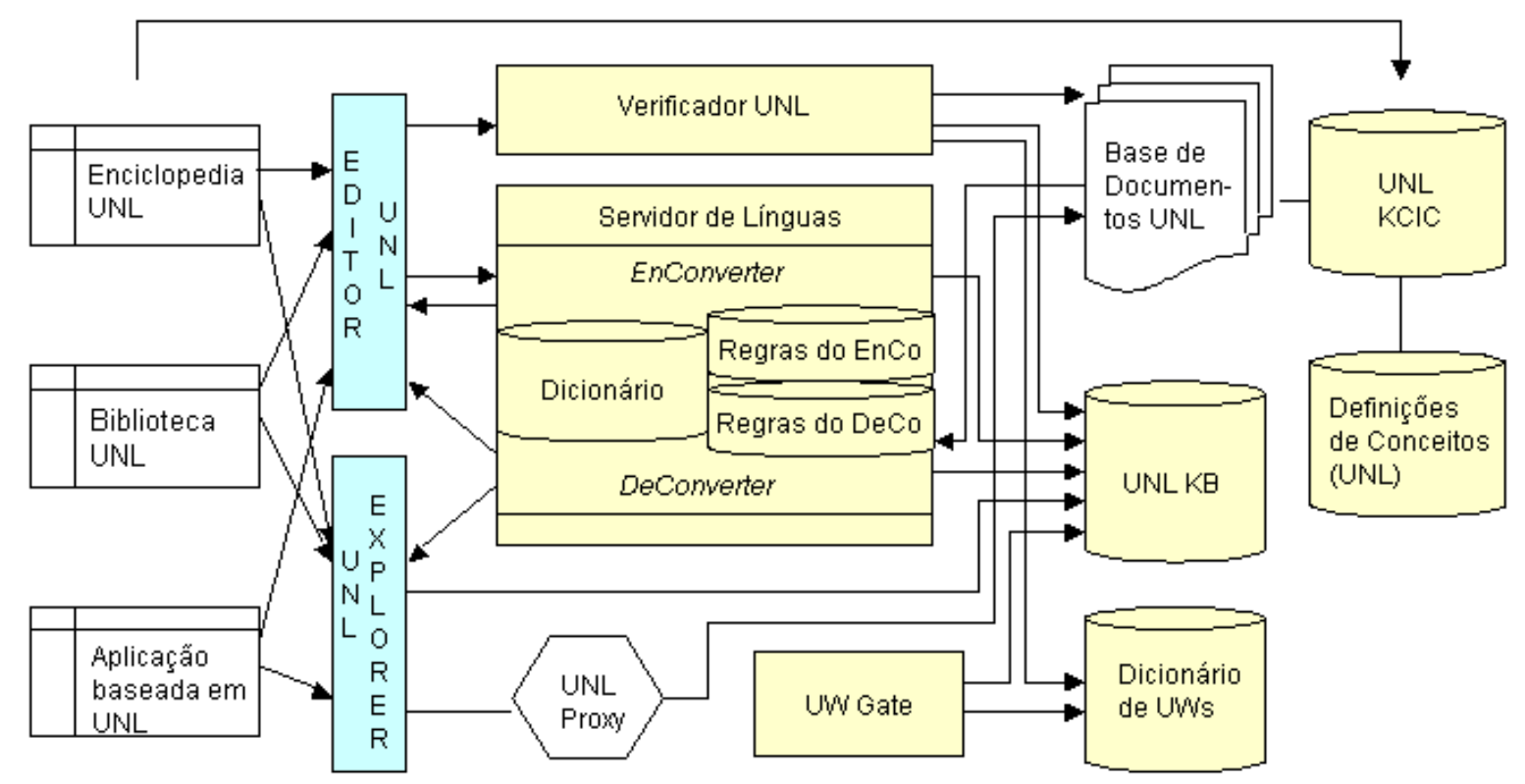

Figura 2.4 - Estrutura do Sistema UNL (UNL Specifications, 2005). 
A Base de Documentos UNL consiste nos documentos onde as expressões UNL são descritas para cada sentença da língua natural. Um documento UNL pode ser um arquivo texto ou um arquivo HTML com UNL embutido.

As Definições de Conceitos são uma coleção de documentos UNL formados por sentenças, onde as UWs são definidas. Esses documentos são necessários para fornecer o conhecimento sobre conceitos, relacionando-os com outros conceitos. Esse conhecimento é indispensável para raciocínio e recuperação de informação.

A UNL KCIC armazena informações sobre conceitos chaves do contexto (Key Concept in Context - KCIC) dos documentos UNL. A UNL KCIC expande o conhecimento de mero conhecimento lingüístico, como relações binárias entre conceitos independentes de contexto, para conhecimento do mundo real, tal como relações entre conceitos sensíveis ao contexto, restritos pelo conhecimento de outros conceitos.

Como já mencionado na seção 2.7, a UNL KB define a semântica das UWs, por meio do conhecimento lingüístico expresso por conceitos relacionados entre si. Ela recebe constantes atualizações, pois desenvolvedores, de diferentes línguas e culturas, podem acrescentar a definição de novas UWs (master definition) na UNL KB.

O Dicionário de UWs armazena e fornece a interface entre UWs e palavras da língua natural.

O Verificador UNL verifica se as expressões UNL estão corretas sintática, léxica e semanticamente. A verificação de sintaxe é feita levando em consideração a especificação de UNL (ver sintaxe nos Anexos A e B). A verificação léxica consiste em averiguar se todas as UWs de uma expressão UNL estão definidas na UNL KB. A verificação semântica certifica se cada relação de uma expressão UNL está definida como possível na UNL KB.

Os Servidores de Línguas estão na Internet e são responsáveis pela conversão entre linguagem natural e expressões UNL. Cada servidor de língua contém um EnCo e um DeCo de determinada língua. Para realizar as conversões, o EnCo e o DeCo necessitam de um dicionário específico da língua em questão e de regras da gramática. Um detalhamento sobre os processos de conversão de expressões UNL pode ser encontrado na especificação de UNL (UNL Specifications, 2005).

UW Gate é uma ferramenta que permite que as pessoas tenham acesso à UNL KB e ao dicionário de UWs através da Internet. 
O UNL Proxy trabalha localmente nos computadores para se comunicar com servidores de línguas. Ele funciona como um filtro para verificar quando uma página web que o usuário requisitou está escrita em UNL. Se as expressões UNL estiverem embutidas na página, o proxy se comunica com o servidor de línguas apropriado para fazer a reversão das expressões UNL contidas na página para sentenças na língua desejada e fornece os resultados a serem exibidos pelo navegador.

O Editor UNL é uma ferramenta para ajudar a produzir documentos UNL. Para isso, ele inclui um EnCo e um DeCo.

O UNL Explorer ajuda a fornecer a infra-estrutura de conhecimento. Ele gerencia a UNL KB, a UNL KCIC e os documentos UNL e fornece conhecimento ou informação por intermédio de UWs. Ele permite aos usuários procurarem por informação usando UWs ou palavras da língua natural. Ele mostra a informação em UNL ou na língua desejada, através do acesso a servidores de línguas e à enciclopédia. Ele também fornece funcionalidades para os desenvolvedores adicionarem ou modificarem informações da base de dados UNL em sua língua nativa.

A Enciclopédia UNL é uma coleção de documentos UNL descrevendo conhecimento ou informação. O mérito na enciclopédia é que ela permite que cada pessoa use sua língua nativa para compartilhar conhecimento ou informação com outras pessoas em suas respectivas línguas, através do UNL Explorer, por exemplo. A enciclopédia UNL basicamente descreve enciclopédias comuns em UNL e integra essas descrições (documentos UNL) na UNL KB, ligando os documentos UNL às UWs correspondentes.

A Biblioteca UNL é uma aplicação baseada em UNL que fornece informações bibliográficas e conteúdo (no futuro) em UNL, permitindo que usuários procurem por livros em UNL.

Alguns dos componentes do sistema UNL, ilustrados na Figura 2.2, se encontram disponíveis para download na página da Fundação UNDL. A UNL KB, por enquanto, é um arquivo texto (.txt), que está sempre recebendo atualizações com novas definições de UWs (master definitions), por diversos desenvolvedores ao redor do mundo e se encontra disponível para o público em geral. O UNL Proxy Server também se encontra disponível. Para fazer o download do verificador UNL e do UW Gate é preciso ser membro do projeto UNL (ter um login e senha válidos). Os servidores de línguas estão sendo desenvolvidos ao redor do mundo 
e para ajudar nesse desenvolvimento, existe um conjunto de ferramentas, o USD (UNL Development Set), que também precisa de autorização para ser obtido. Ele inclui: um DeCo, um EnCo e duas ferramentas para ajudar a desenvolver dicionários (Word Dictionary Builder e Co-occurrence Relation (CR) Dictionary Builder). Os demais componentes do sistema UNL, assim como a integração entre eles, estão em desenvolvimento e muito trabalho ainda é necessário.

\subsection{Considerações Finais}

UNL é uma linguagem que permite que informações e conhecimento descritos em linguagem natural possam ser formalizados em computadores. A definição das UWs permite expressar conceitos das línguas naturais sem ambigüidades e de maneira compreensível para computadores e para humanos. A maneira como o Projeto UNL é conduzido permite que todas as línguas possam ter interfaces com UNL e torna possível que diversas pessoas ao redor do mundo possam participar do desenvolvimento de aplicações baseadas em UNL.

A meta do Projeto UNL para o futuro é que os computadores possam "raciocinar" utilizando o conhecimento fornecido por UNL, permitindo o processamento inteligente de informação, tal como semântica computacional. Mas, até o momento, UNL expressa apenas o conhecimento referente às línguas naturais. Enquanto isso, pesquisas estão sendo feitas no caminho da semântica computacional, com o objetivo de, por exemplo, integrar UNL, RDF, OWL e outras (Uchida \& Zhu, 2005).

O objetivo geral deste trabalho é encontrar métodos de componentes de software que sejam apropriados para executar requisições feitas em linguagem natural. Dentro do contexto deste trabalho, UNL será utilizada para permitir que usuários possam fazer requisições em sua língua nativa, bastando para isso que dicionários e gramáticas sejam desenvolvidos para as línguas desejadas. Para fazer a conversão de linguagem natural para UNL foi utilizado um EnCo, desenvolvido pelo NILC (Martins et al., 2004). As UWs e as relações das expressões UNL são utilizadas para extrair informações semânticas que ajudam a encontrar os métodos mais apropriados para executar as requisições em linguagem natural. Para auxiliar neste processo, tornando-o mais flexível, foi criada uma ontologia (Capítulo 3), que tem como base as relações UNL e o sistema de UWs. A ontologia, juntamente com um conjunto de regras 
Capitulo 2 - O Projeto UNL

apropriado, tem como objetivo inferir informações semânticas que podem ajudar a encontrar os métodos dos componentes. O Capítulo 5 descreve os detalhes sobre como UNL está inserida neste trabalho. 


\section{CAPÍTULO}

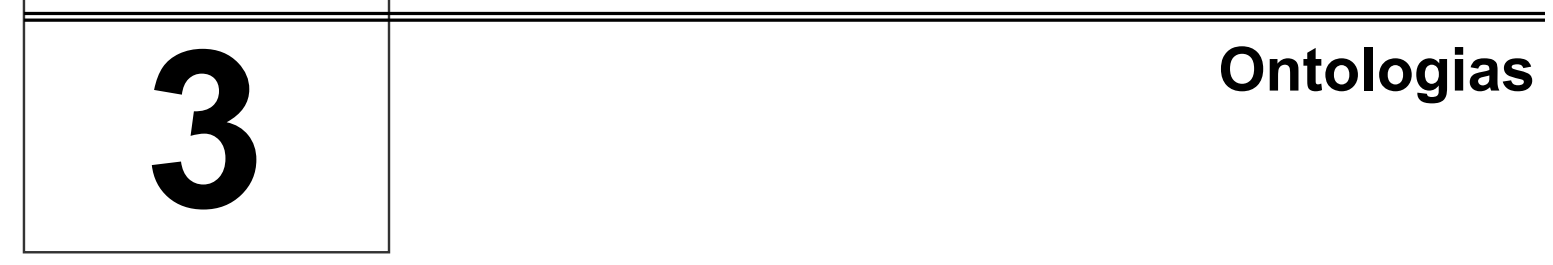

\subsection{Considerações Iniciais}

A partir de meados dos anos 90, as ontologias começaram a ser utilizadas na área de Inteligência Artificial (IA) para representar conhecimento. Mais recentemente, as ontologias estão deixando de ser usadas apenas em IA e passando a ter aplicações nas mais diversas áreas da computação que necessitam representar conhecimento a respeito de determinado domínio (Noy \& McGuiness, 2001).

De acordo com Brank et al. (2005), o foco dos sistemas de informação modernos está se movendo do processamento de dados para o "processamento de conceitos", isto é, a unidade básica de processamento é cada vez menos um pedaço atômico de dado e está começando a se tornar um conceito semântico, o qual possui uma interpretação e faz parte de um contexto com outros conceitos. Uma ontologia é comumente utilizada como uma estrutura que representa o conhecimento sobre uma determinada área por meio de conceitos relevantes e relacionamentos entre eles.

Para estruturar o conhecimento e poder processá-lo, é preciso utilizar um formalismo para representá-lo. Esse assunto é abordado na seção 3.2. A seção 3.3 apresenta as principais definições utilizadas na literatura para o termo ontologia e a seção 3.4 apresenta os principais tipos de ontologias. Ao começar o desenvolvimento de uma ontologia ou a reutilização de ontologias, é importante fazê-los de uma maneira estruturada, isto é, seguindo uma 
metodologia. Depois que a ontologia estiver pronta ou durante o seu processo de desenvolvimento é necessário avaliar o grau de adequação do resultado final. As principais metodologias para a construção de ontologias são descritas na seção 3.5 e as abordagens que podem ser utilizadas para avaliação são apresentadas na seção 3.6. Além da metodologia a ser adotada, outra decisão importante no desenvolvimento de uma ontologia é a linguagem a ser usada para formalizá-la. A escolha de uma linguagem dependerá basicamente de sua expressividade, da existência de mecanismos de inferência, do suporte de ferramentas que irão auxiliar no processo de desenvolvimento e do tipo de aplicação da ontologia. Assuntos relacionados às principais linguagens para representação de ontologias, destacando as linguagens para aplicações na web semântica, são abordados na seção 3.7. As principais ferramentas para auxiliar no desenvolvimento de ontologias são descritas na seção 3.8.

\subsection{Formalismos para Representação de Conhecimento}

Quando executam tarefas, os computadores possuem algumas vantagens sobre os seres humanos, principalmente no que diz respeito à velocidade e à consistência com que executam determinadas funções. Mas, para resolver problemas nas áreas em que, até o momento, o ser humano é mais bem sucedido que a máquina, as máquinas precisam conhecer o que os humanos sabem sobre o assunto (ou domínio). Por isso, durante as três últimas décadas, o conhecimento específico sobre um domínio tem sido utilizado como um requisito importante na solução de problemas computacionais. Uma maneira de organizar e estruturar tal conhecimento é por meio de ontologias.

Nesta seção são apresentados vários formalismos que podem ser usados para representação de conhecimento em ontologias, divididos em dois grupos de acordo com a abordagem utilizada para modelar o conhecimento. No primeiro grupo, estão os formalismos orientados a predicados e, no segundo, formalismos orientados a classes e relações hierárquicas (Freitas, 2003). 


\subsubsection{Formalismos Orientados a Predicados}

Os formalismos apresentados nesta seção visam, essencialmente, a utilização de predicados lógicos como sendo os principais elementos de um domínio. São eles as regras de produção e as linguagens baseadas em lógica matemática.

\subsubsection{Regras de Produção}

As regras de produção são estruturas do tipo:

SE <condições> ENTÃO <conclusões> FAÇA <ações>

A parte SE é uma lista de condições a serem satisfeitas, a parte ENTÃO é uma lista de conclusões e a parte FAÇA é opcional e consiste nas ações a serem executadas. Uma regra simples poderia ser "se está chovendo então a grama está molhada; abra o guarda-chuva". Dado o fato de que "está chovendo", pode-se também inferir que "a grama está molhada", e armazenar isso como um novo fato na base de conhecimento. A ação a ser executada é "abrir o guarda-chuva" (Rezende et al., 2003).

Em sistemas baseados em regras de produção, a inferência pode ser do tipo forward chaining (encadeamento para frente) ou backward chaining (encadeamento para trás). $\mathrm{O}$ processo de inferência realizado com forward chaining consiste em analisar os dados fornecidos pelo usuário, baseando-se no conhecimento, até chegar a uma conclusão. Esta estratégia corresponde a perguntar: "O que é possível concluir a partir dos dados que temos?" (Rezende et al., 2003). A regra a seguir pode ser interpretada da seguinte maneira: "Para todo $\mathrm{x}$, se existe um fato afirmando que $\mathrm{x}$ é animal e outro fato afirmando que é de estimação e outro fato afirmando que é pequeno, isto implica a validade de um novo fato, o de que x é doméstico" (Freitas, 2003). O mecanismo de inferência para o processamento dessa regra é forward chaining.

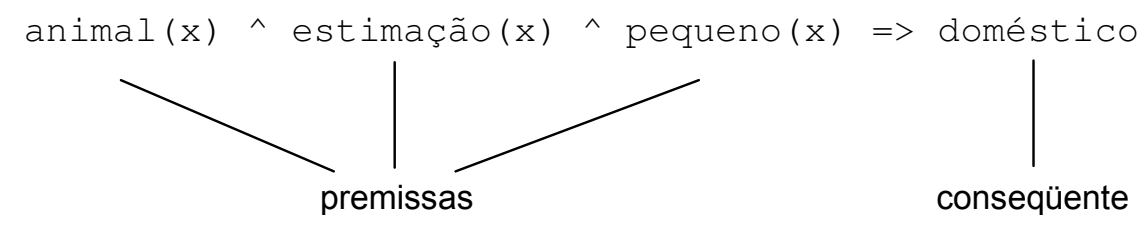


O processo de inferência realizado com backward chaining parte da suposição de que cada provável solução é verdadeira. Feito isso, tenta-se reunir evidências que comprovem ser correta a solução previamente considerada. Esta estratégia corresponde a perguntar: "É possível provar as hipóteses a partir dos dados que temos?” (Rezende et al., 2003). A regra a seguir pode ser interpretada como "x é avô de z, se x é pai de y e y é pai de z" (Freitas, 2003). O mecanismo de inferência para processar essa regra é backward chaining.

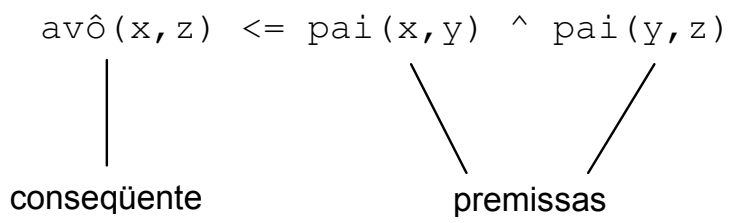

As regras de produção consistem no formalismo mais procedimental dentre os existentes, uma vez que, no lado do conseqüente, tanto pode haver a criação de novos fatos na base de conhecimento quanto a execução de comandos e procedimentos. Aproveitando-se disso, foram criadas máquinas de inferência que podem ser ligadas ao código imperativo de linguagens convencionais, como "C" e Java. Entre essas máquinas de inferência, as mais populares são $\operatorname{JESS}^{10}$ (Java Expert System Shell) (Friedman-Hill, 2003), que é amplamente utilizada devido a sua boa integração com objetos Java, e CLIPS ${ }^{11}$ ("C " Language Integrated Production System) (Riley, 2006) que se integra à linguagem "C". Manter o conhecimento fora dos programas constitui uma grande vantagem, pois não é preciso recompilar os programas quando as regras se alteram. O conhecimento fora dos programas, portanto, torna o sistema naturalmente mais flexível (Freitas, 2003).

\subsubsection{Linguagens Baseadas em Lógica Matemática}

A lógica matemática é uma linguagem formal, na qual uma seqüência de símbolos é usada para construir expressões. A lógica matemática possui várias regras sintáticas de dedução, isto é, formas de realizar inferências dedutivas a partir do formato sintático das expressões. Existem vários tipos de lógicas usadas para a realização de dedução automática, dentre elas o cálculo proposicional, o cálculo de predicados (ou lógica de primeira ordem) e a lógica de segunda ordem (Rezende et al., 2003).

\footnotetext{
${ }^{10} \mathrm{http}: / /$ herzberg.ca.sandia.gov/jess. Acesso em 04 set. 2006.

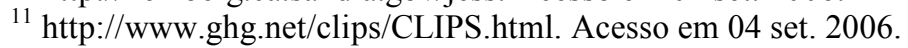


O cálculo proposicional é muito simples, pois se baseia apenas na existência de constantes e no uso de operadores lógicos. Essa linguagem tem um baixo poder descritivo, não sendo capaz de descrever objetos sobre os quais relações são observadas.

A lógica de primeira ordem permite descrever e raciocinar sobre objetos e predicados que especificam propriedades de objetos ou relacionamentos entre objetos de um domínio. Um subconjunto importante da lógica de primeira ordem é composto pelas "cláusulas de Horn". Uma cláusula de Horn consiste de uma regra cuja cabeça contém um único predicado e um corpo com zero ou mais predicados (Rezende et al., 2003). A linguagem baseada em lógica de primeira ordem mais utilizada para representar conhecimento é Prolog (Rowe, 1988). Outro exemplo é a linguagem KIF (Knowledge Information Format), que foi uma das primeiras linguagens criadas especificamente para representar informação a ser transmitida de um programa a outro (comunicação entre agentes) (Finin et al., 1997).

$\mathrm{O}$ exemplo a seguir, escrito em Prolog, descreve que uma pessoa X é irmão da pessoa $Y$ se $X$ é homem e ambos $X$ e $Y$ possuem o mesmo pai $Z$, onde $X, Y$ e $Z$ são variáveis que representam objetos (Rezende et al., 2003).

$\operatorname{irmao}(X, Y):-\operatorname{homem}(X), \operatorname{pai}(Z, X)$, pai $(Z, Y)$.

O elemento à esquerda do símbolo : - é a cabeça e o que está à direita é o corpo da cláusula. O símbolo : - é equivalente à implicação lógica $\leftarrow$. As vírgulas separando cada predicado significam conjunções lógicas. As variáveis entre parênteses são chamadas de argumentos. A lógica de primeira ordem possui um grande potencial expressivo e, entre as linguagens baseadas em lógica matemática, é a preferida para formalizar o conhecimento.

As linguagens baseadas em lógica de primeira ordem normalmente utilizam inferência baseada em algoritmos de backward chaining (Freitas, 2003). O raciocínio disponível é então baseado em metas, que o sistema deseja atingir. A máquina de inferência tenta provar essas metas a partir das cláusulas armazenadas na base de conhecimento. Novas sentenças são criadas de acordo com as conseqüências de um conjunto de predicados.

A lógica de segunda ordem é uma extensão da lógica de primeira ordem, permitindo que os predicados sejam considerados como variáveis (Rezende et al., 2003). Por exemplo:

$$
P_{1}(X, Y):-P_{2}(X), P_{3}(Z, X), P_{4}(Z, Y) \text {. }
$$


$\mathrm{P}_{1}, \mathrm{P}_{2}, \mathrm{P}_{3}$ e $\mathrm{P}_{4}$ são variáveis que representam predicados e $\mathrm{X}, \mathrm{Y}$ e $\mathrm{Z}$ são variáveis que representam objetos. Uma possível instanciação poderia ser:

$\operatorname{irmao}(X, Y)$ :- homem(X), pai(Z,X), pai(Z,Y).

Com a instanciação, apenas os nomes dos predicados podem variar. É conveniente salientar que essa lógica de representação é tão rica e flexível, que seu uso é, em muitos casos, computacionalmente inviável.

\subsubsection{Formalismos Orientados a Classes e Relações Hierárquicas}

Os formalismos apresentados nesta seção adotam um ponto de vista diferente dos anteriores: priorizam as classes de objetos presentes no domínio, buscando relações entre elas, principalmente herança ou especialização. Os maiores representantes desse tipo de formalismo são os frames, as redes semânticas e a lógica de descrições. O foco desses formalismos é a criação de taxonomias de classes, que ajudam a perceber o domínio como um todo. Não é por acaso que eles constituem a base para as ontologias (Freitas, 2003).

\subsubsection{Frames}

Os frames (quadros) são poderosas estruturas conceituais usadas para designar conhecimento sobre um objeto, um indivíduo, uma situação ou um conceito (Chang et al., 2002). São estruturas de dados complexas que proporcionam uma maneira útil de modelar objetos do mundo real. Os frames são considerados um dos precursores dos atuais objetos por terem uma substancial semelhança com esses, pois possuem (Freitas, 2003):

- Conceitos (ou classes): consistem em conceitos existentes no domínio que se deseja modelar. São normalmente organizados em hierarquias.

- Slots (ou atributos): definem as características de um conceito. Os slots podem conter valores de tipos básicos (inteiro, string, float, etc) ou o tipo especial “instância”, que é responsável por uma função muito importante em sistemas de frames: definir relações entre os conceitos. 
- Instâncias: são indivíduos (ou objetos) criados e modelados de acordo com a definição das características do conceito (seus slots).

- Herança: consiste de relações do tipo "é-um" entre os conceitos, bem semelhantes às subclasses dos objetos. Diferentemente de vários sistemas orientados a objetos, pode existir herança múltipla.

Além disso, os frames possuem ainda as facetas, que são estruturas pré-definidas para especificar restrições sobre os slots. Além do tipo, outras facetas comuns são domínio, valor default e cardinalidade.

Apesar de possuírem características em comum, a semelhança entre frames e objetos é apenas aparente. Enquanto objetos e suas classes visam modelar estruturas de dados e reusar código, frames têm por intuito modelar aspectos de um domínio real. Por exemplo, "elipse" não é, no mundo real, uma subclasse de círculo, mas para reusar código, modelagens orientadas a objeto podem violar essa premissa.

A inferência sobre frames normalmente é realizada por meio de unificação, mas nada impede que frames e regras sejam combinadas. O sistema de produção CLIPS, para ganhar expressividade, inclui uma linguagem interna (COOL - “C” Object-Oriented Language) para definir e manipular frames. As regras de produção referenciam esses frames (Riley, 2006). Outra linguagem baseada em frames freqüentemente usada para a definição de ontologias é a F-Logic (Kifer et al., 1995).

\subsubsection{Redes Semânticas}

Uma rede semântica é um grafo rotulado e direcionado, formado por um conjunto de nodos representando objetos (indivíduos, coisas, conceitos, situações em um domínio) e por um conjunto de arcos representando relações entre objetos. Um arco é rotulado com o nome da relação que ele representa (Rezende et al., 2003). Vários arcos podem ter o mesmo rótulo, entretanto cada objeto é representado por apenas um nodo, como ilustrado na Figura 3.1. A rede semântica da figura mostra dois objetos (Maria e João) e quatro conceitos (Mamíferos, Pessoas, Mulheres e Homens). Um dos atrativos das redes semânticas é a possibilidade de visualização gráfica das estruturas de conhecimento e suas relações (Russel \& Norving, 2003; Rezende et al., 2003). 


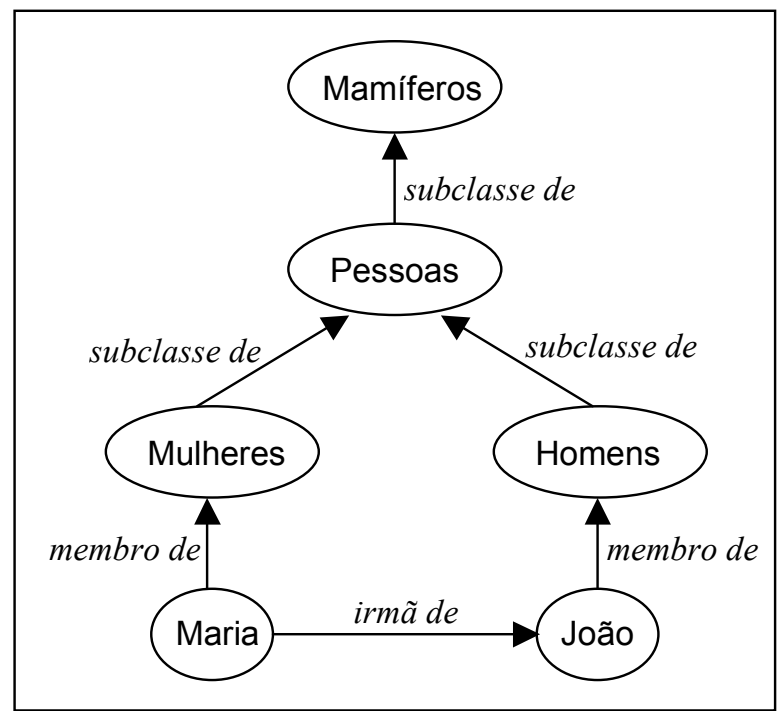

Figura 3.1 - Exemplo de uma rede semântica (Russel \& Norving, 2003).

De acordo com Freitas (2003), se a hierarquia de conceitos for mais importante na representação do domínio tratado do que os atributos, a representação em frames possui vantagens em termos de organização, pois as relações de herança e os conceitos de classe constituem o cerne de um frame. Quando os atributos são mais importantes, as redes semânticas são mais adequadas. Por sua expressividade nesses casos, elas têm sido largamente aplicadas em processamento de linguagem natural. Não é por acaso que o Projeto UNL utiliza as redes semânticas para representar informação e conhecimento de línguas naturais (ver seção 2.3).

\subsubsection{Lógica de Descrições (DL - Description Logics)}

A lógica de descrições foi criada para ser uma extensão dos frames e das redes semânticas (Russel \& Norving, 2003). A sintaxe da Lógica de Descrições é formada por símbolos representando conceitos, papéis, construtores e quantificadores. Os conceitos são representações de classes, conjuntos de indivíduos que apresentam as mesmas características gerais. Os construtores são operadores que permitem a criação de conceitos complexos, dando um significado especial à interpretação do conceito. Os papéis são propriedades dos conceitos, que representam relacionamentos entre os elementos da base de conhecimento. Os quantificadores são operadores que quantificam os papéis. Existem vários tipos de Lógicas de 
Descrições e estas são caracterizadas pelos construtores que possuem e quais propriedades podem ser atribuídas aos papéis, por exemplo, simetria, inversão, transitividade, etc (Vieira et al., 2005).

As bases de conhecimento em lógica de descrições são compostas pelos chamados TBoxes e ABoxes. Um TBox representa as características gerais dos conceitos, que são grupos de indivíduos semelhantes. Normalmente a declaração de um TBox consiste em definir um novo conceito em termos de outros conceitos definidos previamente. O ABox representa o conhecimento sobre cada indivíduo que faz parte de um conjunto. Ele é a instanciação da estrutura de conceitos (Vieira et al., 2005).

Um aspecto importante da lógica de descrições é sua ênfase no tratamento da inferência. As principais tarefas relacionadas à inferência consistem em verificar se um conceito é subconjunto de outro conceito por meio da comparação de suas definições, verificar quando um indivíduo pertence a uma categoria (classificação) e verificar se os critérios para pertencer a uma categoria são satisfeitos (consistência) (Russel \& Norving, 2003).

A lógica de descrições é o formalismo utilizado pelas linguagens da web semântica OIL (Horrocks et al., 2000), DAML+OIL (McGuinness et al., 2002) e OWL-DL (McGuinness \& van Harmelen, 2004). Um sistema de inferência popular entre as linguagens da web semântica é o RACER ${ }^{12}$ (Haarslev \& Möller, 2004), que oferece serviços de inferência para subclassificação, equivalência, disjunção, verificação de consistência, verificação de instância, etc (Vieira et al., 2005).

\subsection{Definição de Ontologias}

A palavra ontologia foi usada primeiramente na área de filosofia, com o objetivo de explicar a existência de uma maneira sistemática. De acordo com Corcho et al. (2003), desde quando as ontologias começaram a ser utilizadas em IA, muitas definições foram dadas para o termo ontologia. Essas definições passaram por modificações e evoluíram com o passar do tempo.

Uma das primeiras definições foi dada por Neches et al. (1991) e diz que "uma ontologia define os termos e relacionamentos básicos que compreendem o vocabulário de

\footnotetext{
${ }^{12} \mathrm{http}: / /$ www.racer-systems.com/. Acesso em 08 fev. 2007.
} 
uma área, define ainda as combinações desses termos e as relações para definir extensões desse vocabulário". De acordo com essa definição, uma ontologia não inclui apenas os termos definidos nela, mas também o conhecimento que pode ser inferido a partir deles. Poucos anos depois, Gruber (1993) definiu uma ontologia como sendo "uma especificação explícita de uma conceituação". Em 1997, a definição de Gruber foi ligeiramente modificada para "uma ontologia é uma especificação formal de uma conceituação compartilhada". Essa definição tem sido amplamente aceita e utilizada na comunidade científica. Baseadas na definição de Gruber, muitas outras foram propostas.

O trabalho de Studer et al. (1998) fornece uma explicação para alguns termos presentes na definição de Gruber. De acordo com eles, a palavra conceituação refere-se a um modelo abstrato de algum domínio do mundo, por terem sido identificados os conceitos relevantes para aquele domínio. Explícito significa que o conjunto de conceitos utilizados e as restrições aplicadas são explicitamente definidos. Formal refere-se ao fato de que se espera que uma ontologia seja processável por computador. Finalmente, uma ontologia é compartilhada porque descreve um conhecimento consensual, que é utilizado por mais de um indivíduo e aceito por um grupo.

De acordo com Corcho et al. (2003), apesar de existirem diversas definições para o termo na literatura, pode-se dizer que existe um consenso entre a comunidade que utiliza ontologias, o que evita confusões sobre seu uso. Definições diferentes fornecem pontos de vista diferentes e complementares sobre a mesma realidade.

É importante diferenciar ontologias de taxonomias. Essas últimas classificam e organizam o conhecimento em um domínio, utilizando relações de generalização e especialização por meio de herança simples e múltipla. As taxonomias são consideradas ontologias porque fornecem uma conceituação consensual de um determinado domínio, mas elas não modelam o domínio mais profundamente, por exemplo, com restrições sobre a semântica do domínio (Corcho et al., 2003).

Como conclusão a respeito das definições do termo ontologia, pode-se dizer que ontologias pretendem estruturar conhecimento consensual, de uma maneira formal, que possa ser compartilhado e reutilizado por agentes (aplicações e grupos de pessoas). 


\subsection{Classificação de Ontologias}

As ontologias podem ser classificadas levando-se em consideração diferentes aspectos, tais como, a função da ontologia, o grau de formalismo do seu vocabulário, a sua estrutura, o conteúdo da sua conceituação, etc. Entretanto, a classificação mais utilizada está relacionada à função, que normalmente divide as ontologias em três níveis (Guarino, 1998): ontologias de alto nível (ou upper ontologies), ontologias de domínio/tarefa e ontologias de aplicação. A Figura 3.2 ilustra o relacionamento entre esses três níveis de ontologias.

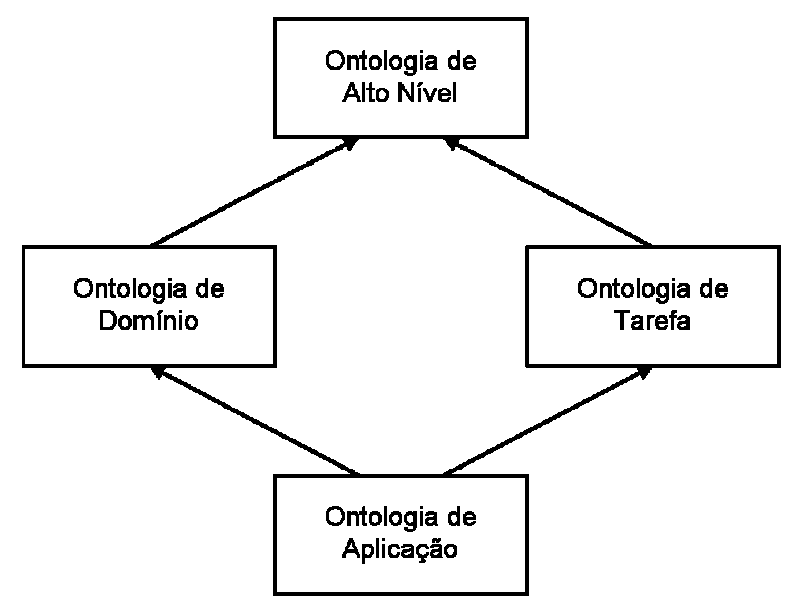

Figura 3.2 - Classificação de ontologias segundo Guarino (1998).

As ontologias de alto nível trazem definições abstratas, independentes de um problema ou domínio específico, necessárias para a compreensão de aspectos do mundo, como espaço, tempo, assunto, objeto, evento, ação, processo, seres, etc. Exemplos de ontologias de alto nível são $\mathrm{Cyc}^{13}$, WordNet ${ }^{14}$ e SUMO ${ }^{15}$.

As ontologias de domínio e tarefa descrevem o vocabulário relacionado a um domínio (como medicina e automóvel), ou a uma tarefa (como diagnóstico e venda), especializando os termos introduzidos na ontologia de alto nível.

As ontologias de aplicação descrevem conceitos dependendo de um domínio e tarefa específicos, os quais são freqüentemente especializações das ontologias (de domínio e tarefa)

\footnotetext{
${ }^{13} \mathrm{http}: / /$ www.cyc.com/. Acesso em: 22 jan. 2007.

${ }^{14} \mathrm{http}: / /$ wordnet.princeton.edu/. Acesso em: 22 jan. 2007.

${ }^{15} \mathrm{http}: / /$ ontology.teknowledge.com/. Acesso em: 22 jan. 2007.
} 
relacionadas. São ontologias que procuram solucionar um problema específico de um domínio, como identificar doenças no coração a partir de uma ontologia de domínio de cardiologia. Normalmente, ela referencia termos de uma ontologia de domínio.

\subsection{Metodologias para Desenvolvimento de Ontologias}

A metodologia adotada para desenvolvimento das ontologias deste trabalho foi proposta por Noy \& McGuiness (2001) e está apresentada na próxima seção. Entretanto, outras metodologias, tais como METHONTOLOGY, Ushold \& King e Grüninger \& Fox, também são consideradas importantes na literatura e estão brevemente descritas na seção 3.5.2.

\subsubsection{Metodologia de Noy e McGuinness}

Em sua metodologia, Noy e McGuinness (2001) propõem os seguintes passos:

1) Determinar o domínio e o escopo da ontologia: primeiramente é preciso responder perguntas como: qual é o domínio que a ontologia irá cobrir? Para que a ontologia será utilizada? Para quais tipos de questões a informação na ontologia deverá fornecer respostas?

As respostas a essas perguntas podem mudar durante o processo de desenvolvimento, mas a qualquer momento elas podem ajudar a limitar o escopo do modelo. Uma das maneiras de determinar o escopo da ontologia é esboçar uma lista de questões de competência (Grüninger \& Fox, 1995), que são perguntas que a base de conhecimento da ontologia deverá ser capaz de responder. As questões de competência podem ajudar na fase de avaliação.

2) Considerar a reutilização de outras ontologias: é recomendável verificar o que as outras pessoas já fizeram (se fizeram) e refinar ou estender para domínio ou tarefa no qual se deseja trabalhar.

3) Enumerar termos importantes para a ontologia: para ajudar neste passo, pode-se responder a perguntas como: quais são os termos mais comuns no domínio? Que propriedades esses termos possuem? O que é preciso dizer sobre esses termos? 
4) Definir as classes e a hierarquia entre elas: este constitui o passo mais capcioso do desenvolvimento, devido às sutilezas das hierarquias. É preciso observar a clareza e a consistência da hierarquia ao serem criadas subclasses. Isto é, deve-se observar se uma classe tem subclasses a mais - neste caso é preciso verificar se o uso de classes intermediárias não seria adequado -, ou a menos - caso em que a informação dos atributos pode tornar-se insuficiente para refletir diferenças entre as instâncias. Uma maneira efetiva é considerar se entre a superclasse e a subclasse não é plausível existirem outras classes. Uma das três abordagens propostas por Ushold \& King (1995) para a definição de hierarquias pode ser usada: top-down, bottom-up ou middle-out.

5) Definir as propriedades das classes (slots): as propriedades dizem respeito à estrutura interna dos conceitos. Elas podem ser tipos de dados comuns (como inteiro, string, boolean, etc) ou relacionamentos, que são instâncias de outras classes. Este passo está muito ligado ao anterior, pois tipicamente são criados alguns conceitos na hierarquia e, logo em seguida suas propriedades, e assim por diante. Este passo e o anterior são os mais importantes no processo de conceituação de uma ontologia.

6) Definir as facetas dos slots: os slots podem ter facetas diferentes, descrevendo, por exemplo, valor dos tipos, valores permitidos, número máximo e mínimo de valores (cardinalidade), etc.

7) Criar instâncias: o último passo consiste em criar instâncias para as classes, o que envolve escolher a classe para a qual se deseja criar as instâncias, criar uma instância e preencher os valores dos slots para cada instância. É importante salientar que as instâncias não fazem parte da ontologia, pois não carregam semântica - elas são caracterizadas pela semântica da ontologia. As instâncias, juntamente com a ontologia, formam a base de conhecimento. O processo descrito nos passos 1 a 7 são interativos e devem continuar durante o ciclo de vida da ontologia.

De acordo com o exposto nesta seção, a metodologia de Noy e McGuinness (2001) se concentra principalmente na fase de conceituação, que é a mais crítica no desenvolvimento de uma ontologia, pois é a mais ligada à definição do conhecimento. 


\subsubsection{Outras Metodologias}

A metodologia METHONTOLOGY (Fernández-López et al., 1997) foi proposta para o desenvolvimento de ontologias a partir do ponto zero, reutilizando outras ontologias ou por um processo de reengenharia. De acordo com os autores, o ciclo de vida de uma ontologia é parecido com o de um software tradicional, pois, assim como na maioria dos sistemas de software, é difícil especificar todos os requisitos de uma ontologia antes de começar a construí-la. Por isso, os autores consideram o ciclo de vida com protótipos evolutivos como sendo o mais adequado, pois com ele pode-se especificar apenas parcialmente os requisitos antes de começar o desenvolvimento, permitindo que a ontologia cresça conforme a necessidade, e que definições sejam adicionadas, removidas ou modificadas na ontologia a qualquer momento.

De acordo com METHONTOLOGY, as fases do ciclo de vida de uma ontologia são: especificação, conceituação, formalização, integração, implementação e manutenção. São definidas ainda outras três atividades que acontecem durante todo o ciclo de vida da ontologia: aquisição de conhecimento, avaliação e documentação.

Ushold e King (1995) propõem uma metodologia que, assim como as metodologias de Noy e McGuinness e METHONTOLOGY, é independente de aplicação, pois o processo de desenvolvimento da ontologia é totalmente independente do uso da ontologia. Os autores propõem quatro atividades em sua metodologia: identificar o propósito da ontologia, construíla, avaliá-la e documentá-la. Durante a atividade de construção, os autores propõem estruturar o conhecimento, codificá-lo e integrá-lo com outras ontologias. Eles ainda propõem três estratégias para identificar os principais conceitos da ontologia:

- Uma abordagem de cima para baixo (top-down), na qual os conceitos mais abstratos são identificados primeiro e então são especializados.

- Uma abordagem de baixo para cima (bottom-up), na qual os conceitos mais específicos são identificados primeiro e então são generalizados em conceitos mais abstratos.

- Uma abordagem que parte do meio (middle-out), na qual os conceitos mais importantes são identificados primeiro e generalizados ou especializados em outros conceitos. Uschold e Grüninger (1996) apresentam um bom argumento em favor da 
abordagem middle-out. De acordo com eles, essa abordagem permite identificar os termos fundamentais da ontologia. Depois de chegar a um acordo sobre esses termos e suas definições, pode-se especializá-los ou generalizá-los, apenas se necessário. Como resultado, os termos usados são mais estáveis e o trabalho requerido para defini-los é menor.

Grüninger e Fox (1995) propõem uma metodologia que é inspirada no desenvolvimento de sistemas baseados em conhecimento usando lógica de primeira ordem. Primeiramente deve-se identificar, de maneira intuitiva, os principais cenários, isto é, possíveis aplicações que farão uso da ontologia. Então, questões em linguagem natural são usadas para determinar o escopo da ontologia. Essas questões são chamadas de questões de competência e devem ser utilizadas posteriormente para a avaliação da ontologia. As questões de competência e suas respostas são utilizadas para extrair os principais conceitos, suas propriedades e relações. Depois disso, os componentes da ontologia são formalmente expressos em lógica de primeira ordem. Essa metodologia é parcialmente dependente de aplicação, pois considera possíveis aplicações da ontologia.

\subsection{Avaliação de Ontologias}

Na seção anterior, foram apresentadas metodologias para a construção de ontologias. A maior parte delas considera a necessidade de avaliação, entretanto, cada uma trata a avaliação de uma maneira diferente. Por exemplo, a metodologia de Ushold e King (1995) inclui a atividade de avaliação, mas não descreve como ela deve ser feita; Grüninger e Fox (1995) propõem avaliar a ontologia por meio da identificação de um conjunto de questões de competência; METHONTOLOGY (Fernández-López et al., 1997) propõe que a avaliação seja feita ao longo de todo o ciclo de vida do processo de desenvolvimento da ontologia (GómezPérez, 1999).

A avaliação de uma ontologia é uma questão que deve ser considerada, pois a quantidade de aplicações que utiliza ontologias para representar semântica é cada vez maior. Usuários, ao se depararem diante de várias ontologias, precisam saber decidir qual delas é a mais adequada aos requisitos de uma aplicação. Do mesmo modo, ao construir uma ontologia, é preciso haver uma maneira de avaliar o resultado. Apesar das evidências sobre a importância 
da avaliação, esse tópico ainda precisa amadurecer e continua em aberto. Não há nenhuma abordagem considerada a melhor ou preferida para avaliação de ontologias. Ao invés disso, a escolha da abordagem mais apropriada depende do objetivo da avaliação, da aplicação na qual a ontologia será usada e quais aspectos (ou níveis) da ontologia se pretende avaliar. As principais abordagens que podem ser usadas para avaliar ontologias são apresentadas a seguir (Brank et al., 2005):

- Avaliação baseada em um padrão (Golden Standard): esse tipo de avaliação consiste em comparar a ontologia a um golden standard, que pode ser um conjunto de strings considerado como sendo uma boa representação dos conceitos do domínio, ou pode ser até mesmo uma ontologia.

- Avaliação baseada na aplicação: tipicamente, a ontologia será utilizada em algum tipo de aplicação ou tarefa. Os resultados da aplicação ou seu desempenho em uma dada tarefa pode ser melhor ou pior dependendo parcialmente da ontologia que está sendo usada. Com isso, pode-se dizer que uma boa ontologia é aquela que ajuda a aplicação em questão a produzir bons resultados para uma dada tarefa. Essas ontologias podem, portanto, ser avaliadas simplesmente sendo ligadas à aplicação e avaliando os resultados da aplicação.

- Avaliação orientada a dados (data-driven): esse tipo de avaliação consiste em comparar a ontologia com um conjunto de dados (por exemplo, uma coleção de documentos) sobre o domínio tratado pela ontologia.

- Avaliação baseada em critérios: esse tipo de avaliação tenta medir o quanto a ontologia está de acordo com um conjunto de critérios, padrões e requisitos prédefinidos. Para cada critério, a ontologia é avaliada e uma "pontuação" é dada. Nesse tipo de avaliação pode ser necessário muito trabalho manual de especialistas humanos.

\subsection{Linguagens para Representação de Ontologias}

No início dos anos 90, um conjunto de linguagens para implementação de ontologias começou a ser desenvolvido devido a uma grande demanda pela formalização de informações em ontologias. A maioria das linguagens utiliza um ou mais entre os formalismos descritos na 
seção 3.2 para representar conhecimento, o que determina seu poder de expressividade. $\mathrm{Na}$ seção 3.7.1 são apresentadas algumas das principais linguagens para representar ontologias, sem considerar as linguagens da web semântica. Na seção 3.7.2 são apresentadas as linguagens desenvolvidas para representar ontologias na web semântica e a seção 3.7.3 apresenta um resumo comparando as linguagens apresentadas.

\subsubsection{Linguagens para Representar Ontologias fora da Web Semântica}

A Ontolingua (Farquhar et al., 1997) é uma das primeiras linguagens significativas criada para representar ontologias. Ela foi desenvolvida em 1992 e combina frames e lógica de primeira ordem para representar conhecimento. Essa combinação permite que Ontolingua represente taxonomias de conceitos, relações n-árias, funções, axiomas, instâncias e procedimentos. $\mathrm{O}$ grande poder de expressividade de Ontolingua dificulta o desenvolvimento de máquinas de inferência para essa linguagem.

A linguagem LOOM (McGregor, 1991) foi desenvolvida na mesma época de Ontolingua. Inicialmente, não foi criada para representar ontologias, mas bases de conhecimento genéricas. LOOM é baseada em lógica de descrições e regras de produção, fornece a classificação automática de conceitos e pode representar taxonomias de conceitos, relações n-árias, funções, axiomas e regras de produção.

OCML (Operational Conceptual Modeling Language) (Mota, 1998) foi desenvolvida em 1993 e é considerada uma "Ontolingua operacional". De fato, a maioria das definições que podem ser representadas em OCML são similares às definições correspondentes em Ontolingua e alguns componentes adicionais podem ser definidos, como regras dedutíveis e de produção.

F-Logic (Frame Logic) (Kifer et al., 1995) combina frames e lógica de primeira ordem, permitindo a representação de taxonomias de conceitos, relações binárias, funções, instâncias, axiomas e regras dedutíveis. F-Logic é a única entre as anteriores que não tem uma sintaxe baseada em Lisp. Sua máquina de inferência, Ontobroker, pode ser utilizada para a verificação de restrições e para deduzir novas informações.

O rápido avanço da Internet levou à criação de linguagens de ontologias que exploram características da web. Tais linguagens são usualmente chamadas de linguagens de ontologias 
baseadas na web ou linguagens de marcação para ontologias, que são apresentadas na próxima seção.

\subsubsection{Ontologias na Web Semântica}

A necessidade de inserir conhecimento na web surgiu porque a mesma possui milhões de páginas, mas a grande maioria delas se encontra em um formato "legível" apenas para os humanos, isto é, em HTML. Como conseqüência disso, agentes de software não podem “entender" e processar essa informação, o que diminui grandemente o potencial da web.

Em resposta a isso, a web semântica (Berners-Lee et al., 2001) foi idealizada e tem sido alvo de intensas pesquisas. Atualmente, a web constitui um dos principais campos de aplicação para as ontologias (Noy \& McGuinness, 2001), pois a web semântica define "estrutura" para os dados e as ontologias descrevem a semântica desses dados. Para fornecer estrutura para as informações contidas na web e possibilitar o uso de ontologias, o W3C (World Wide Web Consortium) propôs uma arquitetura em camadas, ilustrada na Figura 3.3.

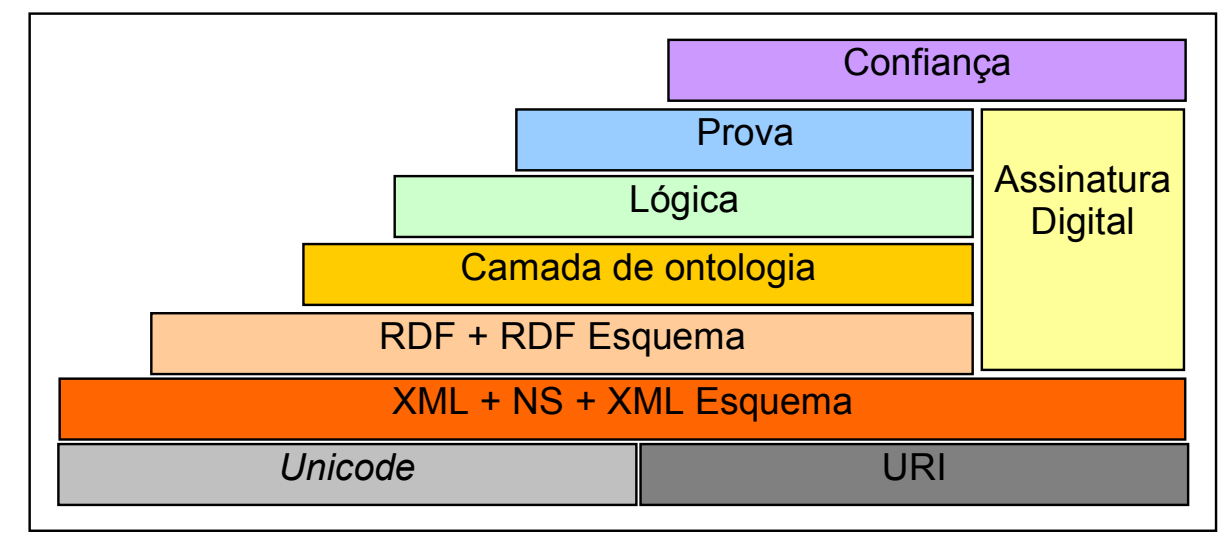

Figura 3.3 - As camadas da web semântica (Koivunen \& Miller, 2001)

A Camada Unicode garante o uso padronizado do mesmo conjunto de caracteres (Unicode) e uma forma unívoca para identificação e localização de recursos (URI - Uniform Resource Identifier). 
A Camada XML + namespace (NS) + XML Schema foi criada com o objetivo de permitir que fossem construídos documentos cuja informação fosse estruturada, isto é, documentos que contivessem não só conteúdo, mas também indicações a respeito desse (metadados).

A Camada RDF + RDF Schema adiciona mais semântica a um documento, com a vantagem de não precisar referir-se a sua estrutura. RDF (Resource Description Framework) (Manola \& Miller, 2004) é uma linguagem baseada em redes semânticas criada para descrever "recursos" da web, que devem ter um identificador na web, seja ele parte específica de um documento ou dados como lugares, pessoas, etc. RDF por si só não provê um vocabulário para especificar termos, por isso foi criada a linguagem RDF esquema (Brickley \& Guha, 2003), que provê um sistema de tipos para RDF, acrescentando primitivas baseadas em frames. A combinação de RDF e RDF esquema é normalmente conhecida como RDF(S). De acordo com Corcho et al (2003), apesar de ter sido criada para adicionar mais semântica aos documentos, $\mathrm{RDF}(\mathrm{S})$ é limitada quando comparada com linguagens para representação de ontologias, pois permite apenas a representação de taxonomias de conceitos e relações binárias.

A Camada de Ontologia tem o objetivo de representar semântica de uma maneira acessível por máquinas, modelando domínios de conhecimento na forma de ontologias. Para desempenhar esse papel surgiu, primeiramente, OIL (Ontology Inference Layer) (Horrocks et al., 2000), que herda primitivas baseadas em frames de RDF(S), mas sua semântica formal é baseada em lógica de descrições (DL). Depois surgiu DAML+OIL (McGinness et al., 2002), que incorpora aspectos tanto da linguagem DAML (DARPA Agente Markup Language) quanto da linguagem OIL. Tanto OIL quanto DAML+OIL permitem a representação de taxonomias de conceitos, relações binárias, funções e instâncias.

Mas, a linguagem que se consolidou como padrão da web semântica é OWL (Web Ontology Language) (McGuinness \& van Harmelen, 2004). A linguagem OWL foi criada a partir de DAML+OIL e é uma revisão desta, incorporando o que se aprendeu no desenvolvimento e aplicação de DAML+OIL. Porém, consciente de que uma linguagem tão expressiva quanto DAML+OIL pode dificultar a criação de ferramentas de edição para a linguagem completa, OWL seguiu a receita modular de OIL, dividindo suas classes em três sub linguagens, de acordo com sua expressividade: 
- OWL Lite: foi criada para usuários que precisam trabalhar principalmente com hierarquias de classificação e restrições simples.

- OWL DL: garante completude e toda a expressividade da lógica de descrições (DL). Diferentemente de OWL Lite, as classes podem ser construídas por união, interseção, complemento, enumeração de instâncias e podem ainda ter disjunções. Tipos são mantidos cuidadosamente separados (por exemplo, uma classe não pode ser instância e propriedade ao mesmo tempo).

- OWL Full: fornece a expressividade de OWL e a liberdade de usar RDF, inclusive permitindo novas metaclasses, que são subclasses definidas em RDF(S). Fazendo esse uso mais complexo, não há garantia de OWL Full ser computável. Aqui, não cabem as restrições de separação de tipos de OWL DL e é possível manipular e modificar metaclasses.

As linguagens menos expressivas (OWL Lite e DL) estão contidas dentro das mais expressivas (OWL DL e Full), de maneira que uma ontologia definida em uma linguagem menos expressiva é aceita por uma linguagem mais expressiva; a recíproca, naturalmente, não é verdadeira.

Algumas máquinas de inferência para $\mathrm{RDF}, \mathrm{RDF}(\mathrm{S})$ e $\mathrm{OWL}$ foram desenvolvidas. Entre elas Pellet ${ }^{16}$ e a máquina de inferência do Jena ${ }^{17}$ têm se destacado. Ambas são de código aberto e possuem uma comunidade ativa de desenvolvedores. Pellet é uma máquina de inferência baseada em lógica de descrições (DL), que suporta OWL nativamente. Jena é um framework Java para a construção de aplicações na web semântica, que representa informações utilizando RDF e inclui uma máquina de inferência baseada em regras.

A Camada de Lógica permite a especificação de regras que atuam sobre instâncias e recursos. A primeira linguagem a merecer destaque para a especificação de regras na web semântica é RuleML ${ }^{18}$ (Rule Modeling Language), que está atualmente em sua versão 0,91. Essa linguagem foi definida para permitir regras forward-chaining (bottom-up) e backwardchaining (top-down), utilizando uma sintaxe XML extensível. RuleML é uma linguagem completa, pois especifica diversos tipos de tarefas relacionadas à definição de regras e

\footnotetext{
${ }^{16} \mathrm{http}: / /$ pellet.owldl.com/. Acesso em: 23 jan. 2007.

${ }^{17} \mathrm{http}: / /$ jena.sourceforge.net/. Acesso em: 23 jan. 2007.

${ }^{18} \mathrm{http}: / /$ www.ruleml.org/. Acesso em: 23 jan. 2007.
} 
transformações para fazer inferência, o que a torna complexa. Como alternativa mais simples, surgiu SWRL (Semantic Web Rule Language) (Horrocks et al., 2004), que propõe a definição de regras utilizando OWL DL e OWL Lite em combinação com um subconjunto da linguagem RuleML.

As Camadas de Prova e Confiança ainda estão tomando corpo. A camada de prova tem a função de executar as regras especificadas na camada de lógica e a camada de confiança avalia se a prova está correta ou não. Algumas máquinas de inferência para processar SWRL e RuleML estão amadurecendo. Um exemplo é Bossam ${ }^{19}$, que está em sua versão 0.8 , processa regras forward-chaining e suporta subconjuntos de regras SWRL e RuleML. Outras iniciativas procuram traduzir regras SWRL ou RuleML para linguagens de regras tradicionais, que possuem máquinas de inferência já consolidadas. Um exemplo é o editor SWRL proposto por O'Connor et al. (2005), que traduz regras SWRL para regras JESS e utiliza a máquina de inferência da linguagem JESS para processá-las.

\subsubsection{Comparação entre as Linguagens para Representação de Ontologias}

A Tabela 3.1, adaptada e atualizada de Corcho et al. (2003), sumariza as características das linguagens apresentadas. O símbolo '+' significa que a linguagem possui a característica em questão, o símbolo '-' significa que a linguagem não possui a característica e o símbolo ‘ \pm ' significa que a linguagem não possui a característica diretamente, mas pode representá-la usando algum recurso adicional.

Pode-se concluir que a escolha de uma boa linguagem para representar uma ontologia é crucial para o seu desenvolvimento. De acordo com Corcho et al. (2003), antes de escolher a linguagem, é preciso decidir quais são as necessidades da aplicação em termos de expressividade e serviços de inferência, pois nem todas as linguagens permitem a representação das mesmas características e raciocínio ao mesmo tempo. A representação das características básicas, como conceitos, taxonomia e relações binárias normalmente não são suficientes se for necessário criar ontologias mais completas e fazer raciocínio mais complexo. Entretanto, de acordo com Freitas (2003), ao escolher uma linguagem de representação ou um

\footnotetext{
${ }^{19} \mathrm{http}: / /$ bossam.wordpress.com/. Acesso em: 23 jan. 2007.
} 
formalismo, não se deve levar em consideração apenas a expressividade. Outros itens também relevantes garantem a efetiva utilização de uma linguagem, como a existência de ferramentas de edição de ontologias que dão apoio à linguagem, a existência de máquinas de inferência, a possibilidade de acoplamento da máquina de inferência a uma ferramenta de edição e a popularidade da linguagem.

Tabela 3.1 - Características das linguagens para representação de ontologias.

\begin{tabular}{|c|c|c|c|c|c|c|c|c|}
\hline Características & $\begin{array}{l}\text { Onto } \\
\text { lingua }\end{array}$ & OCML & LOOM & FLogic & RDFS & OIL & $\begin{array}{l}\text { DAML } \\
+ \text { OIL }\end{array}$ & OWL \\
\hline \multicolumn{9}{|l|}{ Sobre Conceitos } \\
\hline Metaclasses & + & + & + & + & + & - & - & + \\
\hline Documentação & + & + & + & \pm & + & + & + & + \\
\hline \multicolumn{9}{|l|}{ Sobre atributos } \\
\hline Atributos de instância & + & + & + & + & + & + & + & + \\
\hline Atributos de classes & + & + & + & + & - & + & + & + \\
\hline Atributos locais & + & + & + & + & + & + & + & + \\
\hline Atributos globais & \pm & \pm & + & - & + & + & + & + \\
\hline \multicolumn{9}{|l|}{ Sobre Facetas } \\
\hline Valores default & - & + & + & + & - & - & - & + \\
\hline Restrições de tipos & + & + & + & + & + & + & + & + \\
\hline Cardinalidade & + & + & + & \pm & - & + & + & + \\
\hline Documentação do slot & + & + & + & - & + & + & + & + \\
\hline \multicolumn{9}{|l|}{ Sobre Taxonomias } \\
\hline Subclasses & + & + & + & + & + & + & + & + \\
\hline Classes disjuntas & + & \pm & + & \pm & - & + & + & + \\
\hline Não subclasse & \pm & - & \pm & - & - & + & + & + \\
\hline \multicolumn{9}{|l|}{ Sobre relações } \\
\hline Relações n-árias & + & + & + & \pm & \pm & \pm & \pm & \pm \\
\hline Restrições de tipos & + & + & + & + & + & + & + & + \\
\hline \multicolumn{9}{|l|}{ Sobre Axiomas } \\
\hline Lógica de primeira ordem & + & + & + & + & - & \pm & \pm & \pm \\
\hline Axiomas embutidos & + & + & + & - & - & - & - & - \\
\hline \multicolumn{9}{|l|}{ Sobre Instâncias } \\
\hline Instâncias de conceitos & + & + & + & + & + & + & + & + \\
\hline fatos & + & + & + & + & + & + & + & + \\
\hline Regras embutidas & - & + & + & - & - & - & - & \pm \\
\hline
\end{tabular}




\subsection{Ferramentas para Desenvolvimento de Ontologias}

Existem ferramentas que fornecem suporte ao desenvolvimento de ontologias e seu subseqüente uso. Alguns fatores tornam uma ferramenta popular: facilidade de uso, entendimento intuitivo da interface, visibilidade da ontologia, interfaces gráficas, conexão a repositórios, portabilidade, interoperabilidade, organização dos arquivos gerados, documentação de alterações, suporte a trabalho cooperativo, extensibilidade (capacidade de inclusão de componentes) e ferramentas de apoio que facilitem o desenvolvimento (Freitas, 2003). Nesta seção as ferramentas mais relevantes são apresentadas.

O Servidor Ontolingua ${ }^{20}$ (Farquhar et al., 1997) surgiu no início dos anos 90 e foi a primeira ferramenta criada para trabalhar especificamente com ontologias. Inicialmente, o principal módulo do Servidor Ontolingua era o editor de ontologias, depois foram acrescentados outros módulos, como um servidor OKBC (Open Knowledge Based Connectivity) e Chimaera, uma ferramenta para fazer o merging de ontologias. Apesar de fornecer tradutores para outras linguagens, o Servidor Ontolingua foi criado para trabalhar com Ontolingua, por isso possui um relacionamento muito forte com essa linguagem.

Assim como o Servidor Ontolingua, existem outras ferramentas que possuem um forte relacionamento com linguagens específicas. Por exemplo, a ferramenta Ontosaurus ${ }^{21}$ manipula bases de conhecimento apenas na linguagem LOOM, a ferramenta OilEd ${ }^{22}$ apenas na linguagem OIL e a ferramenta WebOnto $^{23}$ na linguagem proprietária OCML (Freitas, 2003; Corcho et al., 2003).

Nos últimos anos, uma nova geração de ambientes para a engenharia de ontologias tem surgido. Esses ambientes são bem mais ambiciosos que as ferramentas citadas anteriormente, pois eles pretendem integrar as ontologias em verdadeiros sistemas de informação. Eles são construídos como ambientes integrados que fornecem apoio à maioria das atividades do ciclo de vida de uma ontologia. Suas arquiteturas são extensíveis, nas quais novos módulos podem ser acrescentados facilmente para prover mais funcionalidade ao ambiente. Além disso, os modelos de conhecimento que servem como base para esses ambientes geralmente são

\footnotetext{
${ }^{20} \mathrm{http}: / / \mathrm{www} . \mathrm{ksl}$.stanford.edu/software/ontolingua/. Acesso em: 23 jan. 2007.

${ }^{21} \mathrm{http}: / / w w w . i s i . e d u /$ isd/ontosaurus.html. Acesso em: 23 jan. 2007.

${ }^{22} \mathrm{http}: / /$ oiled.man.ac.uk/. Acesso em: 23 jan. 2007.

${ }^{23} \mathrm{http}: / / \mathrm{kmi} . o p e n . a c . u k /$ projects/webonto/. Acesso em: 23 jan. 2007.
} 
independentes de linguagem (Corcho et al., 2003). Entre esses ambientes, pode-se citar WebODE, OntoEdit, Protégé e Swoop.

O ambiente WebODE ${ }^{24}$ (Arpírez et al., 2001) é o sucessor do ODE (Ontology Design Environment). A base do ambiente WebODE é o serviço de acesso à ontologia, o qual é utilizado por todas as aplicações cliente conectadas ao servidor, especialmente pelo editor de ontologias. Há serviços para importar e exportar linguagens (XML, RDF(S), OIL, DAML+OIL, F-Logic, JESS, Prolog), editar axiomas, documentar, avaliar e fazer merging de ontologias. $\mathrm{O}$ ambiente fornece suporte à maioria das atividades do processo de desenvolvimento de ontologias proposto por METHONTOLOGY, apesar de poder ser utilizado com outras ou com nenhuma metodologia.

OntoEdit $^{25}$ (Sure et al., 2002) é similar ao WebODE, fornecendo também edição, navegação, exportação e importação de diferentes formatos. Há duas versões de OntoEdit disponíveis: OntoEdit Free e OntoEdit Profissional. Recentemente, o pacote KAON incorporou OntoEdit.

O pacote de ferramentas $\mathrm{KAON}^{26}$ (the KArlsruhe ONtology and semantic web tool suite) (Volz et al., 2003) foi desenvolvido pela Universidade de Karlsruhe e pela empresa Ontoprise. Além de OntoEdit como editor de ontologias, o pacote possui diversas ferramentas comerciais para a aplicação de ontologias em comércio eletrônico, gestão de conhecimento e web semântica. As principais ferramentas servem para criação de ontologias a partir de texto (Text-to-Onto), busca sobre bases de texto baseada em ontologias (SemanticMiner), anotação semi-automática de referências a ontologias em páginas web, e agrupamento de textos baseados em ontologias. Um dos produtos comerciais mais inovadores consiste de um assistente que sugere e provê informações relacionadas a ontologias para ajudar a digitação de textos no Word, o OntoOffice. Mais recentemente o projeto $\mathrm{KAON} 2^{27}$ foi iniciado e trabalha com ontologias em OWL-DL, SWRL e F-Logic.

Protégé (Noy et al., 2000) ${ }^{28}$ é uma ferramenta de código aberto com uma arquitetura extensível. O núcleo de seu ambiente é o editor de ontologias, mas é possível acrescentar mais

\footnotetext{
${ }^{24}$ http://webode.dia.fi.upm.es/WebODEWeb/index.html. Acesso em: 23 jan. 2007.

${ }^{25} \mathrm{http}$ ://www.ontoknowledge.org/tools/ontoedit.shtml. Acesso em: 23 jan. 2007.

${ }^{26} \mathrm{http} / / /$ kaon.semanticweb.org/. Acesso em: 23 jan. 2007.

${ }^{27} \mathrm{http}: / /$ kaon2.semanticweb.org/. Acesso em: 23 jan. 2007.

${ }^{28} \mathrm{http}: / /$ protege.stanford.edu/. Acesso em: 23 jan. 2007.
} 
funcionalidade por meio de uma grande gama de plugins, entre eles importação e exportação de linguagens, criação e execução de restrições (PAL - Protégé Axiomatic Language), merging de ontologias (Prompt), etc.

$\mathrm{Na}$ ferramenta Protégé, classes e instâncias não criadas originalmente em CLIPS (Riley, 2006) - a base de conhecimento é gerada nativamente para essa máquina de inferência, a mais popular quando se iniciou a construção da Protégé, nos anos 80. Mas, diversas outras linguagens e máquinas de inferência (OWL, JESS, F-Logic, Prolog, RDF, OIL, XML) podem ser utilizadas com a adição de plugins apropriados. O plugin OWL, por exemplo, permite a criação e gerenciamento de ontologias diretamente nessa linguagem.

De acordo com Freitas (2003), os requisitos corretos foram levados em consideração durante a evolução da Protégé, sempre procurando crescer em número de usuários, passando por várias reengenharias, provendo ferramentas simples e configuráveis. A complexidade de seu modelo de conhecimento (metaclasses), por exemplo, é escondida do usuário, que pode ter acesso a ela, se assim o desejar. O conjunto de metaclasses usados por default pela ferramenta implementa características comuns a frames, tornando-a fácil de usar mesmo para usuários leigos. Todavia, se forem utilizadas metaclasses complexas e distintas das originais - como as para definir classes em RDF, por exemplo - as instâncias alcançarão a expressividade e complexidade desejada. Por isso, a Protégé pode ser adaptado a diversos usos.

A equipe responsável pela Protégé, ao perceber o potencial de desenvolvimento de seus usuários, optou por abrir seu código. Assim, surgiu uma arquitetura integrável a diversas aplicações, via componentes que podem ser conectados ao sistema (plugins). Como conseqüência dessa decisão e de sua difusão, plugins elaborados por vários grupos de pesquisa de usuários, puderam ser adicionados ao sistema. Foram aproveitados, por exemplo, o Jambalaya, um utilitário com animação e vários outros recursos em visualização de dados, e o Ontoviz, um plugin que faz com que o gerador de gráficos Graphviz da AT\&T produza gráficos com instâncias, heranças e outros tipos de relacionamento.

Um dos méritos da ferramenta Swoop (Kalyanpur et al., 2006) ${ }^{29}$ está no paradigma que ela utiliza. Swoop possui um navegador de ontologias inspirado em hipermídia (metáfora da web, usada nos navegadores) e um editor baseado em OWL, que permite extensibilidade por

\footnotetext{
${ }^{29} \mathrm{http}: / /$ code.google.com/p/swoop/. Acesso em: 23 jan. 2007.
} 
meio da adição de plugins. Swoop oferece alguns diferenciais, por exemplo, ela é a única ferramenta a trabalhar especificamente com OWL e seu projeto reflete isso. Seu editor de ontologias entra em contraste com editores tradicionais, os quais são influenciados pelo desenvolvimento tradicional de sistemas para representar conhecimento e não refletem "a web" em seus projetos de interface. Swoop contém duas máquinas de inferência adicionais (além da máquina de inferência nativa que usa a estrutura assertiva da ontologia): RDFS-like e Pellet.

\subsection{Considerações Finais}

Este Capítulo apresentou uma visão geral sobre ontologias. A utilização de ontologias permite desenvolver e integrar sistemas em nível de conhecimento. Além disso, o uso de ontologias proporciona o compartilhamento do conhecimento por humanos e por agentes de software, permitindo, conseqüentemente, que o conhecimento seja formalizado, consultado e inferido, contribuindo para que as aplicações se tornem mais "inteligentes".

Neste trabalho, é realizado o mapeamento semântico entre UNL e componentes de software, sendo as ontologias peças fundamentais para a realização desse mapeamento. $\mathrm{O}$ objetivo geral é receber uma requisição imperativa em linguagem natural, traduzi-la para UNL e encontrar os componentes mais apropriados para executá-la. Para auxiliar nesse processo, foram desenvolvidas duas ontologias: a primeira, chamada de Ontologia InterComp (Interlíngua-Componentes), é uma ontologia genérica, que relaciona relações da Interlíngua UNL com conceitos da UNL KB (seção 2.7), que podem ser especializados dependendo da necessidade da aplicação. Os tokens da sentença UNL são classificados nessa ontologia que, juntamente com regras específicas, tem o objetivo de extrair informações semânticas sobre possíveis componentes para executar a requisição. A segunda, chamada de Ontologia de Componentes, relaciona informações semânticas sobre os componentes com os dados de suas interfaces. O objetivo dessa ontologia é auxiliar no processo de busca pelos componentes mais apropriados para executar a requisição em linguagem natural, levando em consideração a semântica da interface dos componentes.

Durante o processo de desenvolvimento das ontologias, procurou-se seguir a metodologia de Noy e McGuinness por poder ser utilizada para construir ontologias do ponto 
zero ou reutilizando ontologias já existentes. Além disso, essa metodologia apresenta passos claros e bem definidos para auxiliar no processo de desenvolvimento.

Como as ontologias estão inseridas no contexto de uma aplicação (mapeamento semântico entre UNL e componentes), a principal forma de avaliação da ontologia é por meio da avaliação dos resultados da aplicação. Diante da possibilidade de futuramente integrar este trabalho no contexto da web semântica, a linguagem escolhida para representação das ontologias foi OWL. A ferramenta escolhida para o desenvolvimento das ontologias foi Protégé. Entre as vantagens dessa ferramenta que foram levadas em consideração para sua escolha, pode-se citar: bom suporte a OWL, a interface é amigável, tem uma boa documentação (inclusive com tutoriais), possui uma grande gama de plugins que podem ser adicionados conforme a necessidade da ontologia e da aplicação, seu código é aberto, possui uma comunidade ativa de desenvolvedores e usuários, o que a torna uma ferramenta amplamente utilizada para o desenvolvimento de ontologias por diversos grupos de pesquisa.

Entre as várias linguagens para especificação de regras e máquinas de inferência citadas ao longo deste Capítulo, optou-se por utilizar a linguagem JESS e sua máquina de inferência, pois esta possui estabilidade, boa documentação, um grande número de usuários e uma boa integração com Java. Além disso, a ferramenta Protégé oferece o JESSTab ${ }^{30}$ (Eriksson, 2004), que é um plugin para transformar ontologias em fatos JESS, definir regras e realizar inferência sobre os fatos. Protégé oferece ainda o editor SWRL, que também é um plugin e possibilita escrever regras em SWRL, transformá-las em fatos JESS e utilizar sua máquina de inferência. A única desvantagem de JESS está no fato de seu uso não ser aberto ao público. Existe uma licença gratuita, para uso acadêmico, que é fornecida por dois anos. Mas, quando as linguagens para definição de regras da web semântica estiverem suficientemente maduras e suas máquinas de inferência estiverem estáveis, JESS poderá ser facilmente substituída.

\footnotetext{
${ }^{30} \mathrm{http}: / /$ sourceforge.net/projects/jesstab/. Acesso em: 23 jan. 2007.
} 


\section{CAPÍTULO}

\begin{tabular}{l|l}
\hline \hline 4 & Componentes de Software
\end{tabular}

\subsection{Considerações Iniciais}

A reutilização de componentes de software tem evoluído significativamente ao longo da história da computação. Diversas pesquisas na área de reutilização de componentes têm sido feitas, tais como: desenvolvimento de processos de software e estratégias de gerenciamento para permitir ou melhorar a reutilização, mecanismos para integrar os componentes em aplicações, estratégias para configurar bibliotecas contendo componentes reutilizáveis, técnicas de classificação, busca e recuperação em repositórios para ajudar os desenvolvedores a selecionar os componentes mais apropriados para suas aplicações. Entre esses diversos tópicos, as técnicas de busca e recuperação de componentes têm merecido atenção especial, pois não é possível reutilizar um componente sem antes encontrá-lo (Yao \& Etzkorn, 2004).

A tendência na área de reutilização de componentes é que a busca seja realizada levando-se em consideração contextos e domínios específicos, dependentes da funcionalidade do componente e do tipo de aplicação para a qual determinado componente foi desenvolvido. Entretanto, as interfaces dos componentes atuais contêm pouca ou nenhuma informação sobre a semântica da operação desses componentes ou sobre como esses componentes podem interagir entre si num domínio no qual uma aplicação está sendo desenvolvida. As ontologias podem melhorar e facilitar a busca e a reutilização de componentes fornecendo semântica para 
os mesmos, por exemplo, por meio da representação da terminologia do domínio (Tetlow et al., 2006; Fujii \& Suda, 2004).

Nesse sentido, este trabalho propõe utilizar ontologias para melhorar a busca por componentes de software. Ontologias são utilizadas para relacionar informações semânticas, dependentes de domínio, com informações das interfaces dos componentes e assim melhorar a busca pelos componentes mais apropriados.

As duas próximas seções deste Capítulo têm o objetivo de fornecer ao leitor uma visão geral sobre componentes. Na seção 4.2 são apresentados alguns conceitos sobre componentes de software e o conceito que será utilizado neste trabalho. A seção 4.3 descreve brevemente os principais sistemas de componentes, entre eles, CORBA, COM e Java Beans. As seções 4.4 e 4.5 são mais relacionadas ao assunto deste trabalho. A seção 4.4 fornece uma visão geral sobre busca e recuperação de componentes, apresentando os métodos tradicionais de busca e discutindo como as ontologias podem contribuir com a busca. Finalmente, a seção 4.5 descreve especificamente as interfaces dos componentes, pois neste trabalho, os dados das interfaces são relacionados com informações semânticas, por meio de ontologias, para melhorar a busca.

\subsection{Conceito de Componentes de Software}

Os componentes de software têm adquirindo uma crescente importância no desenvolvimento de software, principalmente devido à grande possibilidade de reutilização. $\mathrm{O}$ ideal almejado na área de reutilização de software é a construção de novas aplicações a partir de componentes de software já existentes e devidamente testados. Nesta seção são apresentadas algumas definições para o termo componente de software.

A definição da OMG (Object Management Group) (Herzum \& Sims, 2000) diz que "um componente é um pedaço de software auto contido, com interfaces bem definidas, que pode ser instalado e entregue de maneira independente, pode ser facilmente combinado com outros componentes, o que é fundamental para sua utilidade”.

De acordo Hopkins (2000), "um componente é uma unidade de software bem definida que tem uma interface pública e pode ser usada em conjunto com outros componentes para formar unidades maiores". 
Para D'Souza e Wills (1999), "usa-se o termo componente para denotar um pacote coerente de artefatos de software que possa ser desenvolvido e utilizado independentemente como uma unidade e que possa ser composto, inalterado, com outros componentes para se construir algo maior".

Apesar de não haver uma definição única, todas concordam que um componente deve possibilitar reutilização de código, o que só é possível por meio da divulgação de sua interface, que é composta por um conjunto de operações que determinam quais são os serviços que um determinado componente pode oferecer.

Neste texto, um componente de software será considerado uma unidade desenvolvida isoladamente para uma finalidade específica, projetado para interagir com outros componentes a fim de possibilitar a reutilização. Essas unidades devem interagir entre si através de interfaces (conjuntos de operações) bem definidas.

Essa definição de componente de software o coloca muito próximo ao conceito de um objeto em programação orientada a objetos. $\mathrm{Na}$ realidade, tanto programação orientada a componentes quanto programação orientada a objetos apresentam entre seus conceitos fundamentais o encapsulamento através de interfaces. Entretanto, programação OO tem uma ênfase muito grande em herança de implementação. Já uma abordagem orientada a componentes enfatiza o uso de polimorfismo, pois um de seus objetivos é oferecer suporte à extensão de sistemas já existentes através da simples substituição ou adição de novos componentes. Um componente pode ser substituído por outro em uma aplicação desde que ambos ofereçam a mesma interface ou, pelo menos, interfaces compatíveis. Tipicamente, um componente é tratado como uma caixa-preta, da qual só é conhecida a interface. O uso de herança de implementação é geralmente desaconselhado (Cerqueira, 2000).

Apesar das diferenças de abordagem entre programação orientada a objetos e programação orientada a componentes, e de algumas diferenças entre os conceitos de objeto e de componente, esses dois termos possuem várias características em comum e são usados como sinônimos neste trabalho. 


\subsection{Sistemas de Componentes}

Especificações e implementações de sistemas de componentes têm surgido na indústria de software para servir de infra-estrutura para o desenvolvimento baseado em componentes. Os sistemas de componentes definem padrões de comunicação e ligação entre seus componentes, sendo que alguns definem ainda serviços de apoio ao desenvolvimento tanto dos componentes propriamente ditos quanto das aplicações, tais como serviços de nomes, transações, segurança e persistência (Cerqueira, 2000).

Atualmente, diversos sistemas de componentes podem ser citados, como CORBA, COM, .Net, JavaBeans, EJB e J2EE. Esta seção fornece uma descrição geral de cada um deles.

CORBA (Common Object Request Broker Architecture) é um padrão definido pela OMG (Object Management Group) que especifica uma arquitetura orientada a objetos para dar suporte a aplicações distribuídas (OMG, 2006). Apesar da OMG só definir o padrão, várias implementações já fora feitas e muitas se encontram disponíveis, como Visibroker ${ }^{31}$. CORBA é um middleware que integra aplicações, de diferentes vendedores, distribuídas em diferentes tipos de máquinas. Para cada objeto, são definidas interfaces em OMG IDL. Essas interfaces permitem a um cliente invocar operações definidas para um objeto. A definição da interface em IDL (Interface Definition Language) é independente de linguagem de programação, mas possui mapeamento para diversas linguagens populares, como $\mathrm{C}, \mathrm{C}++$, Java, COBOL, Smalltalk, Ada, Lisp e Python.

COM (Component Object Model) (Microsoft, 2006a) é a tecnologia desenvolvida pela Microsoft para a construção de sistemas baseados em componentes. Essa tecnologia é usada por desenvolvedores Windows para criar componentes reutilizáveis e assim construir aplicações, tirando vantagem dos serviços do Windows. A família de tecnologias COM inclui $\mathrm{COM}+$, DCOM (Distributed COM) e controles ActiveX. COM e .Net são tecnologias de desenvolvimento complementares, podendo ser integradas de maneira transparente. Entretanto, o Framework .Net pode substituir COM, permitindo recursos adicionais.

A .Net (Microsoft, 2006b) é a tecnologia da Microsoft baseada em serviços web (web services). Os serviços são utilizados na integração de sistemas e na comunicação entre diferentes aplicações em uma rede, podendo ser publicados, localizados e invocados através da

\footnotetext{
${ }^{31} \mathrm{http}: / /$ www.borland.com/br/products/visibroker/index.html. Acesso em: 23 jan. 2007.
} 
web. Os serviços web são componentes que permitem às aplicações enviar e receber dados em formato XML, utilizando para isso o protocolo SOAP (Simple Object Access Protocol). Cada aplicação pode ter a sua própria "linguagem", que é traduzida para uma linguagem universal, o formato XML. Outra característica particular dos serviços web é que suas interfaces são descritas em WSDL (Web Services Description Language) (Fensel \& Bussler, 2002). Quando comparada à COM, a tecnologia .Net fornece aos desenvolvedores alguns benefícios, como sistema de segurança mais robusto, gerenciamento de memória automático e suporte nativo a serviços web. Com a tecnologia .Net, integrada com a plataforma Microsoft, pode-se construir, gerenciar e conectar soluções com serviços web, contando com algumas aplicações para facilitar o desenvolvimento, como servidores para hospedar serviços web e ferramentas de desenvolvimento para criar serviços web.

Java Beans (Sun, 2006a) é o sistema de componentes desenvolvido pela Sun Microsystems para a linguagem Java. Um bean é simplesmente uma classe Java, pois a princípio, não precisa herdar de nenhuma classe básica ou interface para ser considerado um bean. As três características mais importantes de um bean são o conjunto de propriedades que ele expõe, o conjunto de métodos que ele permite que outros objetos chamem, e o conjunto de eventos que ele gera. Propriedades são basicamente atributos associados a um bean, que podem ser consultados e alterados através de métodos apropriados do bean. Esses métodos para manipulação de propriedades seguem certas regras de formação de seus nomes. Por exemplo, se um bean tem uma propriedade chamada color, sua interface deve oferecer as operações getcolor e setcolor para consultar e alterar o valor dessa propriedade. Os métodos exportados por um bean são apenas métodos regulares de Java, que podem ser chamados por outros componentes. O mecanismo de eventos oferece um modo para que um componente notifique outros componentes que ocorreu algum evento que lhes interesse.

A tecnologia Enterprise JavaBeans (EJB) (Sun, 2006b), da Sun Microsystems, é uma extensão do sistema de componentes Java Beans, oferecendo suporte mais adequado para componentes servidores, com um ambiente robusto para o suporte a aplicações com rigorosos requisitos de escalabilidade, distribuição e disponibilidade. De acordo como a terminologia EJB, componentes servidores são partes de uma aplicação que executam em um servidor de aplicações, que oferece um ambiente de execução otimizado para os componentes, com gerenciamento de transações, segurança, concorrência, etc. A tecnologia EJB oferece suporte 
ao desenvolvimento de aplicações baseadas em uma arquitetura de objetos distribuídos em várias camadas (multitier), na qual grande parte da lógica da aplicação é movida do cliente para o servidor. A lógica da aplicação é particionada em um ou mais objetos que são disponibilizados em um servidor de aplicações, como JBoss ${ }^{32}$ ou WebSphere ${ }^{33}$. A tecnologia EJB também espera elevar o grau de portabilidade oferecido por Java. Um componente EJB deve não apenas poder executar em qualquer plataforma, como também ser completamente portável entre diferentes implementações de servidores de aplicações compatíveis com EJB. A infra-estrutura de EJB define uma série de interfaces padronizadas para que uma aplicação possa ter acesso a serviços de chamadas remotas de métodos (RMI), de nomes e diretórios (JNDI), de integração com CORBA (Java IDL), de criação dinâmica de páginas HTML (Servlets e JSP), de mensagens (JMS), de transações (JTS), e de acesso a bancos de dados (JDBC). Tanto JavaBeans quanto EJB seguem o modelo de objetos de Java, fazendo com que um componente JavaBeans ou EJB seja, em última análise, um objeto Java.

A plataforma J2EE (Java 2 Enterprise Edition), ou Java EE (Sun, 2006c), é considerada um padrão de desenvolvimento, já que o fornecedor de software nesta plataforma deve seguir determinadas regras se quiser declarar os seus produtos como compatíveis com Java EE. A plataforma é voltada para aplicações multicamadas, baseadas em componentes que são executados em um servidor de aplicações. Java EE inclui diversas especificações de APIs (Application Program Interfaces), tais como JDBC (Java DataBase Conectivity), RMI (Remote Method Invocation), e-mail, JMS (Java Message Service), serviços web, XML, etc, e define como coordená-las. Java EE também caracteriza algumas especificações para componentes, como EJB, servlets, JSP, (Java Server Pages) e diversas tecnologias para serviços web. Isso permite que os desenvolvedores possam criar aplicações corporativas portáveis e escaláveis que são também integradas com tecnologias já consagradas, como EJB, servlets, etc.

\footnotetext{
${ }^{32} \mathrm{http}: / /$ labs.jboss.com/portal/. Acesso em: 23 jan. 2007.

${ }^{33} \mathrm{http} / / /$ www-306.ibm.com/software/websphere/. Acesso em: 23 jan. 2007.
} 


\subsection{Busca e Recuperação de Componentes}

Um dos maiores problemas associados ao uso de componentes está na dificuldade em encontrar componentes que vão de encontro a determinados requisitos do usuário. Por isso, mecanismos para auxiliar na busca e recuperação de componentes têm sido um dos grandes interesses dos pesquisadores que trabalham para melhorar o desenvolvimento de software baseado em componentes (Sousa \& Leite, 2004; Mello et al., 2006). Nesta seção, são descritas algumas técnicas utilizadas para a busca e recuperação de componentes.

Há vários requisitos técnicos que podem ser levados em consideração na busca. Muitos vendedores de componentes indicam parâmetros de busca tais como data, linguagem de programação, (Java, C++, etc.), tecnologia do componente (COM, CORBA, EJB, Java Beans, etc.), domínio da aplicação (comércio eletrônico, interface com o usuário, etc.), sistema operacional (Windows, Unix, etc.). Mas já se sabe que apenas requisitos técnicos não bastam para uma busca eficiente. Os repositórios tradicionais são limitados no sentido de normalmente não conterem informações sobre como cada objeto é usado ou o que seu conteúdo significa. Quando um usuário busca por um objeto, ele usualmente precisa ser muito específico sobre o que está procurando, pois o repositório não contém informação sobre o domínio ou sobre como seus componentes estão relacionados. A busca pelos componentes apropriados normalmente não leva esses relacionamentos, ou dependências, em consideração e, portanto, limitam a usabilidade e consistência da informação retornada ao usuário (Sugumaran \& Storey, 2003). Esses problemas podem ser minimizados com o uso de informações semânticas na busca por componentes. $\mathrm{Na}$ seção 4.4.1 são apresentadas as abordagens tradicionais para busca por componentes e, na seção 4.4.2, é apresentado como as ontologias podem ser usadas para inserir semântica sobre os componentes, e assim melhorar a busca.

\subsubsection{Abordagens tradicionais para busca por componentes}

As abordagens tradicionais para busca e recuperação de componentes podem ser classificadas em quatro tipos diferentes (Mili et al., 2001): 
a) Busca simples por strings ou palavras-chaves (Mili et al., 1997): a maioria das ferramentas de busca usa a busca simples por palavras-chaves, onde o usuário especifica um conjunto de palavras-chaves sobre o assunto de interesse. A ferramenta de busca compara essas palavras-chaves aos nomes dos objetos e retorna os que casam. Essa é a abordagem mais simples e não leva em consideração informações adicionais, tais como relacionamentos entre objetos ou sinônimos.

b) Classificação e recuperação por facetas (Prieto-Díaz \& Freeman, 1987): procura classificar os objetos no repositório baseado em taxonomias pré-definidas, isto é, os objetos são classificados por assunto. Apesar dessa abordagem ser útil para objetos que podem se encaixar claramente em tais categorias, ele é menos útil para objetos cuja classificação não é explícita. As facetas são definidas por especialistas para descrever características dos componentes, tais como funcionalidade, informações sobre execução e implementação.

c) Casamento de assinaturas (signature matching) (Zaremski \& Wing, 1993): essa abordagem compara nomes, parâmetros e tipos de retorno dos métodos dos componentes com a consulta do usuário. Em essência, consiste em uma abordagem indireta para identificar quando um objeto é relevante.

d) Casamento de comportamento (behavioral matching) (Zaremski \& Wing, 1995): leva em consideração o comportamento funcional de objetos. Nessa abordagem, vetores de entrada são fornecidos aos objetos e as saídas geradas são comparadas com as saídas esperadas. Os objetos que exibem um certo comportamento são recuperados e apresentados ao usuário.

Para Sugumaran e Storey (2003), as duas últimas abordagens poderiam ser mais eficientes se levassem em consideração o domínio e a busca por informações semânticas. Na Tabela 4.1 é apresentado um resumo com alguns comentários sobre as abordagens tradicionais.

Outros trabalhos foram propostos para realizar a busca por componentes, como resumido em Lucrédio et al. (2004) e Gracia et al. (2006), sendo alguns deles extensões das abordagens tradicionais apresentadas nesta seção. Em 2003, Sugumaran e Storey (2003), propuseram uma abordagem baseada em semântica para realizar a busca por componentes, como descrito na próxima seção. 


\subsubsection{Ontologias para Auxiliar na Busca por Componentes}

Pesquisas na área de busca e recuperação de componentes têm identificado a necessidade de complementação das técnicas de busca com estratégias que tenham seu foco no conteúdo e na semântica da informação. Nos últimos anos, algumas pesquisas apresentaram soluções com o uso de conteúdo semântico associado aos componentes descritos em ontologias (Sugumaran \& Storey, 2003; Yao \& Etzkom, 2004; Sousa \& Leite, 2004).

Tabela 4.1 - Resumo das abordagens para recuperação de componentes (Sugumaran \& Storey, 2003).

\begin{tabular}{|c|c|c|}
\hline Método & Abordagem utilizada & Comentários \\
\hline $\begin{array}{l}\text { busca por } \\
\text { palavras-chaves }\end{array}$ & $\begin{array}{l}\text { Procura pela ocorrência das strings } \\
\text { especificadas pelo usuário nas } \\
\text { descrições dos componentes e em } \\
\text { seus atributos. }\end{array}$ & $\begin{array}{l}\text { - Pode resultar em muitos ou poucos itens } \\
\text { recuperados porque apenas palavras- } \\
\text { chaves são usadas para a busca. } \\
\text { - Pode resultar em muitos itens não } \\
\text { relacionados. }\end{array}$ \\
\hline $\begin{array}{l}\text { classificação por } \\
\text { facetas }\end{array}$ & $\begin{array}{l}\text { Classifica componentes baseado } \\
\text { em facetas, tais como a função do } \\
\text { software, o meio utilizado, tipo de } \\
\text { sistema, área funcional, etc. }\end{array}$ & $\begin{array}{l}\text { - Os componentes devem se enquadrar no } \\
\text { esquema de classificação. } \\
\text { - Alguns componentes podem estar em } \\
\text { várias categorias. } \\
\text { - É difícil gerenciar o esquema de } \\
\text { classificação quando o domínio de } \\
\text { conhecimento evolui. } \\
\text { - A busca só utiliza as facetas, não pode } \\
\text { ser aumentada com dados adicionais. }\end{array}$ \\
\hline $\begin{array}{l}\text { casamento de } \\
\text { assinatura }\end{array}$ & $\begin{array}{l}\text { Procura pelos mesmos tipos de } \\
\text { funções e argumentos } \\
\text { especificados pelo usuário. O } \\
\text { casamento de assinaturas pode ser } \\
\text { feito em nível de função ou de } \\
\text { módulo (conjunto de funções). }\end{array}$ & $\begin{array}{l}\text { - É difícil mapear os requisitos do usuário } \\
\text { para assinaturas de funções e módulos. } \\
\text { - A busca pelas mesmas assinaturas não } \\
\text { garante o comportamento esperado do } \\
\text { componente. } \\
\text { - Vários componentes podem ter a mesma } \\
\text { assinatura. } \\
\text { - A consulta é rígida, isto é, todos os } \\
\text { parâmetros da consulta devem ser } \\
\text { considerados. }\end{array}$ \\
\hline $\begin{array}{l}\text { casamento de } \\
\text { comportamento }\end{array}$ & $\begin{array}{l}\text { Executa cada biblioteca de } \\
\text { componentes com vetores de } \\
\text { entrada randômicos e gera vetores } \\
\text { de saída. Compara a saída atual } \\
\text { com a saída esperada e assim } \\
\text { escolhe os componentes. }\end{array}$ & $\begin{array}{l}\text { - É difícil de aplicar quando componentes } \\
\text { têm comportamentos complexos. } \\
\text { - É difícil expressar os comportamentos } \\
\text { desejados } \\
\text { - Não há suporte para o aumento da } \\
\text { consulta. }\end{array}$ \\
\hline
\end{tabular}

Com ontologias é possível representar conhecimento do domínio de uma maneira genérica para fornecer uma compreensão comum e aceita de um domínio que pode ser 
reutilizado e compartilhado entre aplicações e grupos. Ontologias, como componentes de software, representam alguns aspectos do mundo real que podem ser usados múltiplas vezes em aplicações diferentes. As ontologias devem, portanto, ser capazes de melhorar a efetividade dos esquemas de busca e recuperação. Primeiro, ontologias fornecem um mecanismo para representar e armazenar conhecimento específico de um domínio, o qual pode ser usado para encontrar os componentes mais apropriados. Isso pode melhorar a precisão da busca. Um método para recuperação de componentes baseado em ontologias pode ainda ser capaz de explorar o conhecimento adicional embutido nas ontologias para aumentar ou revisar a consulta inicial do usuário.

Para Sugumaran e Storey (2003), além de melhorar a busca, a utilização de informações semânticas pode facilitar a "flexibilidade da consulta" e o "aumento da consulta", que são fatores que também podem contribuir para uma busca mais eficiente. A flexibilidade da consulta diz respeito a facilidade com que o usuário pode especificar os requisitos dos componentes sendo buscados. Idealmente, os usuários devem ser capazes de expressar os requisitos dos componentes em linguagem natural. $\mathrm{O}$ aumento da consulta está relacionado à possibilidade de modificar a consulta inicial, com informações apropriadas e adicionais sobre o domínio, para melhorar os resultados da busca.

As ontologias também têm sido usadas para possibilitar a busca por componentes em diferentes repositórios. A utilização de repositórios de componentes é amplamente utilizada para o armazenamento dos mesmos, tornando-os públicos e acessíveis. Considerando a disponibilidade da web como o meio de busca por informações mais utilizado atualmente, a construção de infra-estruturas capazes de facilitar a busca por informações de componentes armazenados em repositórios distribuídos e que possam ser acessados pela web, torna-se uma questão importante para o processo de reutilização (Oliveira et al., 2004; Braga et al., 2001). O objetivo de trabalhos com esse enfoque é reduzir o problema da necessidade de conhecer a estrutura e semântica de dados espalhados nos vários repositórios para um problema menor, que é conhecer os relacionamentos ontológicos entre os termos através das ontologias.

Como pode ser observado, o uso de ontologias têm facilitado e melhorado a busca por componentes de software. Alguns trabalhos a respeito do assunto (busca) e como eles utilizam ontologias são apresentados nos trabalhos relacionados (Capítulo 7). 


\subsection{Interfaces dos Componentes}

A forma usual de descrever um componente consiste na descrição de sua interface, o que corresponde à relação das assinaturas de métodos da interface. Porém essa forma de descrição é pobre porque produz apenas uma visão externa, incapaz de descrever as funcionalidades do componente e como ele interage com outros. Torna-se necessário fazer uma descrição da funcionalidade do componente, que vai além da interface e visa descrever o que o componente faz, pois não é possível saber o que os métodos fazem conhecendo apenas suas assinaturas. Um dos fatores que dificultam a busca e a conseqüente reutilização de componentes é a inexistência de maneiras para realizar tal descrição funcional. Este trabalho propõe usar uma ontologia para relacionar os dados das assinaturas dos métodos dos componentes com informações sobre a funcionalidade dos componentes (informações semânticas).

Para relacionar informações semânticas com dados das assinaturas dos componentes é necessário, antes de tudo, conhecer o que faz parte da interface de um componente. Por isso, nesta seção são apresentas e comparadas uma interface de cada família de componentes apresentadas na seção 4.3 - CORBA, COM e Java.

Mesmo em sistemas de componentes diferentes, uma característica comum para a declaração das interfaces é a dissociação entre a interface e a implementação de um componente: para uma mesma interface podem existir diversas implementações (componentes) diferentes. De acordo com essa separação, componentes só podem ser acessados através das operações definidas em suas interfaces, garantindo o encapsulamento de suas implementações.

\subsubsection{Interfaces CORBA e COM}

Tanto CORBA quanto COM oferecem mecanismos para definir as interfaces de seus componentes de tal forma que essas definições sejam independentes de linguagem de programação, permitindo a interoperabilidade entre componentes desenvolvidos em linguagens diferentes. Para isto, são utilizadas Linguagens de Definição de Interface (Interface Definition Languages - IDL). 
Isso é necessário porque COM e CORBA são classificados como sendo sistemas de middleware. Um middleware é um software que reside entre uma aplicação e o nível básico do sistema operacional e do sistema de rede para aumentar a capacidade de distribuição, interoperabilidade e portabilidade das aplicações entre diferentes plataformas (Bernstein, 1996). Tipicamente, além de fornecer as assinaturas dos métodos, uma interface definida com IDL descreve também informações que podem ser utilizadas para a geração automática dos stubs, responsáveis pelo empacotamento e desempacotamento das mensagens trocadas entre componentes.

Tanto em OMG IDL quanto em COM IDL, a descrição de uma interface é composta pelas assinaturas completas dos métodos oferecidos. Já a assinatura de um método é composta pelo seu nome, o tipo de seu valor de retorno, os tipos de todos os seus parâmetros, e as exceções que podem ser sinalizadas. A descrição de um parâmetro também envolve a definição do sentido em que é feita a troca de informação entre o cliente, que requisita a operação, e o componente, que recebe a requisição (modificadores in, out e inout) (Cerqueira, 2000). As Figuras 4.1 e 4.2 apresentam exemplos de uso de OMG IDL e COM IDL, respectivamente, usando a representação de um mesmo tipo nas duas linguagens.

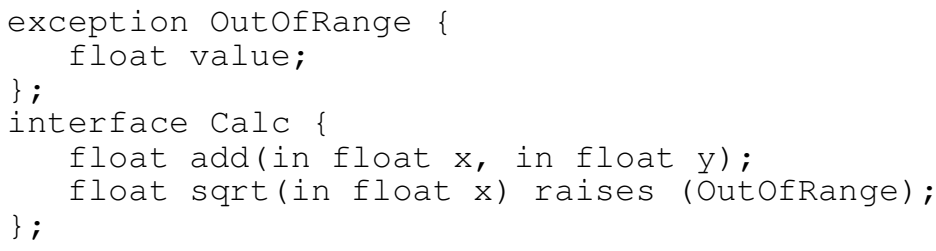

Figura 4.1 - Exemplo de interface em OMG IDL (Cerqueira, 2000).

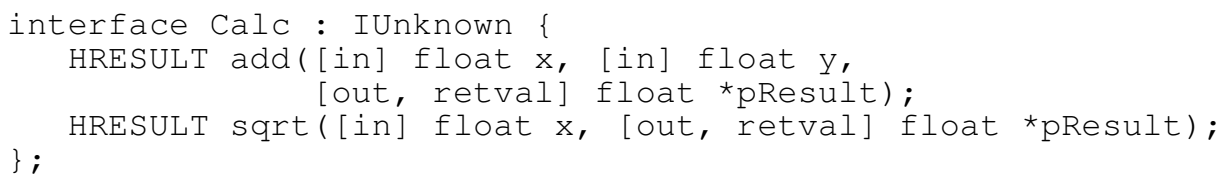

Figura 4.2 - Exemplo de interface em COM IDL (Cerqueira, 2000).

Todas as interfaces em OMG IDL já derivam implicitamente da interface CORBA : : Object. OMG IDL é baseada em um modelo de objetos tradicional, onde um objeto 
tem uma interface única que pode ser composta a partir de outras através de herança múltipla. Em OMG IDL, uma interface também pode conter a definição de constantes e tipos de dados, tais como estruturas e uniões.

De acordo com o modelo de objetos adotado por COM, um objeto pode implementar qualquer número de interfaces. Entretanto, COM IDL apenas oferece um mecanismo de herança simples de interface, que segue o mesmo esquema de OMG IDL para tratar a compatibilidade entre um tipo e seus subtipos. Todas as interfaces em COM derivam implícita ou explicitamente da interface IUnknown, que oferece uma operação que permite o acesso a todas as interfaces implementadas por um objeto. Cabe destacar que as duas IDLs só oferecem herança de interfaces. Em nenhum dos dois casos é possível definir uma relação de herança de implementação.

Apesar dos métodos declarados em ambas IDLs poderem sinalizar exceções, as duas linguagens diferem bastante na maneira como representam isso em uma interface. Em OMG IDL, a definição de um tipo de exceção é feita através da definição de uma estrutura composta por campos de dados. A assinatura de um método define as exceções que podem ser sinalizadas por ele através da cláusula raises. Já em COM IDL, uma exceção é representada por um identificador numérico, que tipicamente tem uma mensagem explicativa associada. Todas as operações retornam um código numérico do tipo HRESULT, que indica se a operação foi realizada com sucesso ou não (Cerqueira, 2000).

\subsubsection{Interfaces Java}

Uma interface em Java é muito similar às interfaces de CORBA e COM, pois também é composta pelas assinaturas dos métodos, que por sua vez possuem nome, tipo do valor de retorno, tipos dos parâmetros e exceções. Entretanto, há uma característica que diferencia as interfaces de componentes Java das outras duas: as interfaces Java não utilizam IDLs, são definidas diretamente em Java, o que simplifica sua declaração. Isso evita, por exemplo, que a descrição de um parâmetro em Java necessite de modificadores como in, out e inout, necessários para a geração de stubs. A Figura 4.3 mostra o trecho de uma interface Java que especifica um tipo chamado course. 
A assinatura de um método define as exceções que podem ser sinalizadas por ele por meio da cláusula throws. Java oferece mecanismos de herança tanto de interfaces quanto de classes. Entretanto, uma classe pode implementar e uma interface pode herdar de tantas interfaces quanto forem necessárias (herança múltipla de interfaces), mas uma classe só pode herdar de uma única classe (herança simples de classes).

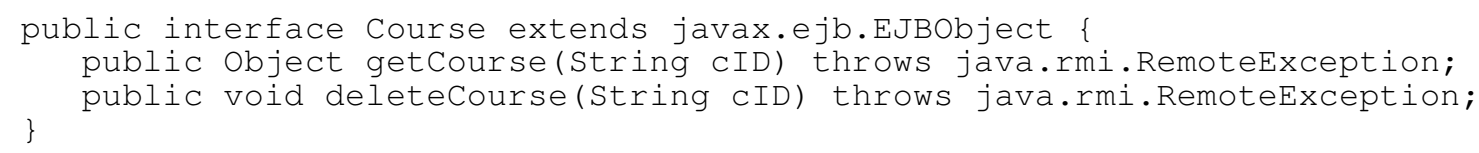

Figura 4.3 - Exemplo de declaração de interface em Java.

As classes que não herdam explicitamente de uma outra classe são implicitamente subclasses da classe primitiva Object. Essa classe define métodos de suporte a threads e mais alguns métodos utilitários, tais como métodos para teste de igualdade entre objetos, clonagem e introspecção. No caso do exemplo da Figura 4.3, além de herdar da classe Object, a classe que implementar a interface declarada herda características de javax.ejb.EJBObject, o que significa que se trata de um Enterprise Java Bean (EJB). Se a declaração se tratasse, por exemplo, de um bean visual, seria necessário herdar java.awt.Component, para que ele pudesse ser adicionado a um recipiente (container) visual de componentes.

\subsection{Considerações Finais}

Este Capítulo apresentou as abordagens tradicionais para busca e recuperação de componentes de software, que podem ser estendidas com informações semânticas para melhorar os resultados da busca. Este trabalho propõe estender as assinaturas dos métodos, por meio de conceitos e relacionamentos ontológicos, contendo informações semânticas do domínio, formalizados na Ontologia de Componentes.

De acordo com o exposto na seção 4.5, os dados das assinaturas dos métodos nas diferentes famílias de componentes são praticamente os mesmos. A Ontologia de Componentes, inicialmente, contempla componentes (ou objetos) Java, mas poderá ser estendida para acomodar particularidades de outras famílias de componentes. 


\section{CAPÍTULO}

\begin{tabular}{r|r} 
OntoMap: uma Arquitetura para \\
\hline Realizar o Mapeamento Semântico \\
entre UNL e Componentes
\end{tabular}

\subsection{Considerações Iniciais}

Há um interesse significativo na possibilidade de acessar operações de um computador por meio da linguagem natural, pois essa é a maneira que as pessoas usam para se comunicarem umas com as outras. O objetivo deste trabalho é poder executar requisições imperativas descritas em diversas línguas naturais restritas. Para alcançar o objetivo desejado, este trabalho propõe que as requisições sejam primeiramente convertidas para UNL (Capítulo 2). Com isso, é possível ter a mesma representação UNL para requisições expressas em diversas línguas naturais como inglês, espanhol, português, etc. A representação UNL é então usada para extrair informações semânticas relevantes das requisições, necessárias para encontrar os componentes de software que sejam apropriados para executar as requisições.

É importante ressaltar que, neste trabalho, requisições se referem a ações descritas em um alto nível semântico de abstração e relacionadas a um determinado domínio. Também é importante ressaltar que os componentes responsáveis por executar as requisições são da camada de aplicação, não da camada de negócios ou de middleware. Isto é, são componentes 
ativados diretamente pela interface de uma aplicação, não os componentes responsáveis por operações de baixo nível, como conexão com banco de dados, controle de transações, etc.

A proposta deste trabalho é que os componentes de software apropriados para executar as requisições sejam encontrados a partir da representação em UNL das requisições. Para conseguir isso, é preciso relacionar UNL com componentes de software, o que está sendo chamado aqui de mapeamento semântico entre UNL e componentes.

$\mathrm{Na}$ seção 5.2 é apresentada a visão geral de uma arquitetura de software ${ }^{34}$ baseada em ontologias, chamada de OntoMap (Ontology-based Semantic Mapping), que está sendo proposta neste trabalho para realizar o mapeamento semântico entre UNL e componentes, com o objetivo de identificar informações semânticas que serão usadas para encontrar os componentes apropriados para executar requisições imperativas em linguagem natural. Nas seções 5.3 a 5.5 os principais módulos da Arquitetura OntoMap são descritos: Conversão para UNL, Mapeamento Semântico e Busca por Componentes, respectivamente. Na seção 5.6 é apresentada uma discussão sobre a solução adotada na Arquitetura OntoMap, destacando pontos fortes e apontando possíveis soluções para pontos fracos.

\subsection{Visão Geral da Arquitetura OntoMap}

Para realizar o mapeamento semântico entre UNL e componentes e a posterior busca por componentes considerando informações semânticas, este trabalho propõe a Arquitetura OntoMap, ilustrada na Figura 5.1.

A arquitetura proposta possui três módulos principais: Conversão para UNL, Mapeamento Semântico entre UNL e Componentes, aqui chamado apenas de Mapeamento Semântico, e Busca por Componentes. O módulo de Conversão para UNL fornece um serviço $(\mathrm{EnCo})$ para converter requisições em linguagem natural para UNL, que utiliza para isso um dicionário e uma gramática da língua em questão. É importante observar que algumas palavras do dicionário devem estar presentes também nas Ontologias de Domínio e de Componentes, o que está representado na Figura 5.1 por uma linha verde.

\footnotetext{
${ }^{34}$ Arquitetura de software é a estrutura de um sistema computacional, que inclui elementos de software, as propriedades externamente visíveis desses elementos (tais como os serviços que ele provê, uso de recursos compartilhados, etc) e os relacionamentos entre eles (Bass et al., 2005).
} 


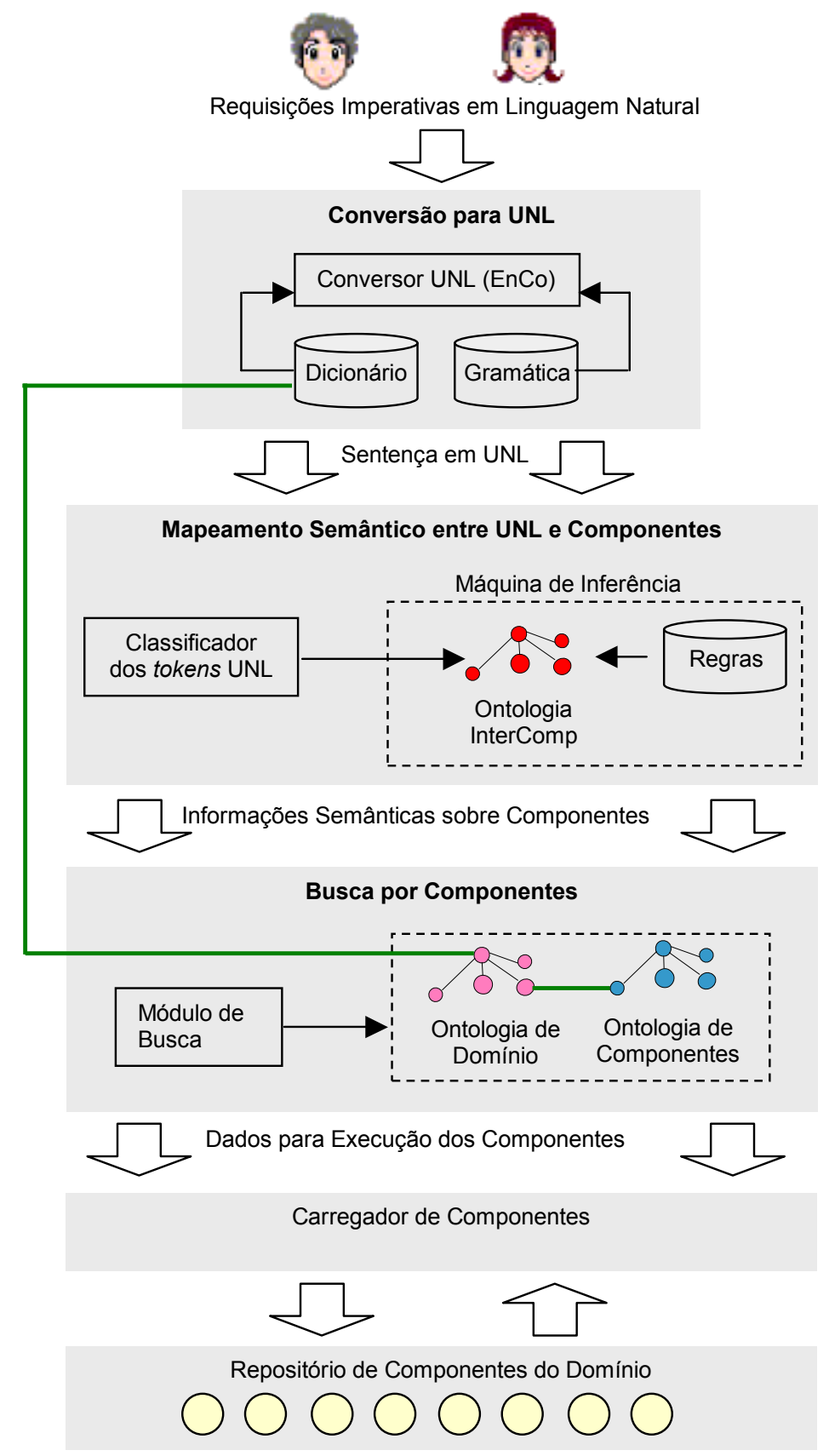

Figura 5.1 - Arquitetura OntoMap.

Para o módulo de Mapeamento Semântico foi desenvolvida a Ontologia InterComp (Interlíngua-Componentes), que relaciona as UWs e as relações da interlíngua UNL com informações semânticas sobre componentes. Nesse módulo foi desenvolvido também um serviço para classificar os tokens da sentença UNL na Ontologia InterComp. Com os tokens 
classificados na ontologia, regras são aplicadas para extrair informações semânticas sobre componentes. O módulo de Busca por Componentes utiliza tais informações para encontrar possíveis componentes que possam executar a requisição. Para realizar a busca utiliza-se a Ontologia de Componentes, que foi desenvolvida para relacionar informações sobre as interfaces dos componentes com informações semânticas sobre a funcionalidade dos mesmos, considerando o domínio de aplicação para o qual foram desenvolvidos, cujos termos estão formalizados na Ontologia de Domínio. O Módulo de Busca por Componentes fornece informações específicas sobre a execução dos componentes para o Carregador de Componentes, que é responsável por executar os métodos necessários para satisfazer a requisição expressa em linguagem natural. Os três módulos da Arquitetura OntoMap são descritos em detalhes nas seções 5.3 a 5.5 .

\subsection{Conversão para UNL}

O objetivo do Módulo de Conversão para UNL é servir de interface entre aplicações e um Conversor UNL (EnCo). Com isso, aplicações baseadas em linguagem natural podem utilizar o EnCo para realizar a conversão de linguagem natural para UNL. Para fazer a conversão, o EnCo precisa de um dicionário e regras gramaticais da língua em questão. A arquitetura OntoMap utiliza o EnCo Hermeto, desenvolvido no NILC (Martins et al., 2004).

Nas Figuras 5.2 e 5.3 são apresentados, respectivamente, trechos de um dicionário e de uma gramática simples desenvolvidos para servir de entrada para o Hermeto. Não é objetivo deste Capítulo descrever detalhadamente a sintaxe utilizada nas gramáticas e nos dicionários, o que pode ser obtido em Martins et al. (2004). Os exemplos foram colocados para destacar algumas particularidades das gramáticas e dos dicionários UNL, que são explicadas a seguir.

No dicionário podem ser definidos sinônimos, instâncias e relações de super e subclasses (hiponímia). Ao observar a Figura 5.2, nota-se que os verbos add, include e insert são considerados sinônimos, pois são representados pelo mesmo conceito, que é add. Isso significa que, se a sentença de entrada, for "Insert student Maria...", o EnCo irá usar o conceito add na sentença de saída. Outra observação importante a ser feita sobre o dicionário é que existe nele uma ontologia implícita. Isso pode ser observado, por exemplo, nas entradas 
student e user, para as quais o EnCo irá gerar as saídas student(icl>person) e user(icl>person), respectivamente, o que significa que student e user são subclasses do conceito person.

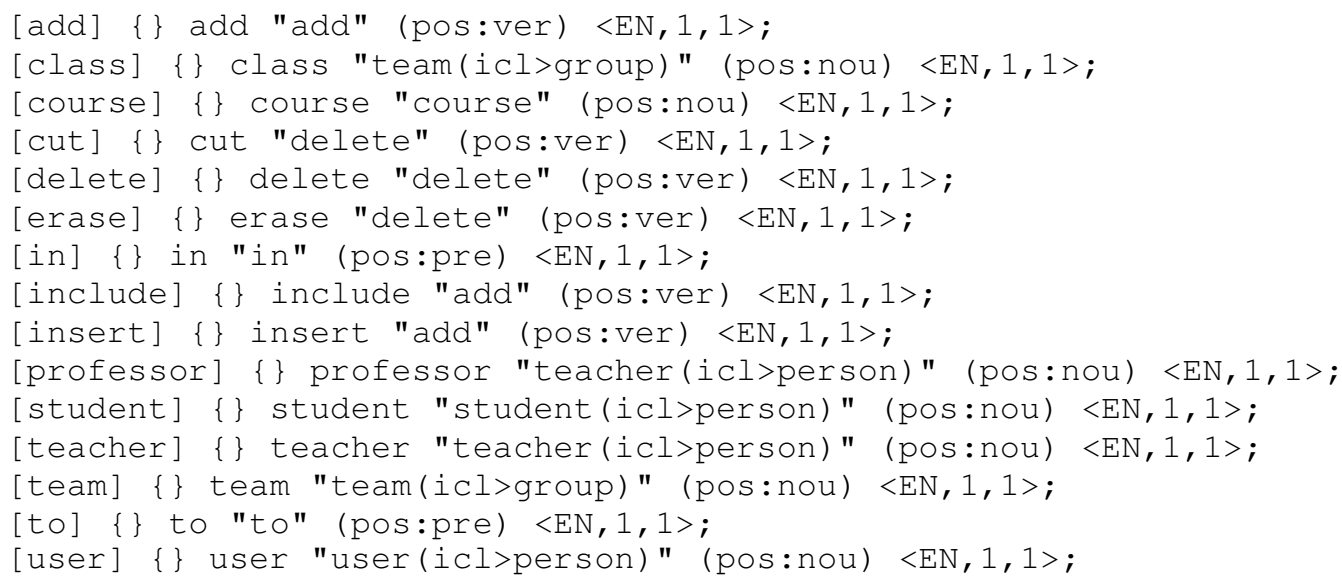

Figura 5.2 - Trecho de um dicionário desenvolvido para o EnCo Hermeto.

O exemplo de gramática da Figura 5.3 define dois tipos de sentenças imperativas. A primeira começa com um verbo seguido de dois substantivos (IMP[1]) e a segunda começa com um verbo seguido de dois substantivos, mais uma preposição, mais dois substantivos (IMP[2]). Exemplos de sentenças válidas para IMP[1] e IMP[2], respectivamente, seriam "Create student Maria" e "Add student Maria to Java course". É importante observar que a própria gramática já contém as relações UNL que serão usadas em cada sentença. Em IMP[1] essas relações são obj(:01,:02), nam(:02,:03) e em IMP[2] são obj(:01,:02), nam(:02,:03), nam(:06,:05), gol(:01,:06). Portanto, além de conhecer a gramática da língua em questão, é preciso saber UNL para desenvolver gramáticas para um EnCo.

Para gerar a saída em UNL, o EnCo utiliza as regras definidas na gramática, juntamente com a definição dos conceitos no dicionário. Para a sentença de entrada "Create student Maria", por exemplo, o EnCo gera a saída obj(create,student(icl>person>)), nam(student(icl>person),Maria). Para gerar essa saída, o parser primeiramente casa a sentença de entrada com a regra gramatical definida em IMP[1]. Depois disso, ele procura a primeira palavra da sentença (create) no dicionário e coloca sua representação na posição da $\mathrm{UW}_{1}$ da relação obj. O mesmo é feito com a segunda palavra da sentença (student), cuja representação no dicionário é student(icl>person>). Essa representação é colocada na posição da $U_{2}$ da 
relação obj e na posição da $\mathrm{UW}_{1}$ da relação nam; e assim sucessivamente. Se um substantivo não existir no dicionário, o parser o interpreta como sendo um nome próprio ( $\mathrm{ppn}$ - proper name) e o coloca normalmente na posição correspondente da sentença UNL. Isso acontece, por exemplo, com o substantivo Maria.

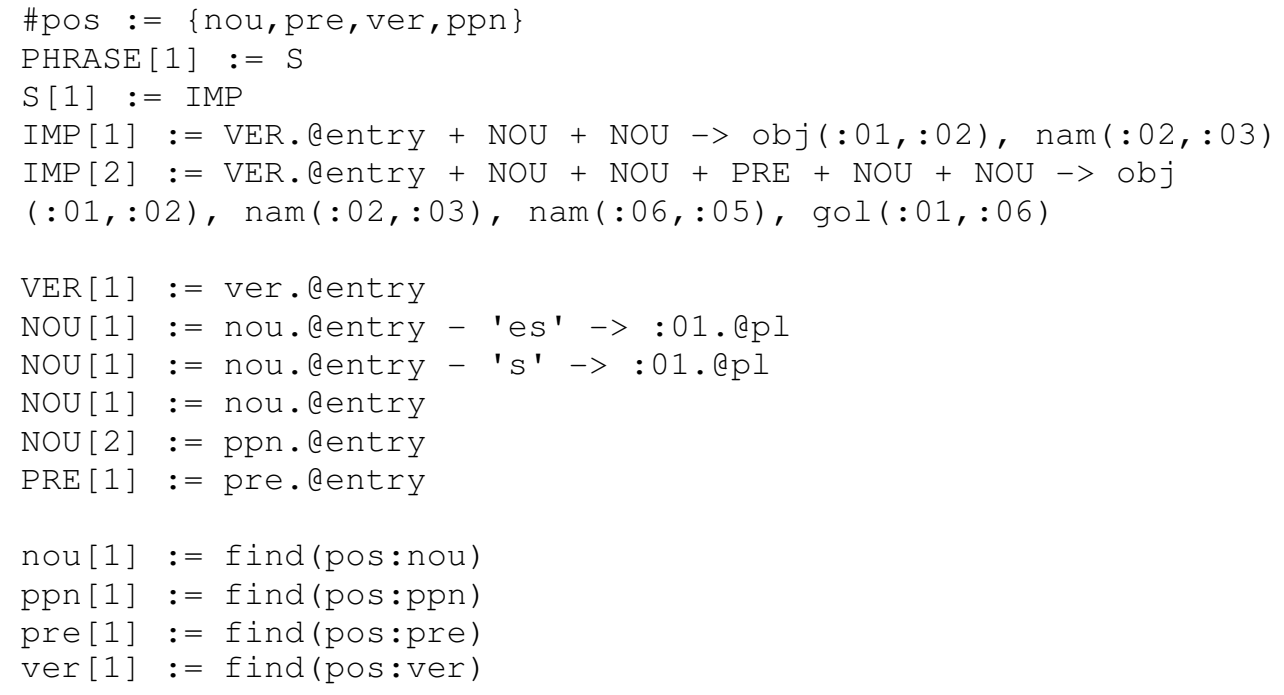

Figura 5.3 - Trecho de uma gramática simples desenvolvida para o EnCo Hermeto.

No contexto deste trabalho, o dicionário deve conter palavras (ou conceitos) de um domínio particular, que devem estar relacionadas com a funcionalidade dos componentes desenvolvidos para o domínio. Os conceitos no dicionário devem estar presentes também nas Ontologias de Componentes e de Domínio, como representado por uma linha verde na Figura 5.1 e detalhado na seção 5.5. Para o exemplo de dicionário da Figura 5.2, apenas os conceitos add, course, delete, person, student e teacher deveriam ser considerados nas Ontologias de Componentes e de Domínio, pois as demais entradas são sinônimos dessas ou não são relevantes, como preposições e artigos.

\subsection{Mapeamento Semântico entre UNL e Componentes}

O mapeamento semântico entre UNL e componentes consiste em indicar, para um conjunto de sentenças UNL, quais são as informações semânticas relevantes que podem ajudar a encontrar os componentes de software apropriados para executar requisições expressas em 
linguagem natural. Tais informações relevantes são encontradas com a utilização das UWs de UNL (conceitos) e das relações UNL, pois essas possuem carga semântica que pode ser relacionada com a funcionalidade dos componentes. Os atributos de UNL não estão sendo considerados no mapeamento semântico, pois todas as sentenças são imperativas e os atributos não representam informações semânticas relevantes para a busca pelos componentes.

Para esclarecer o que é e como é realizado o mapeamento semântico, a sentença “Delete student Maria from Java course" será considerada como exemplo, para a qual o EnCo deverá gerar a seguinte representação (os atributos e as restrições foram desconsiderados):

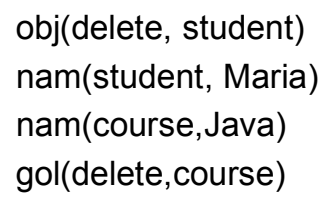

A primeira etapa do mapeamento semântico consiste em analisar cada relação UNL presente nas sentenças de entrada e relacionar suas UWs com informações sobre um determinado conjunto de componentes. Para o exemplo dado em (1), as relações objeto (obj), nome (nam) e estado final (gol) precisam ser analisadas manualmente. O resultado da análise está resumido na Tabela 5.1, que mostra a relação, seu significado genérico (de acordo com a especificação UNL) e seu significado na sentença representada em (1), juntamente com possíveis informações que podem ser inferidas a respeito dos componentes.

Uma análise como a apresentada na Tabela 5.1 deve ser feita para todas as relações presentes na gramática, considerando o significado da relação e a funcionalidade dos componentes desenvolvidos para determinada aplicação. A partir dessa análise é possível concluir como as UWs podem ser mapeadas para informações semânticas a respeito de um determinado conjunto de componentes. Tais informações devem indicar se uma UW corresponde a:

- um conceito associado a um componente;

- um conceito associado a um parâmetro;

- um conceito associado ao valor retornado por um método;

- uma ação associada a um método ou

- um valor de parâmetro, que será passado diretamente para o componente, depois que as devidas conversões de tipos forem realizadas. 
Tabela 5.1 - Relações UNL presentes na sentença analisada e seus significados.

\begin{tabular}{|c|c|c|}
\hline $\begin{array}{l}\text { Relação UNL e } \\
\text { exemplo }\end{array}$ & $\begin{array}{l}\text { Significado genérico da relação } \\
\text { (UNL Specifications, 2005) }\end{array}$ & $\begin{array}{l}\text { Significado da relação na sentença, } \\
\text { considerando componentes }\end{array}$ \\
\hline $\begin{array}{l}\text { obj }\left(U_{1}, W_{2}\right) \\
\text { obj(delete, student) }\end{array}$ & $\begin{array}{l}\text { Define algo que está em foco e } \\
\text { é diretamente afetado por um } \\
\text { evento ou ação. Tipicamente, a } \\
\text { UW }_{1} \text { é uma ação (verbo) e a } \\
\text { UW }_{2} \text { é o objeto afetado. }\end{array}$ & $\begin{array}{l}\text { O exemplo significa que um estudante } \\
\text { será apagado. A UW } W_{1} \text { é sempre uma } \\
\text { ação e fornece uma pista sobre o } \\
\text { possível método a ser chamado no } \\
\text { componente. } A \mathrm{UW}_{2} \text { é um conceito do } \\
\text { domínio, que possivelmente está } \\
\text { relacionado a um componente ou a um } \\
\text { de seus parâmetros. }\end{array}$ \\
\hline $\begin{array}{l}\text { nam }\left(U_{1}, U_{2}\right) \\
\text { nam (course,Java) }\end{array}$ & $\begin{array}{l}\text { Define o nome de alguma } \\
\text { coisa. A } U_{2} \text { é o nome da } \\
U W_{1} \text {. }\end{array}$ & 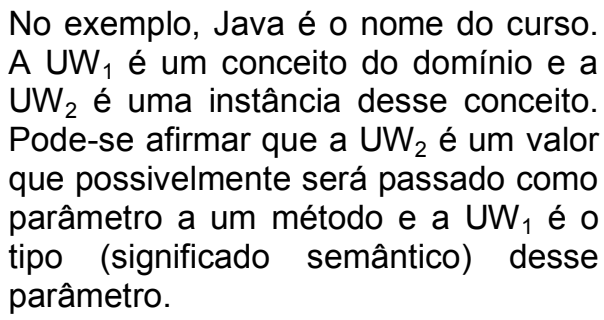 \\
\hline $\begin{array}{l}\text { gol }\left(U_{1}, U_{2}\right) \\
\text { gol(delete,course) }\end{array}$ & $\begin{array}{l}\text { Define o estado final de um } \\
\text { objeto ou de algo que está } \\
\text { associado ao estado final de } \\
\text { um objeto ou evento. A UW } U_{1} \\
\text { está relacionada a um evento } \\
\text { (tipicamente um verbo) e a UW } U_{2} \\
\text { está relacionada a um estado } \\
\text { final. }\end{array}$ & $\begin{array}{l}\text { No exemplo, apagar é um evento e } \\
\text { curso é o estado final. Isso significa } \\
\text { que alguma coisa será apagada do } \\
\text { curso. Assim como na relação objeto } \\
(o b j) \text {, a UW }{ }_{1} \text { é uma ação (verbo). A } \\
\text { UW }_{2} \text { indica o objeto que terá seu } \\
\text { estado final alterado pela ação. Pode- } \\
\text { se concluir que a UW }{ }_{2} \text { está } \\
\text { relacionada a um possível componente } \\
\text { a ser chamado ou a um de seus } \\
\text { parâmetros. }\end{array}$ \\
\hline
\end{tabular}

Na Figura 5.4 é ilustrado um possível mapeamento semântico entre as UWs das relações UNL e componentes de software, para as relações analisadas na Tabela 5.1.

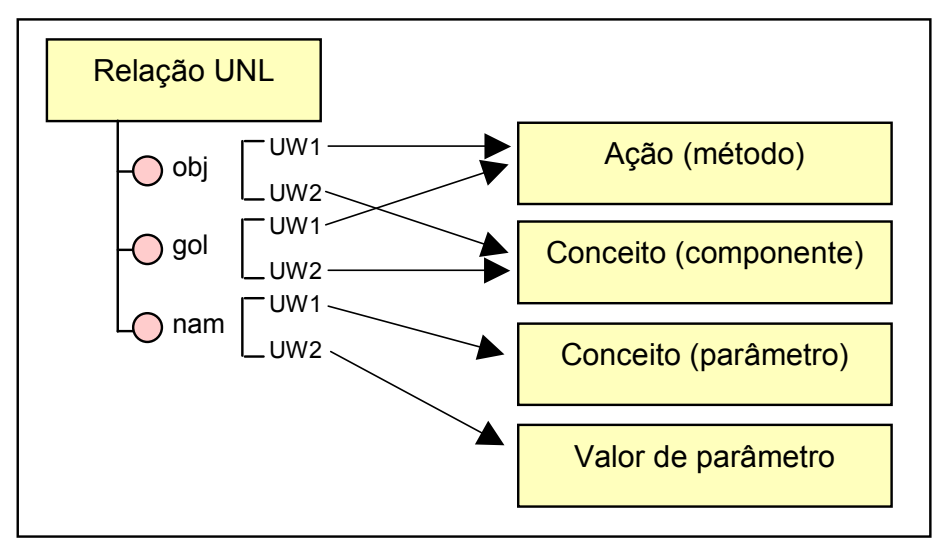

Figura 5.4 - Ilustração de um possível mapeamento semântico entre as relações UNL da sentença em (1) e componentes de software. 
Para tornar o mapeamento semântico um processo semi-automático foram desenvolvidos o Classificador de Tokens, uma ontologia genérica (upper ontology) intitulada InterComp e um conjunto de regras aplicadas à ontologia, como ilustrado na Figura 5.1. As regras são dependentes da funcionalidade dos componentes desenvolvidos para determinado domínio de aplicação. Elas devem ser escritas levando em consideração como as UWs das relações UNL estão relacionadas com informações sobre esses componentes. Devido a esse único fato o mapeamento semântico é considerado um processo semi-automático. Nas seções a seguir são descridos, respectivamente, a Ontologia InterComp, o Classificador de Tokens e as regras.

\subsubsection{A Ontologia InterComp}

A Ontologia InterComp (Interlíngua-Componentes) é uma upper ontology. Seu objetivo é relacionar as UWs e as relações da Interlingua UNL com componentes de software. Para isso, foram usadas as relações definidas nas especificações UNL (UNL Specifications, 2005) e os relacionamentos que essas possuem com conceitos genéricos (UWs), que também estão definidos nas especificações. Isto é, essa ontologia formaliza os relacionamentos existentes entre as relações UNL e suas UWs genéricas. Além disso, existem na ontologia relacionamentos entre as UWs genéricas e componentes de software, com o objetivo de ajudar no mapeamento semântico entre UNL e componentes. O diagrama de classes com a estrutura hierárquica dessa ontologia é apresentado na Figura 5.5.

A Otologia InterComp foi desenvolvida em OWL (McGuinness \& van Harmelen, 2004), por isso todas as classes herdam propriedades da classe owl:Thing. No lado esquerdo da ontologia está a classe relation, que é superclasse de todas as relações UNL (ver Anexo C). No lado direito da ontologia estão as principais classes da hierarquia de conceitos do sistema de UWs de UNL, apresentado na Tabela 2.3. O sistema de UWs é a base da UNL KB (UNL Knowledge Base) e define conceitos genéricos com os quais as relações UNL podem estar relacionadas (UNL Specifications, 2005). Por exemplo, de acordo com a Especificação de UNL (2005), as UWs da relação objeto (obj) são as seguintes: 


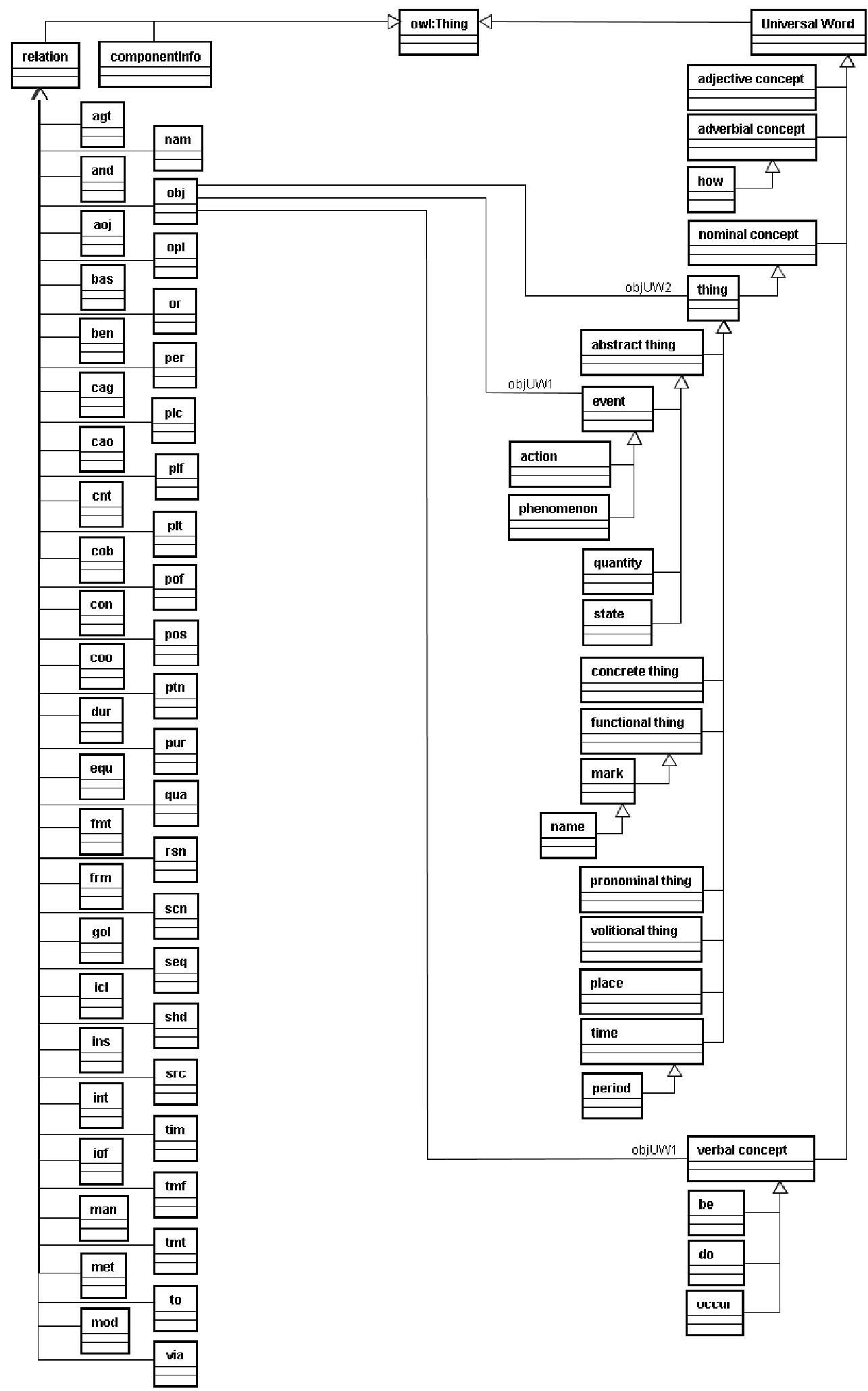

Figura 5.5 - Hierarquia de classes da Ontologia InterComp com relacionamentos da relação objeto (obj). 


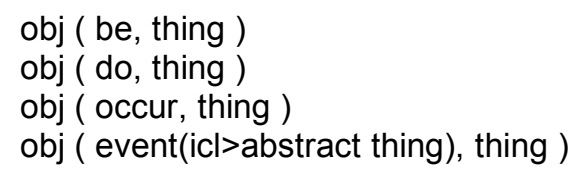

A $U_{1}$ da relação objeto será sempre um evento ou um verbo, derivado de be, do ou occur, os quais são subclasses do conceito verbalConcept. Portanto, pode-se dizer que a $\mathrm{UW}_{1}$ dessa relação será sempre um evento (event) ou um verbo (verbalConcept). A UW 2 será sempre derivada do conceito genérico thing. Os relacionamentos entre a relação objeto e suas UWs genéricas recebem o nome de objUW1 e objUW2. O mesmo padrão de nomes foi seguido para os relacionamentos das demais relações UNL com suas UWs. A Ontologia InterComp formaliza tais relacionamentos para todas as relações UNL, mas apenas os da relação objeto estão no diagrama da Figura 5.5 para não sobrecarregar o diagrama. Devido ao grande número de relacionamentos, foram feitos quatro diagramas de classes para representá-los, que podem ser consultados no Apêndice A.

A classe Component Info possui a maior parte dos relacionamentos que dizem respeito às informações semânticas que são extraídas depois da classificação dos tokens e do disparo das regras. No diagrama de classes da Figura 5.6 são mostrados tais relacionamentos. Na seção 5.4.3 (Regras) é dada uma explicação detalhada da função desses relacionamentos e da classe Component Info.

\section{Metodologia de Desenvolvimento da Ontologia InterComp}

Como descrito na seção 3.5, a metodologia adotada para o desenvolvimento das ontologias deste trabalho foi proposta por Noy e McGuiness (2001), cujos passos são apresentados a seguir:

1) Determinar o domínio e o escopo da ontologia: antes de começar a desenvolver a ontologia, foi estabelecido que seu objetivo era relacionar UNL com componentes e, por meio do disparo de regras, inferir informações semânticas que ajudassem a realizar a busca por componentes. Depois que o objetivo da ontologia foi estabelecido, os conceitos e as relações foram identificados. A hierarquia de conceitos genéricos é a mesma presente no Sistema de UWs, e as relações existentes entre os conceitos estão na Especificação de UNL (2005). Nessa fase, as seguintes perguntas foram respondidas: 
- Qual é o domínio que a ontologia irá cobrir?

A ontologia é genérica (upper ontology), pois deve conter todas as relações UNL e os conceitos genéricos com os quais essas possuem relacionamentos.

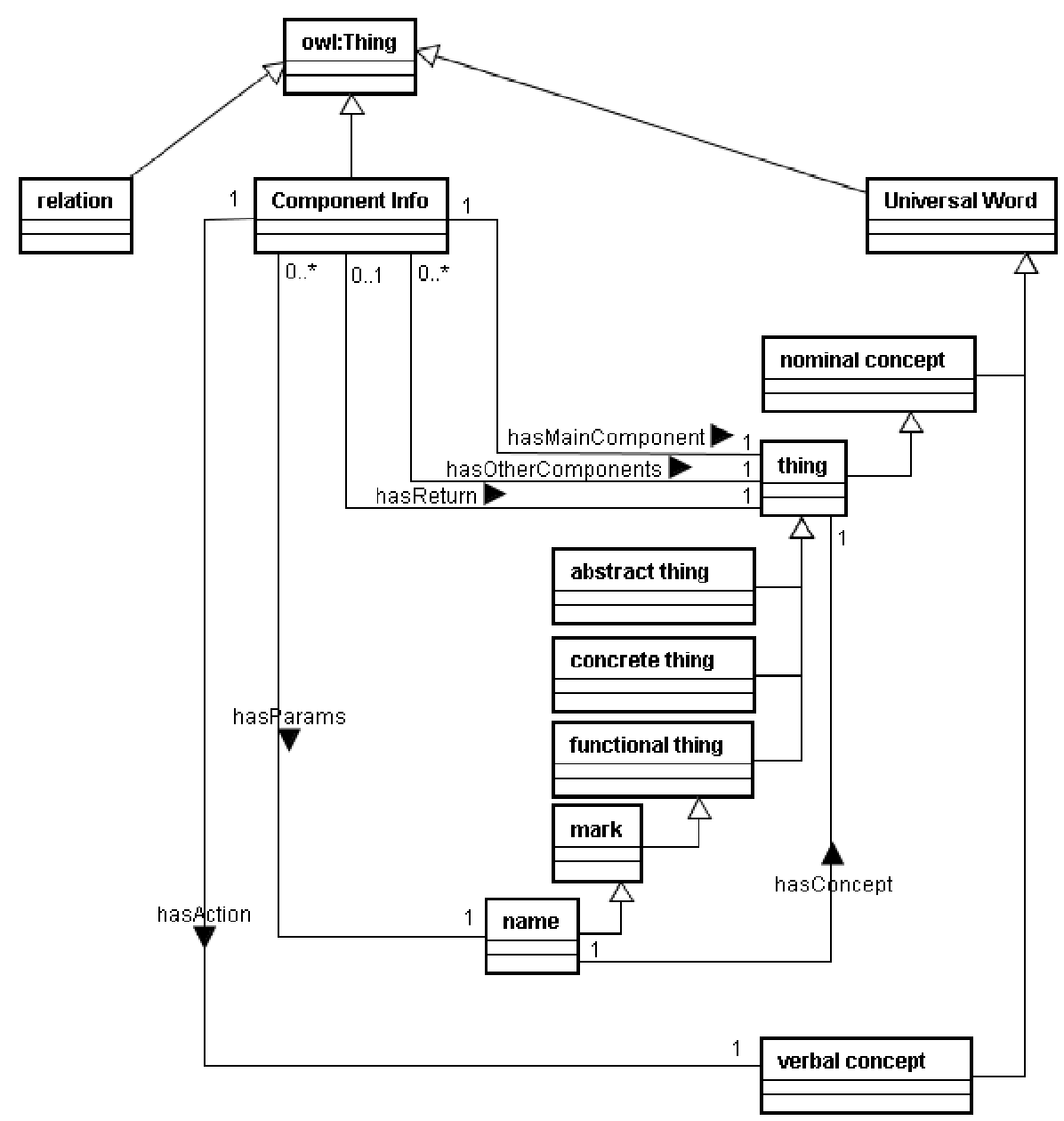

Figura 5.6 - Associações que relacionam UNL com informações semânticas sobre componentes.

- Para que a ontologia será utilizada?

A ontologia será utilizada para ajudar no mapeamento semântico entre UNL e componentes de software.

- Para quais tipos de questões a informação na ontologia deverá fornecer respostas?

A ontologia deverá representar, como instâncias, as relações UNL e as UWs de determinada sentença UNL (requisição imperativa em linguagem natural). Por 
meio de inferência (com as devidas regras criadas), a ontologia deverá fornecer respostas sobre quais são as informações semânticas sobre possíveis componentes para executar uma requisição. Se a ontologia der essas respostas, ela poderá ser considerada adequada.

2) Considerar a reutilização de outras ontologias: a reutilização foi grandemente utilizada no desenvolvimento da Ontologia InterComp. Conforme já mencionado, a hierarquia de classes da ontologia está definida no Sistema de UWs, as subclasses de "relation" são as relações UNL que estão na especificação e os relacionamentos entre as classes da ontologia também estão definidos na especificação de UNL (UNL Specification, 2005). Apesar dessas definições já existirem, elas ainda não se encontram em um formato processável por programas. O Sistema de UWs está formalizado na UNL KB, que atualmente é um arquivo texto, e as demais informações estão na especificação (2005). Outras iniciativas de formalizar a interlíngua UNL em uma ontologia não foram encontradas. Além disso, iniciativas para criar uma ontologia que relacione uma interlíngua com informações semânticas sobre componentes também não foram encontradas na literatura.

3) Enumerar termos importantes para a ontologia: esse passo quase não se aplica, pois os termos importantes e as propriedades deles devem estar de acordo com a especificação UNL. O único fato importante nesse passo foi ter identificado a necessidade de uma classe para armazenar as informações semânticas sobre componentes (classe Component Info). Foi identificado que essa classe deveria ser o "ponto de encontro" entre UNL e componentes. Isto é, as informações semânticas sobre os componentes deveriam ser extraídas por meio de inferência e formalizadas nessa classe.

4) Definir as classes e a hierarquia entre elas: a hierarquia dos conceitos, definida no Sistema de UWs, foi respeitada. A classe Component Info foi criada.

5 e 6) Definir as propriedades das classes (slots) e as facetas dos slots: as propriedades, chamadas de ObjectProperties em OWL, consistem em relacionamentos entre as classes. Os relacionamentos definidos, na especificação UNL, entre uma relação UNL e suas UWs foram todos incluídos na Ontologia InterComp. As únicas propriedades definidas na ontologia, que não fazem parte da 
especificação, estão são as da classe Component Info e a propriedade hasConcept, como ilustrado no diagrama da Figura 5.6.

7) Criar instâncias: as instâncias são criadas primeiramente pelo Classificador de Tokens, descrito na próxima seção. As instâncias são necessárias para fazer o disparo das regras (seção 5.4.3) e assim, inferir informações semânticas sobre os componentes. As informações inferidas são armazenadas nos slots (propriedades) da classe Component Info e no slot hasConcept.

\subsubsection{O Classificador de Tokens}

O Classificador de Tokens é uma classe Java que recebe como entrada uma sentença em UNL. Sua função é separar cada token da sentença e classificá-los de acordo com a Ontologia InterComp. Essa classificação cria instâncias (ou fatos) na ontologia, utilizando para isso a API da ferramenta Protégé. Para o exemplo em (1) o Classificador de Tokens cria as instâncias apresentadas como caixas amarelas no diagrama da Figura 5.7. Para criar essas instâncias, o Classificador de Tokens primeiramente separa o token obj, procura pela classe obj na ontologia e, ao encontrá-la, cria a instância obj-1. Depois disso, o Classificador separa o token create, segue o relacionamento objUW1 e cria a instância create sob a classe verbalConcept. O mesmo é feito para o token student, cuja instância pertence à classe thing, de acordo com o relacionamento objUW2. Isso será feito para cada relação UNL presente na sentença em (1). O Classificador de Tokens não trabalha com atributos UNL (seção 2.5), UWs restritas (seção 2.6.1), nem escopos (seção 2.3).

Após criar as instâncias, o Classificador de Tokens carrega a máquina de inferência do JESS (Java Expert System Shell), carrega o arquivo contendo as regras e dispara as regras, que são executadas pela máquina de inferência do JESS, como descrito na próxima seção.

\subsubsection{As Regras}

Para que o mapeamento semântico possa ser realizado é preciso formalizá-lo em regras. Isso significa que é preciso escrever regras para relacionar as UWs das relações UNL com informações sobre determinado conjunto de componentes. 


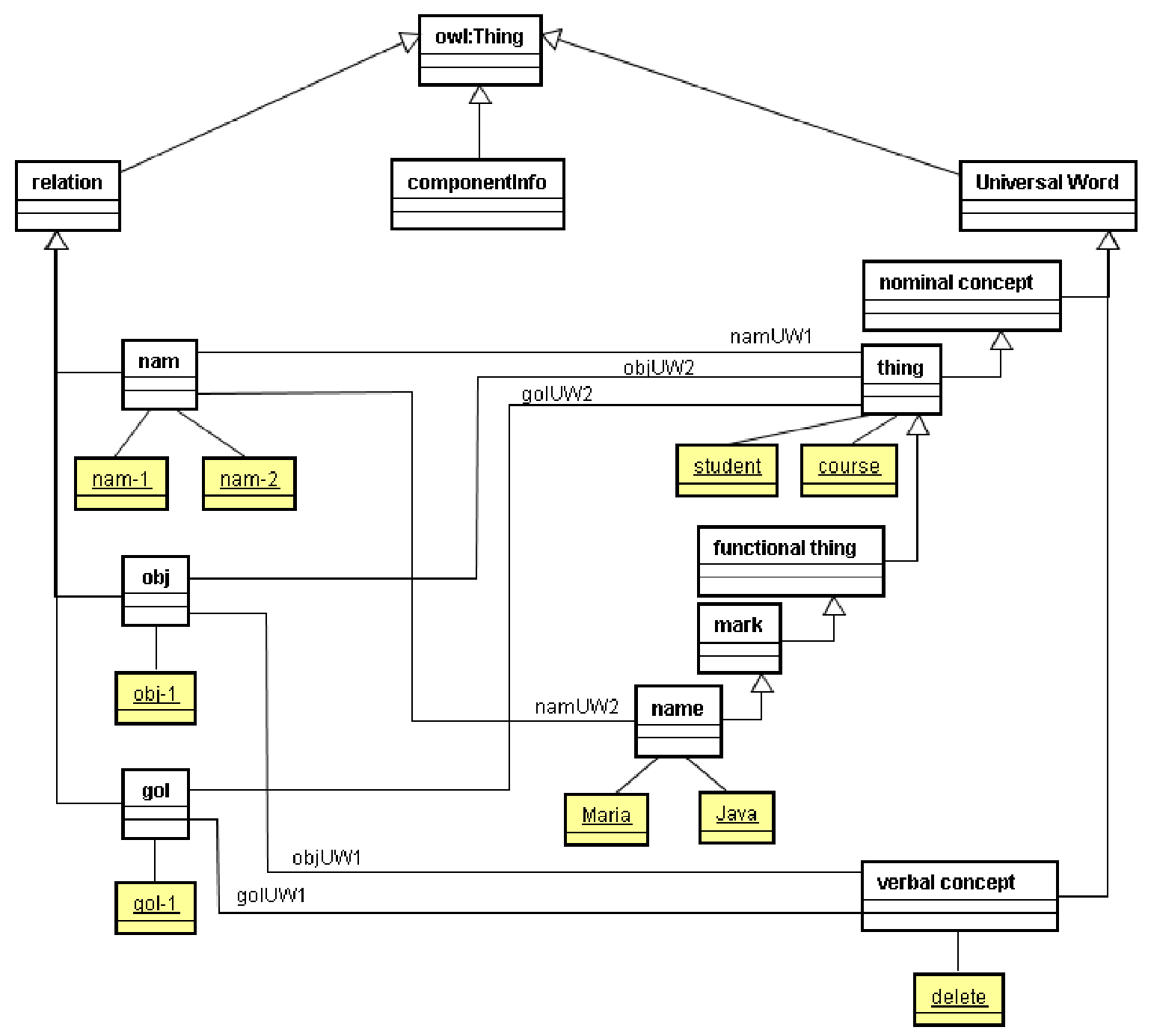

Figura 5.7 - Instâncias criadas na Ontologia InterComp pelo Classificador de Tokens.

As regras utilizam os fatos (instâncias) na Ontologia InterComp para inferir informações sobre os componentes, levando em consideração a semântica das relações UNL e suas UWs, representadas como instâncias. Na Figura 5.8, estão quatro exemplos de regras, escritas em JESS (Friedman-Hill, 2003), para as relações nome (nam) e objeto (obj). As regras devem ser escritas levando em consideração informações sobre a funcionalidade dos componentes.

As regras apresentadas na Figura 5.8 são regras de produção e a máquina de inferência do JESS utiliza um algoritmo forward-chaining para processá-las. As regras devem estar 
localizadas em um arquivo separado da ontologia, pois elas podem mudar de acordo com os componentes.

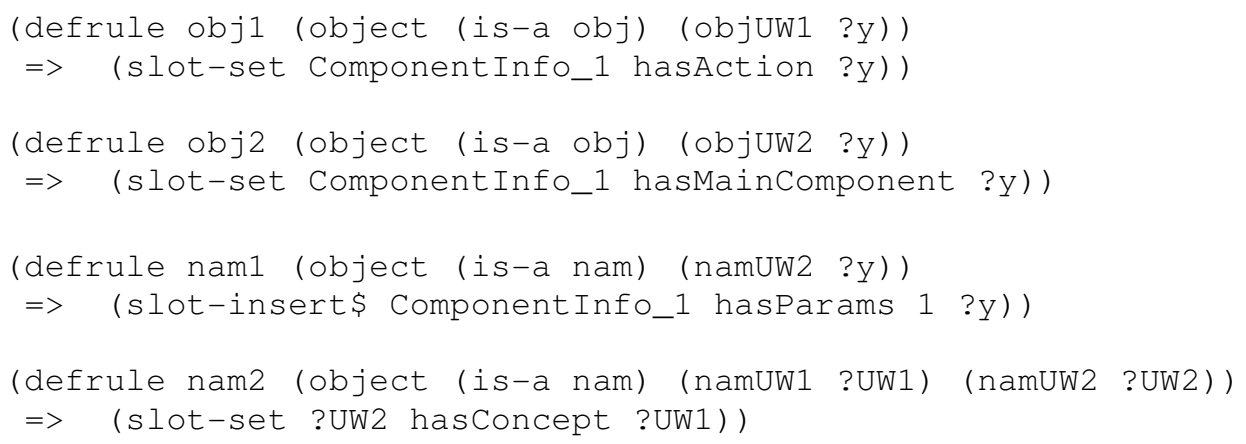

Figura 5.8 - Exemplos de regras para as relações nome e objeto.

A primeira regra da Figura 5.8 (obj1) pode ser interpretada da seguinte maneira: se houver alguma instância da classe obj na ontologia, então, armazene o valor da $\mathrm{UW}_{1}$ da relação obj (objUW1) no slot hasAction da instância Componentınfo_1. Se essa regra disparar, a ação relacionada ao método do componente será inferida e armazenada no slot hasAction. Considerando que os fatos da ontologia são as instâncias representadas na Figura 5.7, então a instância delete será armazenada no slot hasAction. Similarmente, a instância student será armazenada no slot hasMainComponent, as instâncias Maria e Java serão armazenadas no slot hasParams e as instâncias student e course serão armazenadas no slot hasConcept, indicando que os parâmetros Maria e Java estão relacionados aos conceitos student e course, respectivamente.

O resultado da execução das regras é a geração (por meio de inferência) de novos fatos na ontologia, mais especificamente nos slots da classe Components Info e no slot hasConcept. Na Figura 5.9 é apresentado um grafo RDF representando os dados inferidos, considerando as instâncias ilustradas na Figura 5.7 e as regras da Figura 5.8. Os dados inferidos são passados para o Módulo de Busca.

Pelo exposto nesta seção, está claro que o mapeamento semântico não é totalmente independente da interface dos componentes, o que dificulta a criação de regras default. Isto é, mesmo que o domínio de aplicação seja o mesmo, se o conjunto de componentes mudar, as regras do mapeamento semântico também podem mudar, impedindo a utilização das mesmas 
regras (regras default) e impossibilitando que o mapeamento semântico seja um processo totalmente automático. Por exemplo, considerando um componente chamado "Student" com o método vector getstudents(). A sentença "Liste estudantes" iria ativar o método correspondente, pois o conceito estudante estaria relacionado diretamente ao componente "Student", por meio da regra a seguir.

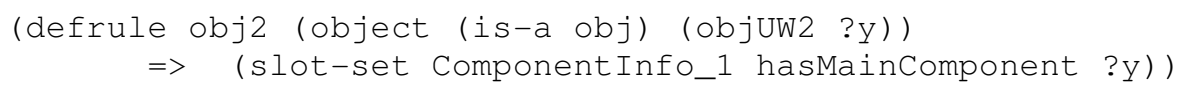

Mas se os componentes mudarem, pode ser que o componente "Student" não exista mais e sua funcionalidade seja substituída pelo componente "User", que possui o método Vector getUsers(String role), onde role pode assumir os valores "estudante", "professor", etc. Neste caso, o conceito estudante estaria relacionado ao conceito role, que é um parâmetro e a regra teria de ser alterada para a regra a seguir. Isso é necessário porque o conceito "estudante" não estaria mais relacionado a um componente, mas a um parâmetro.

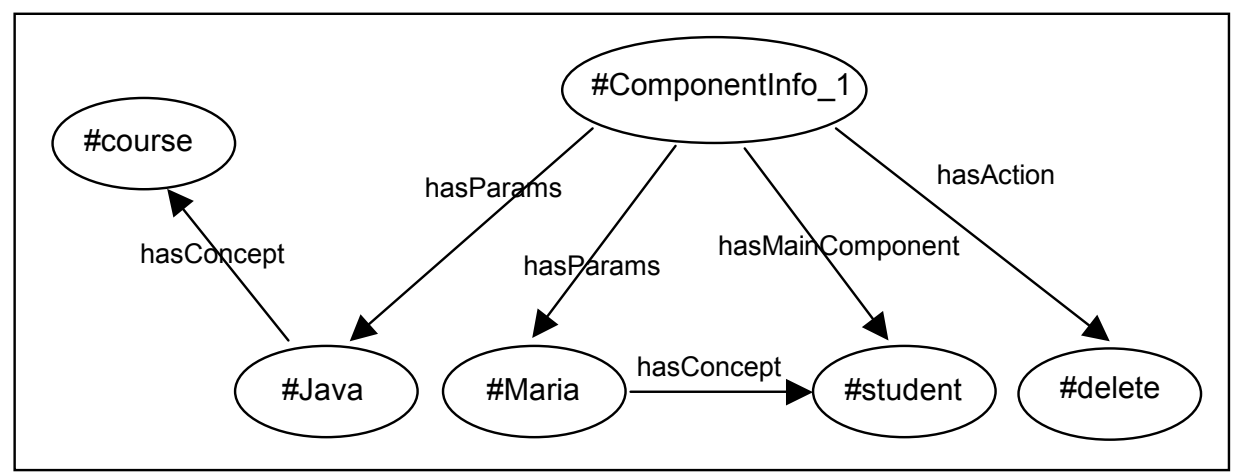

Figura 5.9 - Dados inferidos.

\subsection{Busca por Componentes}

A parte de Busca por Componentes da Arquitetura OntoMap possui a Ontologia de Componentes, a Ontologia de Domínio e o Módulo de Busca, descritos nas seções 5.5.1 a 5.5.3, respectivamente. O Módulo de Busca utiliza as duas ontologias mais as informações 
semânticas inferidas no Mapeamento Semântico para realizar a busca por possíveis componentes para satisfazer a requisição em linguagem natural.

\subsubsection{A Ontologia de Componentes}

A Ontologia de Componentes possui informações semânticas relacionadas com dados das interfaces dos componentes. O Módulo de Busca compara as informações semânticas inferidas da Ontologia InterComp com as informações semânticas da Ontologia de Componentes e assim encontra o componente mais apropriado para executar a requisição. $\mathrm{O}$ diagrama de classes da Ontologia de Componentes é apresentado na Figura 5.10.

A classe Action possui as ações as quais os métodos dos componentes estão relacionados. Nesta classe estão os verbos no imperativo, que são relacionados aos métodos dos componentes e estão presentes no dicionário. A classe DomainConcept possui conceitos (classes) relacionadas ao domínio de aplicação dos componentes, que também estão presentes no dicionário. Esses conceitos podem possuir relacionamentos entre si, formando a Ontologia de Domínio, isto é, a classe DomainConcept é o "ponto de encontro" entre a Ontologia de Componentes e a Ontologia de Domínio.

As classes Component, Method e Parameter descrevem "dados físicos" dos componentes, presentes em suas interfaces, enquanto as classes Action e DomainConcept possuem informações semânticas a respeito da funcionalidade dos componentes. Os relacionamentos entre as três primeiras classes e as duas últimas é que relacionam as interfaces dos componentes com informações semânticas.

Para cada conjunto de componentes, a Ontologia de Componentes deve ser instanciada. Isto é, a Ontologia de Componentes é sempre a mesma, o que muda são suas instâncias, as quais dependem da funcionalidade dos componentes de determinado domínio de aplicação.

\section{Metodologia de Desenvolvimento da Ontologia de Componentes}

Assim como a Ontologia InterComp, a Ontologia de Componentes também foi desenvolvida baseando-se nos passos definidos na metodologia de Noy e McGuiness (2001), como descrito a seguir: 
1) Determinar o domínio e o escopo da ontologia: o objetivo da ontologia é descrever componentes, utilizando para isso os dados de suas interfaces e relacionando esses dados com informações semânticas.

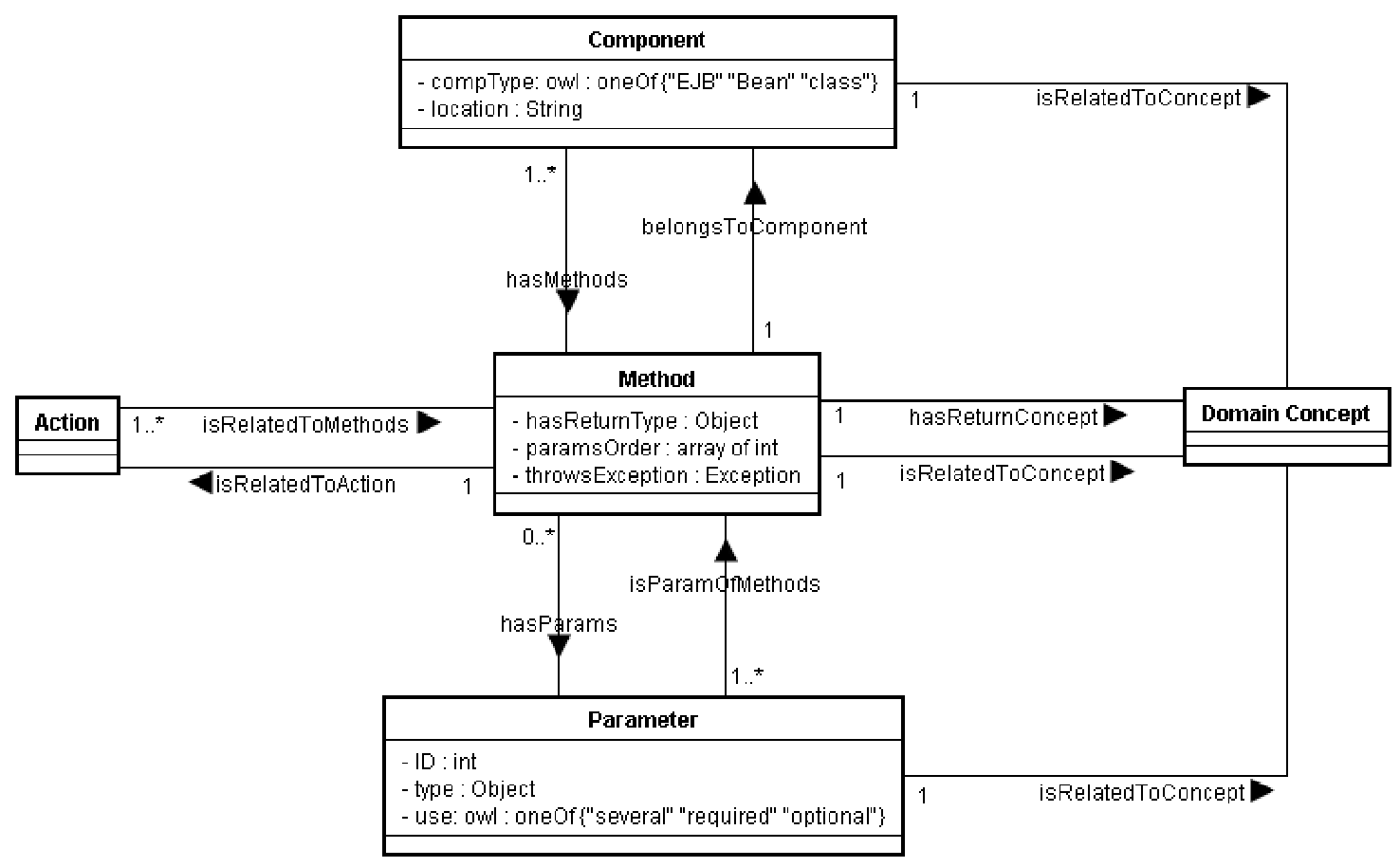

Figura 5.10 - Ontologia de Componentes.

2) Considerar a reutilização de outras ontologias: outros trabalhos já utilizaram ou desenvolveram ontologias de componentes para ajudar na busca e recuperação de componentes, conforme apresentado nos Trabalhos Relacionados (Capítulo 7). Entretanto, nenhuma delas considera dados semânticos extraídos de uma interlíngua para descrever os componentes e assim auxiliar a busca. Por essa razão, outras ontologias que descrevem componentes não foram utilizadas.

3 e 4) Enumerar termos importantes e definir as classes para a ontologia: primeiramente, foram criadas as classes com os dados sobre as interfaces dos componentes (classes Component, Method e Parameter). Posteriormente, foram identificadas as classes para armazenar as informações semânticas (Action e DomainConcept). 
5 e 6) Definir as propriedades das classes (slots) e as facetas dos slots: nessa fase, os dados sobre as interfaces dos componentes foram relacionadas com as informações semânticas. Essa fase e a anterior passaram por refinamentos ao longo do desenvolvimento deste trabalho.

7) Criar instâncias: as instâncias são criadas de acordo com os componentes de determinada aplicação e com os termos identificados para o domínio de aplicação dos componentes. As instâncias das classes Component, Method e Parameter são simples de serem identificadas, pois são informações que estão presentes nas interfaces dos componentes. As instâncias da classe Action são os verbos presentes no dicionário (desconsiderando os sinônimos). A classe DomainConcept é a única que não possuirá necessariamente instâncias, pois ela é composta pelos demais conceitos do dicionário (também desconsiderando os sinônimos), organizados como uma hierarquia de conceitos específicos do domínio. Esses conceitos compõem a Ontologia de Domínio, descrita na próxima seção.

\subsubsection{A Ontologia de Domínio}

A Ontologia de Domínio possui os termos do domínio, que são identificados a partir dos conceitos do dicionário. Portanto, essa ontologia pode mudar dependendo do vocabulário do domínio, que é relacionado à funcionalidade dos componentes. Qualquer uma das metodologias apresentadas na seção 3.5 pode ser utilizada para desenvolver essa ontologia. A Ontologia de Domínio está "ligada" à Ontologia de Componentes por meio da classe DomainConcept.

Uma Ontologia de Domínio foi criada para o domínio de gerenciamento de cursos, com o objetivo de mostrar uma instanciação da Arquitetura OntoMap, conforme apresentado no Capítulo 6.

\subsubsection{O Módulo de Busca}

O objetivo do Módulo de Busca é encontrar possíveis componentes para executar a requisição em linguagem natural. O Módulo de Busca é uma classe Java que recebe, do Classificador de Tokens, as seguintes informações inferidas da Ontologia InterComp: a ação, o 
principal conceito (ao qual estará relacionado o provável componente a ser chamado), outros possíveis conceitos (correspondentes a outros possíveis componentes), os parâmetros, os conceitos relacionados a cada parâmetro e o conceito relacionado ao retorno do método (esses três últimos podem não existir). Por exemplo, considerando as regras apresentadas na Figura 5.8 e os dados inferidos ilustrados na Figura 5.9, o Módulo de Busca receberia os dados apresentados na Figura 5.11. Ele utiliza esses dados para fazer uma busca na Ontologia de Componentes, utilizando para isso a API da ferramenta Protégé. Ao receber as informações citadas acima, o módulo de busca executa os seguintes passos:

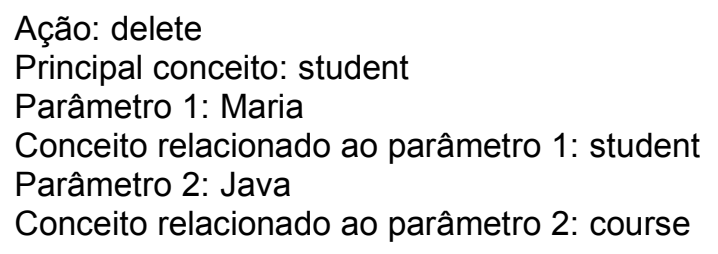

Figura 5.11 - Possíveis dados a serem recebidos pelo Módulo de Busca.

1) Busca na Ontologia de Componentes um método que esteja relacionado com a ação (na classe Action) e com o principal conceito (na classe DomainConcept). Para cada método encontrado neste passo 1, o Módulo de Busca realiza os passos 2, 3 e 4.

2) Verifica se o método retorna algum valor.

3) Verifica o número de parâmetros do método.

4) Verifica os conceitos relacionados aos parâmetros do método.

5) Se nenhum método adequado for encontrado, volta-se ao passo 1, mas utilizando outros possíveis conceitos. Se mais de um método adequado for encontrado, o Módulo de Busca os exibe para o usuário para que uma decisão seja tomada.

Os dados sobre o método a ser executado são passados para o Carregador de Componentes. Esses dados são: localização do componente, nome do componente, nome do método, valores e tipos dos parâmetros e tipo de retorno. Se o Carregador de Componentes precisar de mais informações sobre o componente a ser carregado ou sobre o método a ser executado, ele pode obtê-las diretamente na Ontologia de Componentes. 


\subsection{Discussão sobre a Arquitetura Proposta}

Este trabalho propõe executar componentes de software a partir de requisições imperativas expressas em diversas línguas naturais. Para atingir tal objetivo, foi proposta a Arquitetura OntoMap, que converte as requisições para a Interlíngua UNL e utiliza ontologias para realizar o mapeamento semântico entre UNL e componentes de software e para realizar a busca por componentes utilizando informações semânticas sobre os mesmos. Os pontos fortes e fracos da arquitetura proposta são discutidos a seguir.

\subsubsection{Pontos Fortes}

A Ontologia InterComp pode ser apontada como uma das maiores contribuições deste trabalho e é destacada como um ponto forte da Arquitetura OntoMap. Antes do desenvolvimento da Ontologia InterComp o mapeamento semântico era bastante limitado, pois era preciso alterar e recompilar linhas de código cada vez que o conjunto de componentes do domínio mudava. Estava clara a necessidade de um mecanismo para melhorar o mapeamento semântico entre UNL e componentes. A utilização de uma ontologia se mostrou uma opção flexível. Isto é, a ontologia é apropriada para representar, de maneira genérica, os relacionamentos semânticos entre as relações UNL e suas UWs. Se for necessário especializar as UWs, a ontologia pode ser estendida por meio da criação de novos conceitos a partir dos conceitos genéricos já presentes na mesma. Além disso, a possibilidade de utilizar regras em conjunto com a ontologia trouxe a flexibilidade desejada para o mapeamento semântico, pois se os componentes do domínio mudarem, apenas as regras precisam ser atualizadas. A formalização das relações UNL e de suas UWs genéricas em uma ontologia e o posterior relacionamento dessas UWs com informações sobre componentes foi de grande importância para a realização do mapeamento semântico. Outros trabalhos com esse objetivo não foram encontrados na literatura.

Outro ponto forte que pode ser mencionado é o fato do Módulo de Busca utilizar informações semânticas extraídas de uma interlíngua para fazer a busca na Ontologia de Componentes. Isso pode ser citado como uma contribuição inovadora entre as soluções que fazem busca por componentes. 


\subsubsection{Pontos Fracos}

Um ponto fraco da Arquitetura OntoMap está no fato das requisições de entrada não serem totalmente independentes da interface dos componentes. Isso significa que nas requisições de entrada é preciso ter termos que são necessários para a execução do método, pois objetos correspondentes a esses termos precisam ser passadas como parâmetros para o método. Por exemplo, considerando um componente chamado "User", no domínio de gerenciamento de cursos, que tenha o método object deletestudent(String ID). Para conseguir apagar um estudante utilizando esse método, a sentença "Apague a estudante Maria Linhalis" não poderia ser utilizada, diferente da sentença "Apague a estudante com código 3042890", pois o valor do ID precisa ser passado como parâmetro para o método e essa informação não consta na primeira sentença. A requisição "Apague a estudante 3042890" também não poderia ser considerada, pois o conceito relacionado a 3042890 é código, não estudante. Como a informação de que estudante possui código estaria na Ontologia de Domínio, uma possível solução para esse problema, seria criar instâncias dos estudantes com seus respectivos códigos na Ontologia de Domínio, estender o Módulo de Busca para considerar essas instâncias na busca e mantê-las sempre atualizadas, isto é, sempre refletindo a situação da base de dados da aplicação. Uma solução melhor ainda seria que as instâncias da Ontologia de Domínio fossem a base de dados da aplicação.

Outra limitação consiste no fato das restrições UNL e dos escopos não estarem sendo tratadas pelo Classificador de Tokens e, consequentemente, não poderem estar presentes no dicionário e na gramática, o que é comum em UNL.

O Módulo de Busca possui uma limitação para trabalhar com métodos que passam uma coleção de valores de um mesmo tipo como parâmetro, como vector, List, Collection, etc. O Módulo de Busca teria que ser estendido para considerar parâmetros com essa característica. Pensando nisso, a propriedade use foi criada na classe Parameter da Ontologia de Componentes. O objetivo dessa propriedade é indicar se um parâmetro é obrigatório (required), opcional (optional) ou se é passado junto com uma coleção de outros do mesmo tipo (several). O Módulo de Busca precisa apenas ser estendido para considerar essa propriedade da ontologia. 


\subsection{Considerações Finais}

Este Capítulo apresentou a Arquitetura OntoMap, proposta para possibilitar que requisições imperativas expressas em diversas línguas naturais sejam executadas por componentes de software. Para atingir esse objetivo, a arquitetura utiliza uma ontologia para realizar o mapeamento semântico entre a interlíngua UNL e componentes de software (Ontologia InterComp). As informações inferidas com o mapeamento semântico são utilizadas, pelo Módulo de Busca para encontrar componentes de software que sejam adequados para executar a requisição em linguagem natural, utilizando para isso informações semânticas sobre os componentes relacionadas com os dados de suas interfaces, formalizados na Ontologia de Componentes.

Considerando o que foi apresentado neste Capítulo, as seguintes contribuições podem ser apontadas: (1) definição da Arquitetura OntoMap; (2) definição do mapeamento semântico entre UNL e componentes; (3) desenvolvimento da Ontologia InterComp e de regras para formalizar e flexibilizar o mapeamento semântico; (4) desenvolvimento da Ontologia de Componentes, que relaciona dados das interfaces de um conjunto de componentes com informações semânticas; e (5) desenvolvimento do Módulo de Busca, que utiliza a Ontologia de Componentes para encontrar possíveis componentes para executar a requisição em linguagem natural.

Outro objetivo deste trabalho é possibilitar que a Arquitetura OntoMap seja utilizada por outros grupos de pesquisa, em diversos domínios, com diferentes conjuntos de componentes. Por isso, o próximo Capítulo apresenta a definição de um processo para utilização da Arquitetura OntoMap. 


\section{CAPÍTULO}

\section{Definição e Instanciação de um Processo para Utilização da Arquitetura OntoMap}

\subsection{Considerações Iniciais}

Neste capítulo é descrito um processo para auxiliar os usuários/desenvolvedores a utilizarem a Arquitetura OntoMap, proposta no Capitulo 5. O processo define os fluxos de trabalho (workflows), as atividades e os artefatos que devem ser produzidos, de maneira a possibilitar a utilização da Arquitetura OntoMap tendo como ponto de partida um conjunto de componentes já prontos.

Na seção 6.2, os seis fluxos gerais do processo são definidos. Nas seções 6.3 a 6.8 os processos que fazem parte de cada um dos fluxos gerais são descritos. Na seção 6.9 é apresentada uma instanciação do processo, tendo como ponto de partida componentes desenvolvidos para o domínio de gerenciamento de cursos.

\subsection{Processo para Utilização da Arquitetura OntoMap}

O processo proposto, apresentado na Figura 6.1, está organizado em seis fluxos de trabalho gerais, que são: preparação do ambiente, análise do domínio, desenvolvimento de dicionários e gramáticas, realização do mapeamento semântico, desenvolvimento e instanciação das ontologias, e realização de testes. Esses fluxos são descritos nas seções 6.3 a 6.8 , respectivamente, apontando um conjunto de atividades a serem seguidas e artefatos a serem produzidos. 


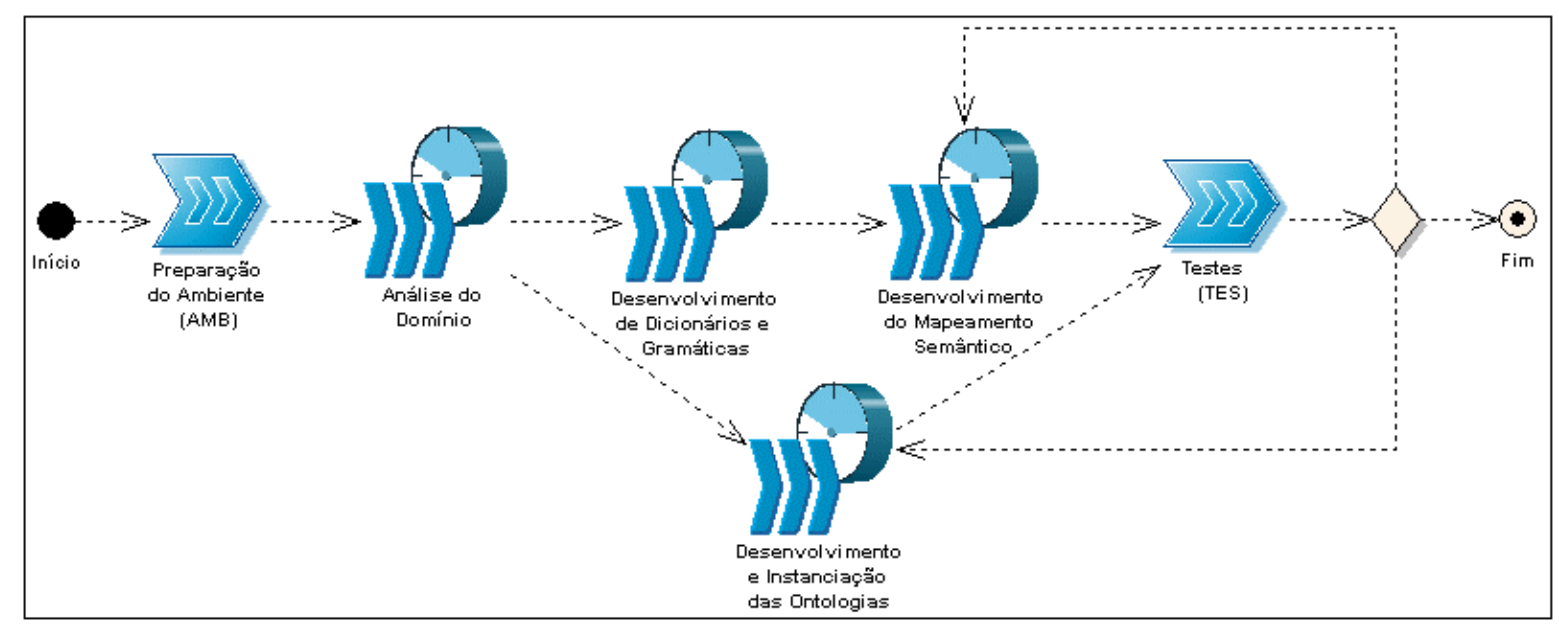

Figura 6.1 - Fluxos de Trabalho do Processo ${ }^{35}$

Para descrever os processos, foi utilizado o template da norma ISO/IEC 15504-5 (ISO/IEC, 2004), apresentado na Tabela 6.1, onde os processos são descritos em função dos seguintes itens:

- Resultados esperados (outcomes): são os resultados esperados com a correta implementação do processo.

- Práticas base (base practices): são os passos necessários para atingir os resultados esperados.

- Produtos de Trabalho (PT) (work products): são os artefatos que serão produzidos durante as diversas fases do processo. Esses artefatos podem ser entradas (inputs) ou saídas (outputs) e estão detalhados no Apêndice B.

Tabela 6.1 - Template da norma ISO/IEC 15504-5 (ISO/IEC, 2004) utilizado para descrição dos processos.

\begin{tabular}{|l|l|}
\hline ID do Processo & \\
\hline Nome do Processo & \\
\hline Objetivo do Processo & \\
\hline Resultados Esperados (outcomes) & \\
\hline Práticas Base (base practices) & Produtos de Trabalho (PT) \\
\hline \multicolumn{2}{|c|}{ Entradas (inputs) } \\
\hline
\end{tabular}

\footnotetext{
${ }^{35}$ A notação utilizada para representação gráfica dos processos é baseada no metamodelo SPEM (Software Process Engineering Metamodel) (OMG, 2005).
} 


\subsection{Preparação do Ambiente}

Para utilizar a Arquitetura OntoMap é preciso ter alguns itens instalados e alguns arquivos copiados para determinados diretórios. O processo para preparação do ambiente é apresentado na Tabela 6.2.

Tabela 6.2 - Processo para preparação do ambiente.

\begin{tabular}{|c|c|}
\hline ID do Processo & AMB \\
\hline Nome do Processo & Preparação do Ambiente \\
\hline Objetivo do Processo & $\begin{array}{l}\text { Preparar o ambiente computacional para que seja possível utilizar a } \\
\text { Arquitetura OntoMap no sistema Windows. }\end{array}$ \\
\hline $\begin{array}{l}\text { Resultados Esperados } \\
\text { (Outcomes) }\end{array}$ & $\begin{array}{l}\text { Como resultado da implementação correta desse processo, espera-se: } \\
\text { 1) Ter o software Protégé (Noy et al., 2000) instalado e funcionado. } \\
\text { 2) Ter o EnCo Hermeto (Martins et al., 2004) instalado e funcionando, } \\
\text { apenas se for preciso desenvolver gramáticas ou dicionários. } \\
\text { 3) Ter a máquina de inferência da linguagem JESS (Friedman-Hill, 2003) } \\
\text { instalada e funcionando. } \\
\text { 4) Ter os arquivos da Arquitetura OntoMap copiados para os diretórios } \\
\text { apropriados. }\end{array}$ \\
\hline Práticas Base & $\begin{array}{l}\text { AMB.PB1: Instalar o Protégé } 3.2^{36} \text { ou superior com OWL plugin [Outcome } \\
\text { 1]. } \\
\text { AMB.PB2: Instalar o Jena }{ }^{37} \text { e colocar seus arquivos no classpath para que } \\
\text { seja possível utilizar a API do Protété [Outcome 1]. } \\
\text { AMB.PB3: Instalar o Visual Studio [Outcome 2]. } \\
\text { AMB.PB4: Instalar o .net framework } 1.1 \text { [Outcome 2]. } \\
\text { AMB.PB5: Instalar o Hermeto 1.1, que pode ser obtido no NILC }{ }^{38} \text {, com } \\
\text { autorização dos responsáveis [Outcome 2]. } \\
\text { AMB.PB6: Instalar a máquina de inferência do JESS }{ }^{39} \text { [Outcome 3]. } \\
\text { AMB.PB7: Obter o arquivo ontoMap.zip em http://sourceforge.net/projects } \\
\text { lontomap. Esse arquivo contém o Classificador de Tokens (arquivo } \\
\text { Tokenizer.class), o Módulo de Busca (RetrieveComponents.class), a classe } \\
\text { para testes (Revgram.class) e as ontologias } \\
\text { ComponentsOntology). } \\
\text { AMB.PB8: Copiar os arquivos Tokenizer.class, RetrieveComponents.class e } \\
\text { Revgram.class no diretório de instalação do Protégé [Outcome 4]. } \\
\text { AMB.PB9: Criar o diretório "ontos" no diretório de instalação do Protégé e } \\
\text { copiar os arquivos das ontologias (InterComp, ComponentsOntology) } \\
\text { [Outcome 4]. Cada ontologia possui dois arquivos: um .pprj e outro .owl. }\end{array}$ \\
\hline
\end{tabular}

\footnotetext{
${ }^{36} \mathrm{http}: / /$ protege.stanford.edu/. Acesso em: 23 jan. 2007.

${ }^{37} \mathrm{http}: / /$ jena.sourceforge.net/. Acesso em: 23 jan. 2007.

${ }^{38} \mathrm{http}: / /$ www.nilc.icmc.usp.br. Acesso em: 23 jan. 2007.

${ }^{39} \mathrm{http}$ ://herzberg.ca.sandia.gov/jess. Acesso em: 23 jan. 2007.
} 


\subsection{Análise do Domínio}

Antes de começar a análise do domínio é preciso ter componentes prontos relacionados ao domínio no qual se deseja trabalhar. Os componentes podem ser desenvolvidos especialmente para determinada aplicação ou podem ser componentes já prontos relacionados ao domínio. Juntamente com os componentes é necessário ter as interfaces dos mesmos bem documentadas. Uma boa documentação das interfaces é muito importante, pois assim será possível conhecer a funcionalidade dos componentes. Tendo os componentes com suas interfaces documentadas, a análise do domínio consiste nos processos ilustrados na Figura 6.2, que estão descritos nas subseções a seguir.

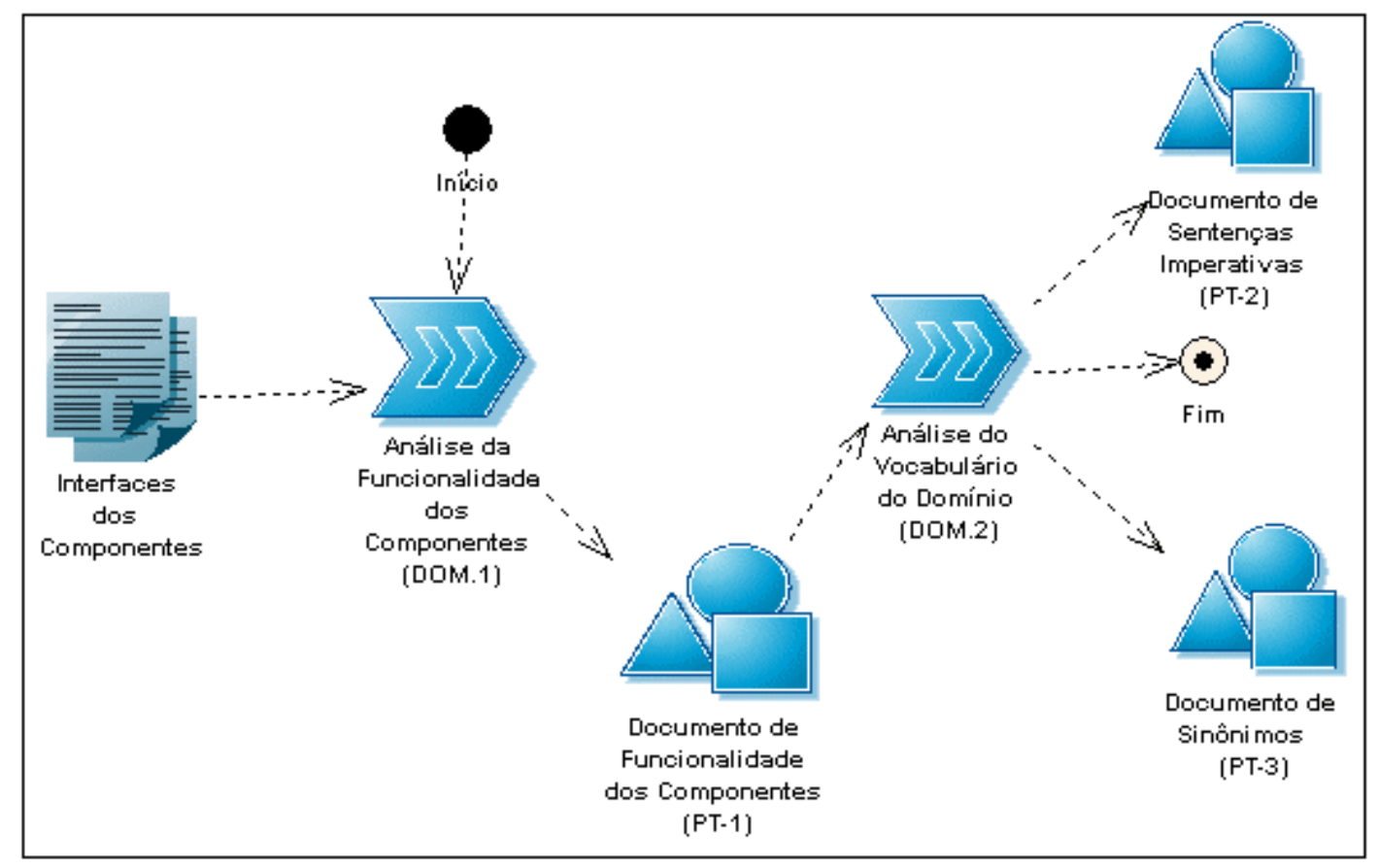

Figura 6.2 - Fluxo de Análise do Domínio.

\subsubsection{Análise da Funcionalidade dos Componentes}

Essa fase consiste em analisar as interfaces dos componentes e indicar um conceito relacionado a cada componente, a cada método, a cada parâmetro e ao retorno de cada método. A entrada desse processo é a interface documentada do componente e a saída é um documento com conceitos relacionados à funcionalidade dos componentes. Esse processo é formalizado 
na Tabela 6.3 e pode ser realizado por um usuário comum, isto é, por um usuário ou desenvolvedor que não tenha conhecimentos específicos nos assuntos relacionados a este trabalho, como UNL, ontologias, regras, desenvolvimento de dicionários e gramáticas.

Tabela 6.3 - Processo de análise da funcionalidade dos componentes.

\begin{tabular}{|c|c|c|}
\hline ID do Processo & \multicolumn{2}{|l|}{ DOM.1 } \\
\hline Nome do Processo & \multicolumn{2}{|c|}{ Análise da Funcionalidade dos componentes. } \\
\hline Objetivo do Processo & \multicolumn{2}{|c|}{$\begin{array}{l}\text { O objetivo desse processo é analisar a funcionalidade dos componentes } \\
\text { para identificar conceitos relacionados ao domínio de aplicação dos } \\
\text { mesmos. }\end{array}$} \\
\hline $\begin{array}{l}\text { Resultados Esperados } \\
\text { (Outcomes) }\end{array}$ & \multicolumn{2}{|c|}{$\begin{array}{l}\text { Como resultado da implementação correta desse processo espera-se: } \\
\text { 1) Identificar conceitos relacionados ao domínio de aplicação dos } \\
\text { componentes. } \\
\text { 2) Produzir um documento com os conceitos relacionados a cada } \\
\text { componente, aqui chamado de "Documento de Funcionalidade dos } \\
\text { Componentes". }\end{array}$} \\
\hline Práticas Base & \multicolumn{2}{|c|}{$\begin{array}{l}\text { DOM.1.PB1: Identificar conceitos relacionados à funcionalidade dos } \\
\text { componentes em função do domínio de aplicação dos mesmos } \\
\text { [Outcome 1]. } \\
\text { DOM.1.PB2: Classificar os conceitos identificados como relacionados a } \\
\text { um componente, a um método, a um parâmetro ou ao retorno de um } \\
\text { método [Outcomes } 1 \text { e 2]. } \\
\text { DOM.1.BP3: Produzir o "Documento de Funcionalidade dos } \\
\text { Componentes" [Outcome 2]. }\end{array}$} \\
\hline \multicolumn{3}{|c|}{ Produtos de Trabalho } \\
\hline \multicolumn{2}{|c|}{ Entradas } & Saídas \\
\hline \multicolumn{3}{|c|}{$\begin{array}{l}\text { Interface documentada dos componentes } \\
\text { [Outcomes } 1 \text { e 2]. }\end{array}$} \\
\hline & & $\begin{array}{l}\text { PT-1 Documento de Funcionalidade dos } \\
\text { Componentes [Outcome 2] (ver Apêndice B). }\end{array}$ \\
\hline
\end{tabular}

\subsubsection{Análise do Vocabulário do Domínio}

A análise do vocabulário consiste em estabelecer um conjunto de sentenças imperativas em determinada língua natural. Essas sentenças devem estar de acordo com o domínio e com a funcionalidade dos componentes e serão utilizadas posteriormente para testes. Esse processo está formalizado na Tabela 6.4 e pode ser feito por um usuário comum que conheça a funcionalidade dos componentes. 
Capitulo 6 - Definição e Instanciação de um Processo para Utilização da Arquitetura OntoMap

Tabela 6.4 - Processo para análise do vocabulário do domínio.

\begin{tabular}{|l|l|}
\hline ID do Processo & DOM.2 \\
\hline Nome do Processo & Análise do Vocabulário do Domínio. \\
\hline Objetivo do Processo & $\begin{array}{l}\text { O objetivo desse processo é analisar o vocabulário do domínio e a } \\
\text { funcionalidade dos componentes para identificar possíveis sentenças de } \\
\text { entrada. }\end{array}$ \\
\hline $\begin{array}{l}\text { Resultados Esperados } \\
\text { (Outcomes) }\end{array}$ & $\begin{array}{l}\text { Como resultado da implementação correta desse processo espera-se: } \\
\text { 1) Identificar sentenças imperativas de acordo com o domínio e com a } \\
\text { funcionalidade dos componentes. } \\
\text { 2) Produzir um documento com possíveis sentenças de entrada, aqui } \\
\text { chamado de "Documento de Sentenças Imperativas". } \\
\text { 3) Produzir o "Documento de Sinônimos". }\end{array}$ \\
\hline Práticas Base & $\begin{array}{l}\text { DOM.2.PB1: Analisar os conceitos identificados no Documento de } \\
\text { Funcionalidade dos Componentes (PT-1) para formular as sentenças } \\
\text { imperativas [Outcomes 1]. } \\
\text { DOM.2.PB2: Produzir o Documento de Sentenças Imperativas, } \\
\text { considerando os conceitos relacionados aos componentes [Outcomes 1 } \\
\text { e 2]. } \\
\text { DOM.2.PB3: Identificar sinônimos dos conceitos existentes no } \\
\text { Documento de Funcionalidade dos Componentes para produzir o } \\
\text { Documento de Sinônimos [Outcome 3]. }\end{array}$ \\
\hline
\end{tabular}

\subsection{Desenvolvimento de Dicionários e Gramáticas}

Esse fluxo consiste em desenvolver o dicionário e a gramática para determinada língua, testá-los no Hermeto (EnCo) e encapsulá-los para que fiquem independentes do ambiente do Hermeto. A Figura 6.3 ilustra os processos envolvidos nesse fluxo, sendo cada um deles detalhado nas próximas subseções. 


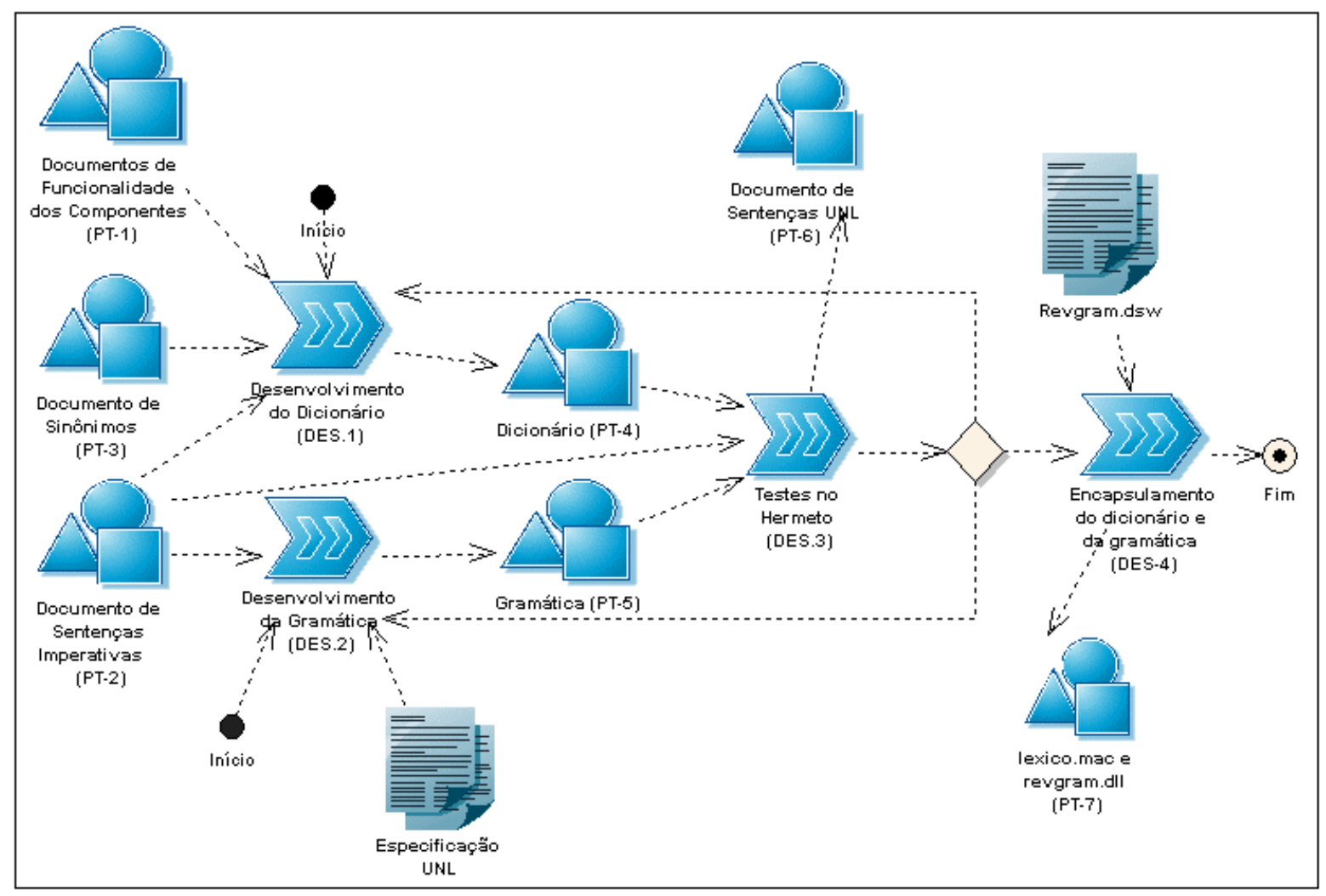

Figura 6.3 - Fluxo do desenvolvimento da gramática e do dicionário.

\subsubsection{Desenvolvimento do Dicionário}

Para desenvolver o dicionário é necessário considerar todos os termos identificados no Documento de Sinônimos (PT-3), isso inclui cada conceito e sua lista de sinônimos. Além disso, termos que não são considerados conceitos, como proposições, conjunções, artigos, etc., mas que são necessários para escrever as sentenças imperativas (PT-2), devem ser considerados no dicionário. A Tabela 6.5 mostra o processo para desenvolvimento do dicionário, que pode ser executado por um usuário comum. 
Capitulo 6 - Definição e Instanciação de um Processo para Utilização da Arquitetura OntoMap

Tabela 6.5 - Processo para desenvolvimento do dicionário.

\begin{tabular}{|l|l|}
\hline ID do Processo & DES.1 \\
\hline Nome do Processo & Desenvolvimento do dicionário \\
\hline Objetivo do Processo & $\begin{array}{l}\text { O objetivo desse processo é definir os termos que estarão presentes no } \\
\text { dicionário (vocabulário do domínio) e formalizar o dicionário para que o } \\
\text { mesmo possa ser processado por um EnCo. }\end{array}$ \\
\hline $\begin{array}{l}\text { Resultados Esperados } \\
\text { (Outcomes) }\end{array}$ & $\begin{array}{l}\text { Como resultado da implementação correta desse processo espera-se: } \\
\text { 1) Identificar termos que irão compor o dicionário. } \\
\text { 2) Produzir o dicionário. }\end{array}$ \\
\hline Práticas Base & $\begin{array}{l}\text { DES.1.PB1: Considerar todos os termos identificados no Documento de } \\
\text { Sinônimos (PT-3) e os respectivos conceitos associados a eles no } \\
\text { Documento de Funcionalidade dos Componentes (PT-1) [Outcome 1]. } \\
\text { DES.2.PB2: Estudar o formalismo do dicionário [Outcome 2]. } \\
\text { DES.2.PB3: Produzir o dicionário [Outcome 2]. }\end{array}$ \\
\hline \multicolumn{3}{|c|}{ Entradas } & \multicolumn{1}{|c|}{ Saídas } \\
\hline $\begin{array}{l}\text { PT-1 Documento de Funcionalidade dos de Trabalho } \\
\text { Componentes [Outcome 1] (Apêndice B). }\end{array}$ \\
\hline $\begin{array}{l}\text { PT-2 Documento de Sentenças Imperativas } \\
\text { [Outcome 1] (Apêndice B). }\end{array}$ \\
\hline $\begin{array}{l}\text { PT-3 Documento de Sinônimos [Outcome 1] } \\
\text { (Apêndice B). }\end{array}$ & PT-4 Dicionário [Outcome: 2] (Apêndice B). \\
\hline \multicolumn{2}{|l|}{ [Otcos } \\
\hline
\end{tabular}

\subsubsection{Desenvolvimento da Gramática}

A gramática deve considerar todas as estruturas de sentenças imperativas identificadas no Documento de Sentenças Imperativas (PT-2). Para desenvolver a gramática é preciso conhecer as estruturas gramaticais da língua alvo, saber formalizar uma gramática e saber utilizar UNL, principalmente conhecer o significado das relações. Portanto, a gramática não pode ser desenvolvida por um usuário comum. O processo para desenvolvimento da gramática é apresentado na Tabela 6.6. 
Tabela 6.6 - Processo para desenvolvimento da gramática.

\begin{tabular}{|l|l|}
\hline ID do Processo & DES.2 \\
\hline Nome do Processo & Desenvolvimento da gramática \\
\hline Objetivo do Processo & $\begin{array}{l}\text { O objetivo desse processo é identificar a estrutura das sentenças que } \\
\text { estarão presentes na gramática e formalizá-las para que a gramática } \\
\text { possa ser processada pelo EnCo. }\end{array}$ \\
\hline $\begin{array}{l}\text { Resultados Esperados } \\
\text { (Outcomes) }\end{array}$ & $\begin{array}{l}\text { Como resultado da implementação correta desse processo espera-se: } \\
\text { 1) Identificar a estrutura gramatical das sentenças da língua. } \\
\text { 2) Produzir a gramática. }\end{array}$ \\
\hline $\begin{array}{l}\text { Práticas Base } \\
\text { DES.2.PB1: Considerar a estrutura gramatical de todas as sentenças } \\
\text { definidas no Documento de Sentenças Imperativas (PT-2) [Outcome 1]. } \\
\text { DES.2.PB2: Estudar UNL, principalmente o significado semântico das } \\
\text { relações [Outcome 2]. } \\
\text { DES.2.PB3: Estudar o formalismo da gramática [Outcome 2]. } \\
\text { DES.2.PB4: Produzir a gramática [Outcome 2]. }\end{array}$ \\
\hline $\begin{array}{l}\text { PT-2 Documento de Sentenças Imperativas } \\
\text { [Outcome 1] (Apêndice B). }\end{array}$ \\
\hline Especificação de UNL
\end{tabular}

\subsubsection{Realização de Testes com a Gramática e o Dicionário no Hermeto}

Depois de terminar o desenvolvimento da gramática e do dicionário é preciso realizar testes com ambos no Hermeto. O objetivo desses testes é verificar se a representação UNL para as sentenças definidas no Documento de Sentenças Imperativas (PT-2) estão sendo geradas adequadamente. O processo para realização de testes com a gramática e o dicionário é apresentado na Tabela 6.7 e deve ser feito por usuários que conheçam UNL. 
Capitulo 6 - Definição e Instanciação de um Processo para Utilização da Arquitetura OntoMap

Tabela 6.7 - Processo para testes com a gramática e o dicionário.

\begin{tabular}{|c|c|c|}
\hline ID do Processo & \multicolumn{2}{|l|}{ DES.3 } \\
\hline Nome do Processo & \multicolumn{2}{|c|}{ Testes com a gramática e o dicionário } \\
\hline Objetivo do Processo & \multicolumn{2}{|c|}{$\begin{array}{l}\text { O objetivo desse processo é testar a gramática e o dicionário no } \\
\text { Hermeto, considerando as sentenças definidas no Documento de } \\
\text { Sentenças Imperativas (PT-2). }\end{array}$} \\
\hline $\begin{array}{l}\text { Resultados Esperados } \\
\text { (Outcomes) }\end{array}$ & \multicolumn{2}{|c|}{$\begin{array}{l}\text { Como resultado da implementação correta desse processo espera-se: } \\
\text { 1) Conhecer o ambiente do Hermeto. } \\
\text { 2) Certificar-se que o dicionário e a gramática estão corretamente } \\
\text { formalizados. } \\
\text { 3) Testar as sentenças do Documento de Sentenças Imperativas (PT-2). } \\
\text { 4) Produzir o "Documento de Sentenças UNL". }\end{array}$} \\
\hline Práticas Base & \multicolumn{2}{|c|}{$\begin{array}{l}\text { DES.3.PB1: Estudar (familiarizar-se) com o ambiente do Hermeto } \\
\text { [Outcome 1]. } \\
\text { DES.3.PB2: Compilar a gramática no Hermeto e corrigir os erros } \\
\text { apontados pelo compilador, se for o caso [Outcome 2]. } \\
\text { DES.3.PB3: Compilar o dicionário no Hermeto e corrigir os erros } \\
\text { apontados pelo compilador, se for o caso [Outcome 2]. } \\
\text { DES.3.PB4: Gerar a representação UNL no Hermeto para cada } \\
\text { sentença do Documento de Sentenças Imperativas (PT-2) [Outcomes } 3 \\
\text { e 4]. } \\
\text { DES.3.PB5: Produzir o Documento de Sentenças UNL considerando a } \\
\text { representação UNL dada pelo Hermeto [Outcome 4]. }\end{array}$} \\
\hline \multicolumn{3}{|c|}{ Produtos de Trabalho } \\
\hline \multicolumn{2}{|c|}{ Entradas } & Saídas \\
\hline \multicolumn{3}{|c|}{$\begin{array}{l}\text { PT-2 Documento de Sentenças Imperativas } \\
\text { [Outcome } 2,3 \text { e } 4 \text { ] (Apêndice B). }\end{array}$} \\
\hline \multicolumn{2}{|c|}{$\begin{array}{l}\text { PT-4 Dicionário [Outcomes } 2 \text { e 3] (Apêndice } \\
\text { B). }\end{array}$} & \\
\hline \multirow{2}{*}{\multicolumn{2}{|c|}{$\begin{array}{l}\text { PT-5 Gramática [Outcomes } 2 \text { e 3] (Apêndice } \\
\text { B). }\end{array}$}} & \\
\hline & & $\begin{array}{l}\text { PT-6 Documento de Sentenças UNL [Outcome } 3 \\
\text { e 4] (Apêndice B). }\end{array}$ \\
\hline
\end{tabular}

\subsubsection{Encapsulamento dos Arquivos da Gramática e do Dicionário}

O objetivo deste processo é tornar a Arquitetura OntoMap independente do ambiente do Hermeto. Nesse processo são gerados dois arquivos, um com o dicionário encapsulado (léxico.mac) e outro com a gramática encapsulada (revgram.dll). Com isso, basta levar esses dois arquivos para a máquina onde a Arquitetura OntoMap estiver em operação, sem ter a necessidade de ter o Hermeto instalado para fazer as conversões de linguagem natural para 
UNL. A Tabela 6.8 mostra o processo para realização do encapsulamento da gramática e do dicionário, que pode ser realizado por um usuário comum.

Tabela 6.8 - Processo para encapsulamento da gramática e do dicionário.

\begin{tabular}{|l|l|}
\hline ID do Processo & DES.4 \\
\hline Nome do Processo & Encapsulamento dos Arquivos do Dicionário e da Gramática \\
\hline Objetivo do Processo & $\begin{array}{l}\text { O objetivo desse processo é encapsular os arquivos do Dicionário e da } \\
\text { Gramática para que o processamento de ambos se torne independente } \\
\text { do Hermeto. }\end{array}$ \\
\hline $\begin{array}{l}\text { Resultados Esperados } \\
\text { (Outcomes) }\end{array}$ & $\begin{array}{l}\text { Como resultado da implementação correta desse processo espera-se: } \\
\text { 1) Gerar os arquivos "léxico.mac" e "revgram.dll". }\end{array}$ \\
& 2) Copiar os arquivos gerados para o diretório apropriado. \\
\hline Práticas Base & $\begin{array}{l}\text { DES.4.PB1: Compilar a gramática e o dicionário no ambiente do } \\
\text { Hermeto [Outcome 1]. } \\
\text { DES.4.PB2: Entrar no Visual C e abrir o projeto Revgram.dsw, que } \\
\text { estará no diretório de compilação da gramática e do dicionário } \\
\text { [Outcome 1]. } \\
\text { DES.4.PB3: Compilar o projeto Revgram.dsw no ambiente do Visual C } \\
\text { [Outcome 1] para gerar os arquivos "lexico.mac" e revgram.dll", no } \\
\text { mesmo diretório de "Revgram.dsw". } \\
\text { DES.4.PB4: Copiar os arquivos "lexico.mac" e revgram.dll" para o } \\
\text { diretório de instalação do Protégé, onde os outros arquivos da } \\
\text { Arquitetura OntoMap também estarão localizados [Outcome 2]. }\end{array}$ \\
\hline \multicolumn{2}{|c|}{ Produtos de Trabalho } \\
\hline Entradas & \multicolumn{1}{|c|}{} \\
\hline Arquivo Revgram.dsw [Outcome 1] & $\begin{array}{l}\text { PT-7 Arquivos léxico.mac e revgram.dll [Outcome } \\
1] \text { (Apêndice B). }\end{array}$ \\
\hline
\end{tabular}

\subsection{Desenvolvimento do Mapeamento Semântico}

O fluxo de Realização do Mapeamento Semântico consiste em identificar quais são as informações semânticas sobre componentes presentes na representação UNL das sentenças e formalizar essas informações em regras. A Figura 6.4 ilustra os processos envolvidos nesse fluxo, sendo cada um deles detalhado nas próximas subseções. 


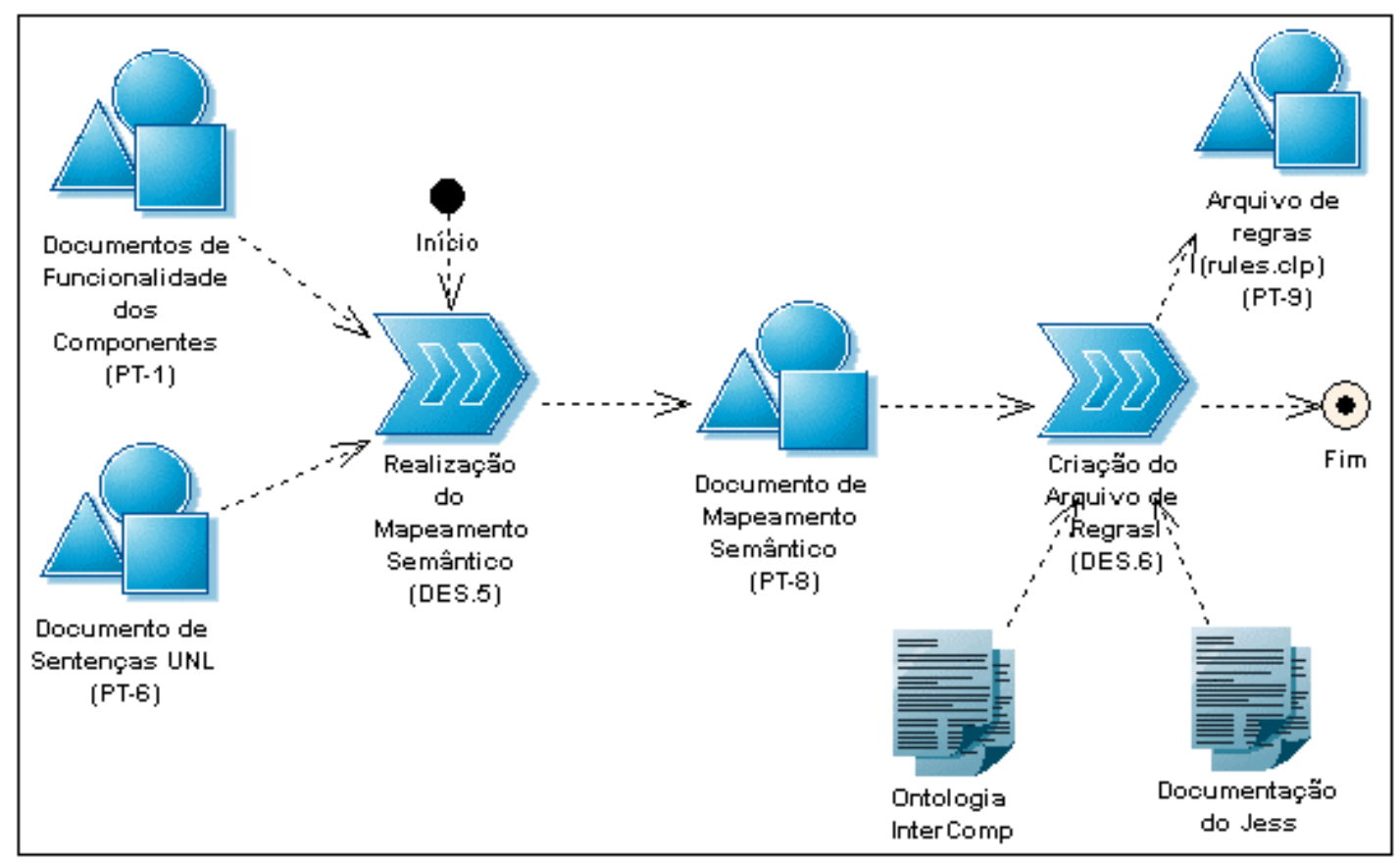

Figura 6.4 - Fluxo de Mapeamento Semântico.

\subsubsection{Realização do Mapeamento Semântico}

A primeira fase do mapeamento semântico consiste em obter cada relação UNL do Documento de Sentenças UNL (PT-6) e dizer com quais informações sobre componentes suas UWs estão relacionadas. Esse processo deve gerar o Documento de Mapeamento Semântico e pode ser realizada por um usuário comum. O processo para realização do mapeamento semântico é apresentado na Tabela 6.9. 
Tabela 6.9 - Processo para realização do mapeamento semântico.

\begin{tabular}{|c|c|c|}
\hline ID do Processo & \multicolumn{2}{|l|}{ DES.5 } \\
\hline Nome do Processo & \multicolumn{2}{|c|}{ Realização do Mapeamento Semântico } \\
\hline Objetivo do Processo & \multicolumn{2}{|c|}{$\begin{array}{l}\text { O objetivo desse processo é realizar o mapeamento semântico entre o } \\
\text { Documento de Sentenças UNL e os componentes. }\end{array}$} \\
\hline $\begin{array}{l}\text { Resultados Esperados } \\
\text { (Outcomes) }\end{array}$ & \multicolumn{2}{|c|}{$\begin{array}{l}\text { Como resultado da implementação correta desse processo espera-se: } \\
\text { 1) Realizar o mapeamento semântico entre o Documento de Sentenças } \\
\text { UNL (PT-6) e as informações semânticas dos componentes } \\
\text { identificadas no Documento de Funcionalidade dos Componentes (PT- } \\
\text { 1). } \\
\text { 2) Gerar o "Documento de Mapeamento Semântico". }\end{array}$} \\
\hline Práticas Base & \multicolumn{2}{|c|}{$\begin{array}{l}\text { DES.5.PB1: Relacionar as UWs do Documento de Sentenças UNL (PT- } \\
\text { 6) com informações semânticas sobre os componentes [Outcomes } 1 \text { e } \\
\text { 2]. } \\
\text { DES.5.PB2: Criar o Documento de Mapeamento Semântico [Outcomes } \\
1 \text { e 2]. }\end{array}$} \\
\hline \multicolumn{3}{|c|}{ Produtos de Trabalho } \\
\hline \multicolumn{2}{|c|}{ Entradas } & Saídas \\
\hline \multicolumn{3}{|c|}{$\begin{array}{l}\text { PT-1 Documento de Funcionalidade dos } \\
\text { Componentes [Outcome 1] (Apêndice B). }\end{array}$} \\
\hline \multirow{2}{*}{\multicolumn{2}{|c|}{$\begin{array}{l}\text { PT-6 Documento de Sentenças UNL [Outcome } \\
\text { 1] (Apêndice B). }\end{array}$}} & \\
\hline & & $\begin{array}{l}\text { PT-8 Documento de Mapeamento Semântico } \\
\text { [Outcome 1] (Apêndice B). }\end{array}$ \\
\hline
\end{tabular}

\subsubsection{Criação do Arquivo de Regras}

$\mathrm{O}$ arquivo de regras formaliza o mapeamento semântico. Para escrever as regras, é preciso ter o Documento de Mapeamento Semântico (PT-8) e saber formalizar as regras usando JESS (Java Expert System Shell). Por isso, este processo não pode ser realizado por um usuário comum. A Tabela 6.10 mostra o processo para criação e teste das regras. 
Capitulo 6 - Definição e Instanciação de um Processo para Utilização da Arquitetura OntoMap

Tabela 6.10 - Processo para criação e teste das regras.

\begin{tabular}{|c|c|c|}
\hline ID do Processo & \multicolumn{2}{|l|}{ DES.6 } \\
\hline Nome do Processo & \multicolumn{2}{|c|}{ Criação e teste de regras } \\
\hline Objetivo do Processo & \multicolumn{2}{|c|}{$\begin{array}{l}\text { O objetivo desse processo é formalizar o mapeamento semântico em } \\
\text { regras e realizar testes. }\end{array}$} \\
\hline $\begin{array}{l}\text { Resultados Esperados } \\
\text { (Outcomes) }\end{array}$ & \multicolumn{2}{|c|}{$\begin{array}{l}\text { Como resultado da implementação correta desse processo espera-se: } \\
\text { 1) Formalizar o mapeamento semântico em regras. } \\
\text { 2) Testar as regras na JESSTab. } \\
\text { 3) Copiar o arquivo de regras para o diretório apropriado. }\end{array}$} \\
\hline Práticas Base & \multicolumn{2}{|c|}{$\begin{array}{l}\text { DES.6.PB1: Estudar regras JESS [Outcome 1]. } \\
\text { DES.6.PB2: Familiarizar-se com o ambiente do Protégé com OWL } \\
\text { plugin [Outcome 2] } \\
\text { DES.6.PB2: Testar cada regra na JESSTab }{ }^{40} \text {, que é um plugin do } \\
\text { Protégé. [Outcome 2] } \\
\text { DES.6.PB3: Criar o arquivo texto "rules.clp" com as regras [Outcome 1]. } \\
\text { DES.6.PB4: Copiar o arquivo "rules.clp" para o diretório de instalação do } \\
\text { Protégé, onde os outros arquivos da Arquitetura OntoMap também } \\
\text { estarão localizados [Outcome 3]. }\end{array}$} \\
\hline \multicolumn{3}{|c|}{ Produtos de Trabalho } \\
\hline \multicolumn{2}{|c|}{ Entradas } & Saídas \\
\hline \multicolumn{2}{|c|}{$\begin{array}{l}\text { PT-8 Documento de Mapeamento Semântico } \\
\text { [Outcome 1] (Apêndice B). }\end{array}$} & \\
\hline \multicolumn{2}{|c|}{ Ontologia InterComp [Outcome 1] } & \\
\hline \multicolumn{2}{|c|}{ Documentação do JESS [Outcome 1] } & \\
\hline & & $\begin{array}{l}\text { PT-9 Arquivo de regras (rules.clp) [Outcome 2] } \\
\text { (Apêndice B). }\end{array}$ \\
\hline
\end{tabular}

\subsection{Desenvolvimento e Instanciação das Ontologias}

O fluxo ilustrado na Figura 6.5 consiste no desenvolvimento da Ontologia de Domínio e na instanciação da Ontologia de Componentes. Os processos envolvidos nesse fluxo são detalhados nas próximas subseções.

\footnotetext{
${ }^{40} \mathrm{http}: / /$ sourceforge.net/projects/jesstab/. Acesso em: 23 jan. 2007.
} 


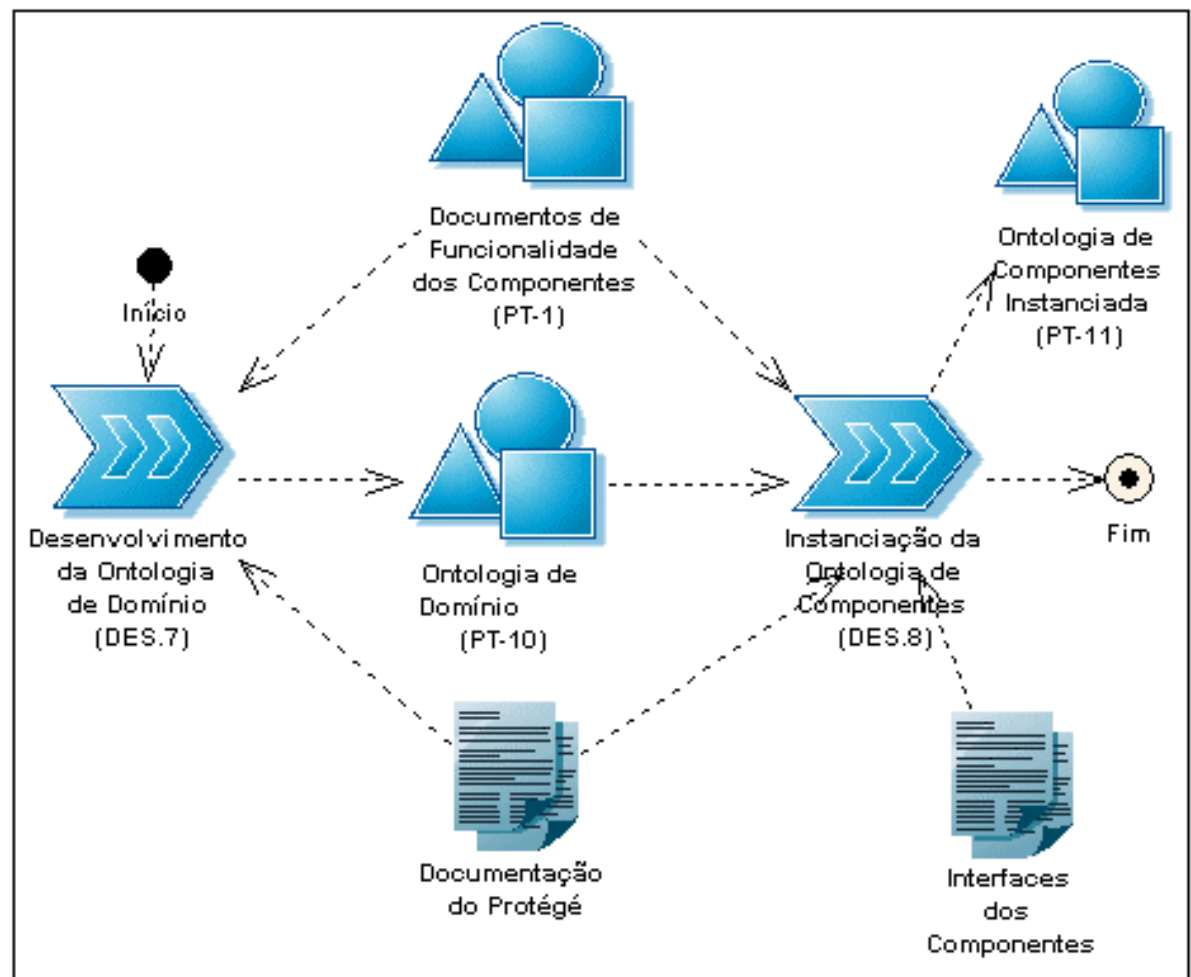

Figura 6.5 - Fluxo para desenvolvimento e instanciação das ontologias.

\subsubsection{Desenvolvimento da Ontologia de Domínio}

Não há um processo detalhado para desenvolver a Ontologia de Domínio, pois ela depende do domínio de aplicação no qual se está trabalhando. A única coisa que se pode afirmar sobre o desenvolvimento dessa ontologia é que os conceitos (substantivos) identificados no Documento de Funcionalidade dos Componentes (PT-1) devem estar presentes em sua hierarquia de classes, mas a maneira como esses conceitos estarão relacionados irá depender do domínio de aplicação. A Tabela 6.11 mostra um processo em alto nível para o desenvolvimento da Ontologia de Domínio, que deve ser desenvolvida por um usuário com conhecimento na criação de ontologias. 
Capitulo 6 - Definição e Instanciação de um Processo para Utilização da Arquitetura OntoMap

Tabela 6.11 - Desenvolvimento da Ontologia de Domínio.

\begin{tabular}{|l|l|}
\hline ID do Processo & DES.7 \\
\hline Nome do Processo & Desenvolvimento da Ontologia de Domínio \\
\hline Objetivo do Processo & $\begin{array}{l}\text { O objetivo desse processo é desenvolver uma Ontologia de Domínio, } \\
\text { levando em consideração os conceitos identificados no Documento de } \\
\text { Funcionalidade dos Componentes (PT-1). }\end{array}$ \\
\hline $\begin{array}{l}\text { Resultados Esperados } \\
\text { Outcomes) }\end{array}$ & $\begin{array}{l}\text { Como resultado da implementação correta desse processo espera-se: } \\
\text { 1) Familiarizar-se com o ambiente Protégé para o desenvolvimento de } \\
\text { ontologias em OWL. } \\
\text { 2) Criar as classes da Ontologia de Domínio considerando os conceitos } \\
\text { no Documento de Funcionalidade dos Componentes (PT-1). } \\
\text { 3) Criar os relacionamentos hierárquicos entre as classes. }\end{array}$ \\
\hline Práticas Base & $\begin{array}{l}\text { DES.7.PB1: Familiarizar-se com o ambiente do Protégé com OWL } \\
\text { plugin [Outcome 1]. } \\
\text { DES.7.PB2: Criar as classes da ontologia de acordo com os conceitos } \\
\text { identificados no Documento de Funcionalidade dos Componentes } \\
\text { [Outcomes 2 e 3] } \\
\text { DES.7.PB3: Criar os relacionamentos entre as classes [Outcome 3]. }\end{array}$ \\
\hline $\begin{array}{l}\text { Pomponentes [Outcomes Produtos de Trabalho } \\
\text { B). }\end{array}$ & \begin{tabular}{l} 
2 e 3] (Apêndice \\
\hline Documentação do Protege [Outcome 1]
\end{tabular} \\
\hline \multicolumn{1}{|c|}{ Entradas } \\
\hline
\end{tabular}

\subsubsection{Instanciação da Ontologia de Componentes}

Para instanciar a Ontologia de Componentes é preciso ter uma certa familiaridade com ontologias. Na instanciação da Ontologia de Componentes os dados das interfaces dos componentes devem ser relacionados com informações semânticas sobre os mesmos, as quais foram identificadas no Documento de Funcionalidade dos Componentes (PT-1) e já foram parcialmente formalizadas na Ontologia de Domínio (PT-10). O processo para instanciação da Ontologia de Componentes é apresentado na Tabela 6.12. 
Tabela 6.12 - Instanciação da Ontologia de Componentes.

\begin{tabular}{|c|c|c|}
\hline ID do Processo & \multicolumn{2}{|l|}{ DES.8 } \\
\hline Nome do Processo & \multicolumn{2}{|c|}{ Instanciação da Ontologia de Componentes } \\
\hline Objetivo do Processo & \multicolumn{2}{|c|}{$\begin{array}{l}\text { O objetivo desse processo é instanciar a Ontologia de Componentes } \\
\text { para que os dados das interfaces dos componentes sejam relacionados } \\
\text { com informações semânticas sobre os mesmos. }\end{array}$} \\
\hline $\begin{array}{l}\text { Resultados Esperados } \\
\text { (Outcomes) }\end{array}$ & \multicolumn{2}{|c|}{$\begin{array}{l}\text { Como resultado da implementação correta desse processo espera-se: } \\
\text { 1) Criar as instâncias na Ontologia de Componentes. } \\
\text { 2) Criar relacionamentos entre as instâncias, por meio do } \\
\text { preenchimento os slots correspondentes. } \\
\text { 3) Ter os dados sobre as interfaces dos componentes relacionados com } \\
\text { informações semânticas. } \\
\text { 4) Ter a ontologia com suas instâncias armazenadas no diretório } \\
\text { apropriado. }\end{array}$} \\
\hline Práticas Base & \multicolumn{2}{|c|}{$\begin{array}{l}\text { DES.8.PB1: Familiarizar-se com o ambiente do Protégé, com OWL } \\
\text { plugin [Outcome 1]. } \\
\text { DES.8.PB2: Abrir a Ontologia de Componentes, que está localizada no } \\
\text { arquivo \{PROTEGE_HOME\}lontoslcomponentsOntology.pprj, no Protégé } \\
\text { [Outcome 4]. } \\
\text { DES.8.PB3: Criar as instâncias da classe Action [Outcome 1]. } \\
\text { DES.8.PB4: Importar a Ontologia de Domínio sob a classe } \\
\text { DomainConcept [Outcome 1]. } \\
\text { DES.8.PB5: Instanciar as demais classes utilizando os dados das } \\
\text { interfaces dos componentes [Outcome 1]. } \\
\text { DES.8.PB6: Criar os relacionamentos entre as instâncias [Outcomes } 2 \text { e } \\
\text { 3] }\end{array}$} \\
\hline \multicolumn{3}{|c|}{ Produtos de Trabalho } \\
\hline \multicolumn{2}{|c|}{ Entradas } & Saídas \\
\hline \multicolumn{3}{|c|}{ Interfaces dos componentes [Outcome 3] } \\
\hline \multicolumn{3}{|c|}{ Documentação do Protégé [Outcome 1 e 2] } \\
\hline \multicolumn{3}{|c|}{$\begin{array}{l}\text { PT-1 Documento de Funcionalidade dos } \\
\text { Componentes [Outcome 1] (Apêndice B). }\end{array}$} \\
\hline \multicolumn{3}{|c|}{$\begin{array}{l}\text { PT-10 Ontologia de Domínio [Outcome 1] } \\
\text { (Apêndice B). }\end{array}$} \\
\hline & & $\begin{array}{l}\text { PT-11 Ontologia de Componentes instanciada } \\
\text { [Outcomes 1, 2, } 3 \text { e 4] (Apêndice B). }\end{array}$ \\
\hline
\end{tabular}

\subsection{Realização de Testes}

O processo de testes consiste em verificar se o mapeamento semântico e a busca por componentes estão funcionando a contento. Além disso, nesta fase de testes é possível 
identificar se os dados das interfaces dos componentes foram corretamente associados com as informações semânticas na Ontologia de Componentes.

Para realizar os teste é preciso entrar com as sentenças imperativas em linguagem natural e verificar se o Módulo de Busca está indicando o método correto a ser executado. As sentenças de entrada, que serão utilizadas para testes, são as definidas no Documento de Sentenças Imperativas (PT-2). O processo para realização de testes é apresentado na Tabela 6.13 .

Tabela 6.13 - Processo para realização de testes.

\begin{tabular}{|l|l|}
\hline ID do Processo & TES \\
\hline Nome do Processo & Realização de Testes \\
\hline Objetivo do Processo & $\begin{array}{l}\text { O objetivo desse processo é testar se o Módulo de Busca está } \\
\text { indicando o método correto a ser executado. }\end{array}$ \\
\hline $\begin{array}{l}\text { Resultados Esperados } \\
\text { (Outcomes) }\end{array}$ & $\begin{array}{l}\text { Como resultado da implementação correta desse processo espera-se: } \\
\text { 1) Testar as sentenças do Documento de Sentenças Imperativas (PT-2). } \\
\text { 2) Gerar o "Relatório de Testes". }\end{array}$ \\
\hline Práticas Base & $\begin{array}{l}\text { TES.PB1: Testar as sentenças do Documento de Sentenças } \\
\text { Imperativas utilizando o arquivo Revgram.class [Outcome 1]. } \\
\text { TES.PB2: Gerar o Relatório de Testes [Outcome 2] }\end{array}$ \\
\hline \multicolumn{3}{|c|}{ Produtos de Trabalho } \\
\hline \multicolumn{3}{|c|}{ Entradas } & \multicolumn{1}{|c|}{ Saídas } \\
\hline $\begin{array}{l}\text { PT-2 Documento de Sentenças Imperativas } \\
\text { [Outcome 1] (Apêndice B) }\end{array}$ & $\begin{array}{l}\text { PT-12 Relatório de Testes [Outcomes 1 e 2] } \\
\text { (Apêndice B) }\end{array}$ \\
\hline \multicolumn{4}{|l|}{} \\
\hline
\end{tabular}

\subsection{Instanciação do Processo}

A instanciação do processo tem como objetivos avaliar (1) a Arquitetura OntoMap, (2) a adequação das ontologias na arquitetura e (2) o processo em si. Para realizar a instanciação, foram desenvolvidos componentes no domínio de gerenciamento de cursos relacionados aos conceitos Estudante, Professor, Candidato, Administrador, Monitor, Curso e Turma. Suas interfaces, devidamente documentadas, estão no Apêndice C.

Especificamente para esta instanciação, como os componentes foram desenvolvidos especialmente para a Arquitetura OntoMap, eles acessam e modificam as instâncias da Ontologia de Domínio por meio da API do Protégé. Com isso, as instâncias da Ontologia de 
Domínio estão sendo usadas como base de dados. Em instanciações com componentes de terceiros, o acesso à base de dados irá depender da aplicação na qual os componentes estão sendo utilizados.

Foi desenvolvido também um Carregador de Componentes que executa classes Java passando strings como parâmetros. Quando o Módulo de Busca identifica o método a ser executado, ele chama o Carregador de Componentes, que carrega o componente correspondente e executa o método apropriado. A execução dos métodos pode acessar e modificar as instâncias da Ontologia de Domínio.

A instanciação do processo teve início com a preparação do ambiente (processo apresentado na Tabela 6.2). Depois disso, os passos definidos nos processos apresentados nas Tabelas 6.3 a 6.13 foram seguidos e os correspondentes Produtos de Trabalho foram produzidos, o que pode ser verificado no Apêndice D. A implementação dos componentes, juntamente com os artefatos necessários para utilizá-los com a arquitetura OntoMap (produzidos com a instanciação do processo apresentada no Apêndice D) estão disponíveis em http://sourceforge.net/projects/ontomap, no arquivo inst1.zip.

Por meio da realização de testes (PT-12 do Apêndice D), foi possível verificar que todas as sentenças definidas no Documento de Sentenças Imperativas (PT-2 do Apêndice D) tiveram métodos devidamente encontrados pelo Módulo de Busca sem problemas. Isso se deve ao fato dos componentes terem sido desenvolvidos especificamente para a Arquitetura OntoMap. Isto é, os componentes possuem as seguintes características:

- Não passam como parâmetro coleções de valores, como List, vector, etc.

- Todos os parâmetros são obrigatórios para a execução do método.

- Cada componente, parâmetro e retorno de método pode ser relacionado a apenas um conceito.

- Cada componente possui sua funcionalidade bem definida com relação ao conceito ao qual está associado. Por exemplo, o componente relacionado ao conceito Professor é o responsável por realizar todas as ações associadas a um professor, como criá-lo, apagá-lo, designá-lo para uma turma, etc.

$\mathrm{O}$ fato dos componentes possuírem as características supracitadas contribuiu para que a instanciação do processo fosse realizada sem problemas, o que foi confirmado com os testes 
(PT-12 do Apêndice D). Testes com componentes de terceiros também foram realizados, o que ajudou a identificar as características supracitadas. Isto é, métodos sem aquelas características não são identificados corretamente pelo Módulo de Busca. Essas limitações podem ser contornadas com refinamentos no Classificador de Tokens e no Módulo de Busca, conforme discutido na seção 5.6.2.

Considerando os testes realizados com a instanciação do processo, pode-se dizer que a Arquitetura OntoMap é adequada ao que se propõe a fazer e que o processo proposto é adequado para sua utilização. Além disso, pode-se afirmar que as ontologias estão adequadamente inseridas na Arquitetura OntoMap. Os resultados do mapeamento semântico e do Módulo de Busca são dependentes das ontologias. Como os resultados da instanciação foram considerados satisfatórios, então as ontologias também o são, pois elas foram desenvolvidas para auxiliar no mapeamento semântico e na busca.

\subsection{Considerações Finais}

O processo descrito neste Capítulo, definido com base nos processos de engenharia de software existentes na literatura, tem por objetivo auxiliar usuários/desenvolvedores a utilizarem a Arquitetura OntoMap. De acordo com o processo proposto, para utilizar a Arquitetura OntoMap é preciso ter inicialmente um conjunto de componentes relacionados a determinado domínio de aplicação. Com a instanciação do processo, esses componentes podem ser utilizados em uma aplicação baseada em linguagem natural, por meio da definição de um conjunto de sentenças válidas, que devem levar em consideração a funcionalidade dos componentes e o domínio de aplicação. Para integrar a Arquitetura OntoMap em uma aplicação baseada em linguagem natural, depois de ter realizado a instanciação do processo, a classe de testes Revgram.java pode ser tomada como ponto de partida, pois ela carrega as ontologias, o dicionário e a gramática, o que é necessário para inicializar a arquitetura.

Este Capítulo apresentou também uma instanciação do processo proposto, que pode ser utilizada como exemplo para futuras instanciações do processo por outros grupos de pesquisa. A instanciação serviu também para avaliar a Arquitetura OntoMap, considerando componentes desenvolvidos para serem utilizados pela arquitetura. Além disso, a instanciação mostrou que as ontologias são adequadas aos propósitos para os quais foram desenvolvidas auxiliar o mapeamento semântico e a busca por componentes. 


\section{CAPÍTULO \\ 7 \\ Trabalhos Relacionados}

\subsection{Considerações Iniciais}

Desde o final da década de 70, pesquisadores têm explorado a possibilidade de ter as ações dos usuários descritas em linguagem natural e executadas por computador. Em linhas gerais, pode-se dizer que este também constitui o principal objetivo deste trabalho.

Diversos trabalhos na literatura têm evidenciado que as linguagens naturais restritas podem ser usadas para descrever requisições dos usuários para serem processadas pela máquina. Esses trabalhos podem ser divididos em dois grupos: os que usam um baixo nível de abstração nas requisições e os que usam um alto nível de abstração. Esses últimos usam componentes de software ou agentes para conseguir um nível de abstração mais elevado. Mas, ao usar componentes e agentes para executar as requisições é necessário também fazer a busca por estes, utilizando dados semânticos sobre os componentes ou sobre o domínio de aplicação dos componentes. Com isso, os trabalhos relacionados a este podem ser divididos em três grupos, que serão abordados nas seções 7.2 a 7.4, respectivamente:

1) Execução de requisições em linguagem natural.

2) Uso de componentes ou agentes para executar requisições em linguagem natural.

3) Busca por componentes usando semântica de ontologias. 


\subsection{Execução de Requisições em Linguagem Natural}

O sistema NLC (Natural Language Computing) (Ballard \& Bierman, 1979) é o resultado de um dos primeiros esforços para programação em linguagem natural. Esse sistema permite ao usuário digitar comandos em inglês e vê-los serem executados na tela. NLC foi projetado para processar dados armazenados em matrizes ou tabelas, ou qualquer outro problema que possa ser representado nessas estruturas.

Na Figura 7.1 é apresentado um exemplo de programa em linguagem natural que pode ser processado por NLC. Como pode ser observado, a seqüência de ações descritas em linguagem natural deve estar na forma de algoritmo.

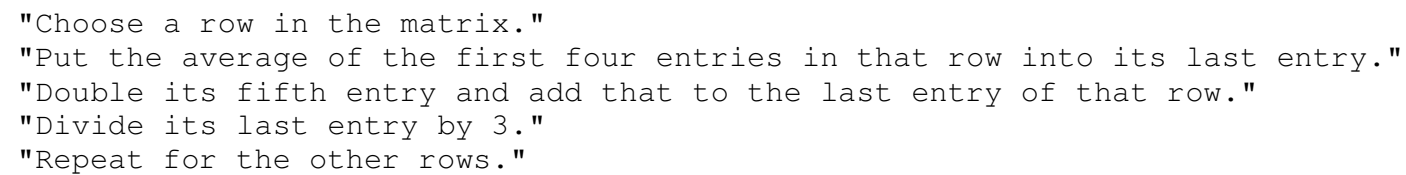

Figura 7.1 - Programa que pode ser processado por NLC (Ballard \& Bierman, 1979).

O sistema NaturalJava (Price et al., 2000) é o protótipo de uma interface baseada em linguagem natural para criar, examinar e modificar programas em Java. O sistema é feito para programadores iniciantes, que podem descrever programas usando sentenças em inglês e o sistema automaticamente constrói o código fonte Java. Mas, assim como em NLC, o programa em linguagem natural deve ser descrito em forma de algoritmo.

Na Figura 7.2 é apresentado um exemplo de programa em linguagem natural que pode ser compreendido por NaturalJava. Na Figura 7.3 é mostrado o código fonte gerado pelo sistema tendo como entrada as declarações da Figura 7.2. 


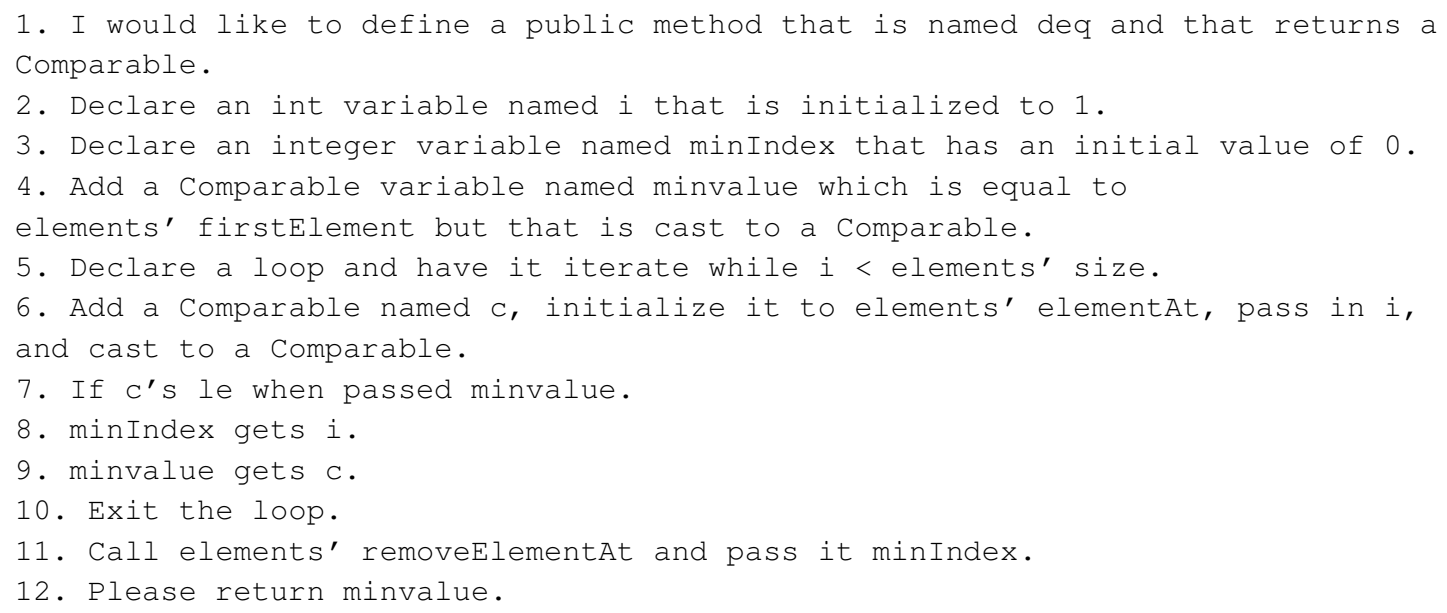

Figura 7.2 - Programa que pode ser processado por NaturalJava (Price et al., 2000).

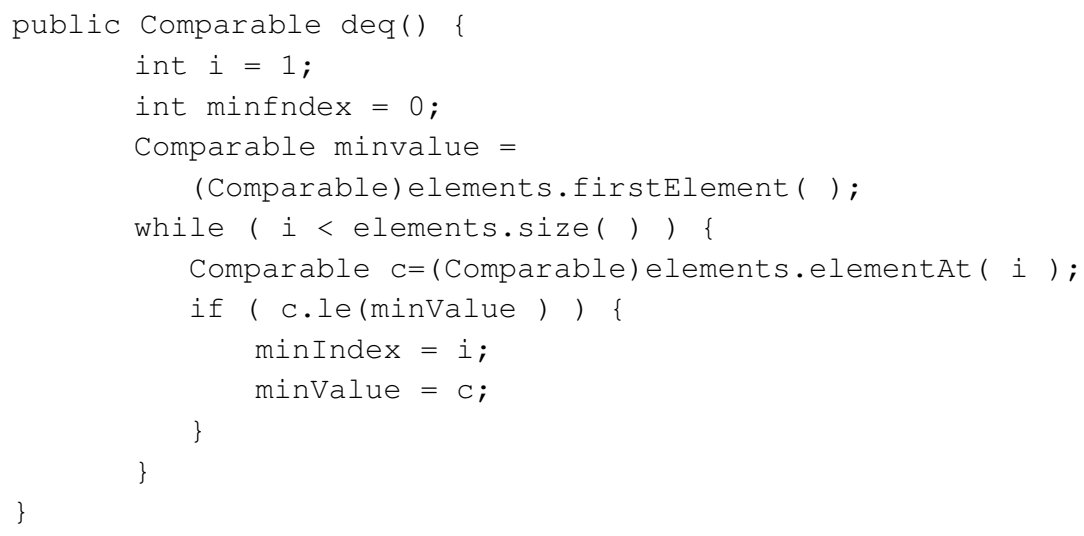

Figura 7.3 - Código Fonte gerado por Natural Java (Price et al., 2000).

A maior diferença entre NaturalJava e NLC é que NaturalJava permite que usuários gerem e manipulem código fonte em uma linguagem de programação real, enquanto NLC toma ações imediatas em resposta a comandos em linguagem natural e não mantêm nenhuma representação interna do código fonte.

Esses dois trabalhos são muito limitados porque as requisições de entrada devem ser em forma algorítmica. Nesses sistemas, requisições em um nível semântico mais elevado não são permitidas. Outros sistemas, assim como o trabalho descrito nesta tese, utilizam 
componentes de software ou agentes para conseguir um nível de abstração mais elevado, como apresentado na próxima seção.

\subsection{Uso de Componentes ou Agentes para Executar Requisições em Linguagem Natural}

Nesta seção, são descritos trabalhos que utilizam agentes ou componentes de software para atingir um nível de abstração mais elevado nas requisições em linguagem natural. Vários trabalhos seguem essa linha como Ishida (2006), Herzog et al. (2004), Bontcheva et al. (2004), Singh et al. (1995) e Guzzoni et al. (1997). Entretanto, nesta seção serão descritos apenas os mais relevantes com relação a este trabalho que são o OAA (Open Agent Architecture) (Cheyer \& Martin, 2001) e o SemanticAgent (Lucena et al., 2003).

O OAA (Zhu et al., 2005; Cheyer \& Martin, 2001) é um framework para construir sistemas baseados em agentes de software. O objetivo do OAA é que os agentes distribuídos trabalhem cooperativamente para executar requisições dos usuários. Ele possui uma interface que aceita requisições como entrada, que são convertidas para ICL (Interagent Communication Language), uma linguagem declarativa baseada em lógica. A comunicação utiliza interfaces multimodais, por isso pode ser feita de várias formas, como apontar, falar, desenhar, usar GUIs (Graphical User Interfaces), etc. Os agentes cooperam entre si para traduzir a requisição do usuário para expressões ICL. Essa linguagem também é usada pelos agentes para que eles possam se comunicar e registrar suas funcionalidades para um agente facilitador. O facilitador é responsável por obter uma requisição em ICL e escolher o agente mais apropriado para executar a requisição. Está claro que ICL é uma linguagem inttemediária, pois as diversas formas de comunicação são traduzidas para ICL. O OAA tem sido utilizado por diversos grupos de pesquisa para construir sistemas baseados em agentes e está atualmente em sua versão 2.3.1, disponível a partir de Novembro de $2005^{41}$.

Assim como o OAA, o trabalho descrito nesta tese utiliza linguagem natural restrita para descrever requisições dos usuários em um alto nível de abstração semântico. No OAA, existe um agente centralizador responsável por encontrar outros agentes para executar as requisições, tendo como base o registro das funcionalidades de um agente, sem a utilização

\footnotetext{
${ }^{41}$ O OAA está disponível para download em http://www.ai.sri.com/ oaa/. Acesso em: 7 fev. 2007.
} 
explícita de ontologias. Em contrapartida, neste trabalho, a execução das requisições é feita por componentes. As informações sobre os componentes são descritas em uma ontologia e relacionadas com informações semânticas sobre a funcionalidade dos mesmos. A utilização das ontologias oferece um maior grau de semântica sobre o domínio no qual os componentes irão atuar.

A plataforma SemanticAgent (Lucena, 2003; Lucena et al., 2003) oferece serviços básicos para execução de ações e manipulação de conhecimento para permitir que agentes, a partir de requisições feitas em linguagem natural restrita, sejam capazes de realizar consultas a uma base de conhecimento e executar ações implementadas como componentes de software.

Para alcançar seus objetivos, o SemanticAgent utiliza a interlíngua UCL (Universal Communication Language) (Montesco \& Moreira, 2002), que é uma linguagem baseada em UNL e representada em XML. Uma requisição do usuário descrita em linguagem natural restrita é transformada em UCL pelo codificador-decodificador UCL e depois processada pelos agentes do sistema com o objetivo de satisfazer a requisição do usuário. Todos os agentes são capazes de se comunicar e existe um agente facilitador que possui o endereço físico de todos os agentes registrados no sistema.

A base de conhecimento do sistema é uma rede semântica composta por conceitos e relações entre conceitos, que podem ser editados, adicionados e excluídos. Também é possível ligar os componentes da plataforma com a rede semântica, isto é, associar métodos ou parâmetros dos componentes com a base de conhecimento.

O SemanticAgent possui alguns pontos em comum com este trabalho, por exemplo, a utilização de uma interlíngua e a utilização de componentes para executar requisições expressas em linguagem natural. Entretanto, este trabalho se mostra mais flexível para trabalhar com domínios específicos e para encontrar os componentes mais apropriados. Algumas limitações do SemanticAgent que evidenciam isso são (Lucena, 2003):

- O sistema utiliza uma ontologia genérica no conversor UCL. Para que novos conceitos sejam adicionados ao sistema de modo que possam ser utilizados em requisições em linguagem natural é necessário que os novos conceitos incorporados estejam presentes nessa ontologia genérica. Isso limita a possibilidade de trabalhar com domínios específicos. 
- O SemanticAgent não possui um mecanismo eficiente para encontrar os métodos nos componentes de maneira a satisfazer a requisição descrita em linguagem natural. Ele utiliza links para relacionar conceitos da ontologia com métodos dos componentes. Por exemplo, pode existir um link entre o método getTime() de um componente e o conceito Time na ontologia. Com isso, se um usuário faz a requisição "What time is it?", o SemantiAgent consegue saber que o método getTime() deve ser ativado porque existe o conceito time na sentença de entrada e, no conceito Time da ontologia, existe um link para o método getTime(). Esse mecanismo é limitado, pois se a requisição não tivesse o conceito time em seu conteúdo, o método apropriado (getTime()) não teria sido ativado.

\subsection{Busca por Componentes Usando Semântica de Ontologias}

As ontologias têm sido utilizadas para descrever informações semânticas sobre componentes e assim ajudar na busca e recuperação dos mesmos. Sugumaran e Storey (2003) usam uma abordagem baseada em ontologias para recuperar componentes de software de um repositório, onde existem componentes relevantes para a criação de novas aplicações. Eles usam modelos de domínios contendo objetivos, processos, ações, atores e uma ontologia de termos do domínio. Usando linguagem natural, um usuário pode especificar os requisitos de um componente que deseja usar. A consulta em linguagem natural é mapeada para uma linguagem baseada em SQL (Structured Query Language). A ontologia de domínio é usada para refinar e aumentar a consulta, a qual é decomposta em processos e ações (métodos). A consulta decomposta é então comparada com as capacidades dos componentes do repositório. A porcentagem de ações suportada por um componente ou objeto mede o quanto ele é relevante.

No trabalho de Sugumaran e Storey (2003), uma ontologia é útil porque fornece uma maneira de "entender" o que um componente faz. Ela fornece informação adicional a respeito de um objeto, o que pode levar o mecanismo de busca a considerá-lo apropriado de acordo com os requisitos do usuário especificados inicialmente. Desse modo, a ontologia serve para "aumentar" o significado dos termos para que uma resposta mais completa e relevante possa ser dada à consulta do usuário. Este trabalho possui alguns pontos em comum com o de 
Sugumaran e Storey, como a utilização de linguagem natural e de ontologias. O trabalho deles leva em consideração medidas para classificar os componentes mais relevantes, o que não é feito neste trabalho. Entretanto, o trabalho de Sugumaran e Storey (2003) leva em consideração critérios de busca especificados em inglês, enquanto neste trabalho as informações sobre a busca são extraídas de uma interlíngua, o que possibilita especificar a busca em qualquer língua natural.

Seguindo a mesma linha do trabalho de Sugumaran e Storey (2003), Yaguinuma et al. (2005) propõe um meta-modelo para armazenamento e recuperação de componentes de software, que considera informações semânticas do domínio representadas em ontologias. Com o meta-modelo proposto é possível que componentes inter-relacionados sejam recomendados pela ferramenta de busca.

Yao e Etzkorn (2004) propõem uma abordagem baseada em semântica para melhorar a reutilização de componentes de software. A abordagem como um todo estende as bibliotecas de software reusáveis para a web; quebra a barreira da busca baseada em palavras-chave na web permitindo que o usuário especifique consultas em linguagem natural; trata um componente de software como um serviço descrito por um formato de representação de serviço semântico; estende a recuperação de componente fazendo o matching entre a representação semântica de uma consulta do usuário e descrições semânticas de componentes de software usando uma ontologia para isso. A abordagem de Yao e Etzkorn propõe métodos para melhorar a busca e recuperação de software em ambos os casos, bibliotecas de componentes de software e a WWW. Alguns pontos em comum são identificados com este trabalho, como a utilização de ontologias para descrever a semântica dos componentes e o uso de linguagem natural. O trabalho de Yao e Etzkorn estende a busca para a web, o que não é feito neste trabalho. É importante observar que o trabalho deles tem como principal objetivo melhorar a reutilização de componentes, enquanto este trabalho tem como principal objetivo encontrar componentes para executar requisições em linguagem natural. Com isso, a utilização de uma interlíngua neste trabalho se torna um diferencial importante.

Assim como o trabalho descrito nesta tese, o trabalho de Khemakhem et al. (2006) define uma ontologia de componentes para realizar a busca. De acordo com Khemakhem et al. (2006), pode-se utilizar ontologias para descrever a semântica dos componentes com relação a três aspectos: 
- Aspectos estruturais: especificam a estrutura interna do componente. O desenvolvedor utiliza essas características para determinar se existe interação entre as operações de determinado componente com outros componentes usados para construir determinada aplicação.

- Aspectos funcionais: identificam as funcionalidades de um componente, as quais são fornecidas principalmente pela interface do componente.

- Aspectos não funcionais: especificam as restrições do componente com relação à comunicação ou à computação, o que inclui características como performance, segurança, adaptabilidade, dependência, etc.

Esses aspectos representam visões diferentes e complementares de um componente e a formalização desses aspectos em uma ontologia depende do tipo de informação que se deseja obter. Khemakhem et al. (2006), propõem duas ontologias que contemplam os três aspectos descritos acima:

- Ontologia de descoberta: serve para organizar os componentes de um repositório, por meio da formalização dos aspectos funcionais e não funcionais.

- Ontologia de integração: tem o objetivo de integrar um componente em uma aplicação, por meio da especificação dos aspectos estruturais.

A primeira ontologia é utilizada por uma ferramenta de busca chamada SEC (Search Engine for Components) para encontrar os componentes mais apropriados de acordo com os critérios selecionados pelo desenvolvedor. A segunda ontologia seve para facilitar a integração de um componente em uma aplicação (Khemakhem et al., 2006). A Ontologia de Componentes proposta neste trabalho contempla os aspectos funcionais dos componentes, pois estes são os mais relevantes quando a busca é feita para satisfazer uma requisição em linguagem natural. Portanto, o diferencial deste trabalho com relação ao trabalho de Khemakhem et al. (2006) é que o objetivo deles é buscar componentes que serão utilizados para compor aplicações, enquanto este trabalho tem o objetivo de buscar componentes para satisfazer uma requisição expressa linguagem natural. Diferente deste trabalho, eles não especificam a busca em linguagem natural.

Os trabalhos apresentados nesta seção são os mais relevantes com relação a este, pois utilizam ontologias com o objetivo de melhorar a busca por componentes e alguns também 
consideram linguagem natural para especificar a busca. Entretanto, diversos outros trabalhos, utilizam ontologias para descrever informações sobre componentes seja para melhorar a busca, seja para ajudar a compor aplicações. Alguns exemplos são CoSMoS (Component Service Model with Semantics) (Fujii \& Suda, 2004), CHESt (Computer History Expert System) (Linckels \& Meinel, 2004), SOTA (Tsai et al., 2003), Oberle et al. (2005), Braga et al. (2006), Oliveira et al. (2004) e Lee et al. (2005).

A Tabela 7.1 apresenta uma comparação do trabalho descrito nesta tese (Arquitetura OntoMap) com outros trabalhos relevantes encontrados na literatura, levando em consideração aspectos relacionados à execução de requisições em linguagem natural e à busca por componentes.

Tabela 7. 1 - Comparação com trabalhos relacionados.

\begin{tabular}{|l|c|c|c|c|c|c|c|}
\hline & $\begin{array}{l}\text { NLC e } \\
\text { Natural } \\
\text { Java }\end{array}$ & OAA & $\begin{array}{l}\text { Semantic } \\
\text { Agent }\end{array}$ & $\begin{array}{l}\text { Sugumaran } \\
\text { \& Storey }\end{array}$ & $\begin{array}{l}\text { Yao \& } \\
\text { Etzkorn }\end{array}$ & SEC & $\begin{array}{l}\text { Arquitetura } \\
\text { OntoMap }\end{array}$ \\
\hline $\begin{array}{l}\text { Execução de } \\
\text { requisições em } \\
\text { linguagem natural }\end{array}$ & $\sqrt{ }$ & $\sqrt{ }$ & $\sqrt{ }$ & & $\sqrt{ }$ & $\sqrt{ }$ \\
\hline $\begin{array}{l}\text { Requisições descritas } \\
\text { em um alto nível } \\
\text { semântico de } \\
\text { abstração }\end{array}$ & & $\sqrt{ }$ & $\sqrt{ }$ & $\sqrt{ }$ & $\sqrt{ }$ & $\sqrt{ }$ \\
\hline $\begin{array}{l}\text { Uso de uma } \\
\text { representação } \\
\text { intermediária ou } \\
\text { interlíngua }\end{array}$ & $\sqrt{ }$ & $\sqrt{ }$ & & $\sqrt{ }$ & $\sqrt{ }$ & \\
\hline $\begin{array}{l}\text { Busca por } \\
\text { componentes } \\
\text { utilizando ontologias }\end{array}$ & & $\sqrt{ }$ & & $\sqrt{ }$ & $\sqrt{ }$ & & $\sqrt{ }$ \\
\hline $\begin{array}{l}\text { Busca por } \\
\text { componentes em } \\
\text { repositórios } \\
\text { distribuídos ou na web }\end{array}$ & & $\sqrt{ }$ & & $\sqrt{ }$ & $\sqrt{ }$ & $\sqrt{ }$ & $\sqrt{ }$ \\
\hline $\begin{array}{l}\text { Classificação dos } \\
\text { componentes por } \\
\text { relevância }\end{array}$ & & & & $\sqrt{ }$ & $\sqrt{ }$ & & \\
\hline $\begin{array}{l}\text { Facilidade de } \\
\text { adaptação para } \\
\text { domínios diferentes }\end{array}$ & & $\sqrt{ }$ & & & & & \\
\hline
\end{tabular}




\subsection{Considerações Finais}

Conforme exposto neste Capítulo, alguns trabalhos já utilizaram ou desenvolveram ontologias de componentes para ajudar na busca e recuperação de componentes. Entretanto, nenhum deles considera dados semânticos extraídos de uma interlíngua para auxiliar a busca por componentes. Por essa razão a Ontologia de Componentes e o Módulo de Busca propostos são contribuições importantes deste trabalho.

Outra contribuição importante é a Ontologia Intercomp, que relaciona informações semânticas de uma interlíngua com informações sobre componentes de software. Outros trabalhos com esse objetivo não foram encontrados na literatura. 


\section{CAPÍTULO}

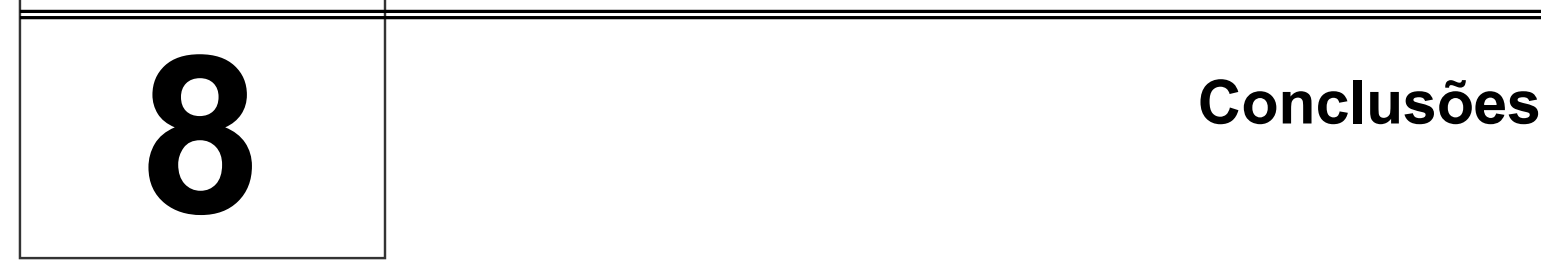

\subsection{Resumo do Trabalho Realizado}

A proposta deste trabalho se deu devido à carência de mecanismos para executar requisições expressas em linguagem natural, que considerassem informações semânticas extraídas de uma interlíngua. Este trabalho propôs que requisições imperativas em linguagem natural fossem convertidas para a interlíngua UNL e, a partir da representação em UNL, informações semânticas fossem inferidas para encontrar componentes de software apropriados para executar essas requisições.

O relacionamento entre a interlíngua e os componentes foi chamado de mapeamento semântico entre UNL e componentes. Para realizar o mapeamento semântico e a posterior busca por componentes foi proposta uma arquitetura baseada em ontologias, chamada Arquitetura OntoMap (Ontology-based Semantic Mapping), apresentada no Capítulo 5. Após converter uma requisição em linguagem natural para UNL, a arquitetura proposta utiliza uma ontologia de alto nível, chamada Ontologia InterComp (Interlíngua-Componentes) que, juntamente com regras e inferência, fornece informações semânticas a respeito dos componentes que podem ser utilizados para executar a requisição em linguagem natural. A Arquitetura OntoMap possui também um Módulo de Busca que recebe as informações semânticas extraídas e utiliza a Ontologia de Componentes para realizar a busca por possíveis componentes para executar a requisição. 
A arquitetura proposta pode ser utilizada em diversos domínios com diferentes conjuntos de componentes. Para auxiliar a utilização da Arquitetura OntMap por outros grupos de pesquisa foi definido um processo, detalhado no Capítulo 6. Para avaliar a arquitetura foram desenvolvidos componentes no domínio de gerenciamento de cursos e o processo foi instanciado considerando esses componentes, tendo apresentado resultados satisfatórios, como exposto no Relatório de Testes do Apêndice D.

\subsection{Contribuições}

A realização deste trabalho gerou contribuições originais dentro das áreas de aplicações baseadas em linguagem natural, busca por componentes de software e aplicações de ontologias, descritas nas subseções 8.2.1 a 8.2.3, respectivamente.

\subsubsection{Aplicações Baseadas em Linguagem Natural}

A Arquitetura OntoMap define os elementos de software e os relacionamentos entre eles necessários para realizar o mapeamento semântico e a busca por componentes. A Arquitetura OntoMap é uma contribuição deste trabalho, pois aplicações baseadas em linguagem natural podem utilizá-la em diversos domínios, com diferentes conjuntos de componentes. O mapeamento semântico realizado entre UNL e componentes, que também é uma contribuição deste trabalho, permite que requisições sejam expressas em diferentes línguas naturais, permitindo assim que aplicações baseadas em linguagem natural não estejam limitadas a apenas uma língua (Linhalis \& Moreira, 2004; Linhalis \& Moreira, 2005a). É importante ressaltar que trabalhos que relacionam uma interlíngua com componentes de software não foram encontrados na literatura.

A definição e instanciação de um processo para utilização da Arquitetura OntoMap também constitui uma contribuição deste trabalho, pois o processo é de fundamental importância para que outros grupos de pesquisa possam utilizar a Arquitetura OntoMap e assim desenvolver aplicações baseadas em linguagem natural que possam se beneficiar do trabalho descrito nesta tese. 


\subsubsection{Busca por Componentes de Software}

Este trabalho propôs uma Ontologia de Componentes, que relaciona dados das interfaces de um conjunto de componentes com informações semânticas. Essa ontologia deve ser instanciada toda vez que o conjunto de componentes mudar. A semântica dos componentes está nas classes Action e DomainConcept, sendo essa última o "ponto de encontro" com uma Ontologia de Domínio, que deve ser substituída quando o domínio de aplicação mudar, trazendo flexibilidade para a solução adotada.

O Módulo de Busca desenvolvido utiliza a Ontologia de Componentes e informações extraídas da representação UNL para encontrar possíveis componentes para executar uma requisição expressa em linguagem natural (Linhalis \& Moreira, 2005b; Linhalis \& Moreira, 2006; Moreira \& Linhalis, 2006).

Outros trabalhos encontrados na literatura (Khemakhem et al., 2006; Sugumaran \& Storey, 2003) também propuseram ontologias para descrever componentes, bem como ontologias de domínio para auxiliar a busca por componentes. O diferencial e conseqüente contribuição deste trabalho está no fato da busca por componentes ser realizada utilizando informações semânticas extraídas de requisições expressas em uma interlíngua, o que não é contemplado em outros trabalhos na literatura.

\subsubsection{Aplicações de Ontologias}

Vários trabalhos encontrados na literatura evidenciam que as ontologias têm sido utilizadas nas mais diversas áreas da computação para auxiliar na solução de uma grande gama de problemas (Tetlow et al., 2006; Yao \& Etzkorn, 2004). Em conseqüência disso, revistas e eventos têm surgido para contemplar trabalhos que aplicam ontologias para solucionar ou auxiliar na solução de problemas computacionais.

Este trabalho conta com uma contribuição na área de aplicações de ontologias. A Arquitetura OntoMap proposta utiliza a Ontologia InterComp, juntamente com regras, para realizar o mapeamento semântico entre a interlíngua UNL e componentes de software. A Ontologia InterComp foi desenvolvida para flexibilizar o mapeamento semântico, por meio do relacionamento de UNL com componentes de software. Além disso, a aplicação de regras possibilita inferir informações semânticas relacionadas ao possível método que será utilizado 
para executar a requisição em linguagem natural. Outros trabalhos que propõem uma ontologia para formalizar o relacionamento entre uma interlíngua e componentes de software não foram encontrados na literatura.

\subsection{Trabalhos Futuros}

O trabalho descrito nesta tese ainda pode originar outros trabalhos de pesquisa, por exemplo:

- O Carregador de Componentes, ilustrado na Figura 5.1, foi implementado apenas parcialmente. Um trabalho de mestrado que inclui sua implementação já se encontra em andamento. $\mathrm{O}$ trabalho em questão também pretende investigar como retornar as respostas dos componentes para a aplicação que os chamou.

- Algumas limitações da Arquitetura OntoMap, descritas na seção 5.6.2 podem ser contornadas em trabalhos futuros. O Classificador de Tokens pode ser estendido para considerar UWs restritas, o que pode enriquecer a representação UNL da requisição de entrada e conseqüentemente fornecer mais dados para serem classificados na Ontologia InterComp e considerados na inferência. O Módulo de Busca pode ser estendido para trabalhar com métodos que passam uma coleção de valores como parâmetro (Vector, List, etc) e para considerar instâncias da Ontologia de Domínio na busca.

- Ao definir o processo para utilização da Arquitetura OntoMap, no Capítulo 6, foram identificados diversos processos que podem ser feitos de maneira automática. Por exemplo, o Documento de Funcionalidade dos Componentes (PT1) pode ser gerado automaticamente, baseando-se em anotações na documentação das interfaces dos componentes. O Documento de Sinônimos (PT-3) também pode ser gerado automaticamente, bastando ter como entrada o Documento de Funcionalidade dos Componentes e um dicionário genérico da língua em questão.

- Fazer o mapeamento semântico para outros tipos de sentenças, não apenas as imperativas. Sentenças condicionais ou interrogativas poderiam ser consideradas. Neste caso, alguns atributos UNL (seção 2.5) podem ser utilizados para distinguir um tipo de sentença de outro. 
Os trabalhos futuros apresentados até agora têm o objetivo de melhorar ou complementar alguns pontos da Arquitetura OntoMap e podem ser realizados como trabalhos de mestrado e iniciação cientifica. Entretanto, trabalhos mais complexos, em nível de doutorado, podem ser realizados para estender a arquitetura proposta. Por exemplo:

- Trabalhos para considerar especificamente as interfaces das aplicações que utilizam a Arquitetura OntoMap podem ser realizados. Neste caso, vale a pena investigar a utilização de interfaces multimodais.

- O presente trabalho trata da busca por um único método de componente para satisfazer a requisição em linguagem natural. Vale a pena explorar requisições que necessitem de mais de um componente para serem executadas. Neste caso, componentes de software estariam sendo ligados para formar novas aplicações a partir de requisições em linguagem natural. Um trabalho como esse estaria explorando também a programação em linguagem natural (Linhalis \& Moreira, 2005c).

- Como a interlíngua utilizada no mapeamento semântico é UNL, pode-se investigar a possibilidade de integrar o presente trabalho no contexto da web. A Internet tem se tornado uma base abundante de software reutilizável, com uma quantidade crescente de software disponível gratuitamente para usuários. Em diversas situações, a web pode ser considerada uma imensa biblioteca de software reutilizável (Yao \& Etzkorn, 2004). Pode-se investigar a possibilidade de estender a arquitetura proposta para considerar a web como fonte de busca por componentes ou por serviços web.

\subsection{Publicação dos Resultados}

Alguns resultados deste trabalho foram publicados em eventos nacionais $\mathrm{e}$ internacionais. A primeira publicação (1), cuja referência completa se encontra a seguir, apresenta a Arquitetura OntoMap em sua fase inicial de projeto e desenvolvimento. Nessa fase do trabalho a Arquitetura OntoMap se chamava Módulo SeMaComp (Semantic Mapping between UNL relations and software Components). O Módulo SeMaComp tratava o mapeamento semântico em código, isto é, sempre que o conjunto de componentes mudasse 
seria necessário alterar e recompilar o código. O foco do artigo é o mapeamento semântico, mas o módulo SeMaComp já trabalhava com um esboço da Ontologia de Componentes, apesar do uso das ontologias ainda não estar bem definido.

(1) LINHALIS, F.; MOREIRA, D.A. Semantic Mapping between UNL Relations and Software Components to the Execution of Natural Language Requisitions. In: INTERNATIONAL INFORMATION AND TELECOMMUNICATION TECHNOLOGIES SYMPOSIUM (I2TS'04), 3., 2004, São Carlos. Proceedings. BOUKERCHE, A.; ARAUJO, R. B. (Eds.). 2004, pp. 109-116.

A segunda publicação (2) também descreve o Módulo SemaComp e também possui seu foco no mapeamento semântico, que já havia evoluído. Essa publicação propõe a utilização da Ontologia de Domínio, que pode ser substituída de acordo com o domínio de aplicação dos componentes, trazendo flexibilidade para a solução adotada.

(2) LINHALIS, F.; MOREIRA, D.A. Execution of Imperative Natural Language Requisitions Based on UNL Interlingua and Software Components. In: INTERNATIONAL CONFERENCE ON ENTERPRISE INFORMATION SYSTEMS (ICEIS'05), 7., 2005, Miami. Proceedings. Setúbal: INSTICC Press, 2005, pp. 254-259.

As publicações (3) e (4) têm seu enfoque nas ontologias. Parte do mapeamento semântico (relacionamento entre UNL e os componentes) passou a ser definido na Ontologia de Componentes. A necessidade de regras para flexibilizar o mapeamento semântico já havia sido identificada, embora essas regras ainda não tivessem sido implementadas.

(3) LINHALIS, F.; MOREIRA, D. A. Servidor de Aplicações Baseado em Ontologias para Executar Requisições Imperativas em Linguagem Natural. In: SIMPÓSIO BRASILEIRO DE SISTEMAS MULTIMÍDIA E WEB (WEBMEDIA'05), 11., 2005, Poços de Caldas. Anais. CD-ROM, 2005, pp. 116-128.

(4) LINHALIS, F.; MOREIRA, D. A. Ontology-Based Application Server to the Execution of Imperative Natural Language Requests. Berlin: Springer, 2006. International Conference on Flexible Query Answering Systems - FQAS'06 (7, Milano, 2006). In: LECTURE NOTES IN ARTIFICIAL INTELLIGENCE. BERLIN, v. 4027, p. 589-600, 2006. 
A publicação (5) é um resumo estendido que discorre sobre a composição de aplicações utilizando componentes e sobre a possibilidade de programar utilizando linguagem natural restrita.

(5) LINHALIS, F.; MOREIRA, D. A. Geração de Programas Utilizando Linguagem Natural Restrita, Ontologias e Componentes de Software. In: WORKSHOP DE TESES E DISSERTAÇÕES DO SIMPÓSIO BRASILEIRO DE SISTEMAS MULTIMÍDIA E WEB (WEBMEDIA'05), 11., 2005, Poços de Caldas. Anais em CD-ROM. pp. 259-262.

A publicação (6) é um resumo estendido que foi apresentado na Conferência do Protégé. O artigo descreve sucintamente as ontologias de componentes e de domínio, apontando o Protégé (Noy et al., 2000) como ferramenta de desenvolvimento e a API do Protégé, que utiliza o framework $\mathrm{Jena}^{42}$, para acessar e modificar as ontologias e suas instâncias a partir do código Java.

(6) MOREIRA, D. A.; LINHALIS, F. Ontology Based Application Server to Execute Semantic Rich Requests. In: INTERNATIONAL PROTÉGÉ CONFERENCE, 9., 2006, Palo Alto. pp. 1-4.

No último ano de desenvolvimento do doutorado a Ontologia InterComp foi formalizada juntamente com as regras. A Arquitetura OntoMap foi definida conforme apresentado no Capítulo 5. Com esses últimos resultados espera-se produzir no mínimo mais duas publicações, sendo pelo menos uma em periódico.

${ }^{42}$ http://jena.sourceforge.net/. Acesso em: 10 fev. 2007. 


\section{Referências}

(Arpírez et al., 2001) ARPÍREZ, J.C.; CORCHO, O.; FERNANDEZ-LOPEZ, M.; GOMEZ-PEREZ, A. WebODE: a scalable ontological engineering workbench. In: INTERNETIONAL CONFERENCE ON KNOWLEDGE CAPTURE (KCAP'01), 1., 2001, Victoria. Proceedings. New York: ACM Press, 2001, p. 6-13.

(Ballard \& Bierman, 1979)

BALLARD, B.A.; BIERMAN, A. W. Programming in Natural Language: "NLC" as a Prototype. In: ACM ANNUAL COMPUTER SCIENCE CONFERENCE (SCS'79), 1979. Proceedings. New York: ACM Press, 1979. p. 228-237.

(Bass et al., 2005) BASS, L.; CLEMENTS, P.; KAZMAN, R. Software Architecture in Practice. 2. ed. Boston: Addison-Wesley, 2005.

(Berners-Lee et al., 2001)

BERNERS-LEE, T.; HENDLER, J; LASSILA, O. The Semantic Web. Scientific American, v. 284, n. 5, p. 34-43, Mai. 2001.

(Bernstein, 1996)

BERNSTEIN, P. A. Middleware: A Model for Distributed System Services. Communications of the ACM, v. 39, n. 2, p. 86-98, Fev. 1996.

(Boguslavsky et al., 2000)

(Bontcheva et al., 2004)

BOGUSLAVSKY, I. Creating a Universal Networking Language Module within an Advanced NLP System. In: ACM INTERNATIONAL CONFERENCE ON COMPUTATIONAL LINGUISTICS (COLING'00), 2000, Saarbrücken (Germany). Proceedings. New York: ACM Press, 2000, p. 83-89.

BONTCHEVA, K.; TABLAN, V.; MAYNARD, D.; CUNNINGHAM, H. Evolving GATE to meet new challenges in language engineering. Natural Language Engineering, v. 10, n. 3-4, p. 349 - 373, 2004.

(Braga et al., 2001) BRAGA, R. M. M.; MATTOSO, M.; WERNER, C. M. L. The Use of Mediation and Ontology Technologies for Software Component Information Retrieval. In: ACM SYMPOSIUM ON SOFTWARE REUSABILITY (SSR'01), 2001, Toronto. Proceedings. New York: ACM Press, 2001. p. 19-28.

(Braga et al., 2006) BRAGA, R. M. M.; WERNER, C. M. L.; MATTOSO, M. dyssey-Search: A multiagent system for component information search and retrieval. Journal of Systems and Software, v. 79, n. 2, p. 204-215, 2006.

(Brank et al., 2005) BRANK, J.; GROBELNIK, M.; MLADENIC, D. A survey of ontology evaluation techniques. In: INTERNATIONAL MULTI-CONFERENCE INFORMATION SOCIETY, 8., 2005, Ljubljana (Slovenija). Proceedings. p. 166-169.

(Brickley \& Guha, 2003)

BRICKLEY, D.; GUHA, R. V. RDF Vocabulary Description Language 1.0: RDF Schema. W3C Recommendation. 2003. Disponível em: <http://www.w3.org/TR/rdf-schema>. Acesso em: 17 jan. 2007.

(Cardeñosa et. al, CARDEÑOSA, J.; GELBUKH, A.; TOVAR, E (eds.). Universal Networking 2005) Language: Advances in Theory and Applications. 2005. 443p. Disponível em: <http://www.cicling.org/2005/ UNL-book/>. Acesso em: 17 jan. 2007. 
Referências

(Cerqueira, 2000)

(Cheyer \& Martin, 2001)

(Chang et al., 2002)

CERQUEIRA, R. F. G. Um Modelo de Composição Dinâmica entre Sistemas de Componentes de Software. 2000. 114f. Tese (Doutorado) - Departamento de Informática, Pontifícia Universidade Católica do Rio de Janeiro (PUC-Rio), Rio de Janeiro.

CHEYER, A.; MARTIN, D. The Open Agent Architecture. Journal of

Autonomous Agents and Multi-Agent Systems, v.4, n.1, p.143-148, 2001.

Disponivel em: <http://www.ai.sri.com/ oaa>. Acesso em: 17 jan. 2007.

CHANG, N; NARAYANAN, S; PETRUCK, M. R. L. Putting Frames in Perspective. In: INTERNATIONAL CONFERENCE ON COMPUTATIONAL LINGUISTICS (COLING-ACL), 19., 2002, Taipei (Taiwan). Proceedings. Moristown: Association for Computational Linguistics, 2002, p. 1-7. Disponível em: <http://nlp.stanford.edu/quasi >. Acesso em: 17 jan. 2007.

(Corcho et al., 2003) CORCHO, O.; FERNÁNDEZ-LÓPEZ, M.; GÓMEZ-PÉREZ, A. Methodologies, tools and languages for building ontologies: where is their meeting point?. Data \& Knowledge Engineering, v. 46, n. 1, p. 41-64, 2003.

(D'Souza \& Wills, 1999)

D'SOUZA, D.; WILLS, A. Objects, Components, and Frameworks with UML. Addison Wesley, 1999.

(Eriksson, 2004)

ERIKSSON, H. JESSTab Manual Integration of Protégé and JESS. 2004. Disponível em: <www.ida.liu.se/ her/JessTab/JessTab.pdf>. Acesso em: 23 jan. 2007.

(Farquhar et al., 1997)

FARQUHAR, A.; FIKES, R.; RICE, J. The Ontolingua Server: A Tool for Collaborative Ontology Construction. International Journal of Human-Computer Studies, v. 46, n. 6, p. 707-727, 1997.

(Fensel \& Bussler, 2002)

(Fernández-López et al., 1997)

(Finin et al., 1997)

FENSEL, D.; BUSSLER, C. Web Services Modeling Framework (WSMF). Electronic Commerce: Research and Applications, v. 1, n. 2, p. 113-137, 2002.

FERNÁNDEZ-LÓPEZ, M.; GÓMEZ-PÉREZ, A.; JURISTO, N. METHONTOLOGY: From Ontological Art Towards Ontological Engineering. In: AAAI SYMPOSIUM ON ONTOLOGICAL ENGINEERING, 1997, Stanford. Proceedings. p. 33-40.

FININ, T.; LABROU, Y.; MAYFIELD, J. KQML as an Agent Communication Language. In: BRADSHAW, J. M. Software Agents. Cambridge: AAAI Press/The MIT Press, 1997. p. 291-316.

(Freitas, 2003)

(Friedman-Hill, 2003)

(Fujii \& Suda, 2004)

FREITAS, F. L. G. Ontologias e a Web Semântica. In: CONGRESSO DA SOCIEDADE BRASILEIRA DE COMPUTAÇÃO. 13., 2003, Campinas. Anais (Mini-Curso em CD-ROM). p. 1-52.

FRIEDMAN-HILL, E. JESS - the Rule Engine for the Java Platform, 2003. Disponível em: <http://herzberg.ca.sandia.gov/jess>. Acesso em: 17 jan. 2007.

FUJII, K.; SUDA, T. Component Service Model with Semantics (CoSMoS): A New Component Model for Dynamic Service Composition. In: INTERNATIONAL SYMPOSIUM ON APPLICATIONS AND THE INTERNET WORKSHOPS (SAINTW'04), 2004, Tokyo. Proceedings. IEEE Computer Society, 2004, p. 348-354.

(Gachot et at., 1998) GACHOT, D. A.; LANGE, E.; YANG, J. The SYSTRAN NLP browser: An application of machine translation technology in multilingual information retrieval. In: GREFENSTETTE, G. Cross-Language Information Retrieval. Boston: Kluwer Academic Publishers, 1998. cap. 9.

(Garcia et al., 2006) GARCIA, V. C.; ALMEIDA, E. S.; LISBOA, L. B.; MARTINS, A. C.; MEIRA, S. R. LUCRÉDIO, D.; FORTES, R. P. M. Toward a Code Search Engine Based 
(Gómez-Pérez, 1999)

(Gruber, 1993)

(Grüninger \& Fox, 1995)

(Guarino, 1998)

(Guzzoni et al., 1997)

(Haarslev \& Möller, 2004)

(Herzog et al.; 2004)

(Herzum \& Sims, 2000)

(Hopkins, 2000)

(Horrocks et al., 2000)

(Horrocks et al., 2004)

(Horridge et al., 2004)

(Ishida, 2006) on the State-of-Art and Practice. In: ASIA PACIFIC SOFTWARE ENGINEERING CONFERENCE, 13., 2006, Bangalore (India). Proceedings. Washington: IEEE Society Press, 2006, p. 61-70.

GÓMEZ-PÉREZ, A. Evaluation of Taxonomic Knowledge in Ontologies and Knowledge Bases. In: KNOWLEDGE ACQUISITION FOR KNOWLEDGEBASED SYSTEMS (KAW'99), 12., 1999, Banff. Proceedings. v. 2. p. 1-18.

GRUBER, T. R. A translation approach to portable ontology specification. Knowledge Acquisition, v. 5, n. 2, p. 199-220, 1993.

GRÜNINGER, M; FOX, M. S. Methodology for the design and evaluation of ontologies. In: WORKSHOP ON BASIC ONTOLOGICAL ISSUES IN KNOWLEDGE SHARING, 1995, Montreal. Proceedings. 10p.

GUARINO, N. Formal Ontology and Information Systems. In: FORMAL ONTOLOGY AND INFORMATION SYSTEMS (FOIS'98), 1998, Trento (Itália). Proceedings. Amsterdan: IOS Press, 1998, p. 3-15.

GUZZONI, D.; CHEYER, A.; JULIA, L.; KONOLIGE, K. Many robots make short work. Al Magazine, v. 18, n. 1, p. 55-64, 1997.

HAARSLEV, V.; MÖLLER, R. RACER's User Guide and reference Manual. Versão 1.7.19, 2004. Disponível em: <http://coli.lili.uni-bielefeld.de/ felix/lehre /ws04_05/ontologischeRessourcen/addLiterature/haarslev-und-moeller04.pdf>. Acesso em 08 fev. 2007.

HERZOG, G.; NDIAYE, A.; MERTEN, S.; KIRCHMANN, H.; BECKER, T.; POLLER, P. Large-scale software integration for spoken language and multimodal dialog systems. Natural Language Engineering, v. 10, n. 3-4, p. 283-305, 2004.

HERZUM, P.; SIMS, O. Business Component Factory: A Comprehensive Overview of Component-Based Development for the Enterprise. New York: John Wiley \& Sons, 2000.

HOPKINS, J. Component Primer. Communications of the ACM, v. 43, n. 10, p. 27-30, 2000.

HORROCKS, I.; FENSEL, D.; BROEKSTRA, J.; DECKER, S.; ERDMANN, M.; GOBLE C.; VAN HARMELEN, F.; KLEIN, M.; STAAB, S.; STUDER, R.; MOTTA, E. OIL: The Ontology Inference Layer. Disponível em: <http://www.ontoknowledge.org/oil/TR/oil.long.html>. Acesso em: 17 jan. 2007.

HORROCKS, I.; PATEL-SCHNEIDER, P. F.; BOLEY, H; TABET, S.; GROSOF, B.; DEAN, M. SWRL: A Semantic Web Rule Language Combining OWL and RuleML. W3C Member Submission. Mai. 2004. Disponível em: http://www.w3.org/Submission/2004/SUBM-SWRL-20040521/. Acesso em: 17 jan. 2006

HORRIDGE, M.; KNUBLAUCH, R.; RECTOR, A.; STEVENS, R.; WROE, C. A Practical Guide to Building OWL Ontologies Using the Protégé-OWL Plugin and CO-ODE Tools. Edition 1.0. 2004. Disponível em: <www.coode.org/resources/tutorials/ProtegeOWLTutorial.pdf>. Acesso em: 31 jan. 2007.

ISHIDA, T. Language Grid: An Infrastructure for Intercultural Collaboration. In: IEEE INTERNATIONAL SYMPOSIUM ON APPLICATIONS AND THE INTERNET (SAINT'06), 2006, Phoenix (Arizona). Proceedings. Washington: IEEE Computer Society, 2006, p. 96-100. 
Referências

(ISO/IEC, 2004)

INTERNATIONAL ORGANIZATION FOR STANDARDIZATION. ISO/IEC 15504-5: Information Technology - Process Assessment - Part 5: An exemplar Process Assessment Model. ISO/IEC International Standard, 2004. 196p.

(Jaimes \& Sebe, 2005)

JAIMES, A.; SEBE, N. Multimodal Human Computer Interaction: A Survey. Berlin: Springer, 2005. IEEE International Workshop on Human Computer Interaction (Beijing, 2005). In: LECTURE NOTES IN COMPUTER SCIENCE. Berlin, v. 3766, p. 1-15, 2005.

(Kalyanpur et al., 2006)

KALYANPUR, A.; PARSIA, B.; SIRIN, E.; GRAU, B. C.; HENDLER, J. Swoop: A Web Ontology Editing Browser. Journal of Web Semantics, v. 4, n. 2, p. 144153, 2006.

Khemakhem et al. (2006)

KHEMAKHEM, S.; DRIRA, K.; JMAIEL, M. SEC: a search engine for component based software development. In: ACM SYMPOSIUM ON APPLIED COMPUTING, 2006, Dijon. Proceedings. New York: ACM Press, 2006, p. 1745-1750.

(Kifer et al., 1995) KIFER, M.; LAUSEN, G.; WU, J. Logical foundations of object-oriented and frame-based languages. Journal of the ACM, v. 42, n. 4, p. 741-843, 1995.

(Koivunen \& Miller, 2001)

(Manola \& Miller, 2004)

KOIVUNEN, M.; MILLER, E. W3C Semantic Web Activity. 2001. Disponível em: <http://www.w3c.org/2001/12/semweb-fin/w3csw>. Acesso em: 23 jan. 2007.

(Lee et al., 2005)

(Linckels \& Meinel, 2004)

(Linhalis \& Moreira, 2004)

MANOLA, F.; MILLER, E. RDF Primer. W3C Recommendation. 2004. Disponível em: <http://www.w3.org/TR/rdf-primer/>. Acesso em: 25 jan. 2007.

LEE, H.; CHOI, H. J.; KO, I. Y. A Semantically-Based Software Component Selection Mechanism for Intelligent Service Robots. Berlin: Springer, 2005. Mexican International Conference on Artificial Intelligence - MICAl'05 (Monterrey, 2005). In: LECTURE NOTES IN ARTIFICIAL INTELLIGENCE. Berlin, v. 3789, p. 1042-1051, 2005.

LINCKELS, S.; MEINEL, C. Semantic Layer Architecture for an Educational Expert System in Computer History. In: IEEE INTERNATIONAL CONFERENCE ON ADVANCES IN INTELLIGENT SYSTEMS (AISTA'04), 2004, Luxembourg. Proceedings. 8p.

LINHALIS, F.; MOREIRA, D.A. Semantic Mapping between UNL Relations and Software Components to the Execution of Natural Language Requisitions. In: INTERNATIONAL INFORMATION AND TELECOMMUNICATION TECHNOLOGIES SYMPOSIUM (I2TS'04), 3., 2004, São Carlos. Proceedings. p. 109-116.

(Linhalis \& Moreira, 2005a)

LINHALIS, F.; MOREIRA, D.A. Execution of Imperative Natural Language Requisitions Based on UNL Interlingua and Software Components. In: INTERNATIONAL CONFERENCE ON ENTERPRISE INFORMATION SYSTEMS (ICEIS'05), 7., 2005, Miami. Proceedings. Setúbal: INSTICC Press, 2005, p. 254-259.

(Linhalis \& Moreira, 2005b)

LINHALIS, F.; MOREIRA, D. A. Servidor de Aplicações Baseado em Ontologias para Executar Requisições Imperativas em Linguagem Natural. In: SIMPÓSIO BRASILEIRO DE SISTEMAS MULTIMÍDIA E WEB (WEBMEDIA'05), 11., 2005, Poços de Caldas. Anais (em CD-ROM), p. 116128.

(Linhalis \& Moreira, LINHALIS, F.; MOREIRA, D. A. Geração de Programas Utilizando Linguagem 2005c) Natural Restrita, Ontologias e Componentes de Software. In: WORKSHOP DE TESES E DISSERTAÇÕES DO SIMPÓSIO BRASILEIRO DE SISTEMAS 
(Linhalis \& Moreira, 2006)

(Lucena, 2003)

(Lucena et al., 2003)

(Lucrédio et al., 2004)

(Manaris \& Slator, 1996)

(Martins et al., 2004)

(McGregor, 1991)

(McGinness et al., 2002)

(McGuiness \& van Harmelen, 2004)

(Mello et al., 2006)

(Microsoft, 2006a)

(Microsoft, 2006b)

(Mili et al., 1997)

(Mili et al., 2001)
MULTIMÍDIA E WEB (WEBMEDIA'05), 11., 2005, Poços de Caldas. Anais (em $C D-R O M)$. p. 259-262.

LINHALIS, F.; MOREIRA, D. A. Ontology-Based Application Server to the Execution of Imperative Natural Language Requests. Berlin: Springer, 2006. International Conference on Flexible Query Answering Systems - FQAS'06 (7, Milano, 2006). In: LECTURE NOTES IN ARTIFICIAL INTELLIGENCE. BERLIN, v. 4027, p. 589-600, 2006.

LUCENA, P. SemanticAgent, uma plataforma para desenvolvimento de agentes inteligentes. 2003. 132f. Dissertação (Mestrado) - Instituto de Ciências Matemáticas e de Computação (ICMC), Universidade de São Paulo, São Carlos.

LUCENA, P.; MOREIRA, D. A.; MONTESCO, C. A. E. SemanticAgent, a platform for the development of software agents. In: WORKSHOP EM TECNOLOGIA DA INFROMAÇÃO E DA LINGUAGEM HUMANA (TIL'03), 1. 2003, São Carlos. Anais (em CD-ROM). 4p.

LUCRÉDIO, D.; ALMEIDA, E. S.; PRADO, A. F. A Survey on Software Components Search and Retrieval. In: EUROMICRO CONFERENCE, 30., 2004, Rennes (France). Proceedings. Washington: IEEE Society Press, 2004, p. $152-159$.

MANARIS, B. Z.; SLATOR, B. M. Interactive Natural Language Processing: Building on Success. IEEE Computer. v. 29, n. 7, p. 28-32, 1996.

MARTINS, R. T.; HASEGAWA, R.; NUNES, M. G. V. HERMETO: A NL Analysis Environment. In: WORKSHOP DA TECNOLOGIA DA INFORMAÇÃO E DA LINGUAGEM HUMANA (TIL'O4). 2., 2004, Salvador. Anais. p. 64-71.

MCGREGOR, R. Inside the LOOM classifier. SIGART bulletin, v. 2, n. 3, p. 7076, 1991.

MCGUINNESS, D. L.; FIKES, R.; HENDLER, J.; STEIN, L. DAML+OIL: an Ontology Language for the Semantic Web. IEEE Intelligent Systems. v. 17, n. 5, p. 72-80, 2002.

MCGUINNESS, D. L.; VAN HARMELEN, F. Web Ontology Language Overview. W3C Recommendation. 2004. Disponível em: <http://www.w3.org /TR/owl-features>. Acesso em: 19 set. 2006.

MELLO, C. A. S.; MELLO, R. F.; SANTOS, M. T. P.; SENGER, L. J.; YANG, L. T. A New Method for Classifying and Searching Software Components by using a Self-organizing Neural Network Architecture. In: IEEE INTERNATIONAL CONFERENCE ON GRANULAR COMPUTING, 2006, Atlanta. Proceedings. Washington: IEEE Society Press, 2006, p. 136-141.

MICROSOFT. COM: Component Object Model Technologies. 2006. Disponível em: <http://www.microsoft.com/com>. Acesso em: 28 jan. 2006.

MICROSOFT. What Is .NET?. 2006. Disponível em: <http://www.microsoft.com/net>. Acesso: 28 jan. 2006.

MILI, R.; MILI, A.; MITTERMEIR, R. T. Storing and retrieving software components: a refinement based system. IEEE Transaction on Software Engineering, v. 23, n. 7, p. 445-460, 1997.

MILI, H.; VALTCHEV, P.; DI-SCIULLO, A.; GABRINI, P. Automating the Indexing and Retrieval of Reusable Software Components. In: INTERNATIONAL WORKSHOP ON APPLICATIONS OF NATURAL LANGUAGE TO INFORMATION SYSTEMS. 6., 2001, Madrid. Proceedings. p. 
(Montesco \&

Moreira, 2002)

(Moreira \& Linhalis, 2006)

(Motta, 1998)

(Neches et al., 1991)

(Noy \& McGuinness, 2001)

(Noy et al., 2000)

(Oberle et al., 2005)

(O'Connor et al., 2005)

(Oliveira et al., 2004)

(OMG, 2005)

(OMG, 2006)

(Oviatt, 2003)

(Price et al., 2000)
75-86.

MONTESCO, C. A. E.; MOREIRA, D. A. UCL - Universal Communication Language. In: INTERNATIONAL WORKSHOP ON UNL, OTHER INTERLINGUAS AND THEIR APPLICATIONS. 1., 2002, Las Palmas. Proceedings. p. 33-37.

MOREIRA, D. A.; LINHALIS, F. Ontology Based Application Server to Execute Semantic Rich Requests. In: INTERNATIONAL PROTÉGÉ CONFERENCE, 9., 2006, Palo Alto. 4p.

MOTTA, E. An Overview of the OCML Modelling Language. In: WORKSHOP ON KNOWLEDGE ENGINEERING METHODS \& LANGUAGES (KEML'98). 8., 1998, Karlsruhe. Proceedings. 19p.

NECHES, R.; FIKES, R. E.; FININ, T.; GRUBER, T. R.; SENATOR, T.; SWARTOUT, W. R. Enabling technology for knowledge sharing. Artificial Intelligence Magazine, v. 12, n. 3, p. 36-56, 1991.

NOY, N. F.; MCGUINESS, D. L. Ontology Development 101: A Guide to Creating Your First Ontology. 2001. Relatório Técnico - Stanford University, Stanford. Disponível em: <http://www.ksl.stanford.edu/people/dlm/papers /ontology101/ontology101-noy-mcguinness.html>. Acesso em: 28 jan. 2006.

NOY, N. F.; FERGERSON, R. W. MUSEN, M. A. The knowledge model of protege-2000: combining interoperability and flexibility. Berlin: Springer, 2000. International Conference in Knowledge Engineering and Knowledge Management - EKAW'00 (12, Juan-les-Pins, 2000). In: LECTURE NOTES IN ARTIFICIAL INTELLIGENCE. Berlin, v. 1937, p. 17-32, 2000.

OBERLE, D.; STAAB, S.; EBERHART, A. Towards Semantic Middleware for Web Application Development. IEEE Distributed Systems Online, 2005. Disponível em: <http://dsonline.computer.org/portal/site/dsonline/menuitem .9ed3d9924aeb0dcd82ccc6716bbe36ec/index.jsp?\&pName=dso_level1\& path $=$ dsonline/topics $/$ was $/$ papers\&file=oberle $. x m l \& x s l=a r t i c l e . x s l ~>$. Acesso em: 08 fev. 2007.

O'CONNOR, M.; KNUBLAUCH, H.; TU, S.; MUSEN, M. Writing Rules for the Semantic Web Using SWRL and JESS. In: INTERNATIONAL PROTÉGÉ CONFERENCE, 8., 2005, Madrid. Proceedings. p. 18-21.

OLIVEIRA, A.; BRAGA, R. M. M. CAMPOS, F.; MATTOSO, M. GOS: especificação de um mecanismo de busca e recuperação de componentes. In: WORKSHOP IBEROAMERICANO DE INGENIERÍA DE REQUISITOS Y DESARROLLO DE AMBIENTES DE SOFTWARE (IDEAS'04), 7., 2004, Arequipa (Peru). Proceedings. p. 349-359.

OBJECT MANAGEMENT GROUP. Software Process Engineering Metamodel Specification. Version 1.1, 2005. Disponível em: <www.omg.org/docs/formal/ 05-01-06.pdf>. Acesso em: 08 fev. 2007.

OBJECT MANAGEMENT GROUP. Common Object Request Broker Architecture (CORBA). 2006. Disponível em: <http://www.corba.org>. Acesso em: 23 out. 2006.

OVIATT, S. L. Multimodal interfaces. In: JACKO, J.; SEARS, A. The HumanComputer Interaction Handbook: Fundamentals, Evolving Technologies and Emerging Applications. Mahwah: Lawrence Erlbaum Assoc., 2003, p. 286-304.

PRICE, D.; RILOFF, E.; ZACHARY, J; HARVEY, B. NaturalJava: A Natural Language Interface for Programming in Java. In: ACM INTERNATIONAL 
(Prieto-Díaz \&

Freeman, 1987)

(Rezende et al., 2003)

(Riley, 2006)

(Rowe, 1988)

(Russel \& Norving, 2003)

(Singh et al., 1995)

(Sossolote, et al., 1997)

(Sousa \& Leite, 2004)

(Studer et al., 1998)

(Sugumaran \& Storey, 2003)

(Sun, 2006a)

(Sun, 2006b)

(Sun, 2006c)

(Sure et al., 2002)

(Tetlow et al., 2006)

(Tsai et al., 2003)
CONFERENCE ON INTELLIGENT USER INTERFACES, 5., 2000, New Orleans. Proceedings. New York: ACM Press, 2000. p. 207-211.

PIETRO-DÍAZ, R.; FREEMAN, P. Classifying Software for Reuse. IEEE Software, v. 4, n. 1, p. 6-16, 1987.

REZENDE, S. O.; PUGLIESI, J. B.; VAREJÃO, F. M. Sistemas Baseados em Conhecimento. In: REZENDE, S. O. Sistemas Inteligentes: Fundamentos e Aplicações. Barueri: Manole, 2003. p. 13-49.

RILEY, G. C. CLIPS: A Tool for Building Expert Systems, 2006. Disponível em: <http://www.ghg.net/clips/CLIPS.html>. Acesso em: 28 jan. 2007.

ROWE, N. C. Artificial Intelligence through Prolog. Englewood Cliffs: Prentice Hall, 1988.

RUSSEL, S.; NORVING, P. Artificial Intelligence: A Modern Approach. Upper Saddle River: Prentice Hall, 2003.

SINGH, N.; GENESERETH, M; SYED, M. A Distributed and Anonymous Knowledge Sharing Approach to Software Interoperation. International Journal of Cooperative Information Systems, v. 4, n. 4, p. 339-367, 1995.

SOSsOlOTE, C. R. C.; ZAVAGLIA, C.; RINO, L. H. M; NUNES, M. G. V. As Manifestações Morfosintácticas da Linguagem UNL no Portugês do Brasil. 1997. 59f. Relatório Técnico - Instituto de Ciências Matemáticas e de Computação (ICMC), Universidade de São Paulo, São Carlos.

SOUSA, L. G.; LEITE, J. C. Utilizando ontologia para a descrição da interação em componentes de interface de usuário. In: SIMPÓSIO SOBRE FATORES HUMANOS EM SISTEMAS COMPUTACIONAIS (IHC), 6., 2004, Curitiba. Anais. p. 213-116.

STUDER, R.; BENJAMINS, V. R.; FENSEL, D. Knowledge engineering: principles and methods, Data and Knowledge Engineering, v. 25, n. 1-2, p. 161-197, 1998.

SUGUMARAN, V.; STOREY, V. C. A Semantic-Based Approach to Component Retrieval. ACM SIGMIS Database, v. 34, n. 3, p. 8-24, 2003.

SUN DEVELOPER NETWORK. Java Beans. 2006. Disponível em: <http://java.sun.com/products/javabeans/>. Acesso em: 23 out. 2006.

SUN DEVELOPER NETWORK. Enterprise JavaBeans Technology. 2006. Disponível em: <http://java.sun.com/products/ejb/>. Acesso em: 23 out. 2006.

SUN DEVELOPER NETWORK. Java EE: Do more with less work. 2006. Disponível em: <http://java.sun.com/javaee/>. Acesso em: 23 out. 2006.

SURE, Y.; ERDMANN, M.; ANGELE, J.; STAAB, S.; STUDER, R.; WENKE D. OntoEdit: collaborative ontology engineering for the semantic web. In: INTERNATIONAL SEMANTIC WEB CONFERENCE (ISWC'02). 1., 2002, Sardinia (Italy). Lecture Notes in Computer Science, v. 2342, London: Springer-Verlag, 2002, p. 221-235.

TETLOW, P.; PAN, J.; OBERLE, D.; WALLACE, M.; USCHOLD, M.; KENDALL, E. Ontology Driven Architectures and Potential Uses of the Semantic Web in Systems and Software Engineering. W3C Draft. 2006. Disponível em: <http://www.w3.org/2001/sw/BestPractices/SE/ODA/>. Acesso em: 23 out. 2006.

TSAI, T. M.; YU, H. K.; SHIH, H. T.; LIAO, P. Y.; YANH, R. D.; CHOU, S. T. 
Referências

(Uchida, 1986)

(Uchida \& Zhu, 2001)

(Uchida et al., 1999)

Ontology-Mediated Integration of Intranet Web Services, IEEE Computer, v. 36, n. 10, p. 63-71, 2003.

UCHIDA, H. Fujitsu machine translation system: ATLAS. Future Generation Computer Systems: Special issue on machine translation. v. 2, n. 2, p. 95-100. Amsterdam: Elsevier Science Publishers, 1986.

(Uchida \& Zhu, 2005)

(UNDL Foundation, 2006)

UCHIDA, H.; ZHU, M. The Universal Networking Language Beyond Machine Translation. In: INTERNATIONAL SYMPOSIUM ON LANGUAGE IN CYBERSPACE, 2001, Seoul. Proceedings. 14p.

UCHIDA, H.; ZHU, M.; DELLA SENTA, T. UNL: a Gift for a Millennium. Yokohama: UNU Institute of Advanced Studies, 1999.

(UNDL Brasil, 2005) FUNDAÇÃO UNDL NO BRASIL. Mini-curso Introdução à Universal Networking Language (UNL). Jul. 2005. Disponível em: <http://undl.org.br/>. Acesso em: 17 ago. 2006.

(UNL Specifications, FUNDAÇÃO UNDL. The Universal Networking Language Specifications. 2004)

Versão 3, Edição 3. Dez. 2004. Disponivel em: <www.undl.org/unlsys/unl/ UNLSpecs33.pdf>. Acesso em: 10 jul. 2006.

(UNL Specifications, FUNDAÇÃO UNDL. The Universal Networking Language Specifications. Jun. 2005)

(UNL Specifications, 2006)

(Uschold \&

Gruninger, 1996)

(Ushold \& King, 1995)

(Vieira et al., 2005) 2005. Disponivel em: <http://www.undl.org/unlsys/unl/unl2005/>. Acesso em: 17 ago. 2006.

FUNDAÇÃO UNDL. The Universal Networking Language Specifications. Ago. 2006. Disponivel em: <http://www.undl.org/unlsys/unl/unl2006/>. Acesso em: 01 out. 2006.

USCHOLD, M.; GRUNINGER, M. Ontologies: Principles, Methods and Applications. Knowledge Engineering Review. v. 11; n. 2; p. 93-155, 1996.

USCHOLD, M.; KING, M. Towards a Methodology for Building Ontologies. In: IJCAI WORKSHOP ON BASIC ONTOLOGICAL ISSUES IN KNOWLEDGE SHARING, 1995, Montreal. Proceedings. Também disponível como AIAl-TR183 from AIAl, University of Edinburg. 15p.

VIEIRA, R.; SANTOS, D. A.; SILVA, D. M.; SANTANA, M. R. Web Semântica: ontologias, lógica de descrição e inferência. In: SIMPÓSIO BRASILEIRO DE SISTEMAS MULTIMÍDIA E WEB (WEBMEDIA'05), 11., 2005, Poços de Caldas. Anais (Mini-curso em CD-ROM). p. 127-167.

(Volz et al., 2003) VOLZ, R.; OBERLE, D.; STAAB, S.; MOTIK, B. KAON Server: A Semantic Web Management System. In: WORLD WIDE WEB CONFERENCE (WWW'03), 2003, 12., Budapest. Proceedings. 8p.

(Yaguinuma et al., 2005)

YAGUINUMA, C. A.; SANTOS, M. T. P.; VIEIRA, M. T. P. Ontology-Based Meta-model for Storage and Retrieval of Software Components. In: VLDB WORKSHOP ON ONTOLOGIES-BASED TECHNIQUES FOR DATABASES AND INFORMATION SYSTEMS (ODBIS'05), 2005, Trondheim. Proceedings. p. 39-44.

(Yao \& Etzkorn, $\quad$ YAO, H.; ETZKORN, L. Towards a Semantic-based Approach for Software 
Reusable Component Classification and Retrieval. In: ACM SOUTHEAST REGIONAL CONFERENCE, 42., 2004, Huntsville. Proceedings. New York: ACM Press, 2004, p. 110-115.

(Zaremski \& Wing, ZAREMSKI, A. M.; WING, J. M. Signature Matching: A Key to Reuse, Software 1993) Engineering Notes, v. 18, n. 5, p. 182-190, 1993.

(Zaremski \& Wing, 1995)

ZAREMSKI, A. M.; WING, J. M. Specification Matching of Software Components, Software Engineering Notes, v. 20, n. 4, p. 6-17, 1995.

(Zhu et al., 2005)

ZHU, Y.; WU, L.; LI, X.; YUAN, J. A transformer condition assessment framework based on data mining. In: IEEE POWER ENGINEERING SOCIETY GENERAL MEETING, 2005, Baoding (China). Proceedings. v. 2, p. 18751880. 


\section{APÊNDICE}

\section{Diagramas de Classes da Ontologia InterComp}

Este Apêndice apresenta diagramas de classes da Ontologia InterComp mostrando os relacionamentos de todas as relações UNL com suas UWs genéricas. Devido ao grande número de relacionamentos, foram feitos quatro diagramas de classes para representá-los. As multiplicidades dos relacionamentos, nesses quatro diagramas, são todas 1:1 e foram omitidas para não sobrecarregar os diagramas.

O diagrama de classes com os relacionamentos de todas as relações UNL, em ordem alfabética, entre agente (agt) e duração (dur) é apresentado na Figura A.1. O diagrama de classes com os relacionamentos das relações UNL entre sinonímia (equ) até modificação (mod) é apresentado na Figura A.2. Nas Figuras A.3 e A.4, as colunas com os nomes das relações UNL foram trocadas de ordem para facilitar o desenho do diagrama. O diagrama de classes com os relacionamentos das relações UNL entre nome (nam) e propósito (pur) é apresentado na Figura A.3. Finalmente, o diagrama de classes com os relacionamentos das relações UNL entre quantidade (qua) e lugar por onde (via) é apresentado na Figura A.4. 


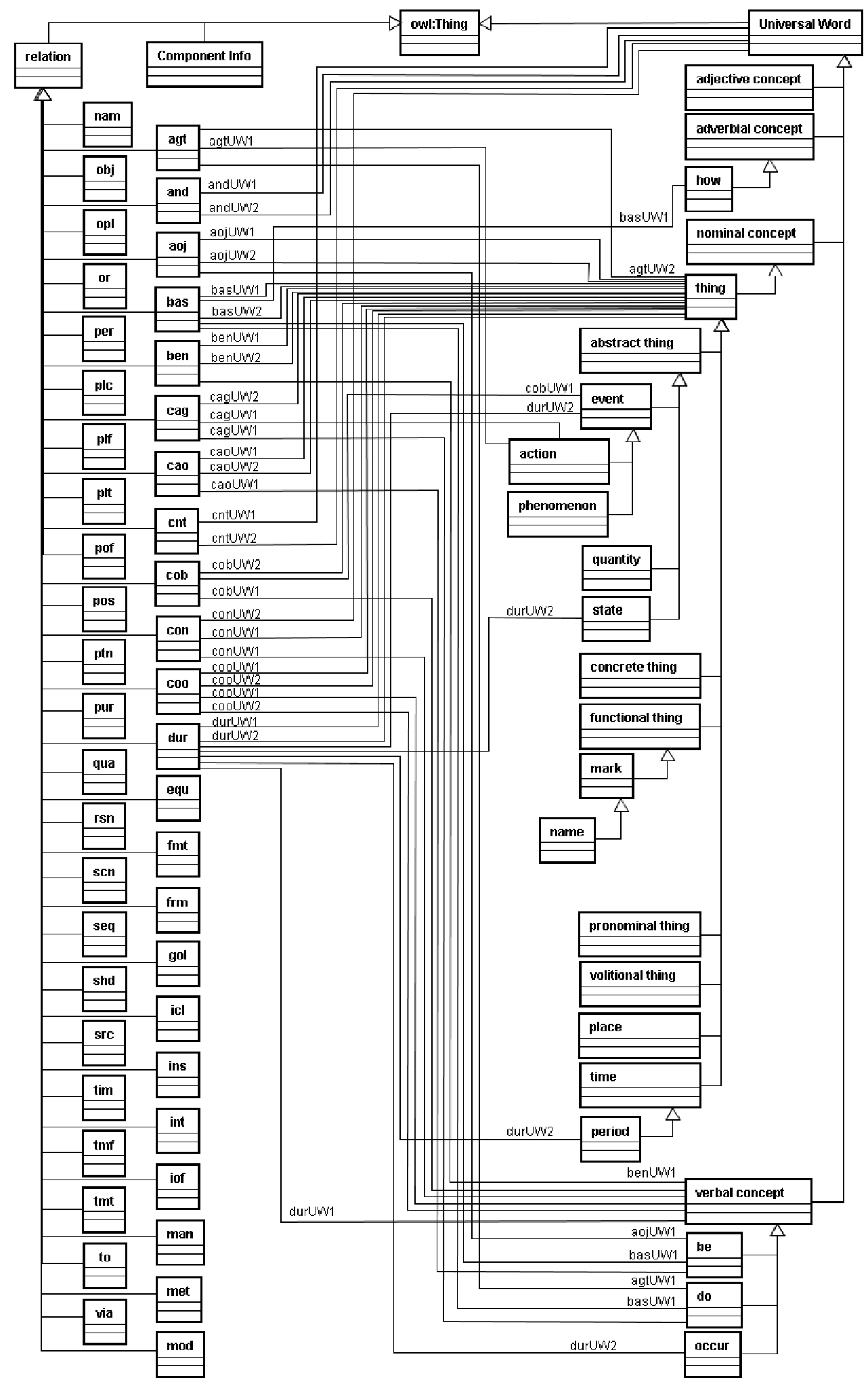

Figura A. 1 - Relacionamentos das relações UNL agente (agt) até duração (dur). 


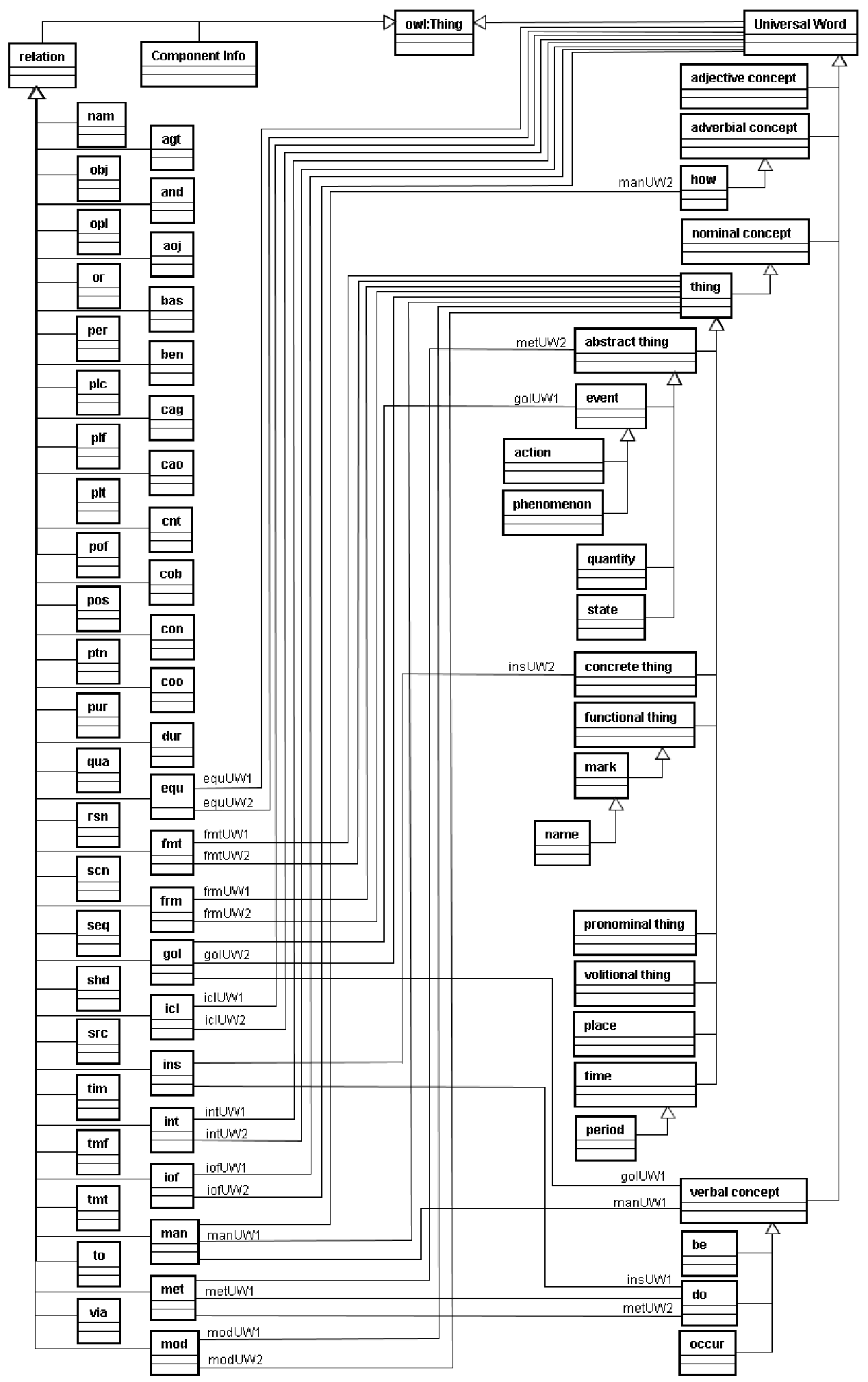

Figura A. 2- Relacionamentos das relações UNL sinonímia (equ) até modificação (mod). 


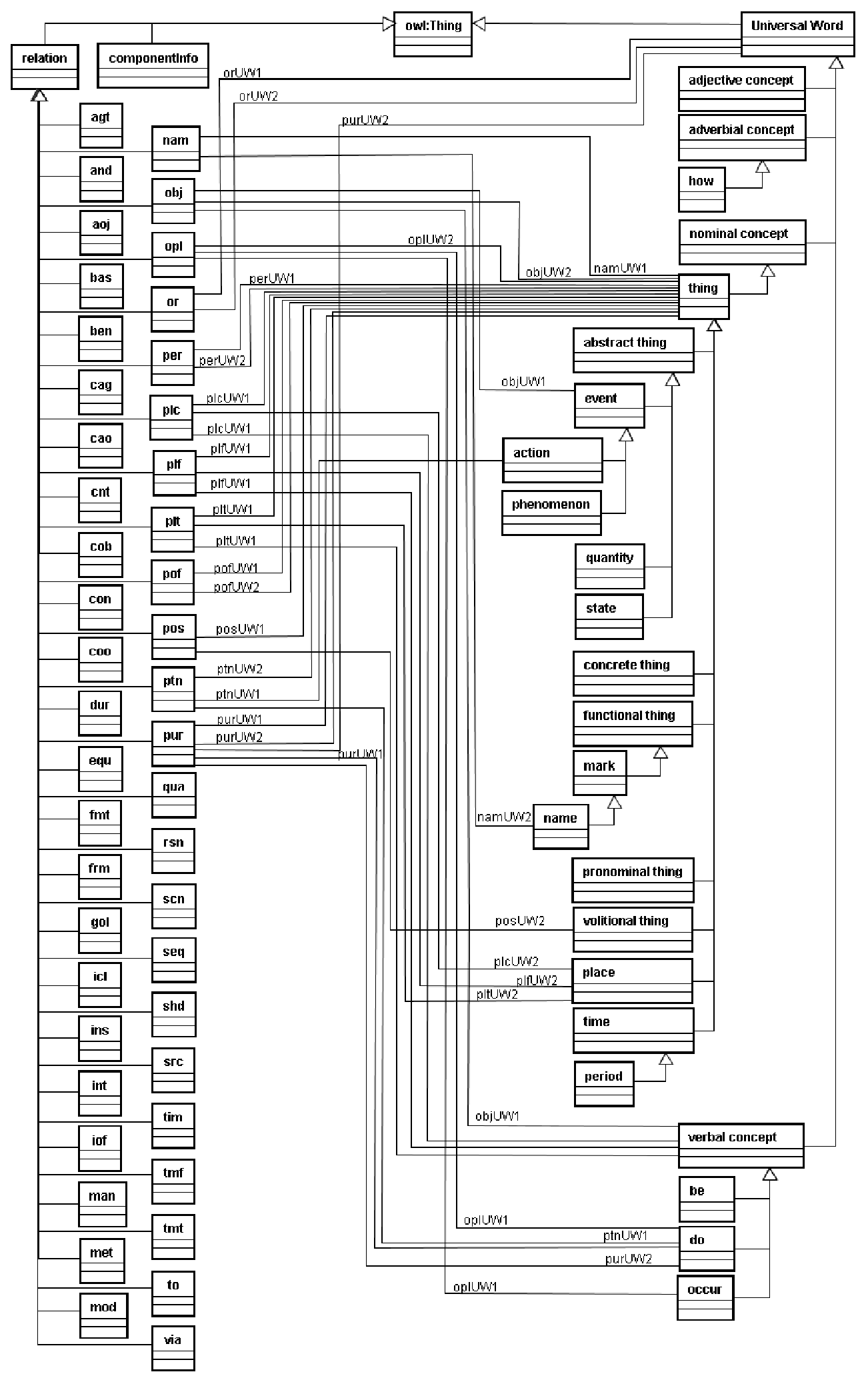

Figura A. 3 - Relacionamentos das relações UNL nome (nam) até propósito (pur). 


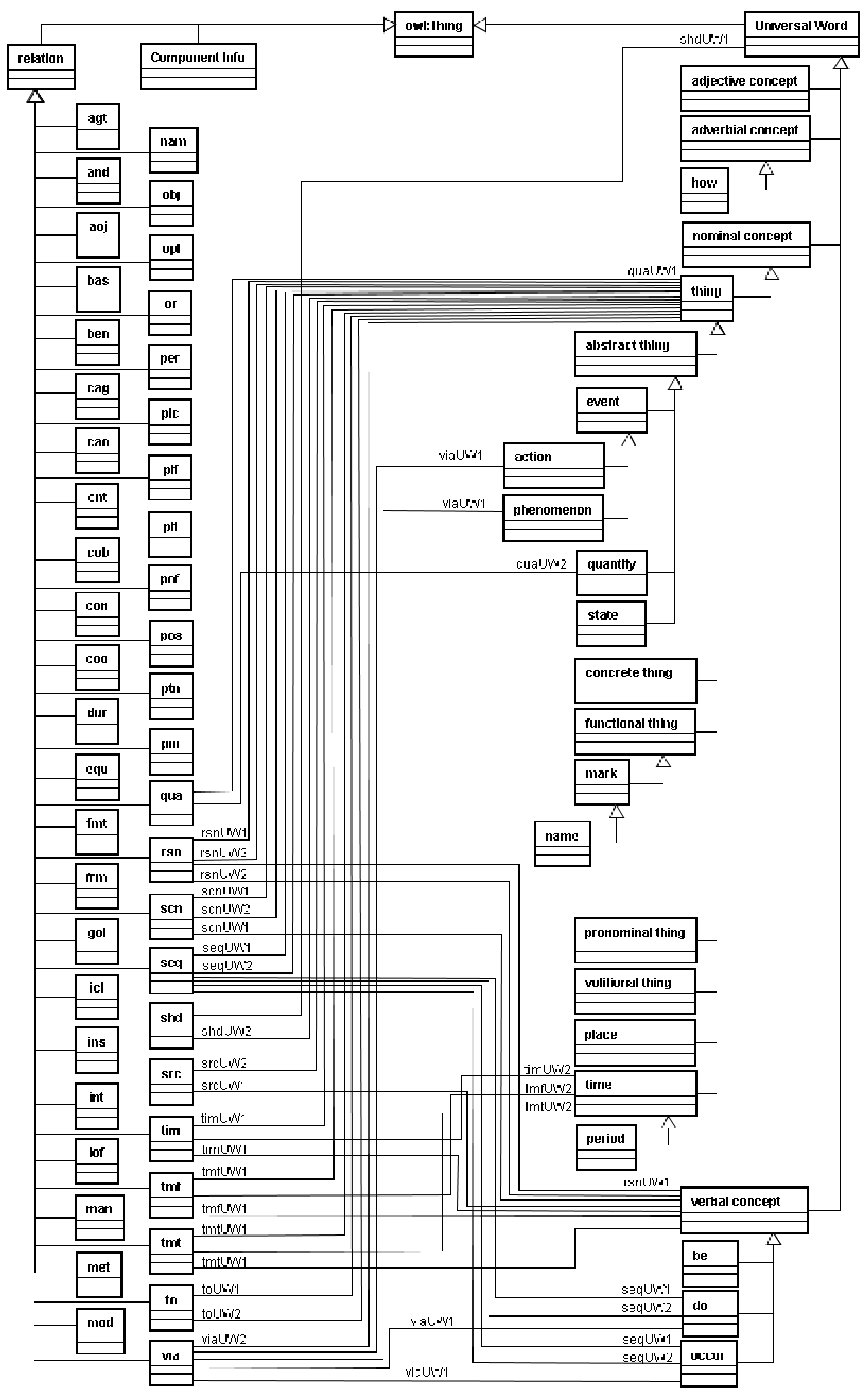

Figura A. 4 - Relacionamentos das relações UNL quantidade (qua) até lugar por onde (via). 


\section{APÊNDICE}

\section{Produtos de Trabalho (PT) do Processo}

\section{PT-1 Documento de Funcionalidade dos Componentes}

Para produzir o Documento de Funcionalidade dos Componentes é preciso ter a interface dos componentes, analisar sua documentação e identificar um conceito do domínio que melhor identifica cada componente, cada método, cada parâmetro e o retorno de cada método (se estes dois últimos existirem). Esse documento deverá possuir a estrutura apresentada na Figura B.1. É importante observar que o conceito relacionado aos métodos deve ser necessariamente uma ação. A parte de "ação relacionada" deve ser um verbo no imperativo e a parte de "conceito relacionado" deve ser um substantivo, ambos especificados em inglês, pois serão usados posteriormente no dicionário UNL, que trabalha com termos em inglês.

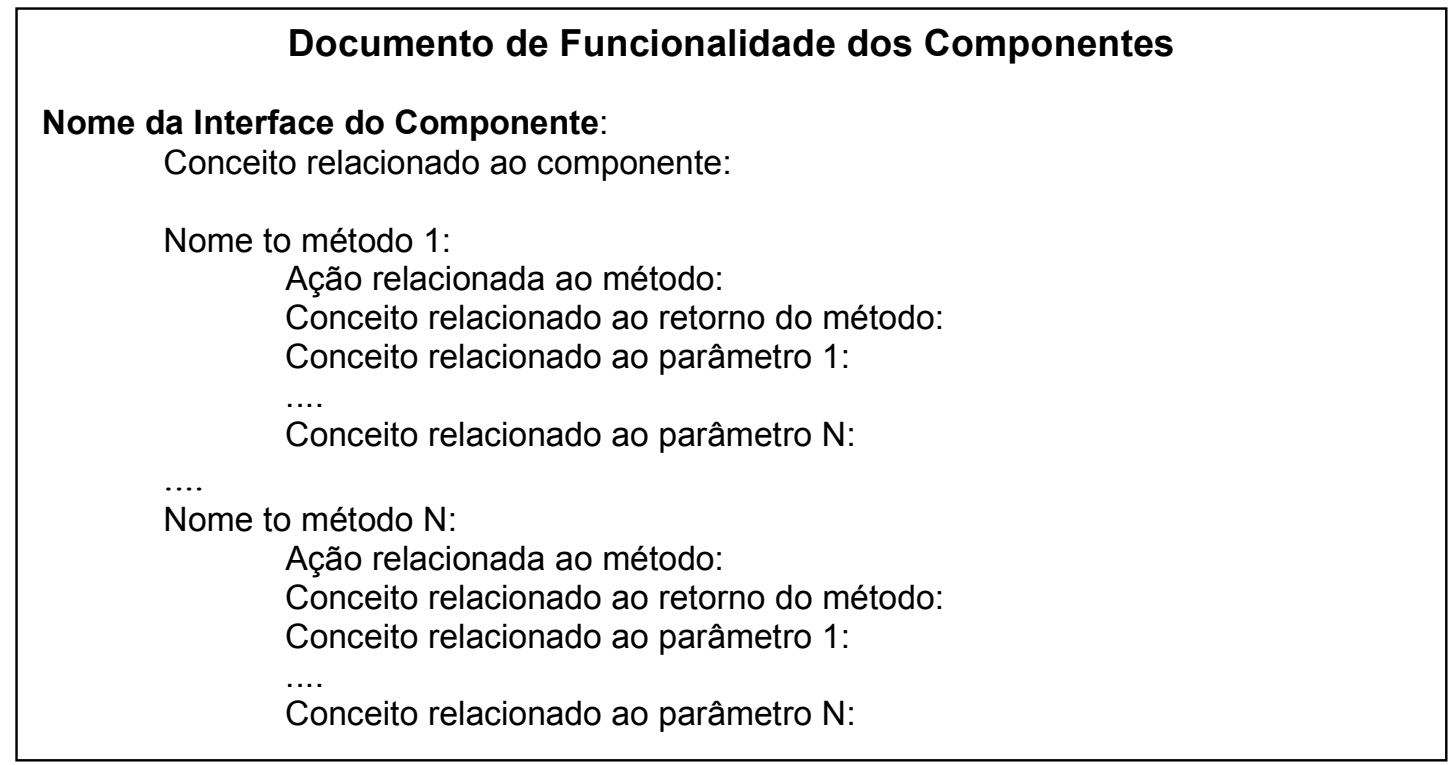

Figura B. 1 - Estrutura do Documento de Funcionalidade do Componente. 


\section{PT-2 Documento de Sentenças Imperativas}

O Documento de Sentenças Imperativas é feito levando-se em consideração a funcionalidade dos componentes, utilizando os conceitos do domínio identificados no Documento de Funcionalidade dos Componentes (PT-1). Esse documento consiste em um conjunto de sentenças imperativas válidas, sem considerar os sinônimos dos conceitos. As sentenças devem cobrir toda a funcionalidade dos componentes, pois serão posteriormente utilizadas para testes.

A língua utilizada no documento deve a mesma para a qual se pretende criar o dicionário e a gramática. Todas as sentenças devem começar com verbos no imperativo, identificados no Documento de Funcionalidade dos Componentes. Para cada sentença é recomendado especificar se um conceito pode ser substituído por outros. Assim o Documento de Sentenças Imperativas não fica muito repetitivo, além de ajudar a desenvolver a gramática. O documento pode ser formalizado seguindo a estrutura da Figura B.2.

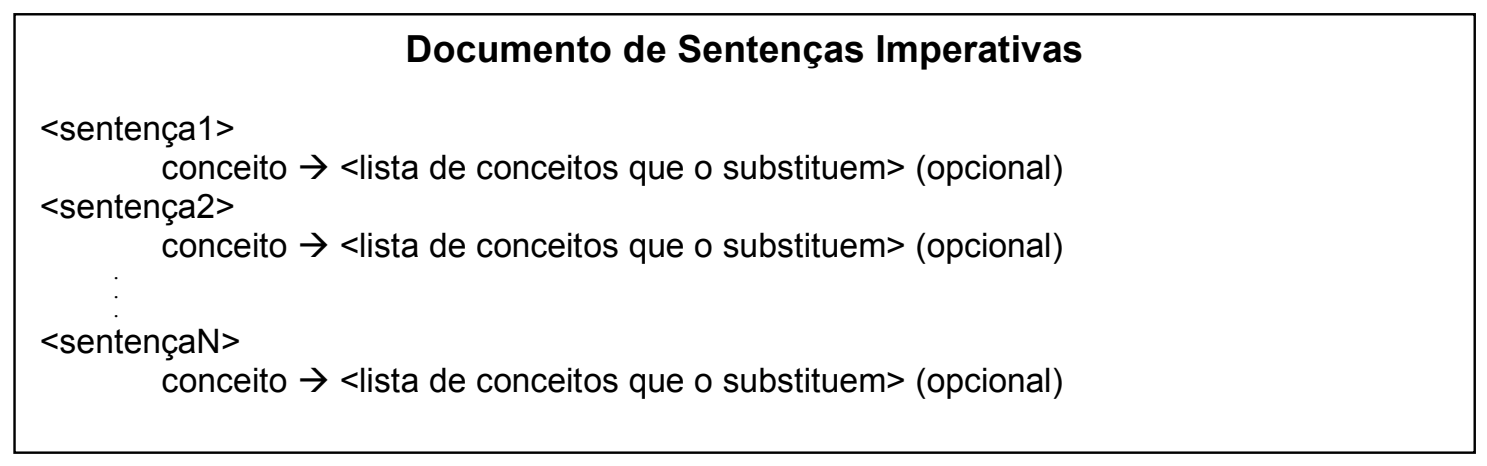

Figura B. 2 - Estrutura do Documento de Sentenças Imperativas.

\section{PT-3 Documento de Sinônimos}

O Documento de Sinônimos consiste em identificar sinônimos para cada conceito e ação presente no Documento de Funcionalidade dos Componentes, aqui chamados de conceitos-chave. Esse documento pode ser formalizado seguindo a estrutura da Figura B.3. Mesmo os conceitos-chave que não possuírem sinônimos devem estar presentes no Documento de Sinônimos. Os conceitos-chave e as listas de sinônimos devem ser 
especificados na língua para a qual se deseja criar o dicionário e a gramática. Isto é, o Documento de Funcionalidade dos Componentes deve ter seus conceitos e ações e especificados em inglês, mas o Documento de Sentenças Imperativas e o Documento de Sinônimos deve ser especificado na língua alvo.

\section{Documento de Sinônimos}

Conceito-chave1: <lista de sinônimos>

Conceito-chave2: <lista de sinônimos>

Conceito-chaveN: <lista de sinônimos>

Figura B. 3 - Estrutura do documento de sinônimos.

\section{PT-4 Dicionário}

Antes de desenvolver o dicionário, é preciso conhecer o formalismo do mesmo. Cada EnCo terá certas particularidades para o formalismo do dicionário. Neste trabalho, foi utilizado o Hermeto, um EnCo desenvolvido pelo NILC, e o formalismo para seu dicionário pode ser encontrado em Martins et al. (2004).

O dicionário para o Hermeto consiste em um arquivo texto e sua sintaxe é simples, podendo ser desenvolvido por um usuário comum. Cada termo do Documento de Sinônimos (PT-3), será uma entrada do dicionário. Isso vale também para preposições, conjunções, artigos, que não estão no Documento de Sinônimos mas fazem parte das sentenças imperativas. Uma atenção especial deve ser dada aos sinônimos, pois, como explicado na seção 5.3, os sinônimos devem gerar a mesma saída em UNL. Isto é, os sinônimos devem ser substituídos pelos "conceitos-chave" do Documento de Sinônimos, no campo "UW" do dicionário, mas ao invés de usar a língua alvo, deve ser usado o termo em inglês correspondente a cada conceito-chave. Esses termos em inglês foram identificados nos Documentos de Funcionalidade dos Componentes (PT-1). A Figura 5.3, apresentou o trecho de um dicionário válido para o Hermeto, que pode ser tomado como base para o desenvolvimento de outros dicionários. 
Limitação do Classificador de Tokens: conforme ilustrado na Figura 5.3 e explicado na seção 5.3, o dicionário pode conter relações UNL para restringir ou dar informações adicionais a certos conceitos, podendo inclusive definir uma ontologia implícita no dicionário. Apesar das restrições serem comuns em dicionários UNL, o Classificador de Tokens ainda não as considera. Por isso, os dicionários desenvolvidos para trabalhar com a Arquitetura OntoMap não devem ter UWs restritas.

\section{PT-5 Gramática}

Para produzir a gramática, é preciso primeiramente saber UNL. Para estudar UNL, recomenda-se ler o Capítulo 2 desta tese. Para se aprofundar em UNL, é recomendado ler a especificação (UNL Specifications, 2005). Além disso, é preciso conhecer o formalismo da gramática do Hermeto, que pode ser obtido em Martins et al. (2004), e conhecer a estrutura gramatical da língua para a qual se deseja fazer a gramática. Uma boa prática para o desenvolvimento a gramática é ver exemplos prontos. A Figura 5.2 mostra o trecho de uma gramática simples para o Hermeto. Com isso, basta criar a gramática respeitando as estruturas gramaticais identificadas no Documento de Sentenças Imperativas (PT-2).

Limitação do Classificador de Tokens: as gramáticas UNL podem conter atributos e escopos, apresentados no Capítulo 2. Apesar de ambos serem comuns em gramáticas UNL, o Classificador de Tokens não os considera. Por isso, as gramáticas desenvolvidas para trabalhar com a Arquitetura OntoMap não devem ter atributos nem escopos.

\section{PT-6 Documento de Sentenças UNL}

O Documento de Sentenças UNL consiste em colocar a representação UNL, gerada pelo Hermeto, para cada estrutura de sentença presente no Documento de Sentenças Imperativas (PT-2). Esse documento é desenvolvido na fase de testes da gramática e do dicionário no Hermeto. Para cada estrutura gramatical, é preciso verificar se o Hermeto está gerando a saída em UNL adequadamente. Se sim, um exemplo de sentença com a estrutura em questão é acrescentado no Documento de Sentenças UNL, juntamente com sua representação UNL. Se o Hermeto não estiver gerando a saída adequada, o dicionário ou a gramática 
deverão ser corrigidos. O Documento de Sentenças UNL deve ter a estrutura apresentada na Figura B.4.

\begin{tabular}{|l|}
\multicolumn{1}{c|}{ Documento de Sentenças UNL } \\
<estrutura gramatical 1> \\
<representação UNL para a estrutura gramatical 1> \\
$\vdots$ \\
<estrutura gramatical N> \\
<representação UNL para a estrutura gramatical N>
\end{tabular}

Figura B.4 - Representação do Documento de Sentenças UNL.

Limitações do Hermeto: algumas limitações no Hermeto devem ser consideradas nas sentenças imperativas de entrada. São elas:

- Há um limite quanto ao tamanho das sentenças de entrada.

- Nomes compostos devem ser separados pelo caractere “_”. Por exemplo a sentença "Apague o curso Sistemas Operacionais" não seria processada corretamente pelo parser. A entrada correta seria “Apague o curso Sistemas_Operacionais”.

- Nomes ou códigos que possuem a combinação de letras e números não são aceitos. Por exemplo, a sentença "Apague a turma sce2345" não seria aceita pelo parser porque o código da turma é composto por letras e números.

\section{PT-7 Arquivos lexico.mac e revgram.dll}

Os arquivos léxico.mac e revgram.dll consistem no dicionário e na gramática encapsulados, de modo a ficarem independentes do ambiente do Hermeto. Para gerar esses arquivos, é preciso abrir e compilar o arquivo Revgram.dsw, que estará no diretório de compilação da gramática e do dicionário. $\mathrm{O}$ arquivo Revgram.dsw consiste em um projeto no Visual C, por isso para abri-lo é preciso abrir um projeto. É preciso ainda modificar algumas configurações para que a compilação do projeto seja feita com sucesso; são elas:

1) Entrar no menu Project e escolher a opção Settings;

2) na tab $C++$, escolher a opção preprocessor; 
3) em "additional include directories" preencher com: \hermetolcomum; \hermetoljava jnilinclude (este último é o mesmo caminho do diretório include do JSDK).

Após isso, pode-se compilar o projeto. $\mathrm{O}$ resultado da compilação será a geração dos arquivos léxico.mac e regram.dll no mesmo diretório de Revgram.dsw.

\section{PT-8 Documento de Mapeamento Semântico}

O Documento de Mapeamento Semântico consiste nas sentenças em UNL (que estão no Documento de Sentenças UNL - PT-6) acrescidas das informações semânticas a respeito dos componentes, identificadas no Documento de Funcionalidade dos Componentes (PT-1). Para cada UW, deve-se apontar se ela está relacionada a um método (ação), a um componente, ao valor de um parâmetro, ao conceito relacionado a um parâmetro ou ao retorno de um método. A estrutura do Documento de Mapeamento Semântico deve ser como ilustrado na Figura B.5, que é uma representação textual da Figura 5.4.

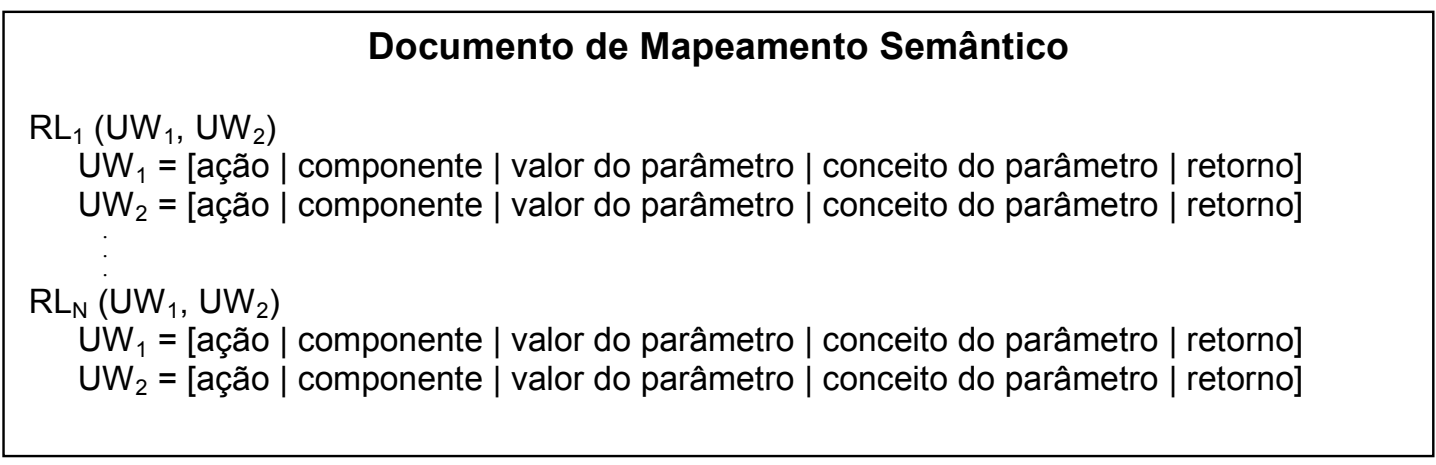

Figura B. 5 - Estrutura do Documento de Mapeamento Semântico.

\section{PT-9 Arquivo de Regras (rules.clp)}

O objetivo da criação das regras é utilizar as sentenças em UNL para inferir informações semânticas a respeito dos componentes. Para gerar o arquivo de regras é preciso ter o Documento de Mapeamento Semântico e saber escrever regras em JESS (Java Expert System Shell). Para isso é preciso estudar primeiramente a introdução à linguagem JESS, o que pode ser encontrado em Friedman-Hill (2003). Posteriormente, é preciso aprender a criar 
regras em JESS. Para isso, pode-se recorrer à Eriksson (2004) e http://sourceforge.net/ projects $/$ jesstab $/ 3$.

Para desenvolver as regras é preciso também conhecer os nomes dos slots da Ontologia InterComp onde as informações inferidas sobre os componentes serão armazenadas. Os itens a seguir mostram em qual slot cada informação deve ser armazenada na Ontologia InterComp (os slots estão ilustrados na Figura 5.6):

- hasMainConcept: armazena o conceito associado ao mais provável componente a ser chamado.

- hasOtherComponents: armazena os conceitos associados a outros possíveis componentes a serem chamados.

- hasAction: armazena a ação relacionada ao método de um componente.

- hasParams: armazena os valores de parâmetros.

- hasConcept: para cada parâmetro, armazena o conceito ao qual ele está associado.

- hasReturn: armazena o conceito que pode estar associado ao valor de retorno do método.

Tendo as informações sobre em qual slot armazenar as informações semânticas identificadas no Documento de Mapeamento Semântico (PT-8), basta criar as regras em JESS, que serão, em sua maioria, similares às regras apresentadas na Figura 5.8.

\section{PT-10 Ontologia de Domínio}

Para desenvolver esse produto de trabalho está sendo assumido que o usuário ou desenvolvedor sabe o que é uma ontologia e outros conceitos relacionados ao desenvolvimento de ontologias. Para isso, pode-se ler o Capítulo 3 desta tese como ponto de partida.

Tendo um conhecimento básico sobre ontologias, é aconselhável familiarizar-se com o ambiente do Protégé, com suporte a OWL, para o desenvolvimento de ontologias, o que pode ser feito por meio da leitura dos documentos em Horridge et al. (2004) e http://protege.stanford.edu/plugins/owl/documentation.html ${ }^{44}$.

\footnotetext{
${ }^{43}$ Acesso em 12 jan. 2007.

${ }^{44}$ Acesso em 12 jan. 2007.
} 
Para desenvolver a Ontologia de Domínio pode-se utilizar uma das metodologias descritas na seção 3.5. Os nomes das classes da Ontologia de Domínio devem ser os mesmos dos conceitos identificados no Documento de Funcionalidade dos Componentes (PT-1). As ações não são consideradas, apenas os conceitos (definidos nos campos "conceito relacionado"). Esses conceitos devem ser formalizados em classes ontológicas com os devidos relacionamentos entre si, o que irá variar dependendo do domínio.

\section{PT-11 Ontologia de Componentes Instanciada}

Para realizar a instanciação da Ontologia de Componentes está sendo assumido que o usuário ou desenvolvedor conhece conceitos relacionados às ontologias e conhece o ambiente do Protégé, com suporte a OWL, como especificado no produto de trabalho anterior (PT-10).

Para começar a instanciação da Ontologia de Componentes, é aconselhável que a primeira classe a ser instanciada seja a classe Action. As instâncias dessa classe correspondem às ações (verbos no imperativo) identificadas no Documento de Funcionalidade dos Componentes (PT-1). Portanto, para instanciar a classe Action basta criar instâncias com os mesmos nomes das ações identificadas.

Posteriormente, deve-se criar a hierarquia de classes sob a classe DomainConcept. Essa hierarquia de classes é a Ontologia de Domínio (PT-10). Como a Ontologia de Domínio já foi criada no processo anterior, basta importá-la, utilizando ferramentas como Prompt ${ }^{45}$, por exemplo. Outra opção é criar a Ontologia de Domínio diretamente sob a classe DomainConcept.

Depois disso, os dados das interfaces dos componentes devem ser colocados na ontologia como instâncias das classes Component, Method e Param. Finalmente, os slots são preenchidos, criando os relacionamentos semânticos entre as classes Component, Method e Param e as instâncias e conceitos das classes Action e DomainConcept.

\footnotetext{
${ }^{45} \mathrm{http} / / /$ protege.stanford.edu/plugins/prompt/prompt.html. Acesso em 12 jan. 2007.
} 


\section{PT-12 Relatório de Testes}

Para fazer o Relatório de Testes é preciso antes executar a classe para testes (Revgram.class). Essa classe exibe uma caixa de diálogo para que as requisições sejam digitadas. Para sair, basta digitar "exit".

O Relatório de Testes consiste em testar cada sentença do Documento de Sentenças Imperativas (PT-2) individualmente, indicar o método que está sendo apontado para executar a sentença e dizer se o método satisfaz à requisição ou não. Caso o método encontrado não seja o correto, as classes Tokenizer e RetrieveComponents exibem um log com os passos executados, o que pode ser consultado para descobrir possíveis erros. O Relatório de Testes deve ter a estrutura apresentada na Figura B.6.

É recomendado testar cada sentença do Documento de Sentenças Imperativas (PT-2) e suas variações, pois pode ter acontecido algum erro ao cadastrar os dados na Ontologia de Componentes, isto é, pode ser que os dados das interfaces dos componentes não tenham sido associados às informações semânticas corretas. Além disso, o Relatório de Testes deve ter pelo menos uma sentença para testar cada método das interfaces dos componentes.

\begin{tabular}{|l|l|l|}
\hline \multicolumn{3}{|c|}{ Relatório de Testes } \\
\hline \multicolumn{1}{|c|}{ Requisição } & \multicolumn{1}{|c|}{ Método encontrado } & \multicolumn{1}{c|}{ Observações } \\
\hline$<$ requisição1 & <nome_do_método $>$ & $\begin{array}{l}\text { Escrever se o método satisfaz à requisição } \\
\text { ou não, apontando possíveis erros. }\end{array}$ \\
\hline$\ldots$. & $\ldots$ & $\ldots$ \\
\hline$<$ requisiçãoN $>$ & $<$ nome_do_método $>$ & \\
\hline \multicolumn{3}{|l|}{ Observações: } \\
\hline \multicolumn{2}{|l|}{ Observações sobre os resultados dos testes, se necessário. } \\
\hline
\end{tabular}

Figura B. 6 - Estrutura do Relatório de Testes. 


\section{APÊNDICE}

Interfaces dos Componentes

\section{Interface do Componente Estudante}

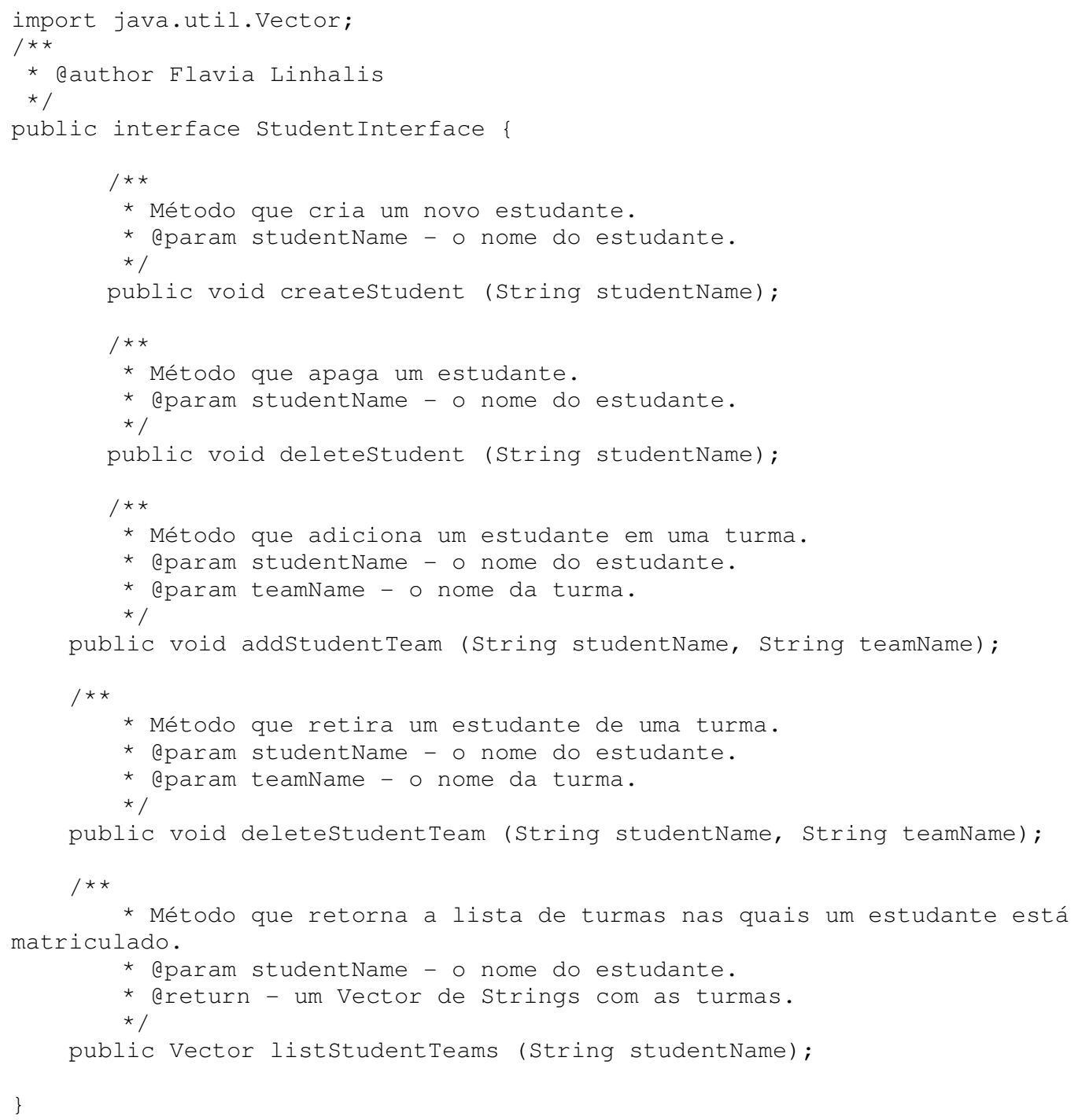




\section{Interface do Componente Professor}

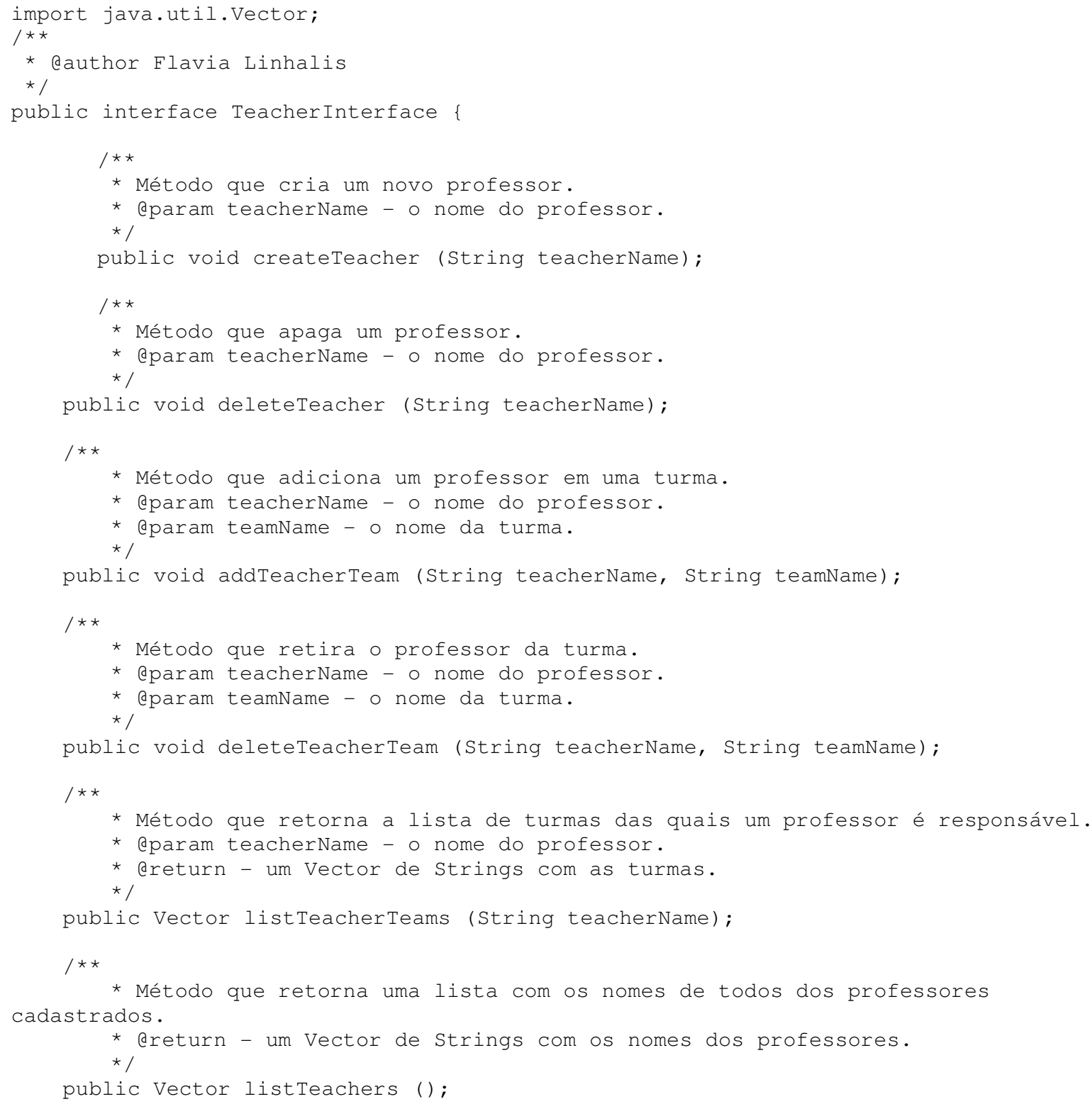




\section{Interface do Componente Monitor}

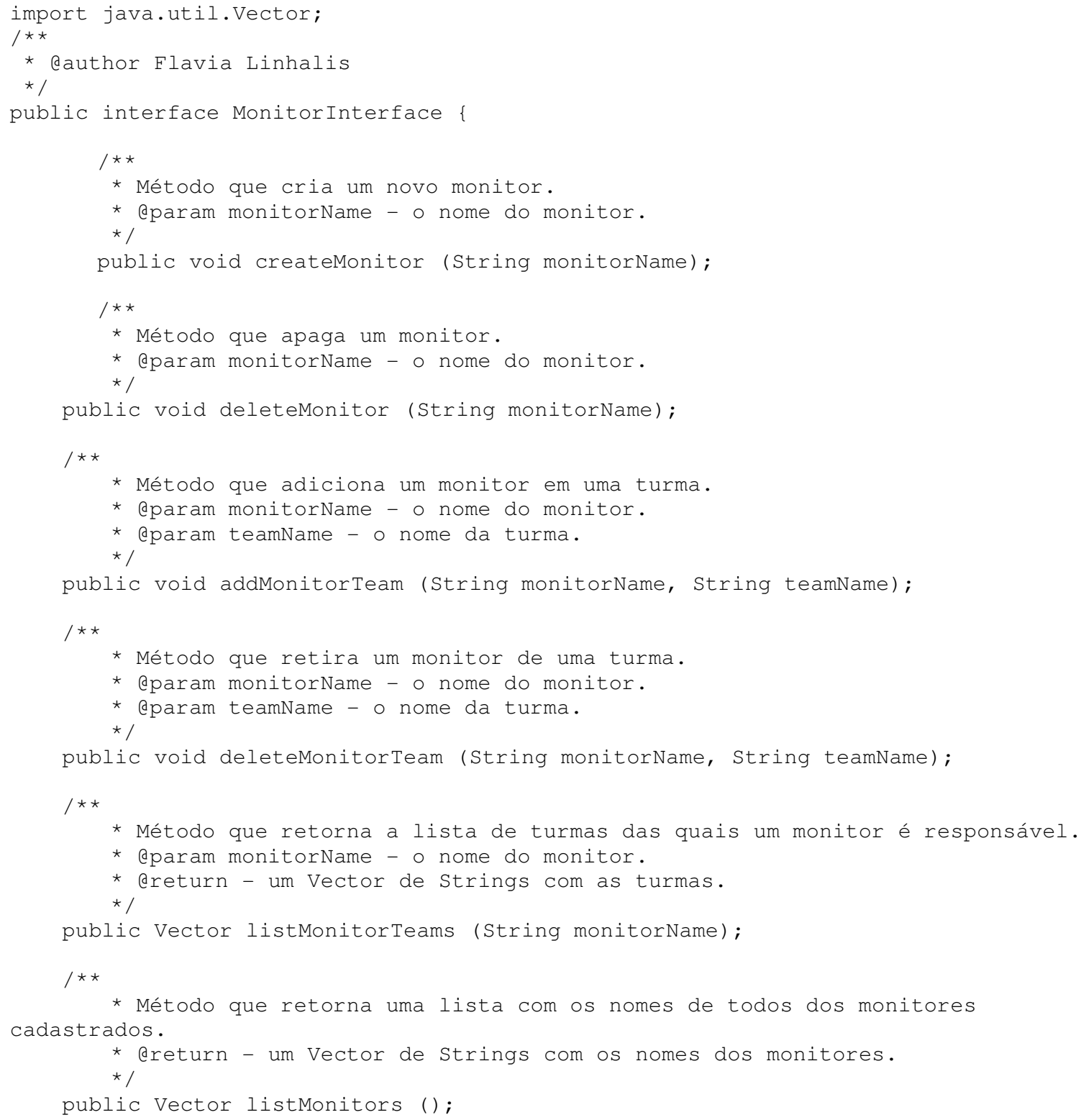




\section{Interface do Componente Candidato}

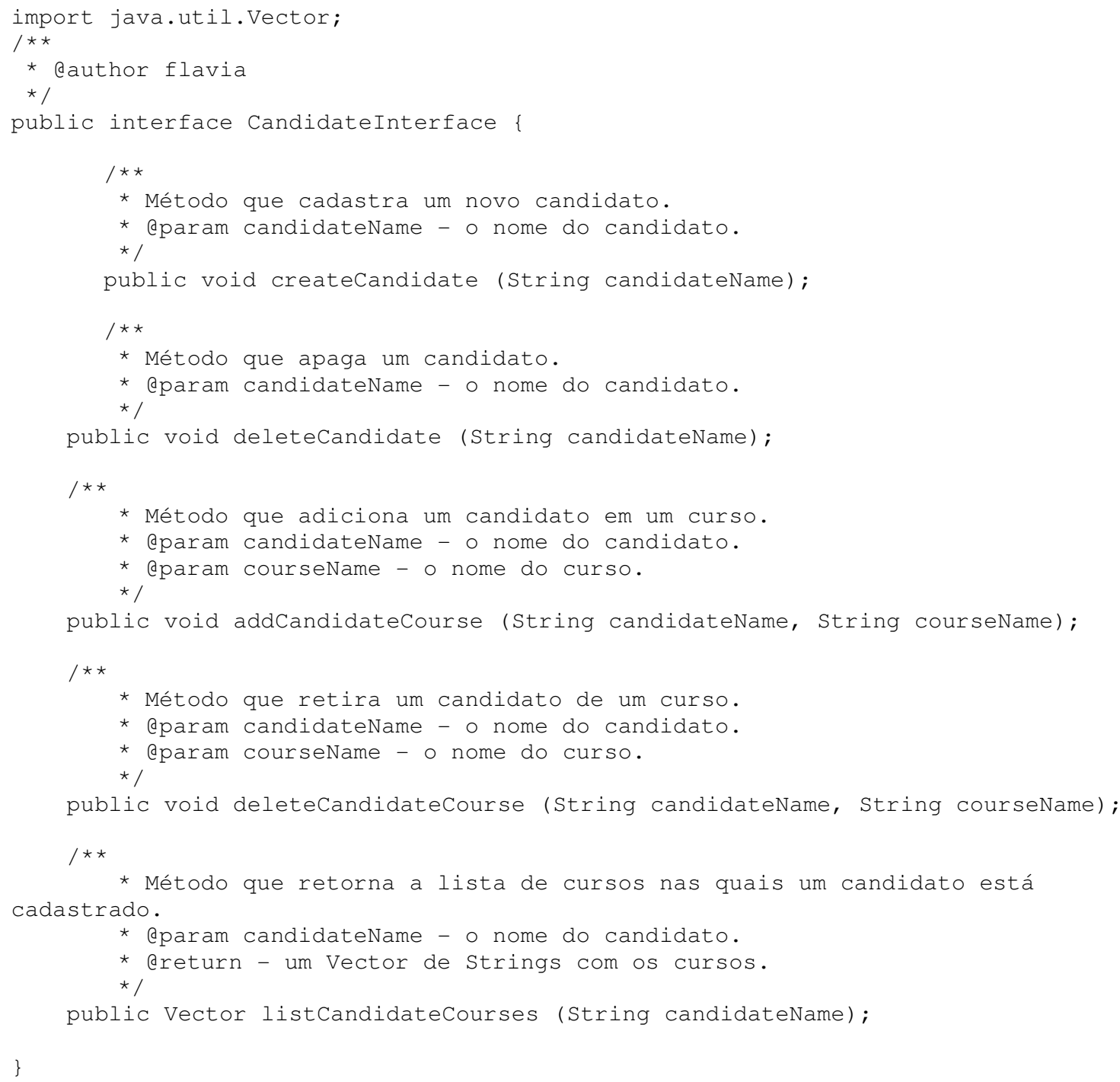




\section{Interface do Componente Administrador}

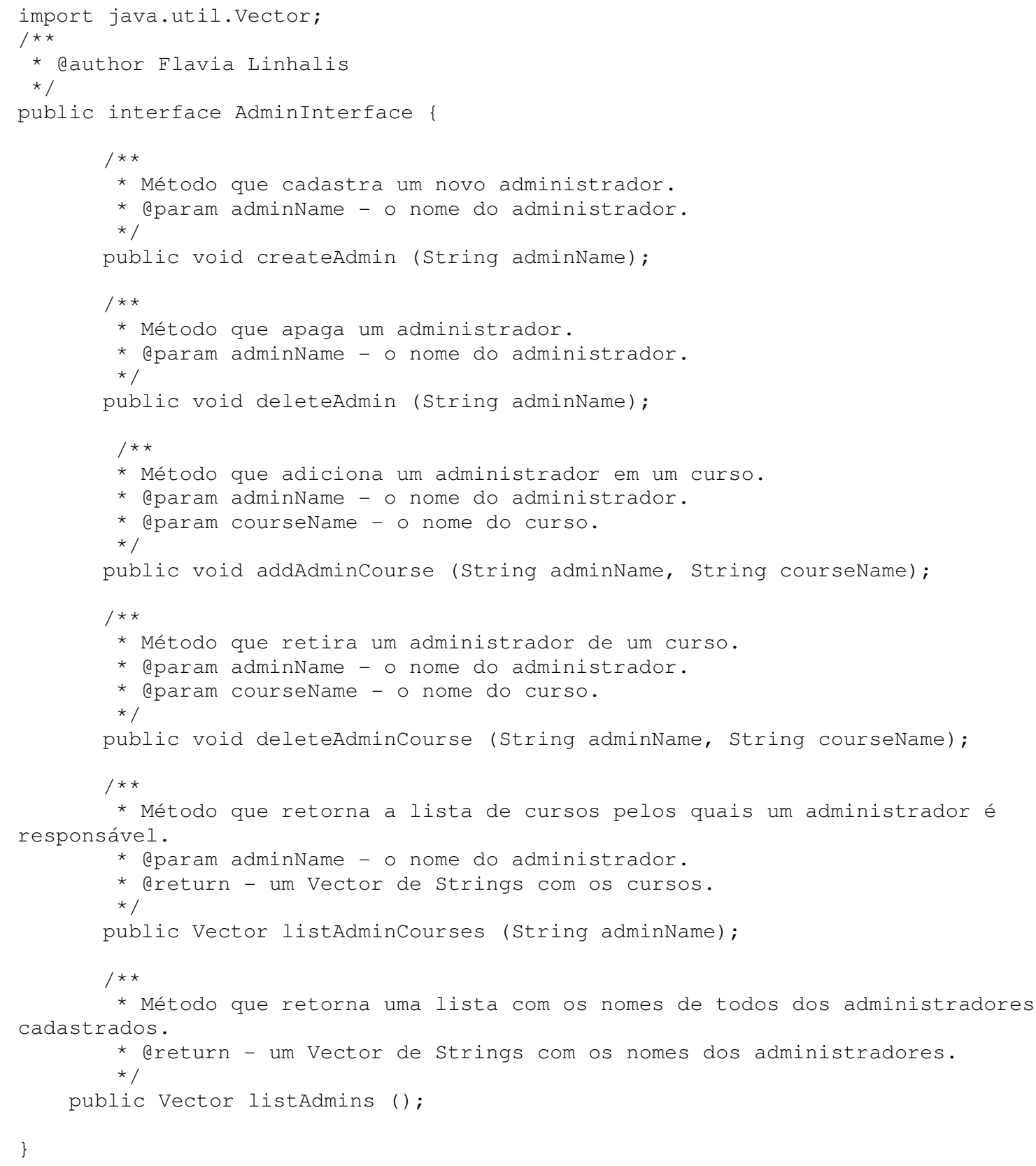




\section{Interface do Componente Turma}

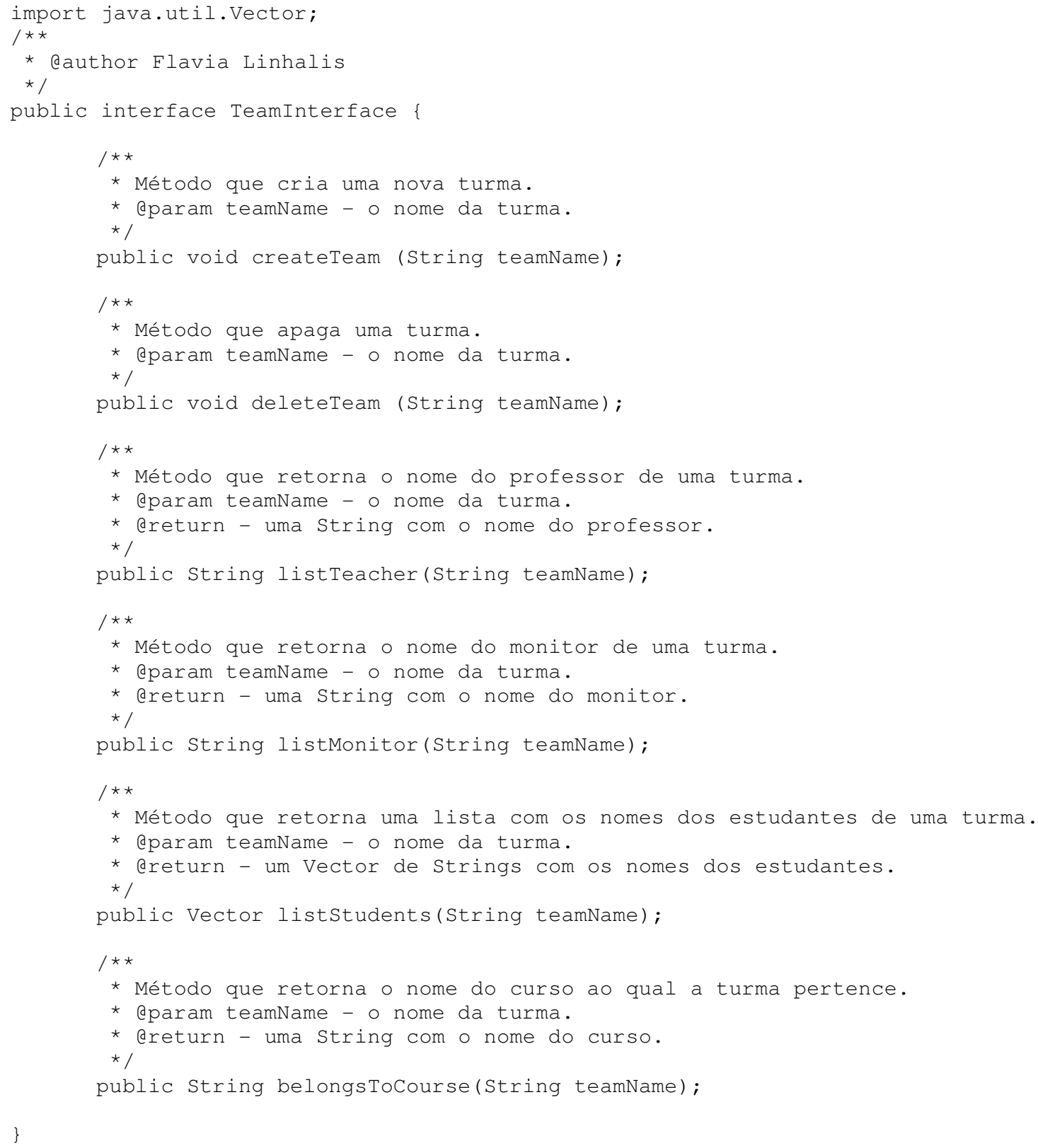




\section{Interface do Componente Curso}

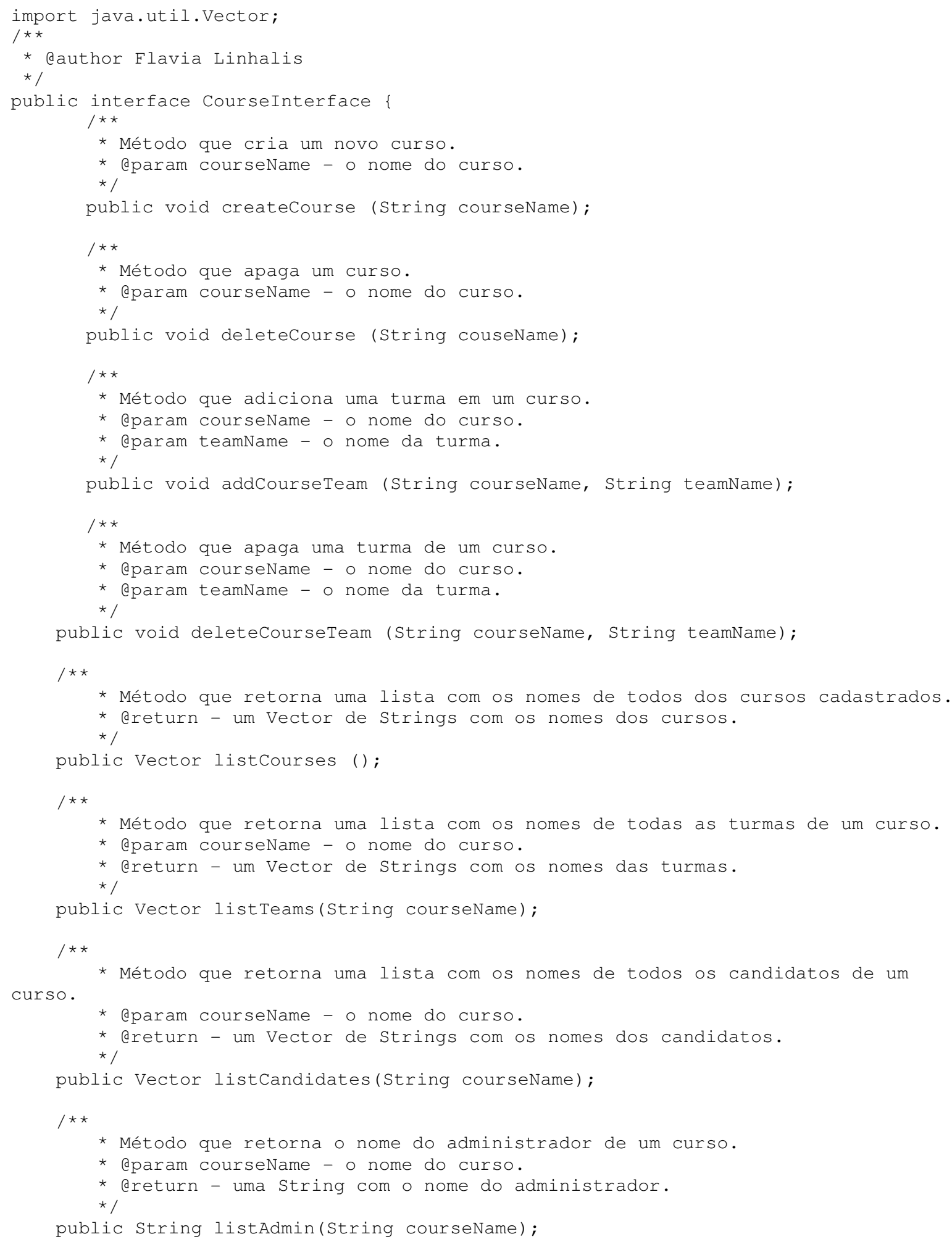




\section{APÊNDICE}

\section{Produtos de Trabalho (PT) da Instanciação do Processo}

\section{PT-1 Documento de Funcionalidade dos Componentes}

Para produzir o Documento de Funcionalidade dos Componentes as interfaces documentadas dos componentes, que estão no Apêndice $C$, foram utilizadas. Foi identificado um conceito relacionado a cada componente, método, parâmetro e retorno de método, sendo que o conceito relacionado ao método é uma ação (verbo no imperativo) e os conceitos relacionados aos demais elementos da interface são substantivos. Todos foram especificados em inglês, pois serão usados no dicionário UNL. O Documento de Funcionalidade dos Componentes é apresentado a seguir.

\section{Documento de Funcionalidade dos Componentes}

\section{Nome da Interface do Componente: StudentInterface}

Conceito relacionado ao componente: student

Nome to método 1: createStudent

Ação relacionada ao método: create

Conceito relacionado ao parâmetro 1: student

Nome to método 2: deleteStudent

Ação relacionada ao método: delete

Conceito relacionado ao parâmetro 1: student

Nome to método 3: addStudentTeam

Ação relacionada ao método: add 
Conceito relacionado ao parâmetro 1: student

Conceito relacionado ao parâmetro 2: team

Nome to método 4: deleteStudentTeam

Ação relacionada ao método: delete

Conceito relacionado ao parâmetro 1: student

Conceito relacionado ao parâmetro 2 : team

Nome to método 5: listStudentTeams

Ação relacionada ao método: list

Conceito relacionado ao retorno do método: team

Conceito relacionado ao parâmetro 1 : student

\section{Nome da Interface do Componente: TeacherInterface}

Conceito relacionado ao componente: teacher

Nome to método 1: createTeacher Ação relacionada ao método: create

Conceito relacionado ao parâmetro 1: teacher

Nome to método 2: deleteTeacher

Ação relacionada ao método: delete

Conceito relacionado ao parâmetro 1: teacher

Nome to método 3: addTeacherTeam

Ação relacionada ao método: add

Conceito relacionado ao parâmetro 1: teacher

Conceito relacionado ao parâmetro 2: team

Nome to método 4: deleteTeacherTeam

Ação relacionada ao método: delete

Conceito relacionado ao parâmetro 1: teacher

Conceito relacionado ao parâmetro 2: team

Nome to método 5: listTeacherTeams

Ação relacionada ao método: list

Conceito relacionado ao retorno do método: team

Conceito relacionado ao parâmetro 1: teacher

Nome to método 6: listTeachers

Ação relacionada ao método: list

Conceito relacionado ao retorno do método: teacher

\section{Nome da Interface do Componente: MonitorInterface}

Conceito relacionado ao componente: monitor

Nome to método 1: createMonitor

Ação relacionada ao método: create

Conceito relacionado ao parâmetro 1: monitor 
Nome to método 2: deleteMonitor

Ação relacionada ao método: delete

Conceito relacionado ao parâmetro 1: monitor

Nome to método 3: addMonitorTeam

Ação relacionada ao método: add

Conceito relacionado ao parâmetro 1: monitor

Conceito relacionado ao parâmetro 2: team

Nome to método 4: deleteMonitorTeam

Ação relacionada ao método: delete

Conceito relacionado ao parâmetro 1: monitor

Conceito relacionado ao parâmetro 2: team

Nome to método 5: listMonitorTeams

Ação relacionada ao método: list

Conceito relacionado ao retorno do método: team

Conceito relacionado ao parâmetro 1: monitor

Nome to método 6: listMonitors

Ação relacionada ao método: list

Conceito relacionado ao retorno do método: monitor

\section{Nome da Interface do Componente: Candidatelnterface}

Conceito relacionado ao componente: candidate

Nome to método 1: createCandidate

Ação relacionada ao método: create

Conceito relacionado ao parâmetro 1: candidate

Nome to método 2: deleteCandidate

Ação relacionada ao método: delete

Conceito relacionado ao parâmetro 1: candidate

Nome to método 3: addCandidateCourse

Ação relacionada ao método: add

Conceito relacionado ao parâmetro 1: candidate

Conceito relacionado ao parâmetro 2: course

Nome to método 4: deleteCandidateCourse

Ação relacionada ao método: delete

Conceito relacionado ao parâmetro 1: candidate

Conceito relacionado ao parâmetro 2: course

Nome to método 5: listCandidateCourses

Ação relacionada ao método: list

Conceito relacionado ao retorno do método: course

Conceito relacionado ao parâmetro 1: candidate 


\section{Nome da Interface do Componente: AdminInterface}

Conceito relacionado ao componente: administrator

Nome to método 1: createAdmin Ação relacionada ao método: create

Conceito relacionado ao parâmetro 1: administrator

Nome to método 2: deleteAdmin

Ação relacionada ao método: delete

Conceito relacionado ao parâmetro 1: administrator

Nome to método 3: addAdminCourse

Ação relacionada ao método: add

Conceito relacionado ao parâmetro 1: administrator

Conceito relacionado ao parâmetro 2: course

Nome to método 4: deleteAdminCourse

Ação relacionada ao método: delete

Conceito relacionado ao parâmetro 1: administrator

Conceito relacionado ao parâmetro 2: course

Nome to método 5: listAdminCourses

Ação relacionada ao método: list

Conceito relacionado ao retorno do método: course

Conceito relacionado ao parâmetro 1: administrator

Nome to método 6: listAdmins

Ação relacionada ao método: list

Conceito relacionado ao retorno do método: administrator

\section{Nome da Interface do Componente: TeamInterface}

Conceito relacionado ao componente: course

Nome to método 1: createTeam

Ação relacionada ao método: create

Conceito relacionado ao parâmetro 1: team

Nome to método 2: deleteTeam

Ação relacionada ao método: delete

Conceito relacionado ao parâmetro 1: team

Nome to método 3: listTeacher

Ação relacionada ao método: list

Conceito relacionado ao retorno do método: teacher

Conceito relacionado ao parâmetro 1: team

Nome to método 4: listMonitor

Ação relacionada ao método: list

Conceito relacionado ao retorno do método: monitor

Conceito relacionado ao parâmetro 1: team

Nome to método 5: listStudents

Ação relacionada ao método: list 
Conceito relacionado ao retorno do método: student

Conceito relacionado ao parâmetro 1: team

Nome to método 6: belongsToCourse

Ação relacionada ao método: list

Conceito relacionado ao retorno do método: course

Conceito relacionado ao parâmetro 1: team

\section{Nome da Interface do Componente: Courselnterface}

Conceito relacionado ao componente: team

Nome to método 1: createCourse

Ação relacionada ao método: create

Conceito relacionado ao parâmetro 1: course

Nome to método 2: deleteCourse

Ação relacionada ao método: delete

Conceito relacionado ao parâmetro 1: course

Nome to método 3: addCourseTeam

Ação relacionada ao método: add

Conceito relacionado ao parâmetro 1: course

Conceito relacionado ao parâmetro 2: team

Nome to método 4: deleteCourseTeam

Ação relacionada ao método: delete

Conceito relacionado ao parâmetro 1: course

Conceito relacionado ao parâmetro 2: team

Nome to método 5: listCourses

Ação relacionada ao método: list

Conceito relacionado ao retorno do método: course

Nome to método 6: listTeams

Ação relacionada ao método: list

Conceito relacionado ao retorno do método: team

Conceito relacionado ao parâmetro 1: course

Nome to método 7: listCandidates

Ação relacionada ao método: list

Conceito relacionado ao retorno do método: candidate

Conceito relacionado ao parâmetro 1: course

Nome to método 8: listAdmin

Ação relacionada ao método: list

Conceito relacionado ao retorno do método: administrator

Conceito relacionado ao parâmetro 1: course 


\section{PT-2 Documento de Sentenças Imperativas}

O Documento de Sentenças Imperativas foi desenvolvido levando em consideração a funcionalidade dos componentes e os conceitos identificados nos Documentos de Funcionalidade dos Componentes (PT-1). A língua utilizada no documento é inglês, pois o dicionário e a gramática serão criados para essa língua.

Abaixo de cada sentença, foram colocados os conceitos que podem ser substituídos na sentença. Os nomes próprios (como Maria, Operating_Systems, etc) podem ser substituídos por quaisquer outros nomes próprios. O Documento de Sentenças Imperativas é apresentado a seguir. As sentenças que se encontram nele não são as únicas que podem ser utilizadas como entrada, mas um conjunto de sentenças precisa ser definido para realizar testes posteriormente. Outras sentenças, que sejam imperativas e considerem a funcionalidade dos componentes, também podem fazer parte do Documento de Sentenças Imperativas.

\section{Documento de Sentenças Imperativas}

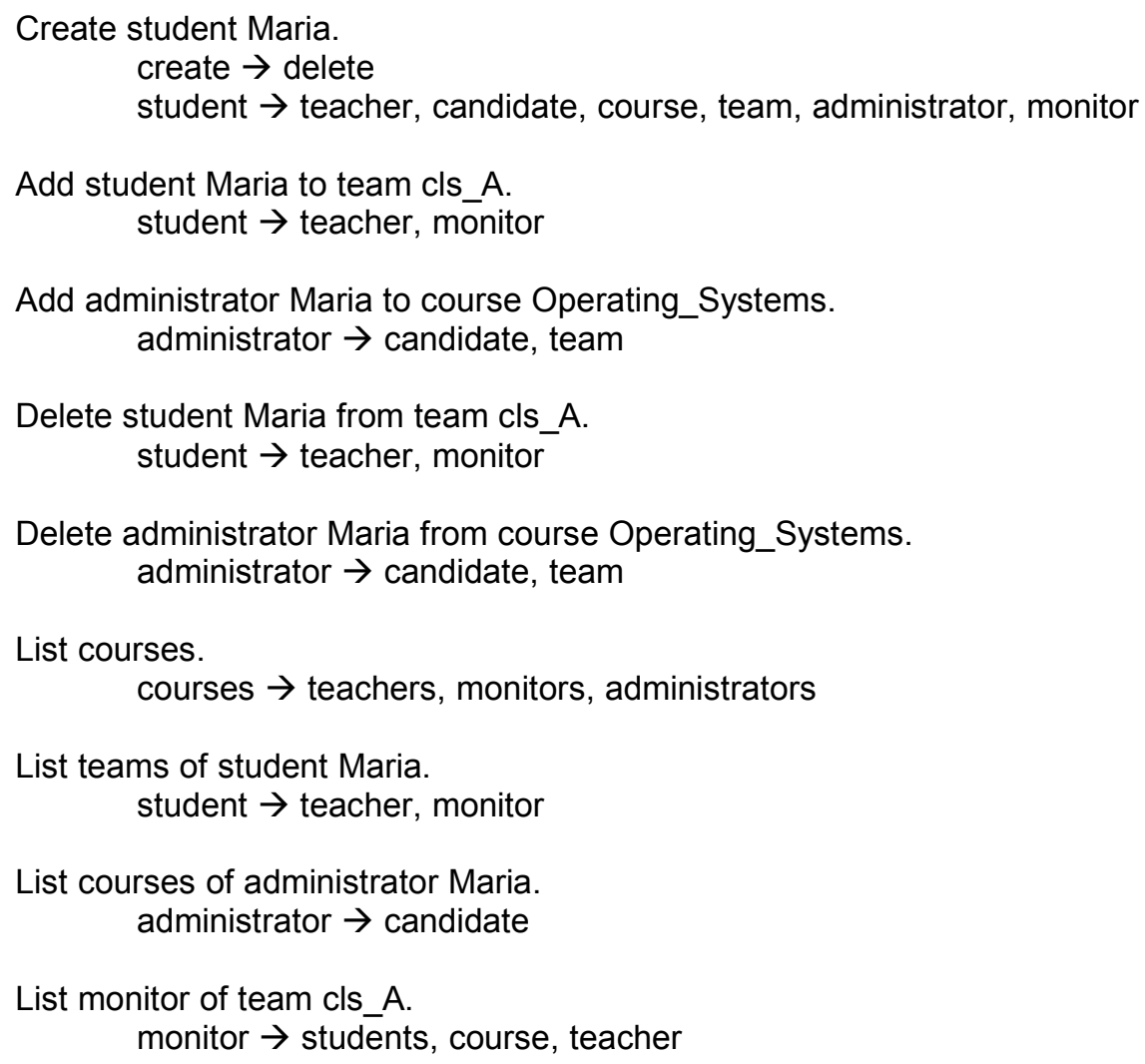


List teams of course Operating_Systems.

teams $\rightarrow$ candidates, administrator

\section{PT-3 Documento de Sinônimos}

Alguns sinônimos foram identificados para os conceitos presentes no Documento de Funcionalidade dos Componentes (PT-1). O Documento de Sinônimos está apresentado a seguir e foi desenvolvido na língua alvo (inglês).

\section{Documento de Sinônimos}

add: enter, include, insert, join

administrator: admin

candidate:

course:

create:

delete: cancel, clear, cut, erase, finish, kill, quit

list: access, check, deliver, exhibit, get, show

monitor:

student:

teacher: professor

team: class, group

\section{PT-4 Dicionário}

As entradas do Dicionário são os termos do Documento de Sinônimos (PT-3) e alguns elementos do Documento de Sentenças Imperativas (PT-2), que são necessários nas sentenças, como preposições e artigos. Além disso, os sinônimos foram substituídos pelos conceitoschave para que a saída em UNL seja sempre em função desses conceitos. O Dicionário é um arquivo texto e seu conteúdo é apresentado a seguir.

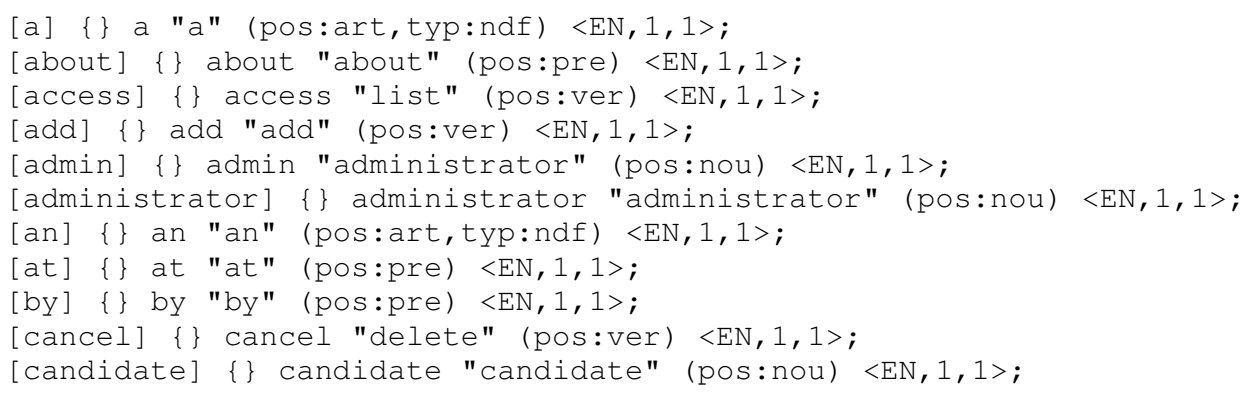




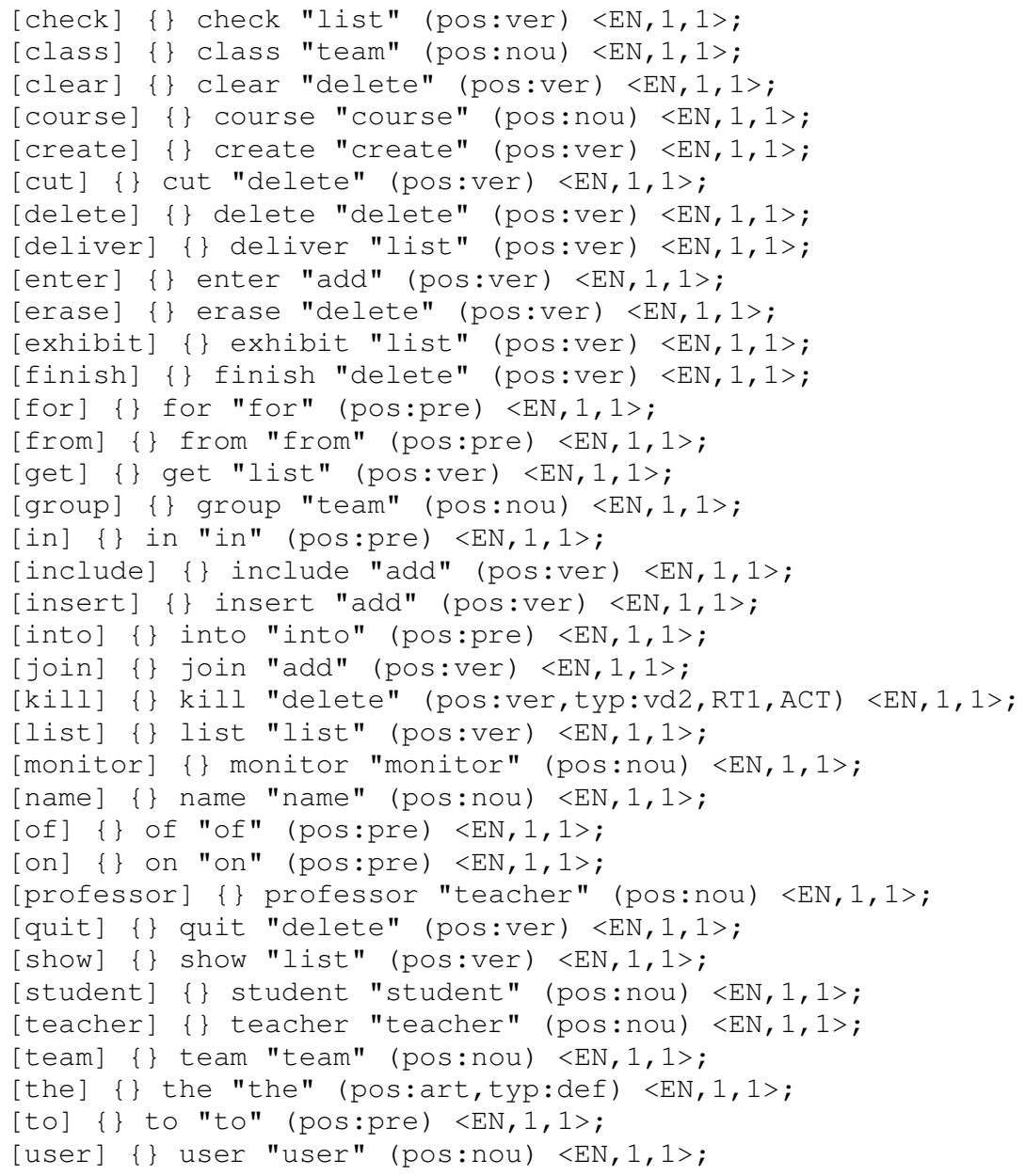

\section{PT-5 Gramática}

A gramática foi produzida considerando as estruturas gramaticais identificadas no Documento de Sentenças Imperativas (PT-2). Assim como o dicionário, a gramática é um arquivo texto e está apresentada a seguir, juntamente com exemplos de sentenças válidas para cada estrutura (ou regra) gramatical.

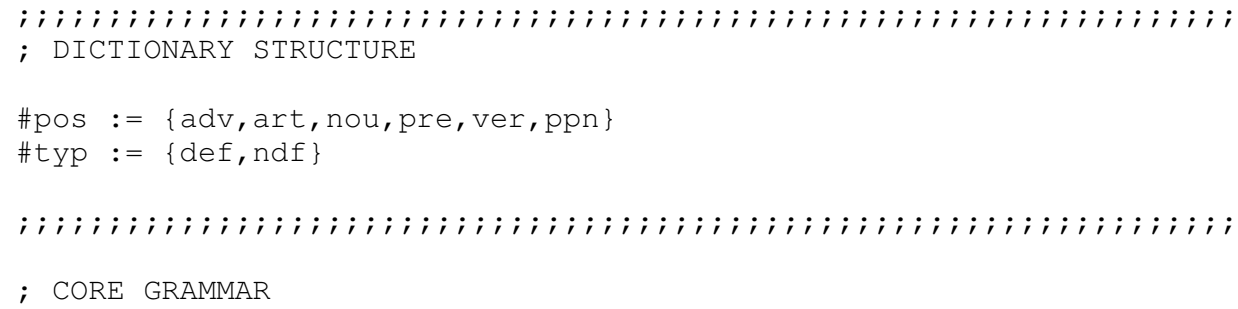


; GRAMMAR STRUCTURE:

; 0. TEXT LEVEL

; 1. SENTENCE LEVEL

; 2. PHRASE LEVEL

; 3. WORD LEVEL

i;i;i;i;i;i;i;i;i;i;i;i;i;i;i;i;i;i;i;i;i;i;i;i;i;i;i;i;i;i;i;i;

; 0. TEXT LEVEL

PHRASE $[1]:=S$

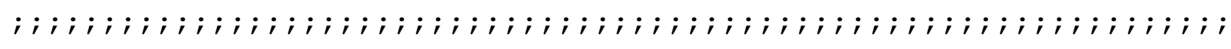

; 1. SENTENCE LEVEL

$\mathrm{S}[1]:=\mathrm{IMP}$

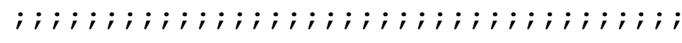

; 2. PHRASE LEVEL

; 2.1. IMPERATIVAS

; Ex: Create student Flavia_Linhalis.

$\operatorname{IMP}[1]:=\mathrm{VER}$. dentry $+\mathrm{NOU}+\mathrm{NOU}->$ obj $(: 01,: 02), \operatorname{nam}(: 02,: 03)$

; Ex1: Add student Flavia_Linhalis to team cls_A.

; Ex2: Add administrator Flavia_Linhalis to course Operating_Systems.

; Ex3: Delete student Flavia_Linhalis from team cls_A.

; Ex4: Delete administrator Flavia_Linhalis from course Operating_Systems.

$\mathrm{IMP}[2]:=\mathrm{VER}$. dentry + NOU + NOU + PRE + NOU + NOU -> obj (:01,:02), nam(:02,:03), $\operatorname{nam}(: 05,: 06), \operatorname{gol}(: 01,: 05)$

; Ex: List courses.

$\operatorname{IMP}[3]:=$ VER. dentry + NOU $->: 02 . @ p l$, obj $(: 01,: 02)$

; Ex1: List teams of student Flavia_Linhalis

; Ex2: List courses of administrator Flavia_Linhalis

$\operatorname{IMP}[4]:=$ VER. dentry + NOU + PRE + NOU + NOU -> :02. (apl, obj (:01,:02), nam(:04,:05), gol $(: 01,: 04)$

; Ex: List monitor of team Cls_A

IMP [5] $:=$ VER. dentry + NOU + PRE + NOU + NOU $->$ obj(:01,:02), nam(:04,:05), gol (:01,:04)

; 3. WORD LEVEL

; 3.1. VERB

$\operatorname{VER}[1]:=$ ver. dentry

; 3.2. NOUN

NOU [1] := nou. dentry - 'es' $->: 01$. apl

NOU [2] := nou. @entry $-' s^{\prime}->: 01$. @pl

NOU [3] := nou.dentry 
Apêndice D - Produtos de Trabalho (PT) da Instanciação do Processo

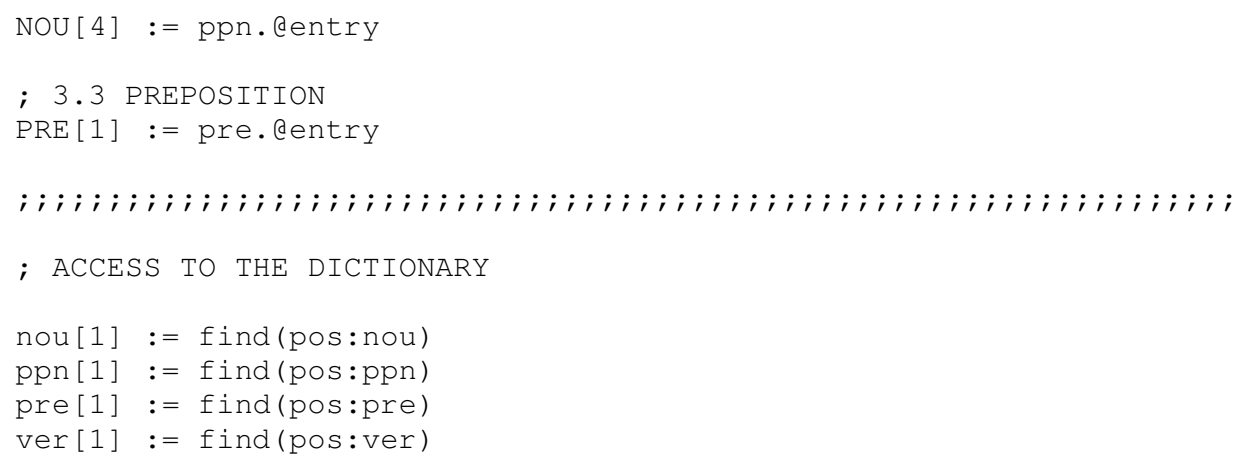

\section{PT-6 Documento de Sentenças UNL}

Para desenvolver o Documento de Sentenças UNL, apresentado a seguir, um exemplo de sentença de cada estrutura gramatical foi convertida em UNL pelo Hermeto e acrescentada no documento.

\section{Documento de Sentenças UNL}

Create student Maria.

obj(create,student)

nam(student,maria)

Add administrator Maria to course Operating_Systems.

obj(add,administrator)

nam(administrator,maria)

nam(course,operating_systems)

gol(add,course)

List courses.

obj(list,course.@pl) 
List teams of student Maria.

obj(list,team.@pl)

nam(student,maria)

gol(list,student)

List monitor of team cls_A.

obj(list,monitor)

nam(team,cls_a)

gol(list,team)

\section{PT-7 Arquivos lexico.mac e revgram.dll}

Os passos necessários para geração dos arquivos com a gramática o dicionário encapsulados (revgram.dll e léxico.mac, respectivamente) foram seguidos, conforme especificado na Tabela 6.8, e os arquivos foram gerados corretamente. Depois disso, foram copiados para o diretório de instalação do Protégé.

\section{PT-8 Documento de Mapeamento Semântico}

Para fazer o Documento de Mapeamento Semântico, cada relação do Documento de Sentenças UNL (PT-6) foi considerada. Conforme apresentado a seguir, cada UW (conceito) foi relacionada com informações sobre componentes, identificadas no Documento de Funcionalidade dos Componentes (PT-1).

\section{Documento de Mapeamento Semântico}

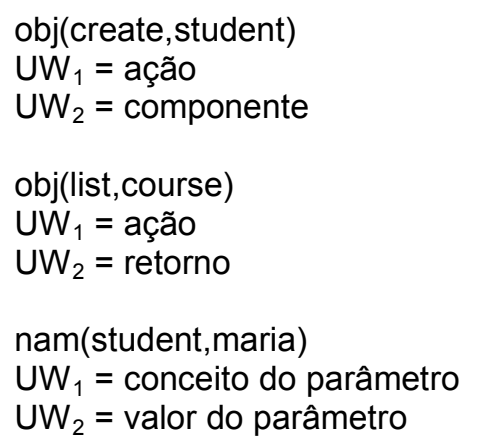


Apêndice D - Produtos de Trabalho (PT) da Instanciação do Processo

gol(add,course)

$\mathrm{UW}_{1}=$ ação

$\mathrm{UW}_{2}=$ componente (secundário)

\section{PT-9 Arquivo de Regras (rules.clp)}

As regras a seguir foram criadas em JESS e são similares às regras apresentadas na Figura 5.8. Depois de testadas na JESSTab, as regras foram armazenadas em um arquivo texto chamado "rules.clp" e copiadas para o diretório de instalação do Protégé.

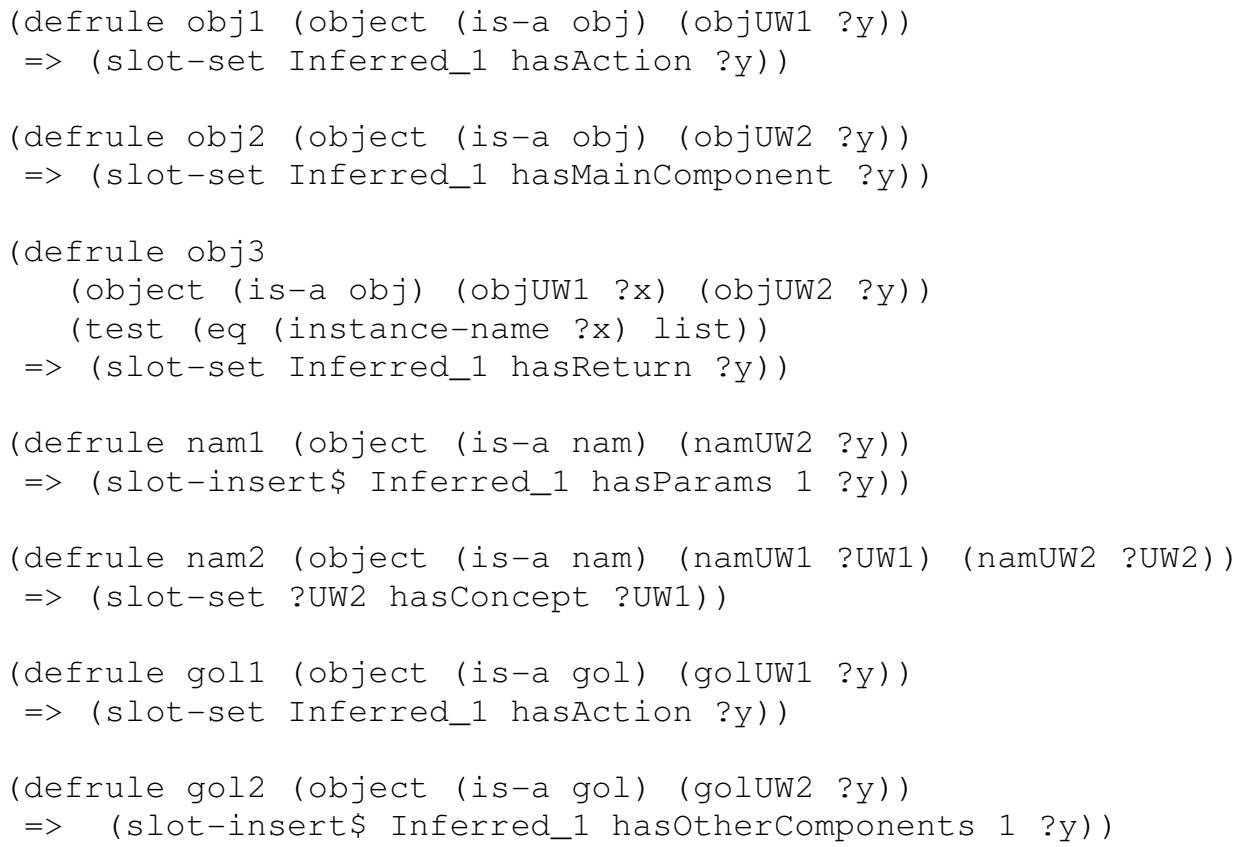

\section{PT-10 Ontologia de Domínio}

A Ontologia de Domínio está representada pelo diagrama de classes da Figura E.1 e o código OWL dessa ontologia se encontra no Apêndice E. Para criar essa ontologia, todos os conceitos identificados no Documento de Funcionalidade dos Componentes (PT-1) foram considerados (Monitor, Student, Teacher, Candidate, Administrator, Team e Course). A classe User também foi criada, pois diversos conceitos presentes na ontologia possuem características em comum que podem ser herdadas dessa classe. 
É importante lembrar que, como os componentes foram desenvolvidos especialmente para a Arquitetura OntoMap, eles acessam e modificam as instâncias da Ontologia de Domínio por meio da API do Protégé. Portanto, as instâncias da ontologia estão sendo usadas como base de dados e os métodos que são executados pelo Carregador de Componentes podem acessar e modificar as instâncias.

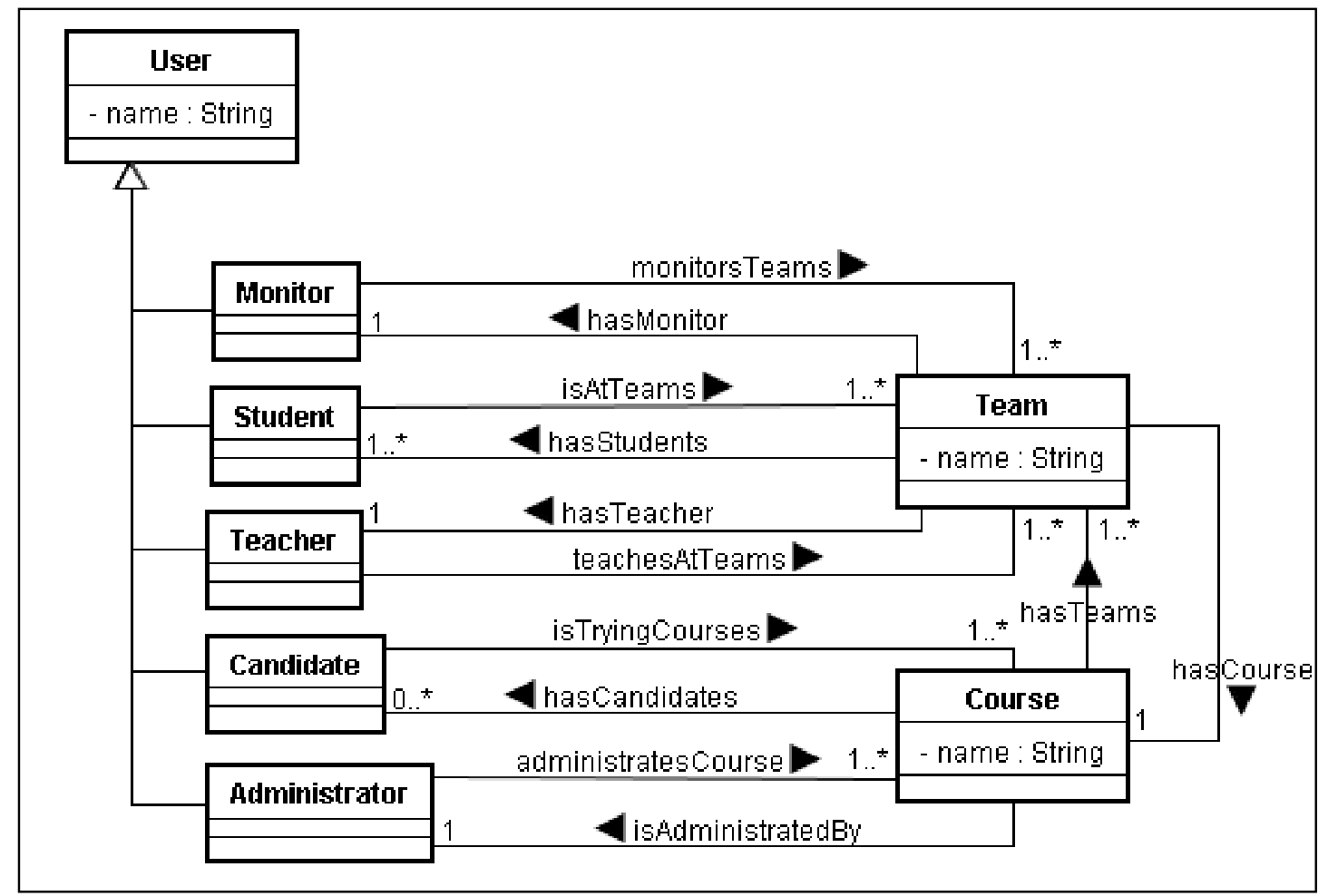

Figura E. 1 - Ontologia de Domínio.

\section{PT-11 Ontologia de Componentes Instanciada}

A Ontologia de Componentes (Figura 5.10) foi instanciada e o código OWL de suas classes, juntamente com as instâncias, se encontra no Apêndice F. As instâncias da classe Action são as ações relacionadas aos métodos dos componentes, identificadas no Documento de Funcionalidade dos Componentes (PT-1). A classe DomainConcept é o "ponto de encontro" da Ontologia de Componentes com a Ontologia de Domínio, que foi desenvolvida diretamente sob a classe DomainConcept. As instâncias das demais classes foram criadas de acordo com a 
interface dos componentes (Apêndice C). O único slot preenchido com um dado que não se encontra na interface dos componentes é o slot da localização do componente, onde é preciso informar o caminho, juntamente com o nome do componente implementado.

\section{PT-12 Relatório de Testes}

Para realizar os testes, a classe Revgram.class foi executada. Cada sentença do Documento de Sentenças Imperativa (PT-2) e suas variações foram testadas. A importância de testar todas as variações das sentenças foi evidenciada com a requisição número 39 do Relatório de Testes apresentado a seguir.

\section{Relatório de Testes}

\begin{tabular}{|l|l|l|l|}
\hline & \multicolumn{1}{|c|}{ Requisição } & Método encontrado & \multicolumn{1}{c|}{ Observações } \\
\hline 1 & Create student Maria. & createStudent & Método satisfaz à requisição. \\
\hline 2 & Delete student Maria. & deleteStudent & Método satisfaz à requisição. \\
\hline 3 & Create teacher Maria. & createTeacher & Método satisfaz à requisição. \\
\hline 4 & Delete teacher Maria. & deleteTeacher & Método satisfaz à requisição. \\
\hline 5 & Create candidate Maria. & createCandidate & Método satisfaz à requisição. \\
\hline 6 & Delete candidate Maria. & deleteCandidate & Método satisfaz à requisição. \\
\hline 7 & Create admin Maria. & createAdmin & Método satisfaz à requisição. \\
\hline 8 & Delete admin Maria. & deleteAdmin & Método satisfaz à requisição. \\
\hline 9 & Create monitor Maria. & createMonitor & Método satisfaz à requisição. \\
\hline 10 & Delete monitor Maria. & deleteMonitor & Método satisfaz à requisição. \\
\hline 11 & Create course Java. & createCourse & Método satisfaz à requisição. \\
\hline 12 & Delete course Java & deleteCourse & Método satisfaz à requisição. \\
\hline 13 & Create class cls_A. & createTeam & Método satisfaz à requisição. \\
\hline 14 & Delete team cls_A. & deleteTeam & Método satisfaz à requisição. \\
\hline 15 & Add student Maria to class cls_A. & addStudentTeam & Método satisfaz à requisição. \\
\hline 16 & Delete student Maria from class & deleteStudentTeam & Método satisfaz à requisição. \\
\hline 17 & Ads_A. teacher Maria to class cls_A. & addTeacherTeam & Método satisfaz à requisição. \\
\hline 18 & $\begin{array}{l}\text { Delete teacher Maria from class } \\
\text { cls_A. }\end{array}$ & deleteTeacherTeam & Método satisfaz à requisição. \\
\hline 19 & Add monitor Maria to class cls_A. & addMonitorTeam & Método satisfaz à requisição. \\
\hline & & & \\
\hline
\end{tabular}


Apêndice D - Produtos de Trabalho (PT) da Instanciação do Processo

\begin{tabular}{|c|c|c|c|}
\hline 20 & $\begin{array}{l}\text { Delete monitor Maria from class } \\
\text { cls_A. }\end{array}$ & deleteMonitorTeam & Método satisfaz à requisição. \\
\hline 21 & Add admin Maria to course Java. & addAdminCourse & Método satisfaz à requisição. \\
\hline 22 & Delete admin Maria from course Java. & deleteAdminCourse & Método satisfaz à requisição. \\
\hline 23 & Add candidate Maria to course Java. & addCandidateCourse & Método satisfaz à requisição. \\
\hline 24 & $\begin{array}{l}\text { Delete candidate Maria from course } \\
\text { Java. }\end{array}$ & deleteCandidateCourse & Método satisfaz à requisição. \\
\hline 25 & Add team cls_A to course Java. & addCourseTeam & Método satisfaz à requisição. \\
\hline 26 & Delete team cls_A from course Java. & deleteCourseTeam & Método satisfaz à requisição. \\
\hline 27 & List courses. & listCourses & Método satisfaz à requisição. \\
\hline 28 & List teachers. & listTeachers & Método satisfaz à requisição. \\
\hline 29 & List monitors. & listMonitors & Método satisfaz à requisição. \\
\hline 30 & List administrators. & listAdmins & Método satisfaz à requisição. \\
\hline 31 & List teams of student Maria. & listStudentTeams & Método satisfaz à requisição. \\
\hline 32 & List teams of teacher Maria. & listTeacherTeams & Método satisfaz à requisição. \\
\hline 33 & List teams of monitor Maria. & listMonitorTeams & Método satisfaz à requisição. \\
\hline 34 & List courses of candidate Maria. & listCandidateCourses & Método satisfaz à requisição. \\
\hline 35 & List courses of admin Maria. & listAdminCourses & Método satisfaz à requisição. \\
\hline 36 & List teacher of team cls_A & listTeacher & Método satisfaz à requisição. \\
\hline 37 & List monitor of team cls_A. & listMonitor & Método satisfaz à requisição. \\
\hline 38 & List students of team cls_A. & listStudents & Método satisfaz à requisição. \\
\hline 39 & List course of team cls_A. & belongsToCourse & $\begin{array}{l}\text { Inicialmente, o Módulo de } \\
\text { Busca não havia encontrado } \\
\text { esse método. Motivo: o } \\
\text { conceito relacionado ao } \\
\text { retorno do método não havia } \\
\text { sido colocado na Ontologia } \\
\text { de Componentes. Depois que } \\
\text { o problema foi resolvido, o } \\
\text { método foi encontrado. }\end{array}$ \\
\hline 40 & List teams of course Java. & listTeams & Método satisfaz à requisição. \\
\hline 41 & List candidates of course Java. & listCandidates & Método satisfaz à requisição. \\
\hline 42 & List admin of course Java. & listAdmin & Método satisfaz à requisição. \\
\hline
\end{tabular}

Observações sobre os testes:

O Relatório de Testes mostra que as sentenças definidas do Documento de Sentenças Imperativas (PT-2) ativam todos os métodos das interfaces dos componentes. Foi testada 
apenas uma sentença por método, mas o Documento de Sentenças Imperativas poderia ser maior, o que resultaria em mais sentenças a serem avaliadas.

O bom resultado dos testes se deve ao fato dos componentes e seus métodos serem simples, desenvolvidos especificamente para a Arquitetura OntoMap. Isto é, cada componente, parâmetro ou retorno de método pode ser associado a um único conceito da Ontologia de Domínio. Por exemplo, para um método como updateStudent (String studentName, String whatToUpdate, String to), ○ Módulo de Busca não trabalharia bem, pois os parâmetros whatToUpdate e To podem estar associados a vários conceitos, como o nome do estudante, a turma do estudante, etc. Uma maneira de resolver esse problema é possibilitar que os dados das interfaces sejam associados a mais de um conceito da Ontologia de Domínio (slot isRelatedToConcept) e estender o Módulo de Busca para considerar vários conceitos (associados ao mesmo dado de interface) na sua busca. Além disso, os componentes não possuem certas características não contempladas pelo Módulo de Busca, tais como parâmetros opcionais ou parâmetros que passam coleções de valores. Pode-se dizer que esses fatores contribuíram para que a instanciação do processo fosse realizada sem problemas, o está sendo confirmado pelos testes. 


\section{APÊNDICE

\begin{tabular}{r|r}
\hline Código OWL da Ontologia de \\
Domínio (PT-10)
\end{tabular}

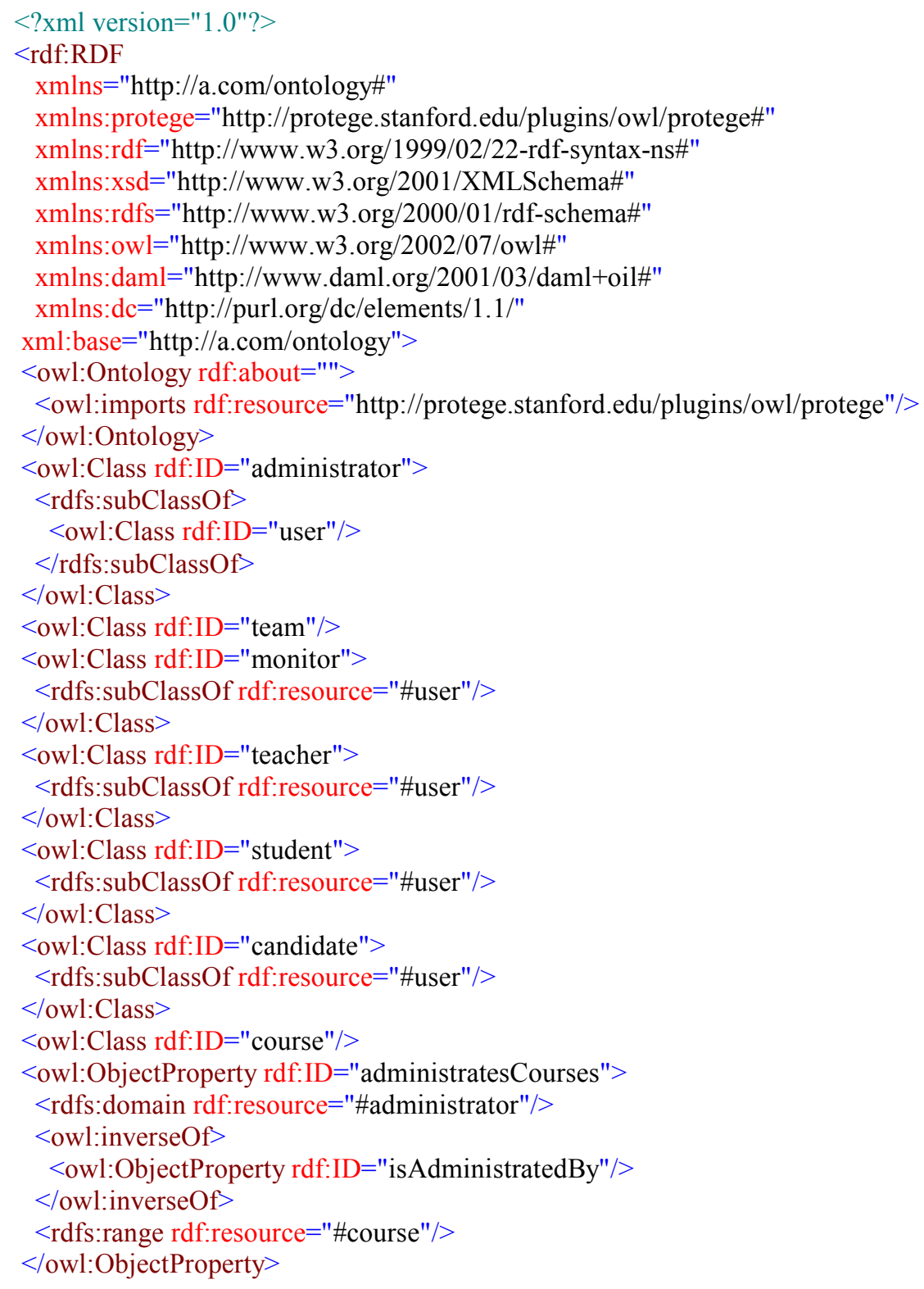




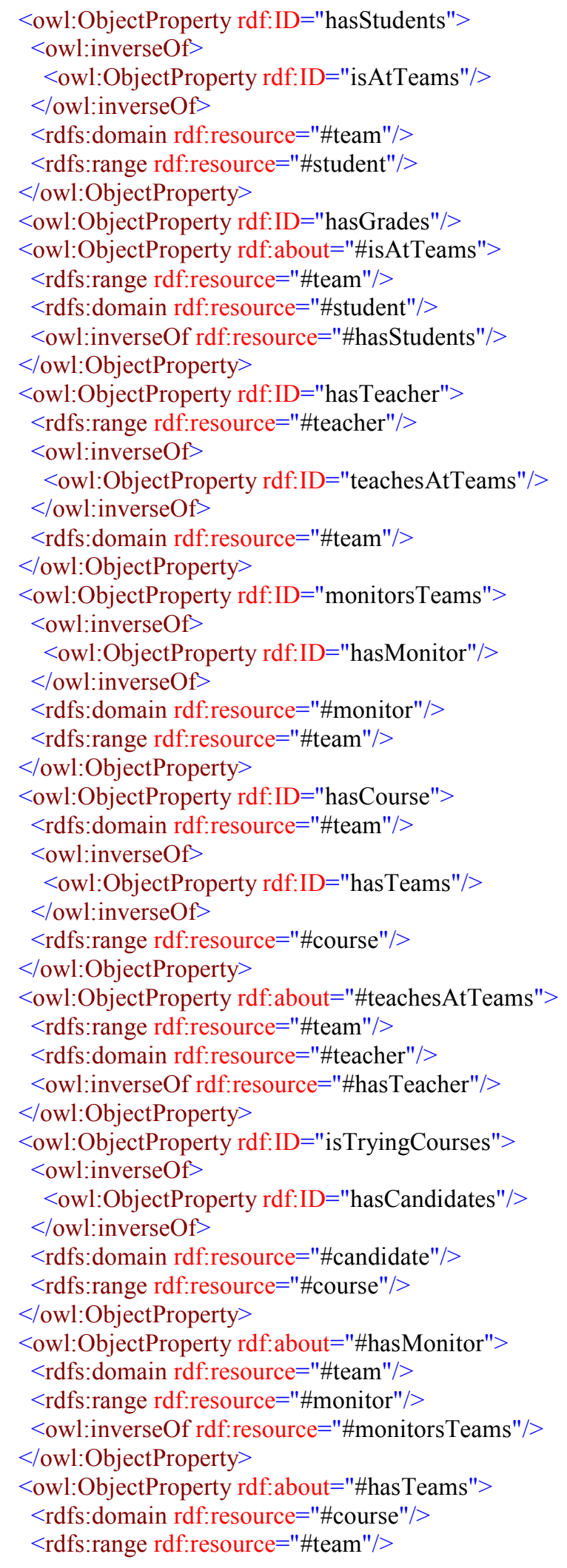




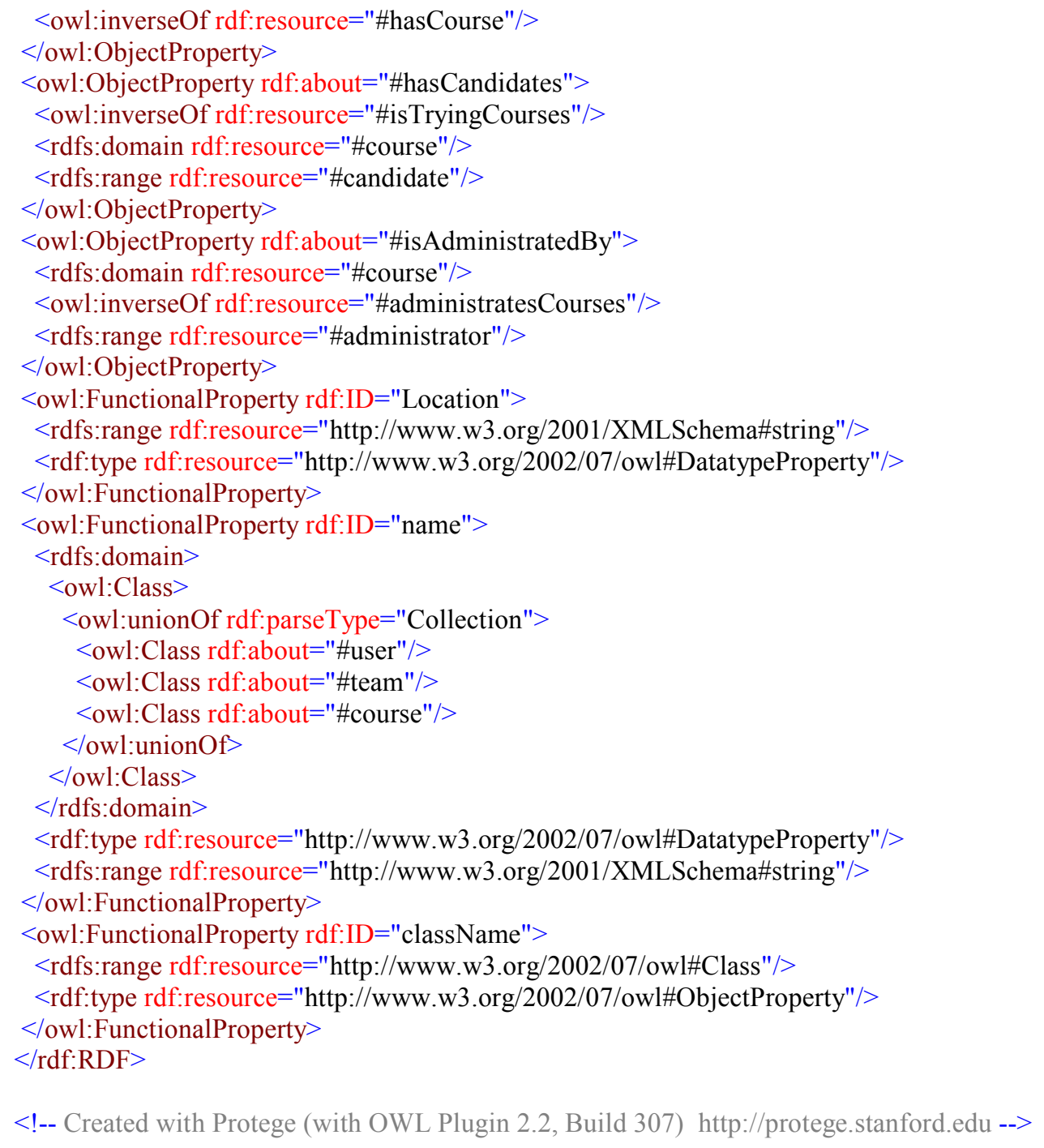




\begin{tabular}{|c|r}
\hline APÊNDICE & \\
\hline \hline & $\begin{array}{r}\text { Código OWL da Ontologia de } \\
\text { Componentes Instanciada e } \\
\text { Relacionada com a Ontologia de } \\
\text { Domínio (PT-11) }\end{array}$
\end{tabular}

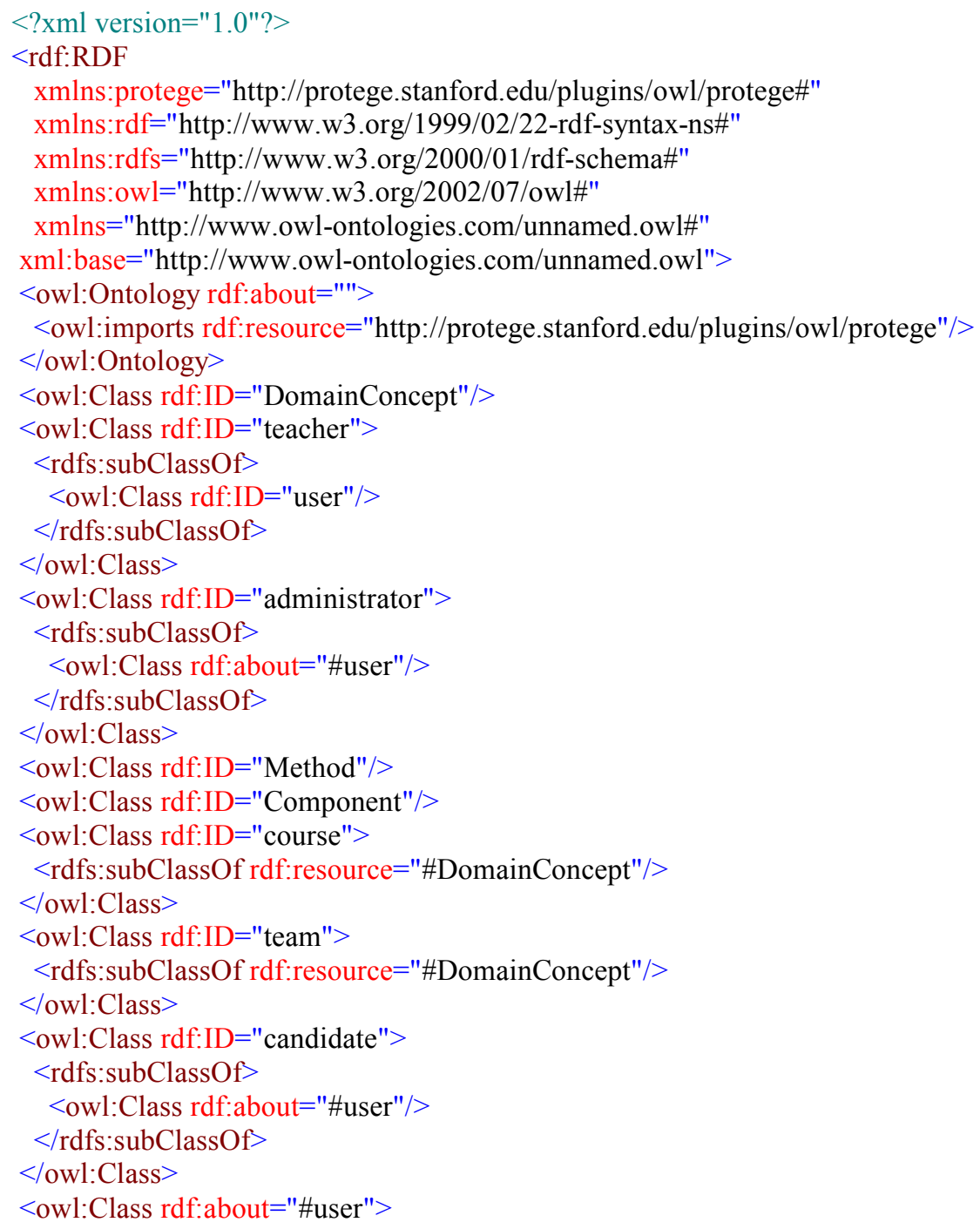




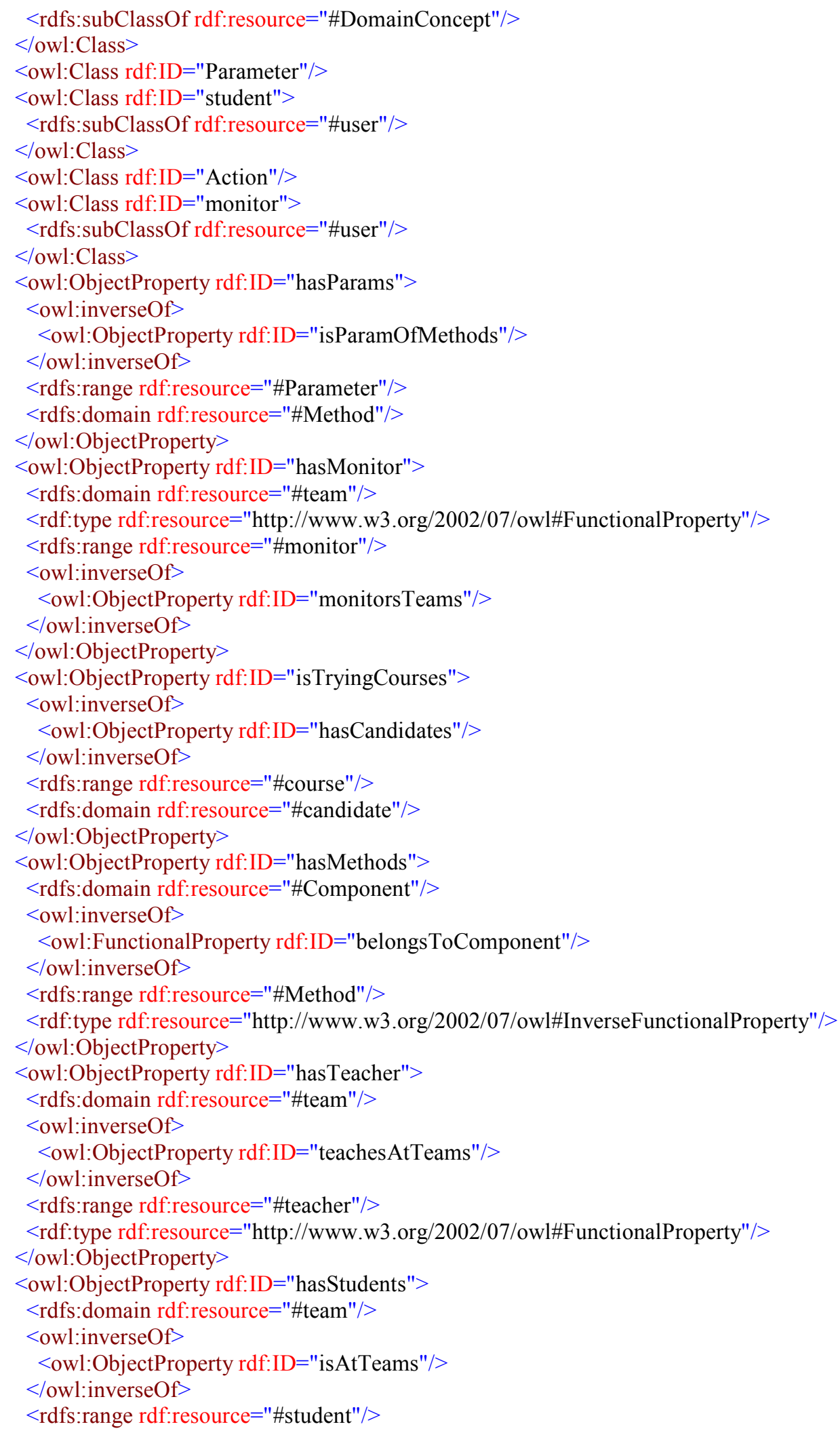




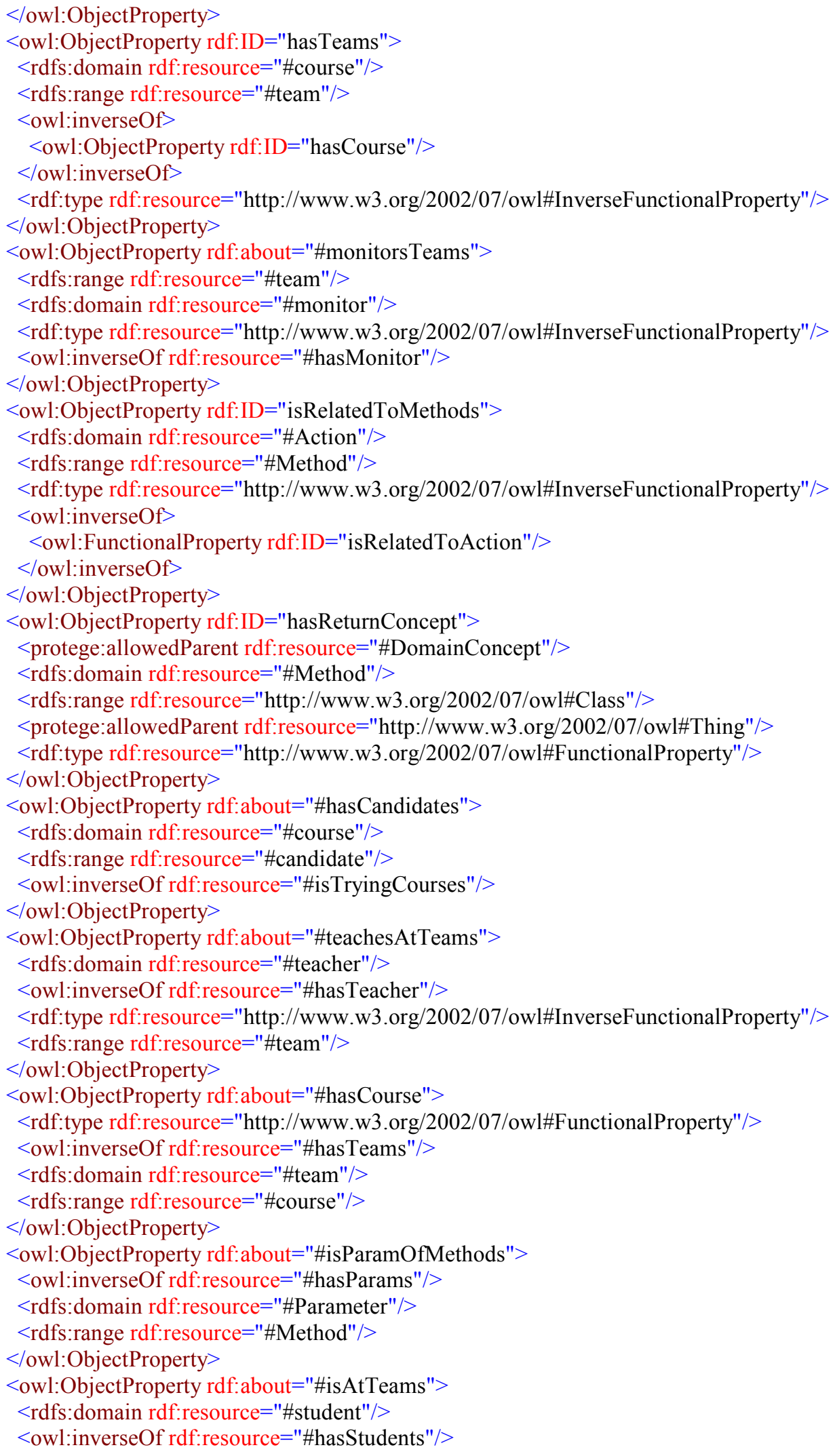


Apêndice F - Código OWL da Ontologia de Componentes Instanciada e Relacionada com a Ontologia de Domínio (PT-11)

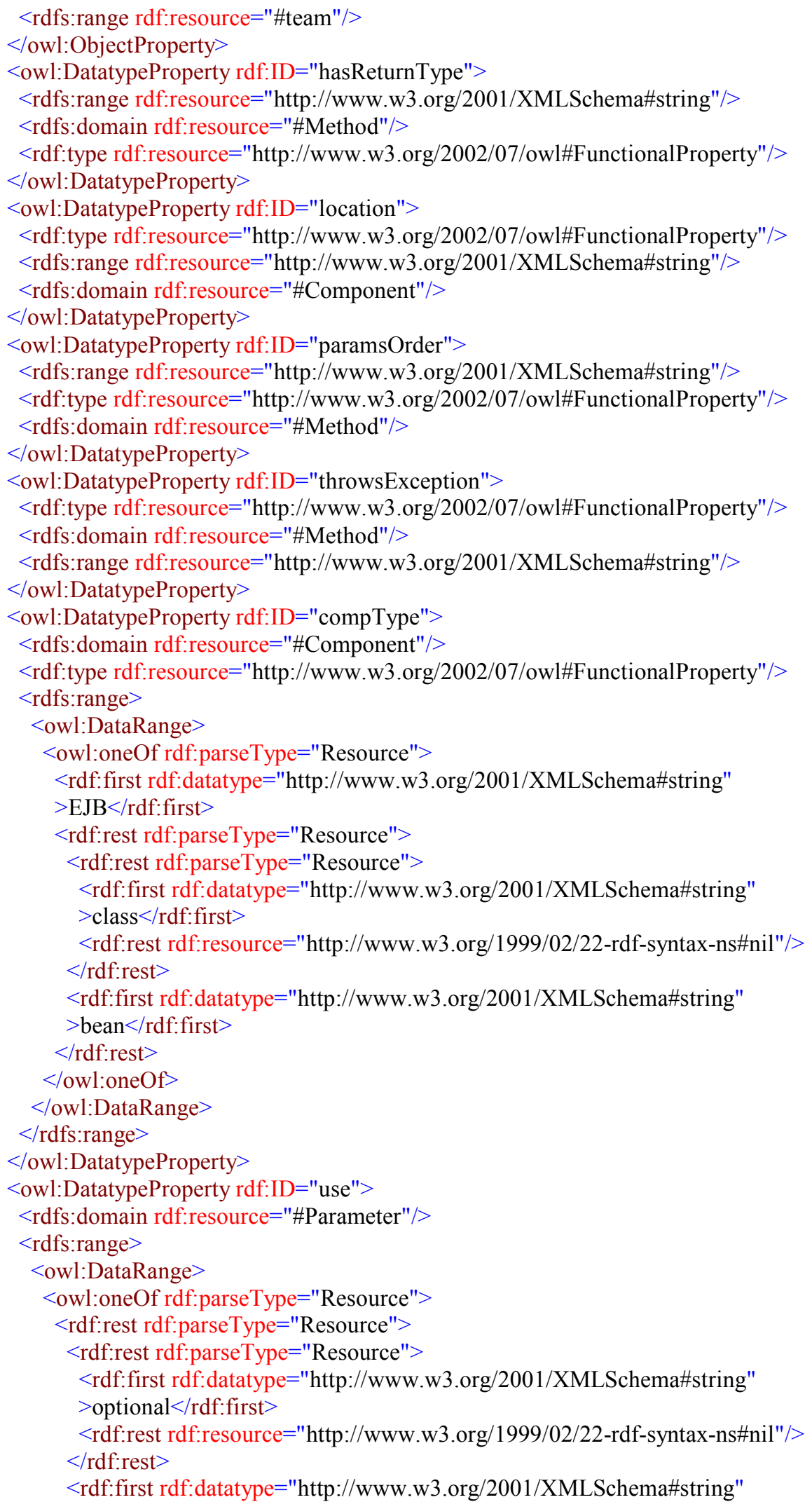




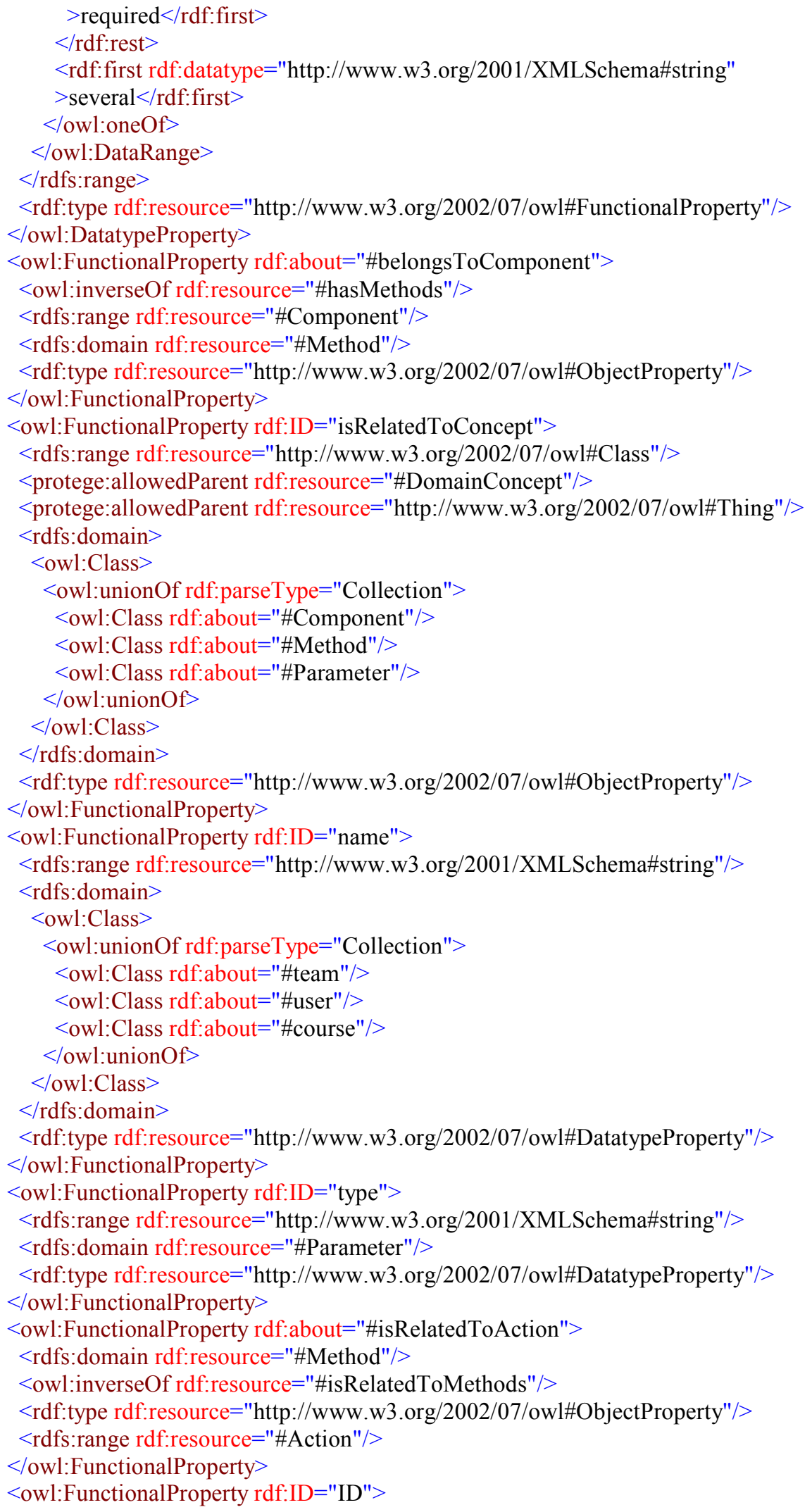


Apêndice F - Código OWL da Ontologia de Componentes Instanciada e Relacionada com a Ontologia de Domínio (PT-11)

$<$ rdfs:domain rdf:resource="\#Parameter"/>

$<$ rdfs:range rdf:resource="http://www.w3.org/2001/XMLSchema\#int"/>

<rdf:type rdf:resource="http://www.w3.org/2002/07/owl\#DatatypeProperty"/>

$</$ owl:FunctionalProperty $>$

$<$ owl:FunctionalProperty rdf:ID="isAdministratedBy" $>$

$<$ rdfs:domain rdf:resource $=" \#$ course" $/>$

$<$ rdfs:range rdf:resource="\#administrator"/>

$<$ owl:inverseOf>

$<$ owl:InverseFunctionalProperty rdf:ID="administratesCourses"/>

$</$ owl:inverseOf $>$

$<$ rdf:type rdf:resource="http://www.w3.org/2002/07/owl\#ObjectProperty"/>

$<$ owl:FunctionalProperty $>$

$<$ owl:InverseFunctionalProperty rdf:about="\#administratesCourses">

$<$ owl:inverseOf rdf:resource="\#isAdministratedBy"/>

$<$ rdfs:range rdf:resource="\#course"/>

$<$ rdfs:domain rdf:resource $=$ "\#administrator"/>

$<$ rdf:type rdf:resource="http://www.w3.org/2002/07/owl\#ObjectProperty"/>

$</$ owl:InverseFunctionalProperty $>$

$<$ Method rdf:ID="deleteAdmin" $>$

$<$ isRelatedToAction>

$<$ Action rdf:ID="delete" $>$

$<$ isRelatedToMethods $>$

$<$ Method rdf:ID="deleteMonitorTeam" $>$

$<$ isRelatedToAction rdf:resource $=" \#$ delete"/>

$<$ hasParams $>$

$<$ Parameter rdf:ID="monitorName" $>$

$<$ isParamOfMethods $>$

$<$ Method rdf:ID="addMonitorTeam" $>$

$<$ belongsToComponent $>$

$<$ Component rdf:ID="MonitorComponent" $>$

$<$ hasMethods rdf:resource="\#deleteMonitorTeam"/>

$<$ hasMethods rdf:resource="\#addMonitorTeam"/ $>$

$<$ hasMethods $>$

$<$ Method rdf:ID="listMonitorTeams" $>$

$<$ isRelatedToAction $>$

$<$ Action rdf:ID="list" $>$

$<$ isRelatedToMethods $>$

$<$ Method rdf:ID="listTeachers" $>$

$<$ hasReturnConcept rdf:resource="\#teacher"/>

$<$ hasReturnType rdf:datatype $=$

"http://www.w3.org/2001/XMLSchema\#string"

$>$ java.util.Vector $<$ /hasReturnType $>$

$<$ isRelatedToAction rdf:resource="\#list"/>

$<$ belongsToComponent $>$

$<$ Component rdf:ID="TeacherComponent" $>$

$<$ hasMethods $>$

$<$ Method rdf:ID="createTeacher" $>$

$<$ belongsToComponent rdf:resource="\#TeacherComponent" $/>$

$<$ isRelatedToConcept rdf:resource="\#teacher"/>

$<$ isRelatedToAction $>$

$<$ Action rdf:ID="create" $>$

$<$ isRelatedToMethods rdf:resource="\#createTeacher"/>

$<$ isRelatedToMethods $>$

$<$ Method rdf:ID="createTeam" $>$

$<$ isRelatedToConcept rdf:resource="\#team"/> 


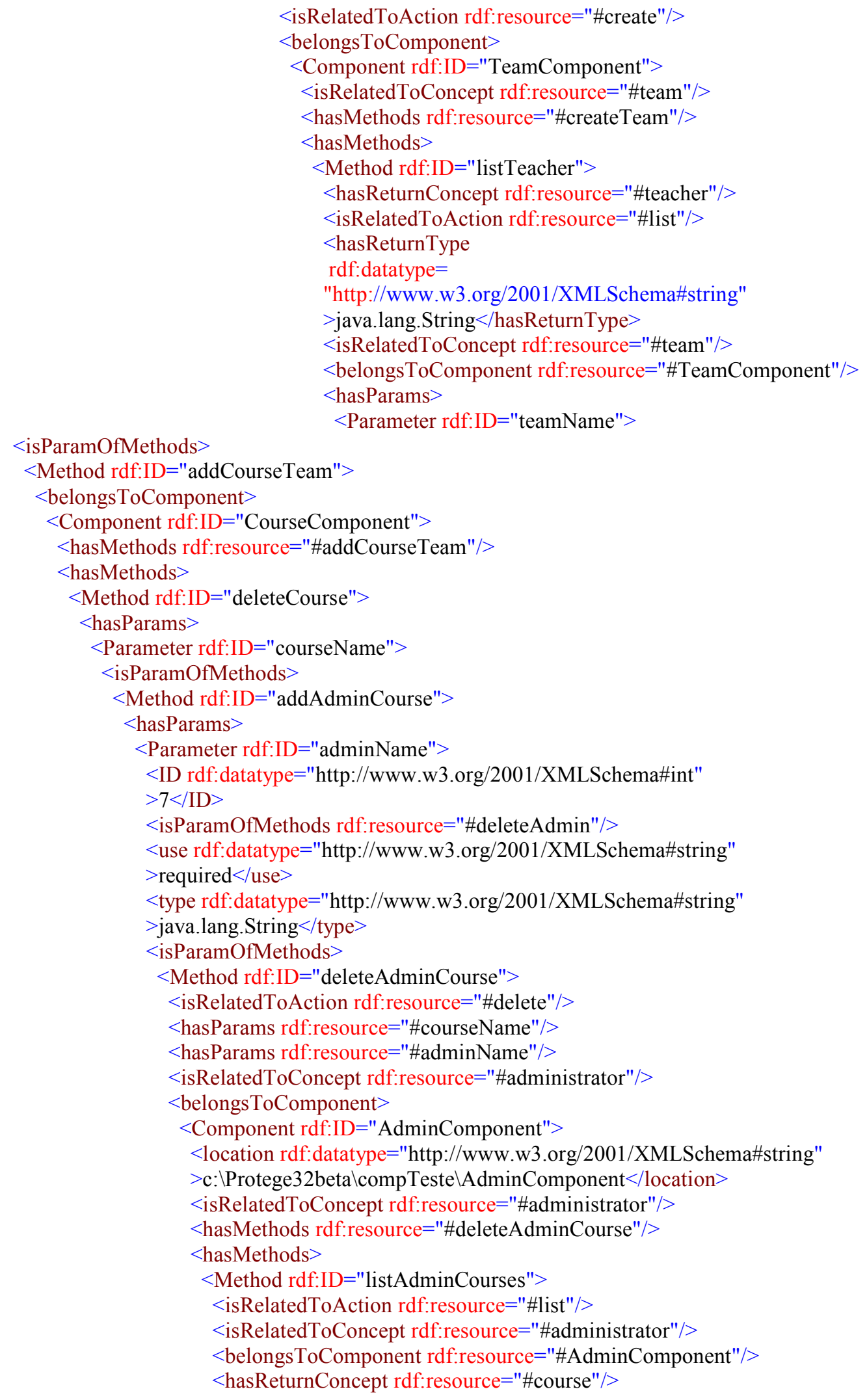


Apêndice F - Código OWL da Ontologia de Componentes Instanciada e Relacionada com a Ontologia de Domínio (PT-11)

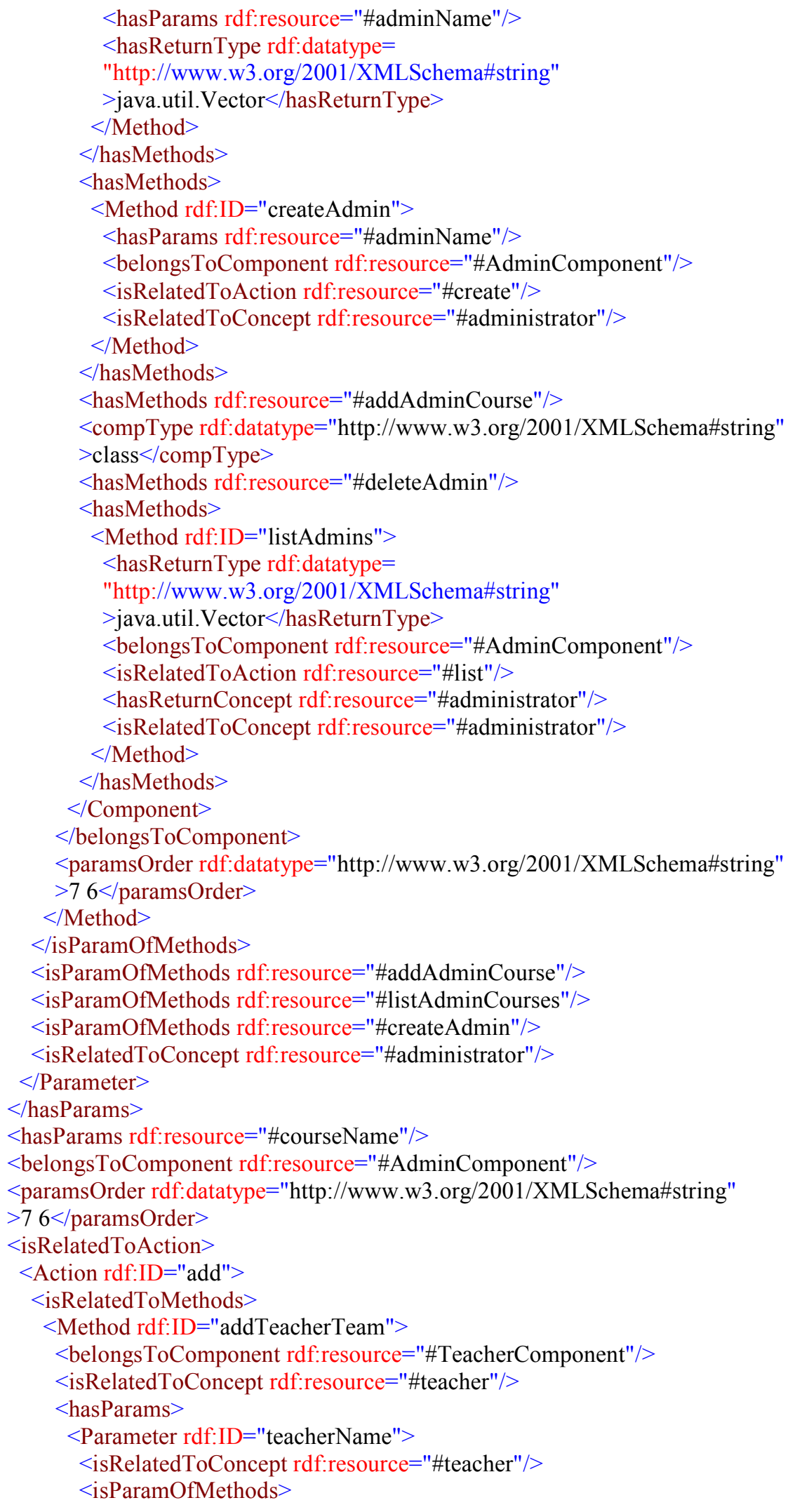




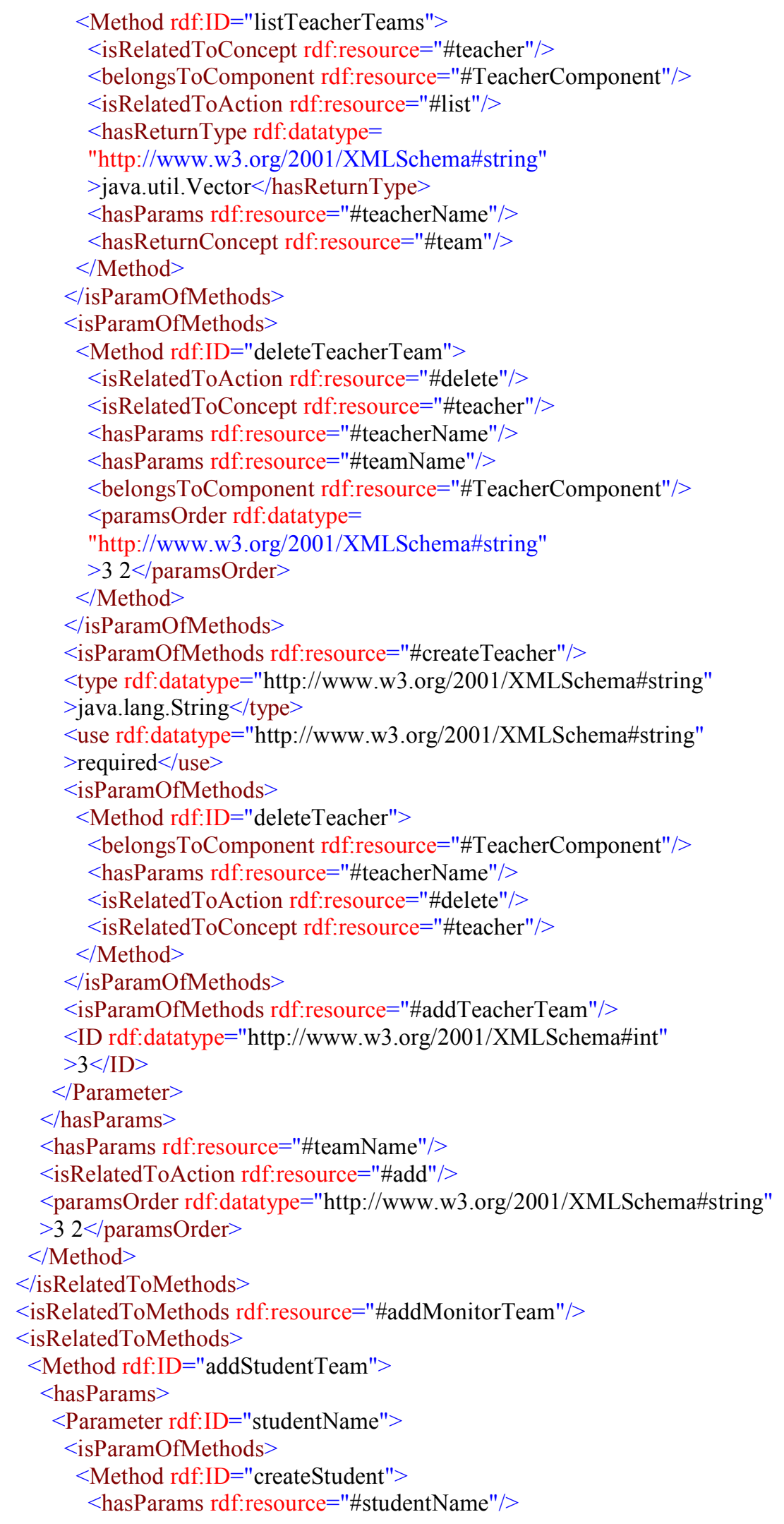




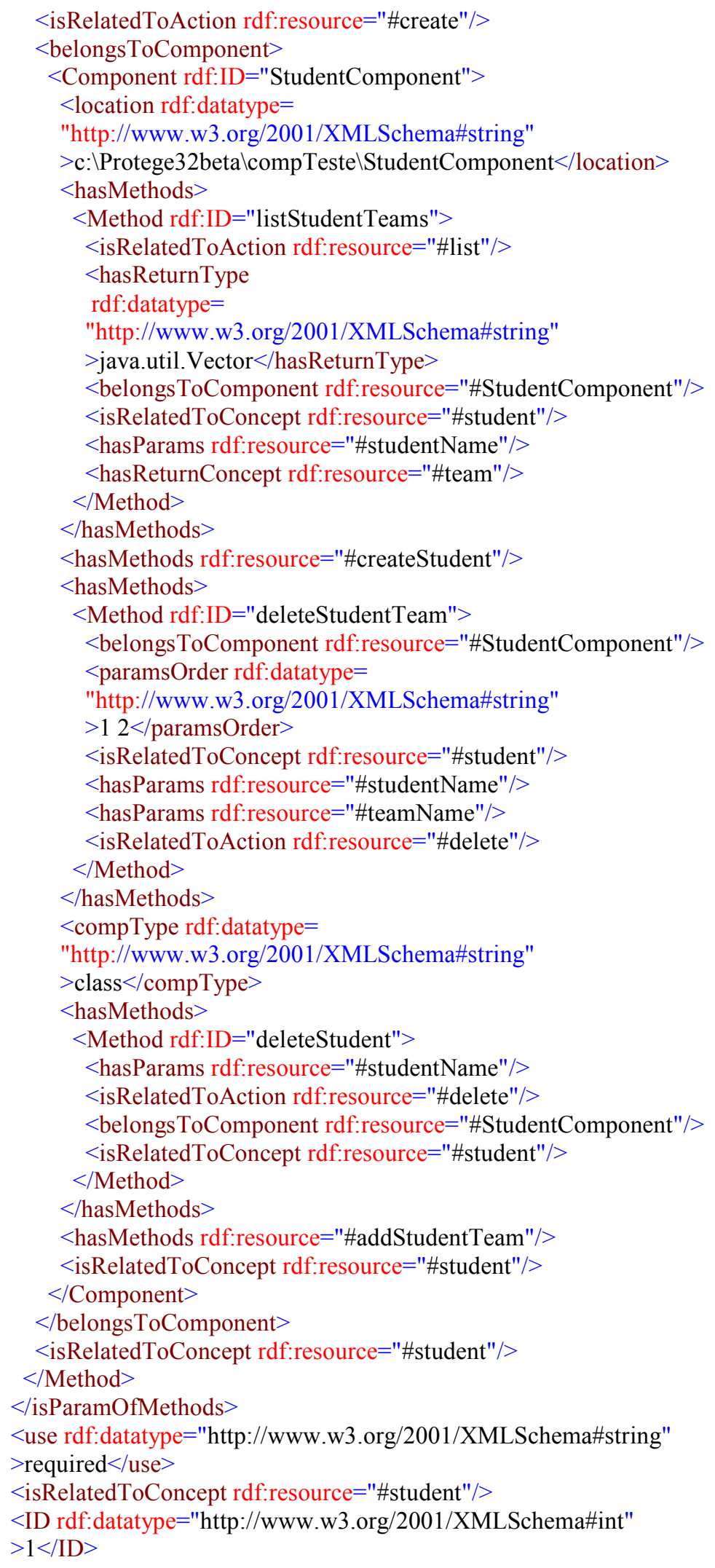




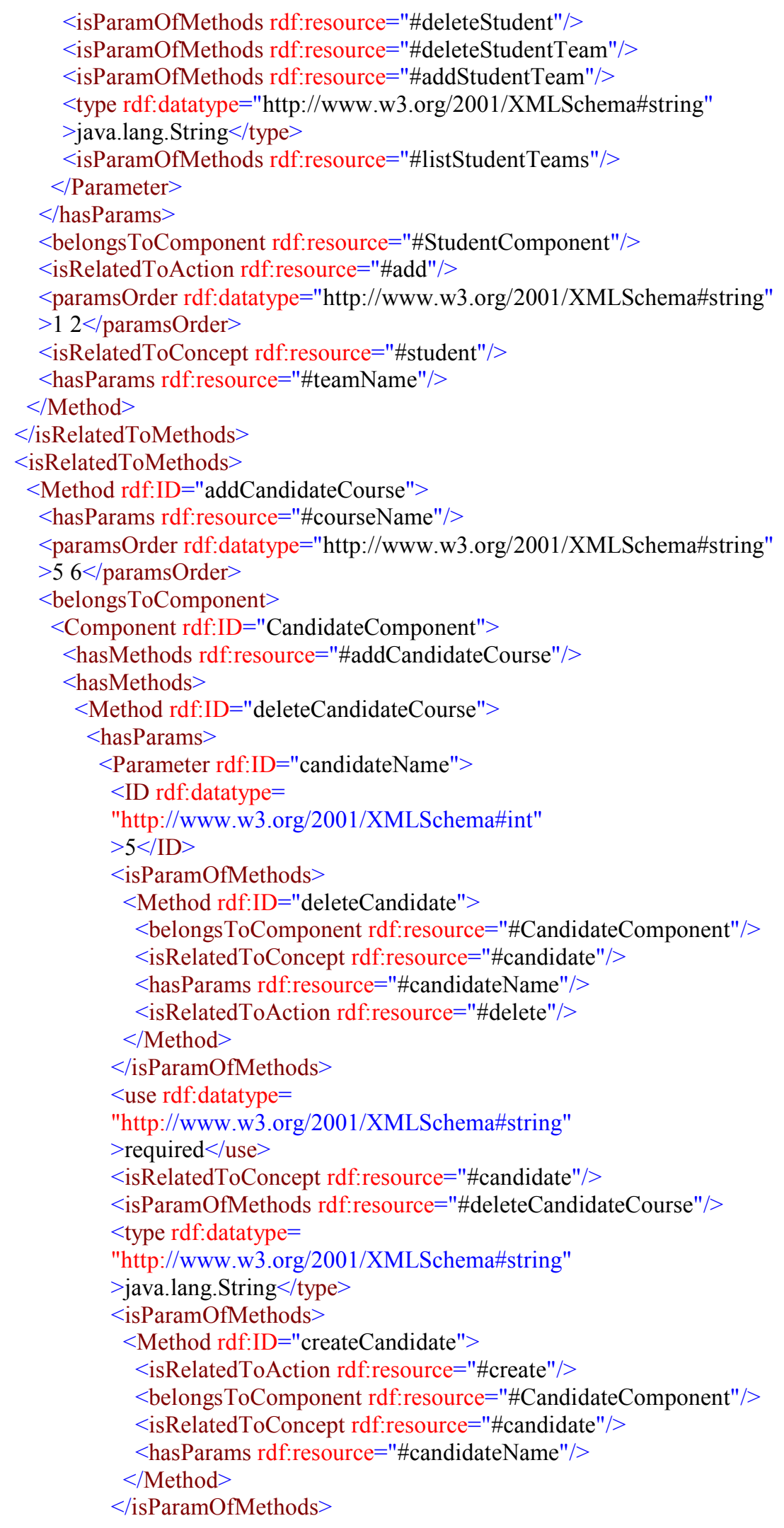


Apêndice F - Código OWL da Ontologia de Componentes Instanciada e Relacionada com a Ontologia de Domínio (PT-11)

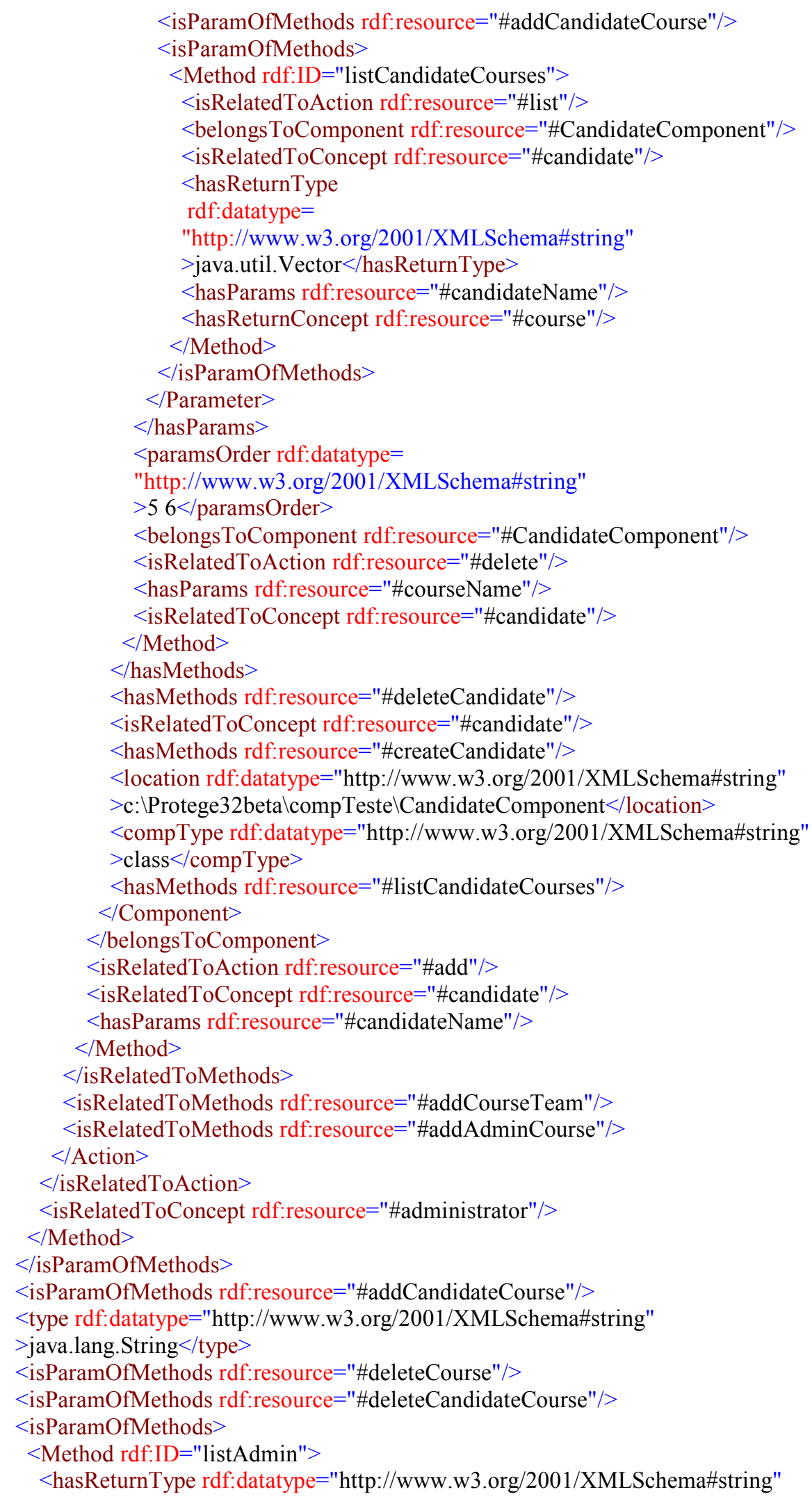




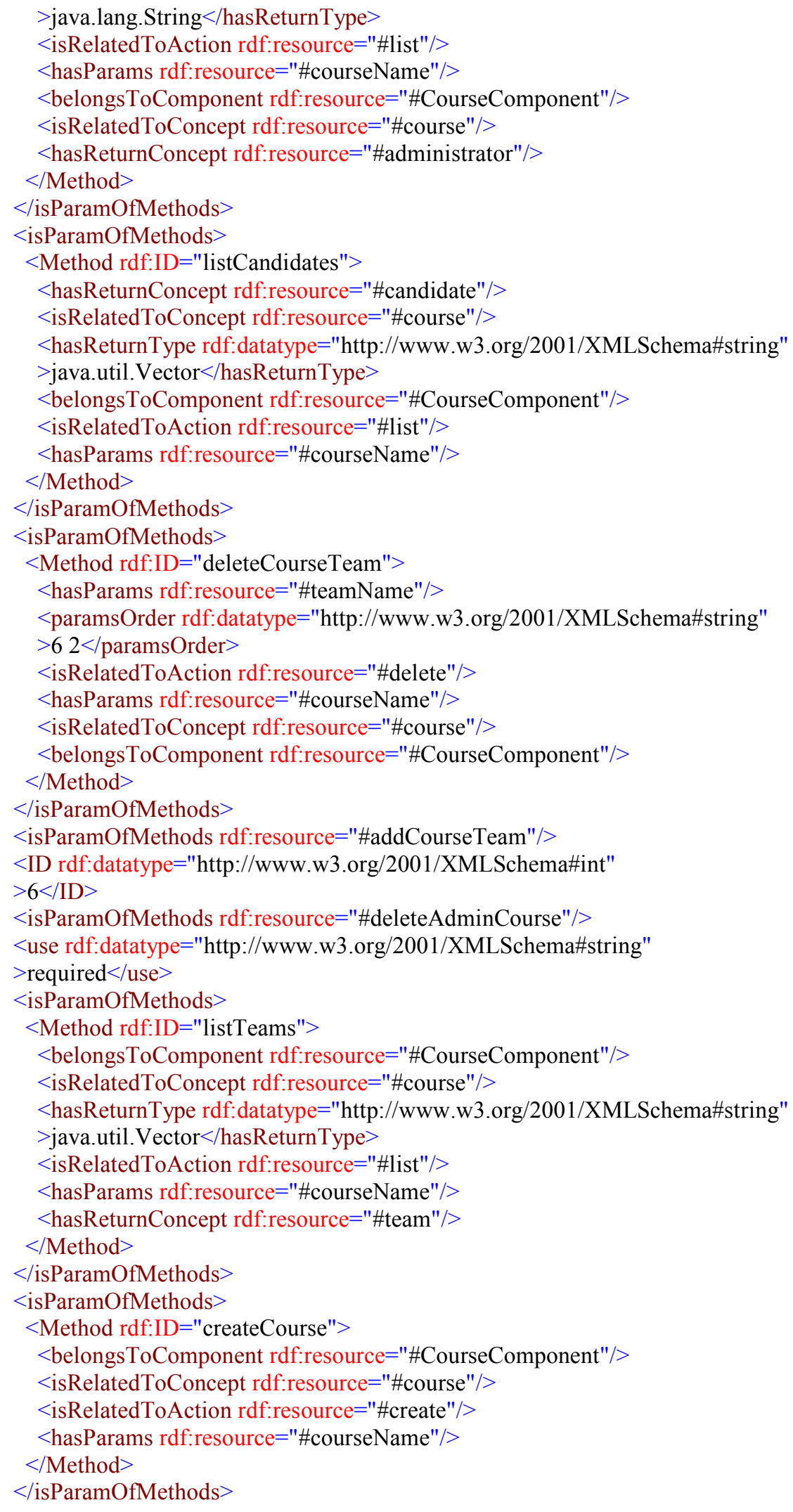


Apêndice F-Código OWL da Ontologia de Componentes Instanciada e Relacionada com a Ontologia de Domínio (PT-11)

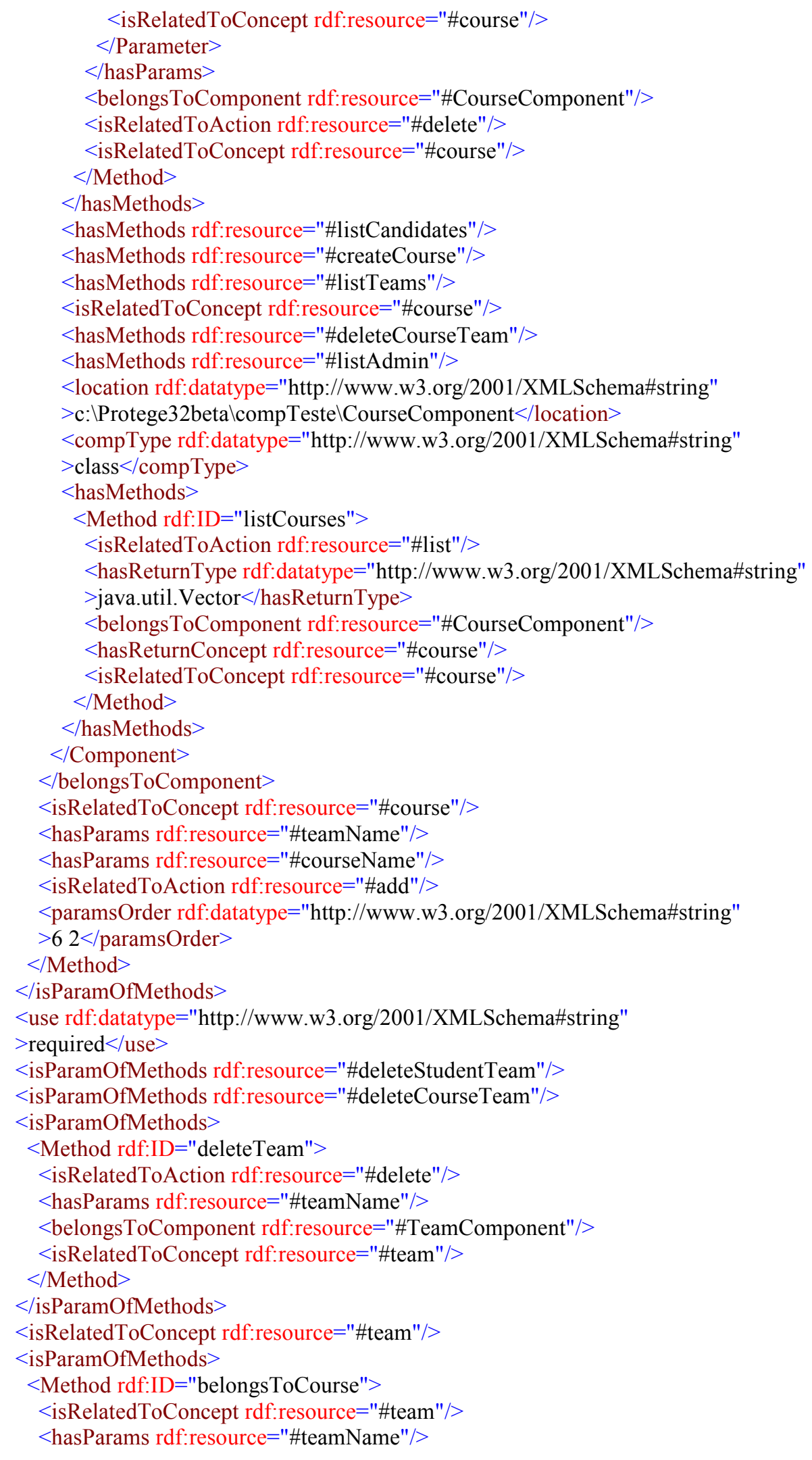




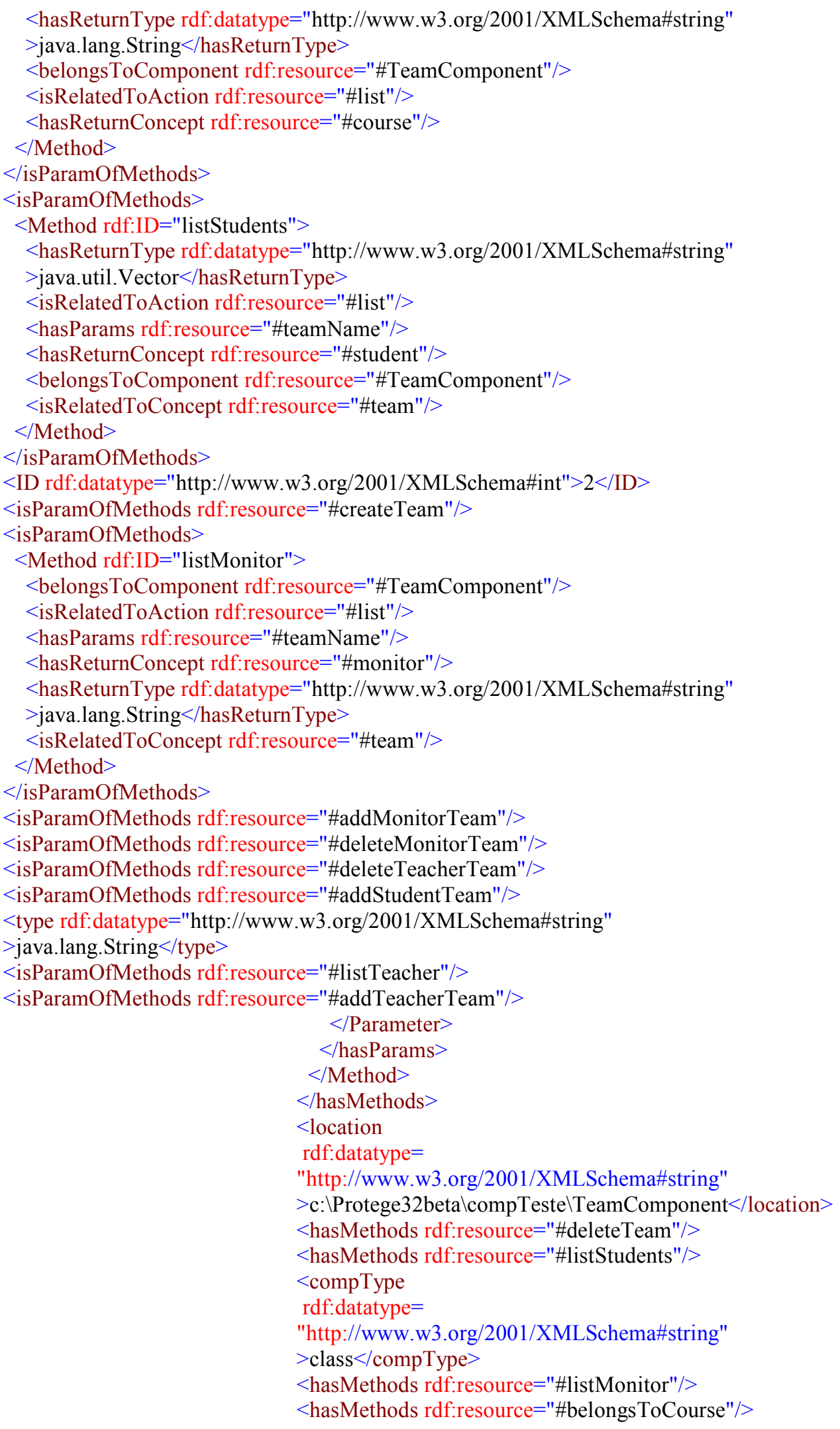


Apêndice F - Código OWL da Ontologia de Componentes Instanciada e Relacionada com a Ontologia de Domínio (PT-11)

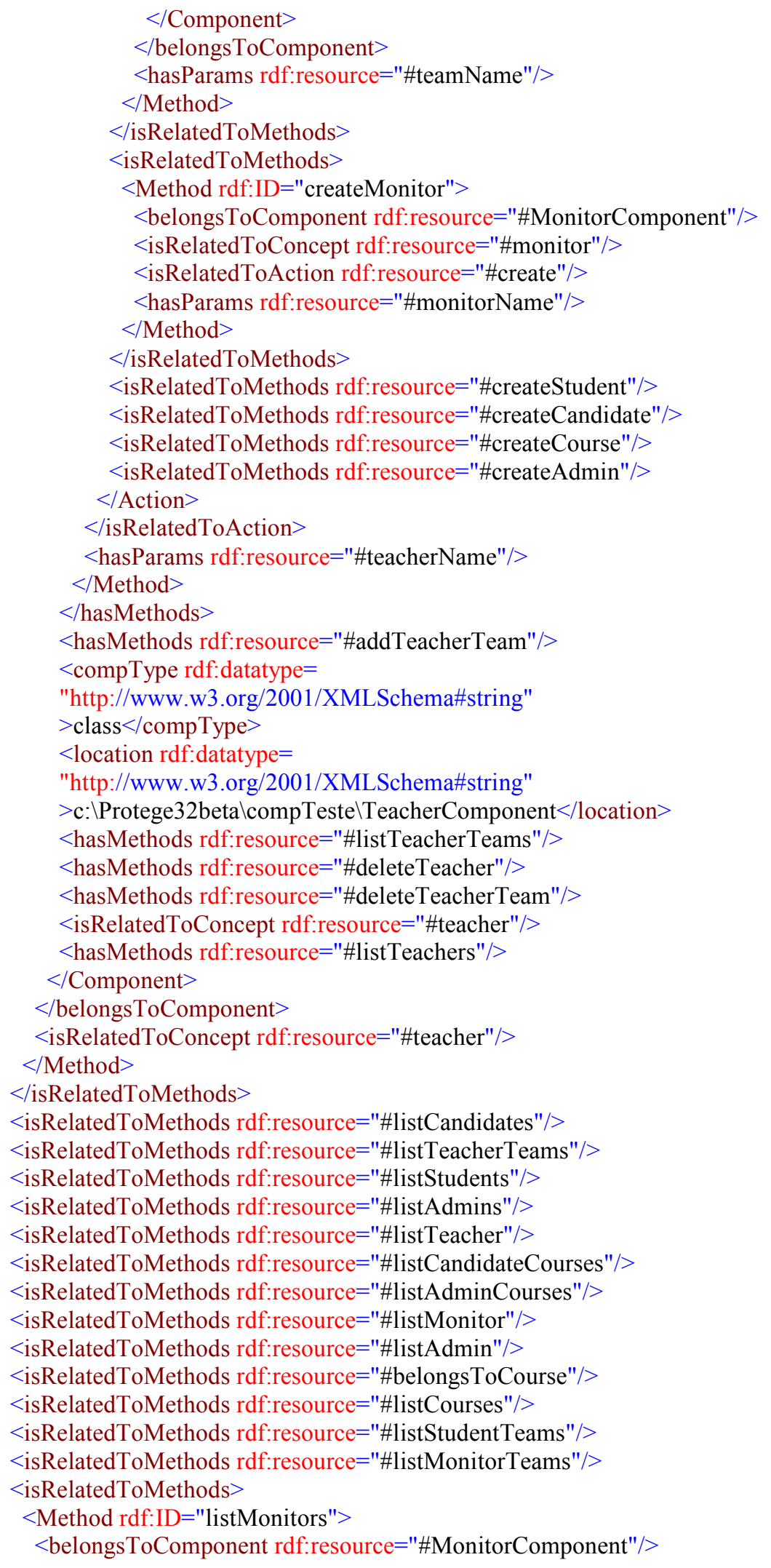




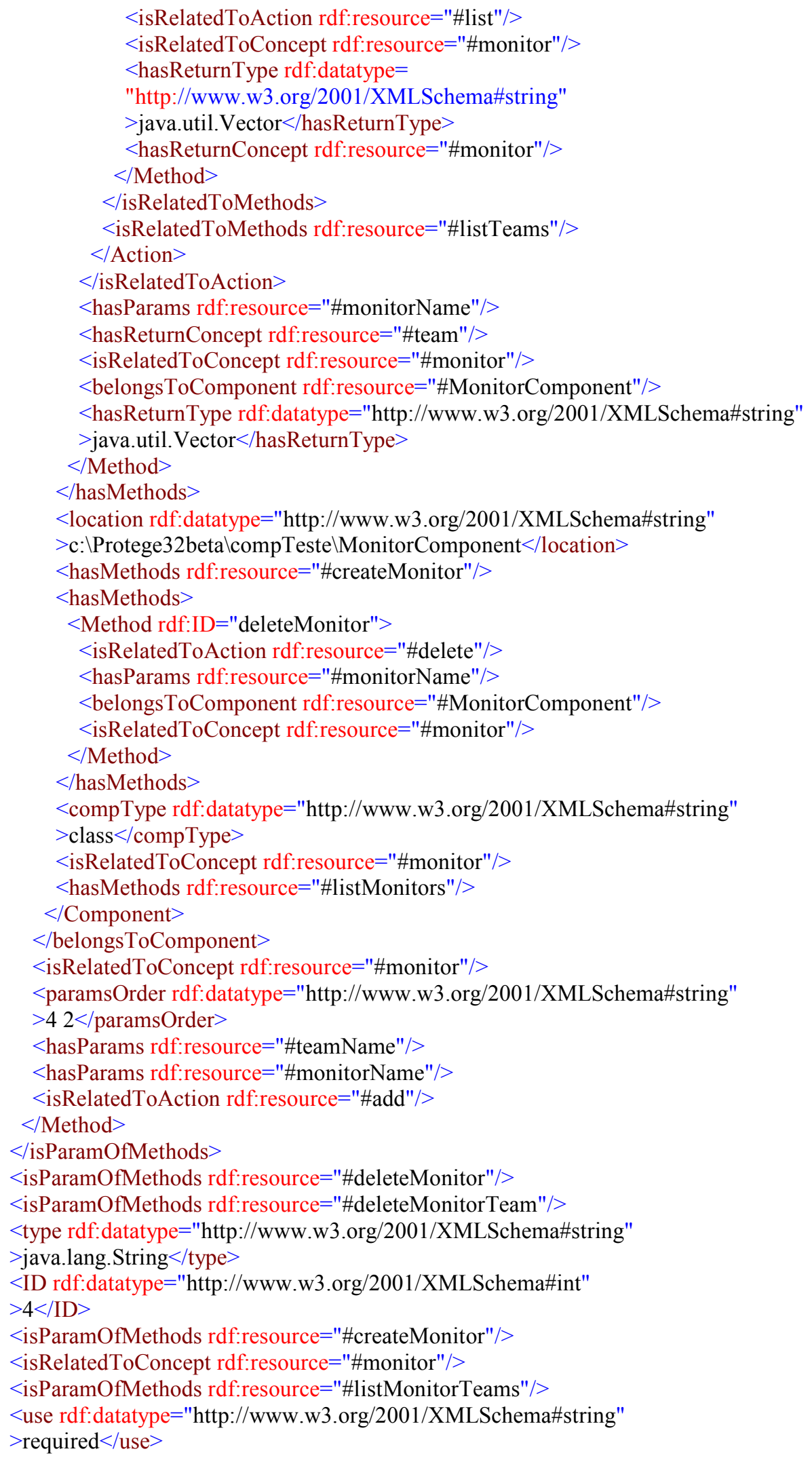


Apêndice F-Código OWL da Ontologia de Componentes Instanciada e Relacionada com a Ontologia de Domínio (PT-11)

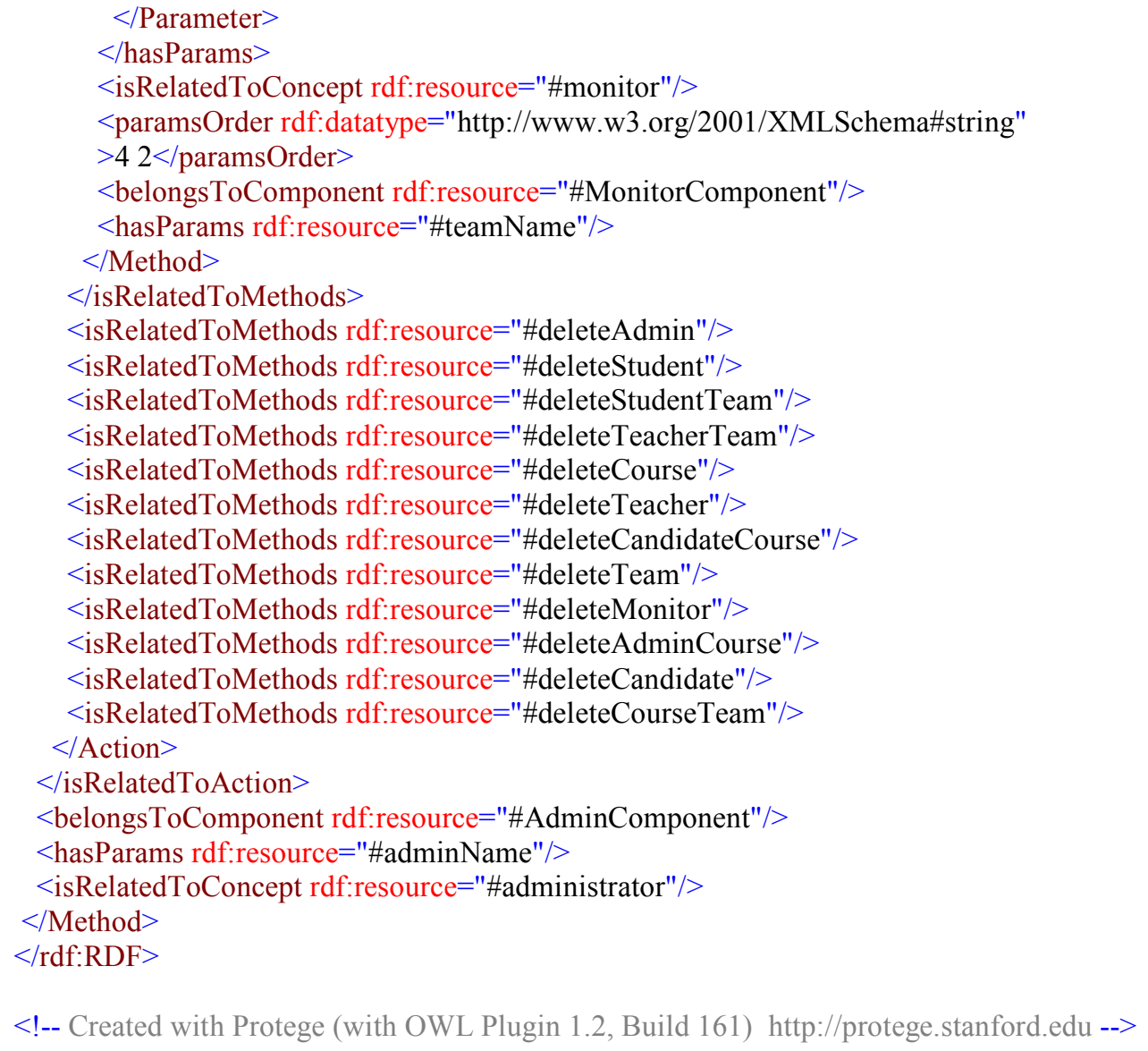




\section{ANEXO}

\begin{tabular}{ll}
\hline \hline & Sintaxe dos Documentos UNL \\
\end{tabular}

Notação utilizada para descrever a sintaxe de UNL:

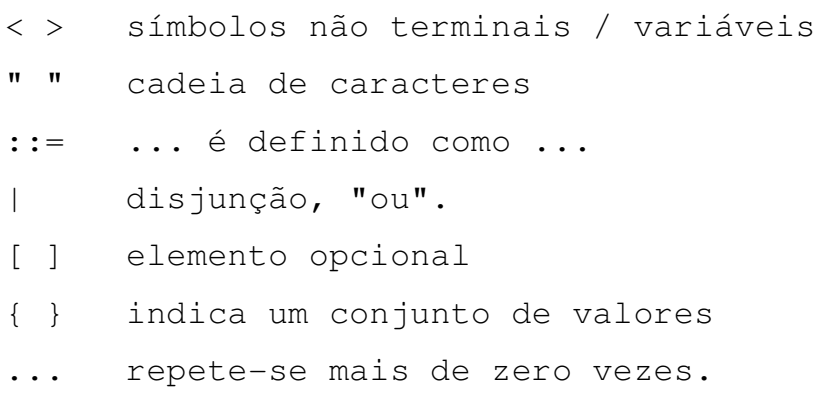

A Tabela 1 apresenta o formato descritivo de um documento UNL.

Tabela 1 - Formato descritivo de um documento UNL (UNL Specifications, 2005).

\begin{tabular}{|c|c|}
\hline$<$ Documento UNL > & $\begin{array}{l}::=\text { "[D:" < <inf> "]" } \\
\{\text { "[P:" <número do parágrafo> "]" } \\
\text { \{ "[S:" <número da sentença> "]" } \\
<\text { sentença> } \\
\text { "[/S]" } \\
\text { ["[RS] } \\
\text { <descrição da referência> (ver Tabela 3) } \\
\text { "[/RS]" } \\
\text { "[DS] } \\
\text { <descrição de estrutura> (ver Tabela 4) } \\
\text { "[/DS]" } \\
\text { ] } \\
\} \\
\ldots \\
\text { "[/P]" } \\
\text { ["[RS] } \\
<\text { descrição da referência> } \\
\text { "[/RS]" }\end{array}$ \\
\hline
\end{tabular}




\begin{tabular}{|c|c|}
\hline & $\begin{array}{l}\text { "[DS] } \\
\text { <descrição de estrutura> } \\
\text { "[/DS]" } \\
\text { ] } \\
\ldots \\
\text { "[/D]" }\end{array}$ \\
\hline$<\operatorname{dinf}>$ & $\begin{array}{l}::=<\text { nome do documento }>\text { ", " < nome do autor }>\text { [ "," <ID do documento }> \\
\text { "," < data }>\text { "," < email }>\text { ] }\end{array}$ \\
\hline <nome do documento > & $::=$ "dn=" <cadeia de caracteres > \\
\hline$<$ nome do autor $>$ & $::=$ "on=" <cadeia de caracteres > \\
\hline$<$ ID do documento $>$ & $::=$ "did=" <cadeia de caracteres $>$ \\
\hline$<$ data $>$ & $::=$ "dt=" <cadeia de caracteres $>$ \\
\hline <email> & $::=$ "mid=" <cadeia de caracteres $>$ \\
\hline <sentença> & $\begin{aligned}::= & \text { "\{org:" <l-tag> [ "=" <code> ] "\}" } \\
& <\text { sentença de origem> } \\
& \text { \{/org\}" } \\
& \text { }\{\text { unl" [ ":" <uinf> ] "\}" } \\
& <\text { expressão UNL de uma sentença> (ver seção 2.3.2) } \\
& \text { }\{\text { /unl\}" } \\
& \{\text { " }\{"<\text {-tag> [ "=" <code> ] [ ":" <sinf> "]" "\}" } \\
& <\text { sentença destino> } \\
& \text { "\{/" <l-tag> "\}" }\} \\
& \ldots \\
& \text { /* toda informação necessária para uma sentença * }\end{aligned}$ \\
\hline$<$-tag $>$ & $\begin{array}{l}\text { ::= "ab" | "cn" | "de" | "el" | "es" | "fr" | "id" | "hd" | "it" | "jp" | "Iv" | "mg" | } \\
\text { "pg" | "ru" | "sh" | "th" } \\
\text { /* códigos das linguagens: etiquetas das linguagens */ }\end{array}$ \\
\hline <código> & $::=<$ nome do código $>$ \\
\hline <nome do código> & $::=<$ cadeia de caracteres $>$ \\
\hline <sentença de origem> & $::=<$ cadeia de caracteres $>$ \\
\hline <sentença destino> & $::=<$ cadeia de caracteres $>$ \\
\hline <uinf> & $\begin{aligned}::= & <\text { nome do sistema }>\text { ", " <nome do post-editor> "," < confiança> [ "," } \\
& <\text { data }>\text { "," <email }>\text { ] }\end{aligned}$ \\
\hline$<\operatorname{sinf}>$ & $\begin{aligned}::= & <\text { nome do sistema }>\text { "," <nome do post-editor> "," < confiança> [ "," } \\
& <\text { data }>\text { "," <email }>\text { ] }\end{aligned}$ \\
\hline$<$ nome do sistema $>$ & $::=$ "sn=" <cadeia de caracteres > \\
\hline <nome do post-editor> & $::=$ "pn=" <cadeia de caracteres> \\
\hline <confiança> & $::=$ "rel=" <um número> \\
\hline <número do parágrafo> & $\begin{aligned}::= & <\text { um número }>\text {, deve ser único dentro do documento UNL e deve ser } \\
& \text { dado em seqüência. }\end{aligned}$ \\
\hline <número da sentença> & $\begin{array}{l}::=<\text { um número }>\text {, deve ser único dentro do documento UNL e deve ser } \\
\text { dado em seqüência. }\end{array}$ \\
\hline
\end{tabular}


A Tabela 2 mostra as etiquetas usadas em um documento UNL.

Tabela 2 - Etiquetas dos documentos UNL (UNL Specifications, 2005).

\begin{tabular}{|c|c|}
\hline$[\mathrm{D}:<\operatorname{dinf}>]$ & $\begin{array}{l}\text { Indica o início de um documento e as informações necessárias sobre o } \\
\text { documento. }\end{array}$ \\
\hline [/D] & Fim de um documento. \\
\hline$\left[P:<p \_n u m>\right]$ & Início de um parágrafo. \\
\hline$[/ \mathrm{P}]$ & Fim de um parágrafo. \\
\hline$\left[S:<S \_n u m>\right]$ & Início de uma sentença e o número da sentença. \\
\hline [/S] & Fim de uma sentença. \\
\hline [RS] & Início de uma descrição de referência. \\
\hline [/RS] & Fim de uma descrição de referência. \\
\hline [DS] & Início da descrição da estrutura de um documento. \\
\hline [/DS] & Fim da descrição da estrutura de um documento. \\
\hline $\begin{array}{l}\{\text { org: }:<1 \text { tag }> \\
=<\text { code }>\}\end{array}$ & $\begin{array}{l}\text { Início da sentença original. A linguagem e o código dos caracteres (“=<code>”) } \\
\text { podem ser omitidos. }\end{array}$ \\
\hline$\{/$ org $\}$ & Fim da sentença original. \\
\hline$\{$ unl: $<$ uinf $>\}$ & $\begin{array}{l}\text { Início das expressões UNL de uma sentença. As informações (“:<uinf>”) podem } \\
\text { ser omitidas. }\end{array}$ \\
\hline$\{/$ unl $\}$ & Fim das expressões UNL de uma sentença. \\
\hline$\left\{<1 \_\right.$tag $\left.>\right\}$ & Início de uma sentença na língua destino, indicada por <l_tag>. \\
\hline$\{|<|$ tag $>\}$ & Fim de uma sentença na língua destino. \\
\hline
\end{tabular}

A Tabela 3 mostra o formato descritivo de < descrição da referência>

Tabela 3 - Formato descritivo de <descrição da referência> (UNL Specifications, 2005).

\begin{tabular}{|c|c|}
\hline $\begin{array}{l}<\text { descrição da } \\
\text { referência }\end{array}$ & $\begin{aligned}::= & \{<\text { nodo referido }>\text { ", }<\text { nodo avaliador }>\} \\
& \ldots\end{aligned}$ \\
\hline$<$ nodo referido $>$ & $::=<$ uw do nodo1 $>\mid<$ nodo da sentença $>$ |<nodo do parágrafo $>$ \\
\hline <nodo avaliador > & $::=<$ uw do nodo2> | <nodo da sentença $>$ | <nodo do parágrafo> \\
\hline <uw do nodo1> & $\begin{array}{l}::=\{<U W>": "<U W-I D>\mid ": "<I D \text { do escopo }>\}[": "<\text { nodo da sentença }>] \\
<\text { nodo da sentença> pode ser omitido. Nesse caso, a UW ou escopo deve } \\
\text { existir na sentença. Essa descrição só pode ser usada seguindo descrições } \\
\text { [S] e [/S]. }\end{array}$ \\
\hline <uw do nodo2> & $\begin{array}{l}::=\{<U W>": "<U W-I D>\mid ": "<I D \text { do escopo }>\} \text { ":"<nodo da sentença> } \\
<\text { nodo da sentença> não pode ser omitido. }\end{array}$ \\
\hline$<$ nodo da sentença $>$ & ::= ":S:"<número da sentença> \\
\hline <nodo do parágrafo > & $::=$ ":P:"<número do parágrafo> \\
\hline
\end{tabular}


Anexo A - Sintaxe dos Documentos UNL

A descrição formal de $<$ descrição de estrutura $>$ é dada da Tabela 4.

Tabela 4 - Formato descritivo de <descrição de estrutura> (UNL Specifications, 2005).

< descrição de estrutura $>\quad::=\{$ < relação $>$ "(" < nodo da sentença $>$ | <nodo do parágrafo > "," <nodo da sentença $>$ <nodo do parágrafo $>$ ")" $\}$ 


\section{ANEXO}

\begin{tabular}{r|r}
\hline \hline Sintaxe das Representações Tabular \\
e em Lista de Expressões UNL
\end{tabular}

Notação utilizada para descrever a sintaxe de UNL:

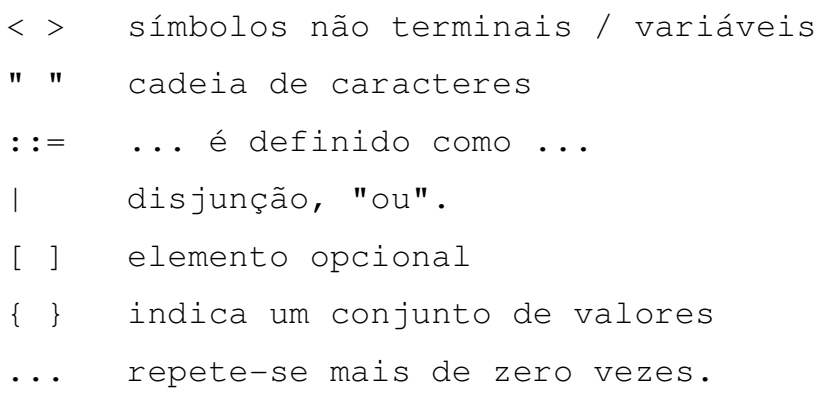

\section{Representação Tabular}

A Tabela 5 mostra a forma tabular para expressões UNL e a Tabela 6 mostra a sintaxe de uma relação binária na forma tabular.

Tabela 5 - Forma tabular de uma expressão UNL (UNL Specifications, 2005).
\begin{tabular}{|l|l|}
\hline Expressão UNL com um & $\{$ unl\} \\
conjunto de relações & $<$ relação binária> \\
binárias & $\ldots$ \\
& $\{$ /unl\} \\
\hline Expressão UNL com uma & $\{$ unl\} \\
UW & {$[W]$} \\
& $<U W><$ lista de atributos > \\
& {$[/ W]$} \\
& $\{/$ unl $\}$ \\
\hline Expressão UNL com & $\{$ unl\} \\
escopo & {$[W]$} \\
& $\cdots:$ "<Scope-ID><lista de atributos > \\
& {$[/ W]$} \\
& $<$ relação binária > \\
& $\ldots$ \\
& $\{/$ unl $\}$ \\
\hline
\end{tabular}


Anexo B - Sintaxe das Representações Tabular e em Lista de Expressões UNL

Tabela 6 - Sintaxe de uma relação binária na forma tabular (UNL Specifications, 2005).

\begin{tabular}{|c|c|}
\hline \multirow[t]{5}{*}{ <relação binária> } & 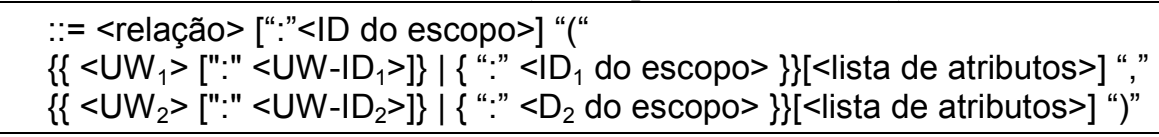 \\
\hline & ou \\
\hline & 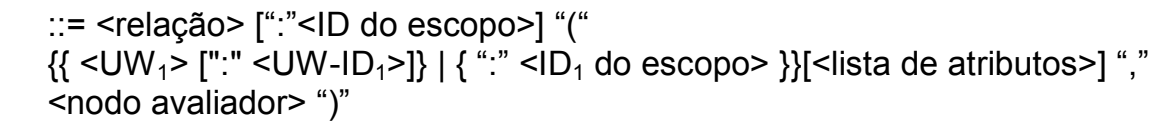 \\
\hline & ou \\
\hline & 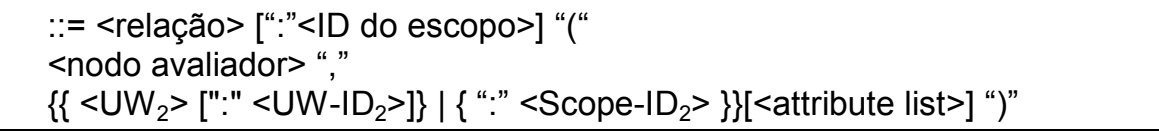 \\
\hline <relação> & $::=$ um rótulo de relação (ver seção 2.4 ) \\
\hline$<U W>$ & $::=$ uma UW (ver seção 2.6) \\
\hline$<$ lista de atributos > & $::=\{“ . "<$ atributo $>\} \ldots$ \\
\hline <atributo> & $::=$ um atributo (ver seção 2.5) \\
\hline$<U W-I D>$ & $::=$ dois caracteres alfanuméricos de '0' - '9' e 'A' - 'Z' \\
\hline$<$ ID do escopo> & $\begin{array}{l}::=\text { dois dígitos de "00" a " } 99 " . \text { "00" deve ser usado para a sentença } \\
\text { principal e pode ser omitido. }\end{array}$ \\
\hline$<$ nodo avaliador $>$ & ver tabela 3 \\
\hline
\end{tabular}

\section{Representação em Lista}

A Tabela 7 mostra o formato em lista para expressões UNL e a Tabela 8 mostra a sintaxe de uma relação binária no formato em lista.

Tabela 7 - Formato em lista de uma expressão UNL (UNL Specifications, 2005).

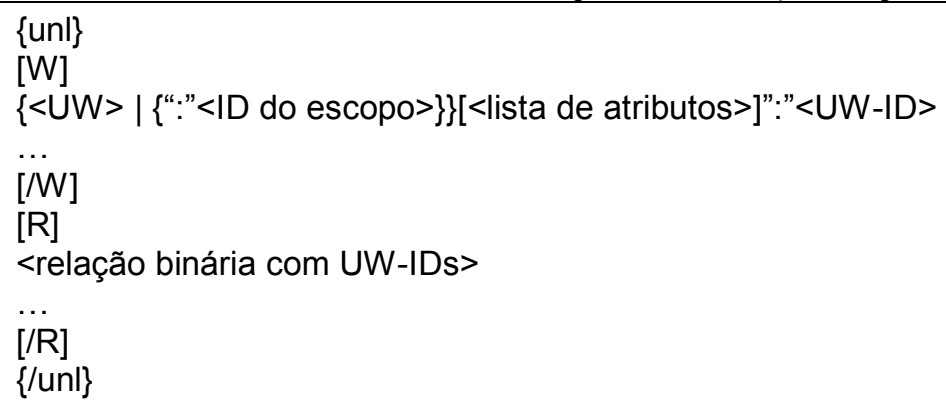

Tabela 8 - Sintaxe de uma relação binária no formato em lista (UNL Specifications, 2005).

\begin{tabular}{|l|l|}
$\begin{array}{l}\text { <relação binária com UW- } \\
\text { IDs> }\end{array}$ & $:=<U W-I D 1><$ relação[":"<ID do escopo>]<UW-ID2> \\
\hline$<U W-I D>$ & $:=$ dois caracteres alfanuméricos de "0" a "9" e "A" - "Z" \\
\hline$<$ ID do escopo> & $:=$ dois dígitos de "00" a "99" \\
\hline
\end{tabular}




\begin{tabular}{ll}
\hline & Relações UNL
\end{tabular}

A Tabela 9 apresenta as relações ontológicas, seus rótulos e significados.

Tabela 9 - Relações ontológicas (UNDL Brasil, 2005; UNL Specifications, 2005).

\begin{tabular}{|l|c|c|l|c|}
\hline RELAÇÃO & RÓTULO & DEFINIÇÃO & \multicolumn{1}{|c|}{ EXEMPLO (UNL) } & $\begin{array}{c}\text { EXEMPLO } \\
\text { (português) }\end{array}$ \\
\hline Hiponímia & icl & $\mathrm{X} \subset \mathrm{Y}$ & $\begin{array}{l}\text { icl(table(icl>furniture), } \\
\text { furniture(icl>functional thing)) }\end{array}$ & mesa \\
\hline Sinonímia & equ & $\mathrm{X} \equiv \mathrm{Y}$ & $\begin{array}{l}\text { equ(UNL(equ>Universal } \\
\text { Networking Language), Universal } \\
\text { Networking Language) }\end{array}$ & São Carlos \\
\hline Instância & iof & $\mathrm{X} \in \mathrm{Y}$ & $\begin{array}{l}\text { iof(São Carlos(iof>city), } \\
\text { city(icl>region)) }\end{array}$ & . \\
\hline
\end{tabular}

A Tabela 10 apresenta as relações lógicas seus rótulos e significados.

Tabela 10 - Relações lógicas (UNDL Brasil, 2005; UNL Specifications, 2005).

\begin{tabular}{|l|c|c|l|l|}
\hline RELAÇÃO & RÓTULO & DEFINIÇÃO & \multicolumn{1}{|c|}{ EXEMPLO (UNL) } & EXEMPLO (português) \\
\hline Disjunção & or & $X \vee Y$ & or(Pedro, Maria) & Maria ou Pedro \\
\hline Conjunção & and & $X \wedge Y$ & and(Pedro, Maria) & Maria e Pedro \\
\hline Condição & con & $X \rightarrow Y$ & con(get wet, rain) & Se chover, molhará. \\
\hline Descrição & cnt & $X \equiv Y$ & cnt(language, UNL) & Uma linguagem: UNL. \\
\hline Interseção & int & $X \cap Y$ & $\begin{array}{l}\text { int(tableware(icl>tool), } \\
\text { cookware(icl>tool)) }\end{array}$ & $\begin{array}{l}\text { Uma interseção de } \\
\text { utensílios de mesa e de } \\
\text { cozinha }\end{array}$ \\
\hline
\end{tabular}


As relações psicológicas podem estar relacionadas a atores, espaço, tempo, qualidade e transformação. As tabelas 11 a 15 mostram as relações psicológicas pertencentes a cada grupo, com seus rótulos e significados.

Tabela 11 - Relações psicológicas sobre atores (UNDL Brasil, 2005; UNL Specifications, 2005).

\begin{tabular}{|l|c|l|l|}
\hline \multicolumn{1}{|c|}{ RELAÇÃO } & RÓTULO & EXEMPLO (UNL) & \multicolumn{1}{|c|}{ EXEMPLO (português) } \\
\hline Agente & agt & agt(hold, João) & JOÃO SEGUROU Maria \\
\hline Co-agente & cag & cag(hold, Pedro) & $\begin{array}{l}\text { João SEGUROU Maria com a ajuda de } \\
\text { PEDRO }\end{array}$ \\
\hline Beneficiário & ben & ben(hold, Pedro) & João SEGUROU Maria por PEDRO \\
\hline Instrumento & ins & ins(hold, kand) & João SEGUROU Maria com a MÃO \\
\hline Objeto & obj & obj(hold, Maria) & João SEGUROU MARIA \\
\hline Co-objeto & cob & cob(hold, Pedro) & João SEGUROU Maria e também PEDRO \\
\hline Parceiro & ptn & ptn(win, Pedro) & João VENCEU com PEDRO \\
\hline
\end{tabular}

Tabela 12 - Relações psicológicas sobre espaço (UNDL Brasil, 2005; UNL Specifications, 2005).

\begin{tabular}{|l|c|l|l|}
\hline \multicolumn{1}{|c|}{ RELAÇÃO } & RÓTULO & \multicolumn{1}{c|}{ EXEMPLO (UNL) } & \multicolumn{1}{c|}{ EXEMPLO (português) } \\
\hline Origem & frm & frm(train, São Paulo) & TREM de São Paulo \\
\hline Destino & to & to(train, São Paulo) & TREM para São Paulo \\
\hline Lugar & plc & plc(meet, church) & João ENCONTROU Pedro na IGREJA \\
\hline Lugar de onde & plf & plf(go, São Carlos) & IR de São Carlos \\
\hline Lugar para onde & plt & plt(go, São Carlos) & IR para São Carlos \\
\hline Lugar por onde & via & via(go, São Carlos) & IR por São Carlos \\
\hline Lugar afetado & opl & opl(hold, backs) & João SEGUROU Maria nas COSTAS \\
\hline Cenário & scn & scn(meet, dream) & João ENCONTROU Pedro em SONHO \\
\hline
\end{tabular}

Tabela 13 - Relações psicológicas sobre tempo (UNDL Brasil, 2005; UNL Specifications, 2005).

\begin{tabular}{|l|c|l|l|}
\hline \multicolumn{1}{|c|}{ RELAÇÃO } & RÓTULO & \multicolumn{1}{|c|}{ EXEMPLO (UNL) } & \multicolumn{1}{|c|}{ EXEMPLO (português) } \\
\hline Duração & dur & dur(meet, party) & $\begin{array}{l}\text { João ENCONTROU Pedro durante a } \\
\text { FESTA }\end{array}$ \\
\hline Intervalo & $\mathrm{fmt}$ & $\begin{array}{l}\text { fmt(São Carlos, São } \\
\text { Paulo) }\end{array}$ & Foi de SÃO CARLOS até SÃO PAULO \\
\hline Tempo & $\mathrm{tim}$ & tim(meet, evening) & João ENCONTROU Pedro à TARDE \\
\hline Tempo inicial & $\mathrm{tmf}$ & tmf(walk, morning) & ESTOU ANDANDO desde a MANHÃ \\
\hline Tempo final & $\mathrm{tmt}$ & tmt(walk, noon) & VOU ANDAR até o MEIO-DIA \\
\hline Co-ocorrência & $\mathrm{coo}$ & coo(meet, walk) & $\begin{array}{l}\text { João ENCONTROU Pedror enquanto } \\
\text { ANDAVA }\end{array}$ \\
\hline Seqüência & seq & seq(run, think) & João PENSOU antes de CORRER \\
\hline
\end{tabular}


Tabela 14 - Relações psicológicas sobre qualidade e determinação (UNDL Brasil, 2005; UNL

Specifications, 2005).

\begin{tabular}{|l|c|l|l|}
\hline \multicolumn{1}{|c|}{ RELAÇÃO } & RÓTULO & \multicolumn{1}{|c|}{ EXEMPLO (UNL) } & \multicolumn{1}{|c|}{ EXEMPLO (português) } \\
\hline Atribuição & aoj & aoj(jealous, João) & JOÃO é CIUMENTO \\
\hline Co-atribuição & cao & cao(Pedro, Maria) & $\begin{array}{l}\text { João encontrou PEDRO que estava } \\
\text { com MARIA }\end{array}$ \\
\hline Comparação & bas & $\begin{array}{l}\text { bas(hold, } \\
\text { professional) }\end{array}$ & $\begin{array}{l}\text { João SEGUROU Maria como um } \\
\text { PROFISSIONAL }\end{array}$ \\
\hline Modificação & mod & mod(story, whole) & a HISTÓRIA INTEIRA \\
\hline Nome & nam & nam(city, São Carlos) & CIDADE DE SÃO CARLOS \\
\hline Parte & pof & pof(neck, Pedro) & O PESCOÇO DE PEDRO \\
\hline Possuidor & pos & pos(house, João) & A CASA DE JOÃO \\
\hline Quantidade & qua & qua(chapter, 3) & TRÊS CAPÍTULOS \\
\hline Proporção & per & per(2, day) & DOIS POR DIA \\
\hline
\end{tabular}

Tabela 15 - Relações psicológicas sobre transformação (UNDL Brasil, 2005; UNL Specifications, 2005).

\begin{tabular}{|c|c|c|c|}
\hline RELAÇÃO & RÓTULO & EXEMPLO (UNL) & EXEMPLO (português) \\
\hline Estado inicial & src & $\operatorname{src}($ change, red) & $\begin{array}{l}\text { MUDAR DE VERMELHO para } \\
\text { azul }\end{array}$ \\
\hline Estado Final & gol & gol(change, red) & $\begin{array}{l}\text { MUDAR de azul para } \\
\text { VERMELHO }\end{array}$ \\
\hline Modo & man & man(meet, quickly) & $\begin{array}{lll}\text { João } & \text { ENCONTROU } & \text { Pedro } \\
\text { RAPIDAMENTE } & \end{array}$ \\
\hline Método & met & met(find, lantern) & $\begin{array}{l}\text { João ENCONTROU a chave com } \\
\text { uma LANTERNA }\end{array}$ \\
\hline Posição & shd & shd(introduction, chapter) & CAPÍTULO 1 INTRODUÇÃO \\
\hline Propósito & pur & pur(meet, explain) & $\begin{array}{l}\text { João ENCONTROU Pedro para } \\
\text { EXPLICAR-SE }\end{array}$ \\
\hline Razão & rsn & rsn(dismiss, corruption) & $\begin{array}{llll}\text { João } & \text { DEMITIU } & \text { Pedro } & \text { por } \\
\text { CORRUPÇÃO } & & \end{array}$ \\
\hline
\end{tabular}




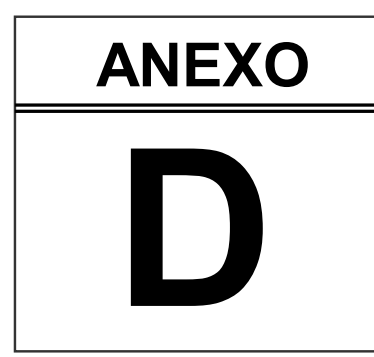

\section{Atributos UNL}

Os atributos UNL são divididos em 8 grupos: expressões lógicas, tempo, aspecto, referência, foco, atitude, ponto de vista, convenção. As tabelas 16 até 23 mostram, respectivamente, os atributos pertencentes a cada grupo.

Tabela 16 - Atributos relativos a expressões lógicas (UNL Specifications, 2005).

\begin{tabular}{|l|l|}
\hline ATRIBUTO & RÓTULO DO ATRIBUTO $(\mathrm{AL})$ \\
\hline transitividade & @transitive \\
\hline simetria & @symmetric \\
\hline identidade & @identifiable \\
\hline disjunção & @disjointed \\
\hline
\end{tabular}

Tabela 17 - Atributos relativos a referência (UNL Specifications, 2005).

\begin{tabular}{|l|l|}
\hline ATRIBUTO & RÓTULO DO ATRIBUTO (AL) \\
\hline definida & @def \\
\hline indefinida & @indef \\
\hline genérica & @generic \\
\hline complementar & @not \\
\hline seqüencial & @ordinal \\
\hline
\end{tabular}

Tabela 18 - Atributos relativos a tempo (UNL Specifications, 2005).

\begin{tabular}{|l|l|}
\hline ATRIBUTO & RÓTULO DO ATRIBUTO $(\mathrm{AL})$ \\
\hline passado & @past \\
\hline presente & @present \\
\hline futuro & @future \\
\hline
\end{tabular}


Anexo D-Atributos UNL

Tabela 19 - Atributos relativos a ponto de vista (UNL Specifications, 2005).

\begin{tabular}{|c|c|}
\hline ATRIBUTO & RÓTULO DO ATRIBUTO (AL) \\
\hline necessidade & @need \\
\hline ação inevitável & @unavoidable \\
\hline evento inevitável & @inevitable \\
\hline possibilidade & @possible \\
\hline probabilidade & @probable \\
\hline capacidade & @ability \\
\hline arbítrio & @will \\
\hline expectativa & @expectation \\
\hline receber benefício & @get-benefit \\
\hline dar benefício & @give-benefit \\
\hline conclusão & @conclusion \\
\hline conseqüência & $@$ consequence \\
\hline suficiente & @suficient \\
\hline consenso & @consent \\
\hline discordância & @dissent \\
\hline permissão & @grant \\
\hline não permissão & @grant-not \\
\hline ação contrária & @although \\
\hline descontentamento & @discontented \\
\hline desejo & @wish \\
\hline persistência & @insistence \\
\hline vontade & @want \\
\hline obrigação & @obligation \\
\hline não obrigação & @obligation-not \\
\hline dever & $@$ should \\
\hline certeza & @certain \\
\hline admissível & @may \\
\hline raro & @rare \\
\hline irreal & @unreal \\
\hline admiração & @admire \\
\hline culpa & @blame \\
\hline desprezo & $@$ contempt \\
\hline remorso & @regret \\
\hline surpresa & @surprised \\
\hline importuno & @troublesome \\
\hline intenção & @intention \\
\hline
\end{tabular}


Tabela 20 - Atributos relativos a convenção (UNL Specifications, 2005).

\begin{tabular}{|l|l|}
\hline ATRIBUTO & RÓTULO DO ATRIBUTO (AL) \\
\hline principal & @entry \\
\hline tópico & @topic \\
\hline título & @title \\
\hline $\begin{array}{l}\text { instância de classe } \\
\text { diferente }\end{array}$ & @theme \\
\hline ênfase & @emphasis \\
\hline foco da interrogação & @qfocus \\
\hline contraste & @contrast \\
\hline
\end{tabular}

Tabela 21 - Atributos relativos a aspecto (UNL Specifications, 2005).

\begin{tabular}{|l|l|}
\hline ATRIBUTO & RÓTULO DO ATRIBUTO $(\mathrm{AL})$ \\
\hline início & @begin \\
\hline fim & @end \\
\hline experiência & @experience \\
\hline continuação & @continue \\
\hline habitual & @custom \\
\hline iterativo & @repeat \\
\hline progressivo & @progress \\
\hline evento completo & @complete \\
\hline estado & @state \\
\hline iminência & @soon \\
\hline recenticidade & @just \\
\hline imediatismo & @yet \\
\hline
\end{tabular}

Tabela 22 - Atributos relativos a atitude (UNL Specifications, 2005).

\begin{tabular}{|l|l|}
\hline ATRIBUTO & RÓTULO DO ATRIBUTO $(\mathrm{AL})$ \\
\hline afirmativa & @affirmative \\
\hline confirmativa & @confirmation \\
\hline exclamativa & @exclamation \\
\hline interrogativa & @interrogative \\
\hline imperativa & @imperative \\
\hline humildade & @humility \\
\hline convidativa & @invitation \\
\hline requisição & @request \\
\hline apelativa & @vocative \\
\hline polidez & @politeness \\
\hline respeito & @respect \\
\hline
\end{tabular}


Anexo D-Atributos UNL

Tabela 23 - Atributos relativos a convenção (UNL Specifications, 2005).

\begin{tabular}{|l|l|}
\hline ATRIBUTO & RÓTULO DO ATRIBUTO $(\mathrm{AL})$ \\
\hline voz passiva & @passive \\
\hline plural & @pl \\
\hline$<>$ & @angle_bracket \\
\hline[] & @square_bracket \\
\hline\{\} & @brace \\
\hline$($ ) & @parenthesis \\
\hline$(())$ & @double_parenthesis \\
\hline ، & @simple_quote \\
\hline “ “ & @double_quote \\
\hline
\end{tabular}

